DIOGO RAFAEL PRADO ZANATA

\title{
DESENVOLVIMENTO DE SENSOR VIRTUAL EMPREGANDO REDES NEURAIS PARA MEDIÇÃO DA COMPOSIÇÃO EM UMA COLUNA DE DESTILAÇÃO
}

\author{
Dissertação apresentada à Escola \\ Politécnica da Universidade de São \\ Paulo para obtenção do título de \\ Mestre em Engenharia.
}

São Paulo 2005 
DIOGO RAFAEL PRADO ZANATA

\title{
DESENVOLVIMENTO DE SENSOR VIRTUAL EMPREGANDO REDES NEURAIS PARA MEDIÇÃO DA COMPOSIÇÃO EM UMA COLUNA DE DESTILAÇÃO
}

\author{
Dissertação apresentada à Escola \\ Politécnica da Universidade de São \\ Paulo para obtenção do título de \\ Mestre em Engenharia.
}

Área de concentração:

Engenharia de Sistemas

Orientador:

Prof. Dr. Claudio Garcia

São Paulo 


\section{FICHA CATALOGRÁFICA}

Zanata, Diogo Rafael Prado

Desenvolvimento de sensor virtual empregando redes neurais para medição da composição em uma coluna de destilação.

D.R.P.Zanata -- São Paulo, 2005.

229 p. - edição revisada

Dissertação (Mestrado) - Escola Politécnica da Universidade de São Paulo. Departamento de Engenharia de Telecomunicações e Controle.

1. Sensor Virtual 2. Redes Neurais 3. Inferência da composição 4. Coluna de destilação 5. Correção de erros I. Universidade de São Paulo. Escola Politécnica. Departamento de Engenharia de Telecomunicações e Controle II.t. 
Aos meus pais que sempre foram os meus grandes mestres. 


\section{Agradecimentos}

Ao Professor Doutor Claudio Garcia pela disponibilidade, incentivo e constância no apoio ao desenvolvimento de todo o projeto.

Aos professores do Laboratório de Automação e Controle da Escola Politécnica da USP, pelo intercâmbio de idéias e experiências.

Ao doutorando e amigo Augusto César Heluy Dantas pelas inestimáveis contribuições e apoio para desvendar o mundo das redes neurais.

Aos meus pais, por tudo.

À FAPESP, pelo apoio financeiro e suporte no desenvolvimento da pesquisa.

À Escola Politécnica da Universidade de São Paulo pela disponibilização do local apropriado e do acesso a todo o material necessário.

E à todos os outros amigos e colegas que de uma forma ou de outra contribuíram para a realização deste trabalho. 


\section{Resumo}

Sensores virtuais empregando modelos de inferência da composição (responsável pela qualidade) dos produtos de uma coluna de destilação correspondem a medidores implementados em software, capazes de estimar, em tempo real, a composição dos produtos da mesma, a partir de informações do tipo temperaturas e pressões em diversos pontos da coluna e vazões de entrada, de saída e de reciclo.

O objetivo deste trabalho é obter esse tipo de sensor para uma coluna de destilação, capaz de estimar instantaneamente a composição dos produtos no topo de uma coluna de destilação multicomponente com condensador parcial, empregando redes neurais artificiais. Foi desenvolvido um simulador dinâmico baseado em modelo não-linear da coluna para aquisição de dados.

Neste projeto foi incluído um estudo sobre a influência do treinamento parcial no desempenho do sensor virtual. A idéia é estudar o desempenho para o caso de um sensor virtual treinado de antemão, com dados coletados a partir de um simulador da coluna. Este procedimento disponibiliza um sensor operacional, treinado através de um conjunto de dados simulados ou através de um pequeno conjunto de pontos e retreinado, quando dados reais ou um conjunto maior de dados estiver disponível.

Outra contribuição importante é o estudo realizado sobre os principais erros que podem ocorrer neste tipo de sensores, que são raramente tratados em publicações científicas. É também proposta uma metodologia para detecção e correção destes erros que foram encontrados e que afetam o comportamento do sensor, alterando sua precisão e capacidade de ser utilizado em um controle inferencial da planta. 


\section{Abstract}

Soft sensors for composition inference models (that are responsible for the quality) of distillation column products, correspond to virtual instruments implemented in software. This software is able to estimate, in real time, the composition of the output products of the column, based on information such as temperature and pressure on several points of the column and on input, output and recycle flow.

The purpose of this work is to obtain a soft sensor that estimates the instantaneous composition of the product at the top of a multicomponent distillation column with a partial condenser, employing artificial neural networks. The chosen architecture was the feedforward neural network with three layers. It was chosen based on many tested options. It was developed a dynamical simulator of this column for data acquisition based on a non-linear model.

In this study, it was included an investigation about the influence of partial training in the performance of the soft sensor. The goal is to study the results achieved in the case of a soft sensor trained beforehand, with data acquired from the simulator of this column. This procedure makes possible to have an operational soft sensor, trained based on a simulated data set or on a small amount of points and then retrained when a real or larger data set is available.

Another important contribution is the study performed about the main errors that may appear in this kind of sensor. These errors are rarely mentioned in scientific papers. It also aims at implementing techniques to enable detection and correction of those errors that the soft sensor may present, and that affect the performance of the soft sensor, changing its precision and making it inadequate for inferential control. 


\section{Sumário}

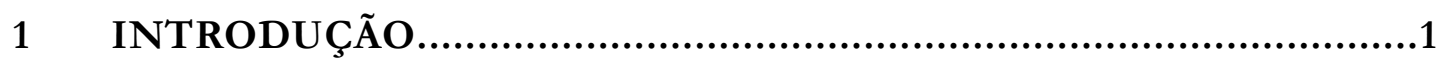

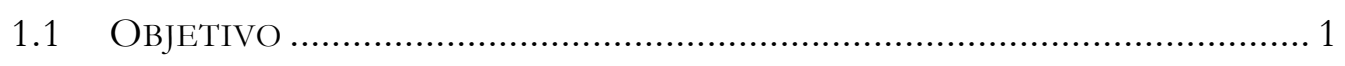

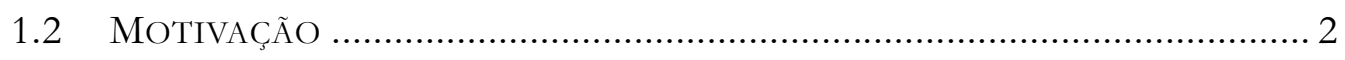

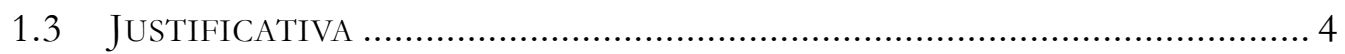

1.4 ESTUDO DAS REFERÊNCIAS BIBLIOGRÁFICAS............................................ 6

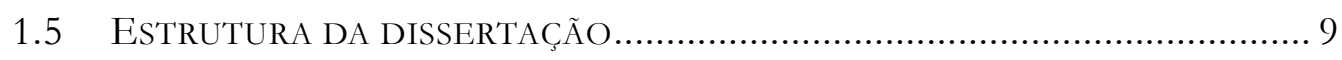

2 SENSORES VIRTUAIS .................................................. 11

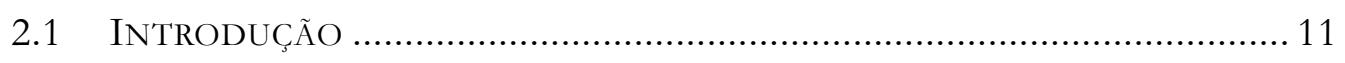

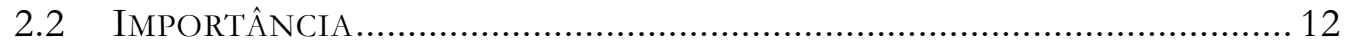

2.3 ÁREAS DE APLICAÇ̃̃O EM PROCESSOS ................................................... 14

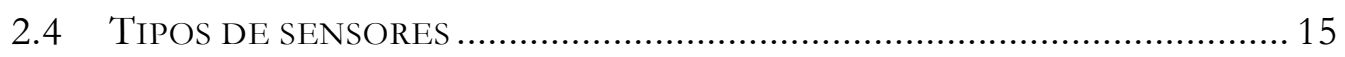

2.5 METOdologia A SER EMPREgADA................................................. 18

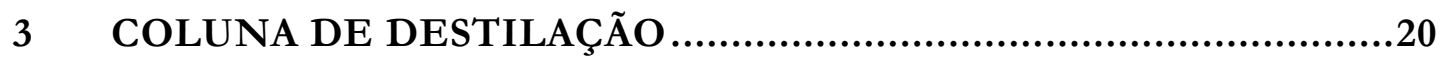

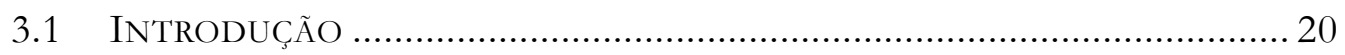

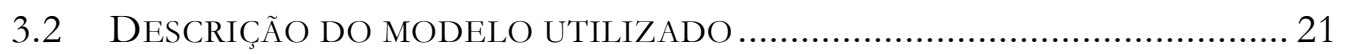

3.2.1 Especificações da coluna ................................................... 23

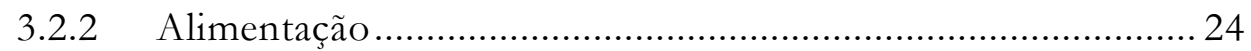

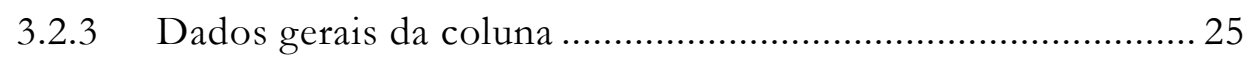

3.3 CARACTERIZAÇÃO DA COLUNA EM REGIME ......................................... 27

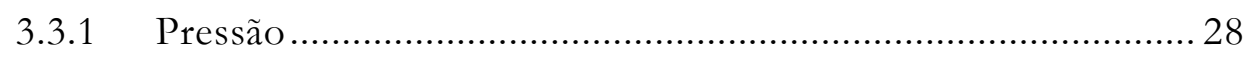




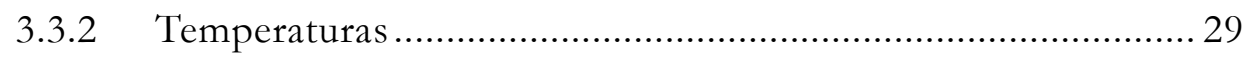

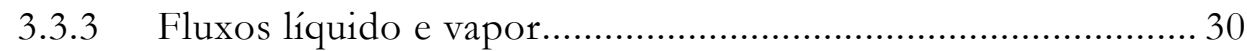

3.3.4 Composição dos componentes ............................................. 31

3.4 CARACTERIZAÇÃO DA COLUNA FORA DO REGIME ................................ 35

3.4.1 Comportamento da coluna para degrau de 10\%.................... 36

3.4.2 Comportamento da coluna para degrau de $-10 \%$................... 41

3.4.3 Comportamento da coluna para rampa de 20\% .................... 46

4 PROJETO DO EXPERIMENTO E COLETA DOS DADOS PARA IDENTIFICAÇÃ O ......................................................53

4.1 PROJETO DO EXPERIMENTO PARA IDENTIFICAÇÃO ............................... 53

4.1.1 Seleção das variáveis de entrada e saída .................................. 55

4.1.2 Escolha do sinal de excitação ................................................. 64

4.1.3 Período de amostragem.......................................................... 65

4.1.4 Implantação da perturbação no sistema................................. 72

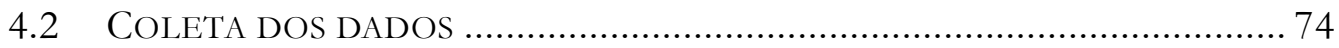

5 REDES NEURAIS ARTIFICIAIS ..................................... 75

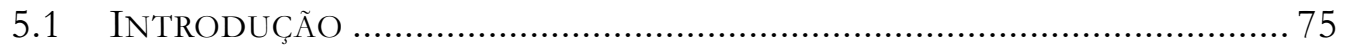

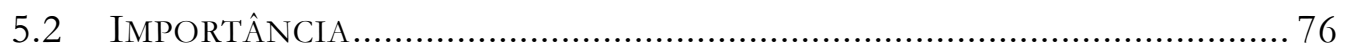

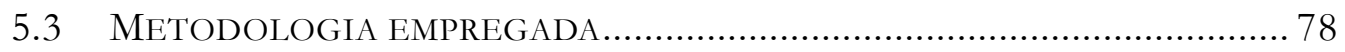

5.3.1 Projeto do experimento e coleta dos dados ........................... 79

5.3.2 Determinação da estrutura da rede neural .............................. 79

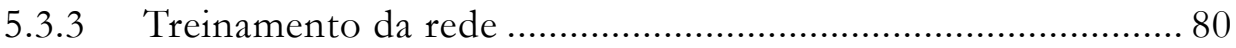

5.3.4 Validação do modelo obtido e análise do desempenho do

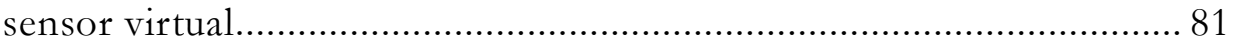

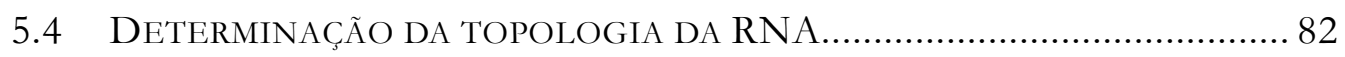

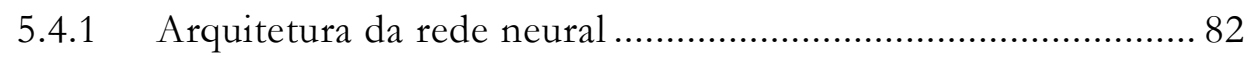

5.4.2 Definição da topologia ....................................................... 86

5.5 TREINAMENTO COM REgRESSORES E ESTIMAdORES .......................... 108 
6 SENSOR VIRTUAL COM TREINAMENTO PARCIAL ................ 114

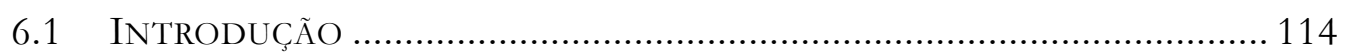

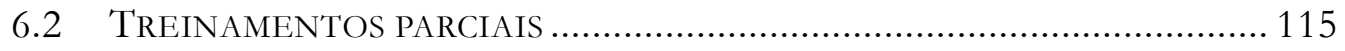

6.3 DADOS “REAIS” PARA VALIDAÇÃO ……................................................ 123

6.4 OPERAÇÃO DO SENSOR COM DADOS “REAIS” ...................................... 128

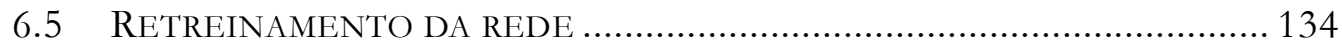

7 SENSOR VIRTUAL COM CORREÇÃO DE ERROS...................... 144

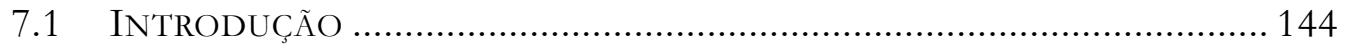

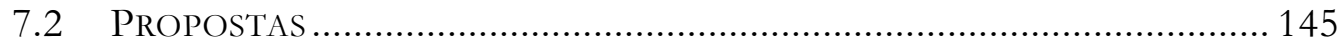

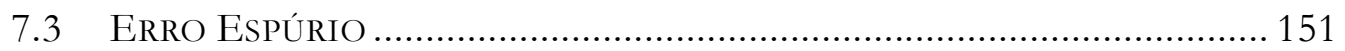

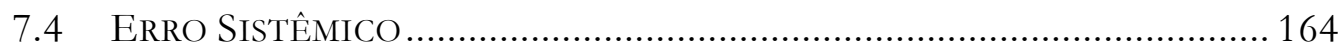

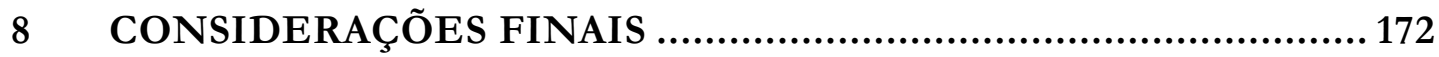

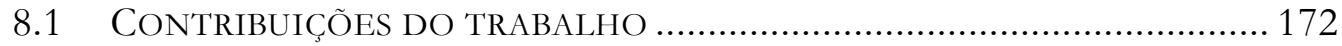

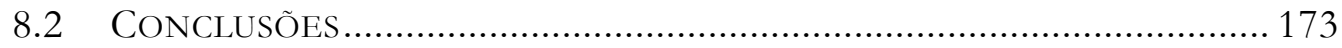

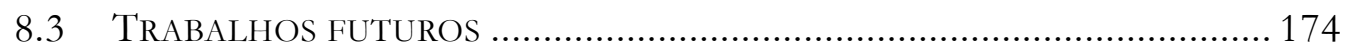

REFERÊNCIAS BIBLIOGRÁFICAS............................................. 175

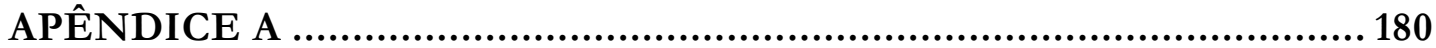

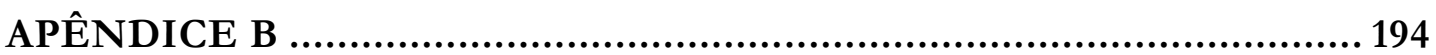




\section{Lista de Tabelas}

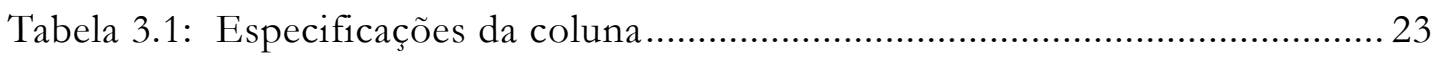

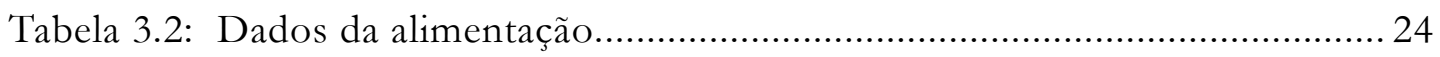

Tabela 3.3: Propriedades dos componentes da alimentação.................................. 25

Tabela 3.4: Valores de operação da coluna ........................................................... 26

Tabela 3.5: Participação de cada componente na alimentação da coluna ............... 32

Tabela 3.6: Composição dos produtos para operação no regime nominal ............ 34

Tabela 3.7: Composição dos produtos após degrau de 10\% ….............................. 39

Tabela 3.8: Composição dos produtos após degrau de $-10 \%$................................. 45

Tabela 3.9: Composição dos produtos após rampa de 20\% …............................... 50

Tabela 5.1: Lista dos algoritmos de treinamento disponíveis no Matlab ${ }^{\circledR}$.............. 96

Tabela 5.2: Cálculo dos erros médios apresentados pelas redes............................ 99

Tabela 5.3: Quadro resumo das 4 melhores redes obtidas após treinamento...... 101

Tabela 5.4: Quadro resumo das 4 melhores redes obtidas após treinamento...... 104

Tabela 5.5: Quadro resumo das 2 melhores redes obtidas após treinamento...... 104

Tabela 6.1: Quadro resumo dos resultados para treinamento intervalado........... 117

Tabela 6.2: Quadro resumo ordenado do treinamento intervalado ..................... 120

Tabela 6.3: Quadro resumo dos erros para as duas avaliações ............................. 132

Tabela 6.4: Quadro comparativo dos retreinamentos do sensor ......................... 136 


\section{Lista de Figuras}

Figura 3.1: Esquema da coluna de destilação simulada dinamicamente................. 22

Figura 3.2: Perfil de pressão ao longo da coluna …............................................. 28

Figura 3.3: Perfil de temperaturas ao longo da coluna .......................................... 29

Figura 3.4: Perfil dos fluxos de líquido e vapor que circulam pela coluna.............. 31

Figura 3.5: Perfil de composições do líquido ao longo da coluna........................... 33

Figura 3.6: Perfil de composições do vapor ao longo da coluna............................. 34

Figura 3.7: Perfil da composição do componente 2 antes e após degrau de 10\%.36

Figura 3.8: Perfil da composição do componente 3 em cada estágio..................... 37

Figura 3.9: Composição dos componentes nos pratos antes e depois do degrau . 38

Figura 3.10: Composição dos componentes na fase vapor..................................... 39

Figura 3.11: Perfil da temperatura ao longo da coluna antes e após o degrau....... 40

Figura 3.12: Perfil da composição do comp. 2 antes e após degrau de $-10 \%$......... 41

Figura 3.13: Perfil da composição do componente 3 em cada estágio.................... 42

Figura 3.14: Perfil da composição do componente 4 em cada estágio.................... 43

Figura 3.15: Composição dos componentes nos pratos antes e depois do degrau 44

Figura 3.16: Composição dos componentes no vapor dos pratos.......................... 44

Figura 3.17: Perfil da temperatura ao longo da coluna antes e após o degrau....... 46

Figura 3.18: Perfil da composição do componente 2 antes e após rampa de $20 \% 47$

Figura 3.19: Perfil da composição do componente 3 em cada estágio................... 48

Figura 3.20: Perfil da composição do componente 4 em cada estágio.................... 48 
Figura 3.21: Composição dos componentes nos pratos antes e depois da rampa. 49

Figura 3.22: Composição dos componentes no vapor dos pratos.......................... 50

Figura 3.23: Perfil da temperatura ao longo da coluna antes e após o degrau........ 51

Figura 4.1: Perfil de temperaturas na coluna durante excitação aleatória .............. 59

Figura 4.2: Detalhe do perfil de temperaturas nos pratos inferiores da coluna..... 60

Figura 4.3: Covariância cruzada das temperaturas nos pratos $\left(\mathrm{T}_{\mathrm{i}}\right)$ e $\mathrm{x}_{2,17} \ldots \ldots \ldots \ldots \ldots . . . .61$

Figura 4.4: Covariância cruzada das temperaturas nos estágios $\left(\mathrm{T}_{\mathrm{i}}\right)$ e $\mathrm{x}_{2,17} \ldots \ldots \ldots \ldots . . .62$

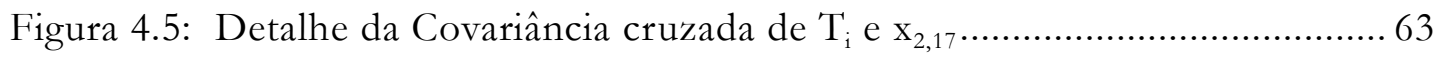

Figura 4.6: Comparação da composição de $x_{2,17}$ após degrau................................. 67

Figura 4.7: Detalhe da obtenção da menor constante de tempo do sistema .......... 68

Figura 4.8: Auto-covariância das composições $\mathrm{x}_{2,17}$ com atraso ............................. 70

Figura 4.9: Detalhe da obtenção do menor tempo de acomodação do sistema .... 71

Figura 4.10: Bloco funcional gerador do sinal aleatório para a variável QR..........73

Figura 4.11: Exemplo da perturbação no fluxo de vapor da alimentação...............73

Figura 5.1: Rede neural com uma camada oculta ................................................ 76

Figura 5.2: Esquema de rede neural MLP feedforward ....................................... 83

Figura 5.3: Esquema simplificado de uma rede recorrente de Elman.................... 85

Figura 5.4: Funções de transferência ….................................................................. 89

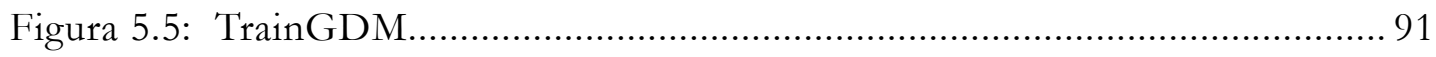

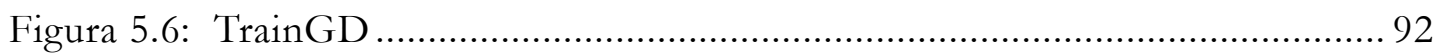

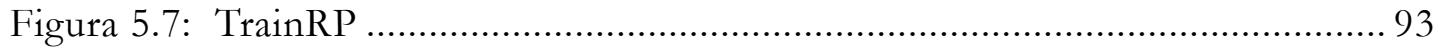

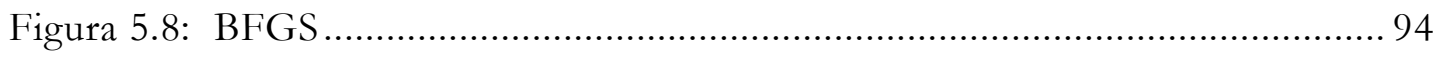

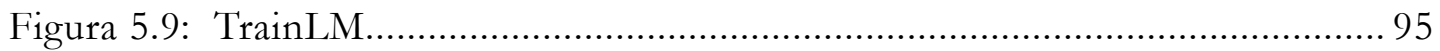

Figura 5.10: Média do erro obtido para a melhor metade das redes de Elman ... 100

Figura 5.11: Erro mínimo apresentado pelas melhores redes de Elman.............. 100

Figura 5.12: Erro obtido para a melhor metade das redes Feedforward.............. 102

Figura 5.13: Erro mínimo apresentado pelas melhores redes Feedforward......... 103 
Figura 5.14: Convergência dos erros de treinamento da rede Elman .................. 106

Figura 5.15: Erro apresentado para conjuntos de treinamento e validação .......... 106

Figura 5.16: Comparação da estimação obtida do sensor e esperada..................... 107

Figura 5.17: Média do erro obtido para a melhor metade das redes Elman........ 110

Figura 5.18: Erro mínimo apresentado pelas melhores redes Elman.................. 110

Figura 5.19: Erro obtido para a melhor metade das redes Feedforward.............. 111

Figura 5.20: Erro mínimo apresentado pelas melhores redes Feedforward......... 111

Figura 6.1: Erro MSE apresentado pela rede para treinamento parcial ............... 118

Figura 6.2: Erro Máximo apresentado pela rede para treinamento parcial.......... 118

Figura 6.3: Erro MSE em ordem apresentado para treinamento parcial .............. 121

Figura 6.4: Erro Máx em ordem apresentado para treinamento parcial .............. 121

Figura 6.5: Histogramas da composição do componente 2 no topo...................... 126

Figura 6.6: Histogramas da vazão de refluxo na coluna ....................................... 126

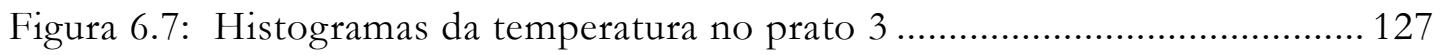

Figura 6.8: Histogramas da temperatura no condensador.................................. 127

Figura 6.9: Gráfico do desempenho durante o treinamento do sensor virtual.... 129

Figura 6.10: Erro percentual entre os valores estimado e esperado..................... 130

Figura 6.11: Valor estimado pelo sensor e esperado utilizado no treinamento ... 131

Figura 6.12: Valor estimado pelo sensor e esperado fornecido pelo simulador .. 131

Figura 6.13: Valor estimado pelo sensor e esperado............................................ 133

Figura 6.14: Erro percentual entre os valores estimado e esperado..................... 133

Figura 6.15: Erro apresentado pelo sensor sem treinamento prévio ................... 137

Figura 6.16: Resultados apresentados pelo sensor sem treinamento prévio........ 138

Figura 6.17: Detalhe dos resultados apresentado pelo mesmo sensor.................. 138

Figura 6.18: Resultado apresentado pelo sensor para os dados de treinamento.. 139

Figura 6.19: Detalhe da resposta estimada após treinamento com 2.000 pontos 140

Figura 6.20: Erro apresentado pelo sensor sem treinamento prévio 140 
Figura 6.21: Erro apresentado pelo sensor treinado com o simulador 142

Figura 7.1: Exemplo de resposta do sensor virtual com erro espúrio 147

Figura 7.2: Exemplo de resposta do sensor virtual com erro sistêmico 148

Figura 7.3: Erro apresentado pelo sensor virtual 151

Figura 7.4: Comparação das respostas apresentadas pelo sensor e pela planta ... 152

Figura 7.5: Detalhe do pico de erro entre sinal esperado e estimado 152

Figura 7.6: Convergência do erro no retreinamento da rede com 100 pontos .... 154

Figura 7.7: Erro após retreinamento com 100 pontos 154

Figura 7.8: Convergência do erro no retreinamento da rede com 1.100 pontos. 155

Figura 7.9: Erro após retreinamento com 1.100 pontos 156

Figura 7.10: Comparação dos erros antes e após retreinamento (1.100 pontos). 157

Figura 7.11: Detalhe do erro antes e após retreinamento com 1.100 pontos ....... 157

Figura 7.12: Detalhe do erro antes e após retreinamento com 1.100 pontos ....... 158

Figura 7.13: Convergência do treinamento da rede com 500 pontos 159

Figura 7.14: Erro apresentado após treinamento com 500 pontos..... 160

Figura 7.15: Convergência do treinamento da rede anterior para novos pontos. 160 Figura 7.16: Erro apresentado após retreinamento com $(500+100)$ pontos........ 161

Figura 7.17: Convergência do treinamento da rede com 100 pontos do pico ..... 162

Figura 7.18: Erro geral após retreinamento com $(500+100+100)$ pontos........... 162

Figura 7.19: Convergência do erro durante o treinamento da rede. 165

Figura 7.20: Erro apresentado pela rede durante validação com estimadores..... 166

Figura 7.21: Comparação das composições no início do erro sistêmico .............. 167

Figura 7.22: Visão geral das composições esperada e estimada pelo sensor......... 167

Figura 7.23: Funções de transferência utilizadas............................................... 168

Figura 7.24: Erro apresentado durante validação com dados do simulador ........ 169

Figura 7.25: Composições esperada e estimada durante o erro espúrio 169 


\section{Capítulo 1}

\section{Introdução}

\subsection{Objetivo}

Sensores virtuais empregando modelos de inferência da composição (responsável pela qualidade) dos produtos de uma coluna de destilação correspondem a medidores implementados em "software", capazes de estimar, em tempo real, a composição dos produtos de saída da mesma, a partir de informações do tipo temperaturas e pressões em diversos pontos da coluna e vazões de entrada, de saída e de reciclo.

Neste trabalho, o objetivo é obter esse tipo de sensor para uma coluna de destilação simulada dinamicamente, com base em redes neurais artificiais. Propõese ainda realizar um estudo dos efeitos do treinamento intervalado na rede neural, com vistas a que um sensor desenvolvido a partir de um modelo simulado dinamicamente possa ser adaptado à coluna real em que operará. Além disso, propõe-se ainda um método que possibilite correções das estimativas atuais apresentadas pelo sensor caso apresente erros decorrentes do treinamento. 


\subsection{Motivação}

As variáveis de interesse em processos químicos são normalmente variáveis físicas e químicas, sendo que as mais comuns são temperatura, pressão, vazão e nível. Para medir as variáveis físicas, há uma grande variedade de sensores e transdutores com boa precisão, normalmente disponíveis a custos bastante acessíveis para as indústrias e que operam com tempos de resposta baixos, da ordem de décimos de segundo ou, no pior caso, de poucos segundos.

Quando se trata de variáveis químicas (analíticas), há casos em que os medidores também operam com tempos de resposta baixos e que são vendidos a preços relativamente baixos, como, por exemplo, o caso de medidores de $\mathrm{pH}$ ou de potencial de óxido-redução. No entanto, quando se fala de medir variáveis químicas ou bioquímicas relacionadas com composição, como medição de DO (concentração de oxigênio dissolvido), $\mathrm{O}_{2}, \mathrm{CO}, \mathrm{CO}_{2}, \mathrm{NH}_{3}$ ou outras variáveis relacionadas com biomassa, a situação, em termos de medidores, fica bem mais difícil. Há muitos casos em que as análises são feitas em laboratório, através da coleta de amostras e o tempo de resposta pode ser de minutos ou até mesmo horas. Mesmo que se disponha de um analisador em linha (“on-line”), o atraso na medição pode ser longo e o custo do instrumento muito elevado.

Por outro lado, caso se deseje manter as especificações de qualidade de certos produtos, é necessário conhecer sua composição para poder se implementar um sistema de controle eficiente. Nestes casos, se existe um analisador em linha, com tempo aceitável de resposta, precisão razoável e baixo custo, é possível se cogitar a implementação de uma estratégia de controle avançado. Infelizmente, no entanto, tal tipo de analisador não está disponível em muitas situações práticas na indústria. Um sensor virtual, medidor inferencial, medidor indireto ou "soft sensor” deve ser considerado como uma possível opção para estimar a(s) variável(is) de interesse nestas situações (CHU et al., 1998). 
Um sensor virtual corresponde a um método indireto ou inferencial de medição em tempo real, em que um modelo matemático estático, ou preferencialmente dinâmico do processo é empregado em conjunto com uma ou mais variáveis medidas, normalmente do tipo vazão, pressão ou temperatura (variáveis físicas), para as quais os medidores disponíveis no mercado, conforme já citado anteriormente, são de baixo custo, de boa precisão e de resposta rápida. $\mathrm{O}$ modelo dinâmico empregado deve ter como entradas essas variáveis físicas e, como saída, o valor da composição dos produtos de interesse.

Segundo Zamprogna et al. (2001), "apesar de a cromatografia gasosa estar disponível para obter análises "on-line” de amostras de produtos, raramente são utilizadas em aplicações de coluna de destilação, porque são caras de implementar e manter e (mais importante) elas introduzem atrasos nas medidas, como tempo de amostragem e tempo morto. O atraso introduzido pela cromatografia pode causar prejuízo ao controle do processo, inviabilizando sua implementação. Outras técnicas como medida baseada na análise de índice de refração, densidade ou constante dielétrica também não são suficientemente confiáveis ou precisas, para utilização em aplicações de destilação".

Outro inconveniente dos medidores de composição disponíveis refere-se ao seu tempo de resposta. Por exemplo, em (WANG; RONG, 1999) cita-se que o período necessário para um analisador em linha fornecer os resultados da composição do produto destilado em uma coluna de destilação é de 16,5 minutos.

No caso deste trabalho, a proposta é empregar sensores virtuais para analisar a composição dos produtos que saem de uma coluna de destilação, a partir da medição da temperatura em alguns pratos, da vazão de reciclo e das vazões de entrada e saída. Essas variáveis inferidas poderiam então ser fornecidas a um sistema de controle inferencial, que busque manter a qualidade desses produtos dentro das especificações, ou então a um sistema supervisório, para acompanhamento temporal do valor dessas composições. 


\subsection{Justificativa}

Para o controle da composição dos produtos de saída em colunas de destilação é raro que medições dessa variável sejam diretamente utilizadas como variáveis controladas, visto que a medição da composição em linha, feita de forma precisa e em tempo real é ainda pouco utilizada. A maioria dos analisadores, como o cromatógrafo gasoso, apresenta grandes atrasos na medição (quando realizado com o auxílio de laboratórios), ou são difíceis de manter (quando realizados "online"), além de custos altos de aquisição e manutenção (KANO et al., 2000).

Em vez de controlar a composição através da medição direta da mesma utilizando um analisador de composição, é amplamente empregado na indústria o controle da temperatura em determinadas bandejas ou pratos. Neste caso, supõe-se que a medição da temperatura nestas bandejas possa ser utilizada para inferir a composição real. Este tipo de controle é baseado na hipótese que a composição do produto possa atender sua especificação quando uma temperatura adequada em um determinado prato é mantida em certo valor de referência.

Para uma coluna de destilação operando com uma mistura binária a pressão constante, a regra de fase de Gibbs indica que há uma relação entre a composição e a temperatura de equilíbrio. Tem-se então que a temperatura em um extremo da coluna é um indicador exato da correspondente composição do produto. Dessa forma, uma equação termodinâmica pode ser empregada para relacionar a temperatura, por exemplo, do prato de topo da coluna à composição do destilado.

No entanto, para a separação de misturas multicomponente, modelos empíricos devem ser utilizados para estimar as composições. Através da utilização de dados da planta, modelos empíricos podem ser obtidos, através de técnicas de identificação de sistemas, relacionando a fração molar do componente chave pesado às temperaturas em diversas bandejas (normalmente próximas ao topo da coluna). Dessa forma, a composição do destilado pode ser inferida a partir das medições 
disponíveis de temperatura. Neste caso, os parâmetros do modelo obtido podem ser atualizados, se necessário, conforme medições reais da composição se tornem disponíveis (MARLIN, 1995), (SOROUSH, 1998). No entanto, as variações de temperatura nos extremos da coluna costumam ser muito pequenas e pode ser difícil distinguir o sinal do ruído de medição (KANO et al., 2000).

$\mathrm{Na}$ prática, o que normalmente se faz é selecionar um prato apropriado (denominado prato sensível), que não são os pratos dos extremos da coluna, com base em sua sensibilidade de temperaturas a alterações na composição da alimentação e nos fluxos de reciclo e do refervedor. Nos casos em que ocorram mudanças na composição ou na vazão de alimentação, em colunas multicomponentes, é muito difícil manter a composição do produto em seu valor de referência através do controle de temperatura, visto que a temperatura do prato sensível não corresponde exatamente à composição dos produtos. Além disso, mudanças na pressão também podem causar variações na temperatura (KANO et al., 2000).

Para poder fazer o controle de composição em linha, um sistema de controle inferencial é altamente recomendável. No controle inferencial, a composição dos produtos é estimada a partir de outras variáveis medidas do processo e as estimativas são utilizadas para controle. Portanto, é essencial obter-se um modelo inferencial bastante preciso.

Um modelo fenomenológico seria o ideal, desde que disponível e que provesse precisão suficiente com uma carga computacional razoável. No entanto, na prática, para colunas de grande porte, o número de equações diferenciais envolvido é muito alto e, portanto, há uma tendência na demora em sua execução, o que pode inviabilizar o controle, que deve ocorrer em tempo real.

Uma solução mais rápida, que não gera um modelo interno com variáveis de estado, mas sim um modelo externo apenas com variáveis de entrada e saída, é utilizar um modelo empírico, determinado a partir de dados do processo. 
Para calcular uma estimativa de uma quantidade desconhecida a partir de um conjunto de quantidades conhecidas, deve existir um modelo matemático que descreva quantitativamente a relação entre essas quantidades. O estimador, o qual é projetado com base nesse modelo, deve prover uma estimativa confiável da quantidade desconhecida, isto é, uma estimativa em que o erro de estimação seja nulo em estado estacionário, mesmo quando existam divergências entre as saídas da planta e do modelo, quando perturbações não medidas estejam presentes ou quando o processo é variante no tempo (SOROUSH, 1998).

Além disso, uma prática muito empregada em plantas industriais é a utilização de laboratórios de análise, que empregando técnicas precisas de análise, conseguem medir a composição de uma dada amostra. Porém, estes dados são apresentados com um atraso bastante considerável, o que inviabiliza sua utilização para o controle do processo de destilação. Porém, estes valores podem ser utilizados para aferir a predição feita pelo sensor virtual no momento em que foi feita a coleta da amostra. A proposta é desenvolver um método para utilizar estes dados fornecidos pelo laboratório para efetuar verificações e eventuais correções na predição feita, caso apresentem distorções e corrigir as predições atual e futura com base nos valores fornecidos.

\subsection{Estudo das referências bibliográficas}

A seguir estão listadas algumas das principais referências encontradas, cujo tema tratado está de alguma forma relacionado ao tema desenvolvido na dissertação. É fornecido também um pequeno resumo dos tópicos apresentados que despertaram maior interesse. Os artigos, listados a seguir, estão ordenados de acordo com o grau de afinidade que possuem com o tema da presente dissertação.

Zamprogna, Barolo e Seborg (2001): Neste artigo os autores propõem um sensor virtual para uma coluna de destilação batelada. A técnica empregada 
utiliza uma rede neural recorrente que recebe informações de temperaturas e fluxos da coluna. Aborda também técnicas estatísticas para redução do número de entradas através de análise dos componentes principais e os efeitos de ruído no conjunto de dados.

Fileti et al. (1999): Propõe um sensor virtual para uma coluna de destilação multicomponente batelada de uma planta piloto empregando redes neurais "feedforward". Utiliza como entradas para a rede basicamente as temperaturas de topo e base e compara os resultados obtidos com medições laboratoriais por cromatografia gasosa.

Bhartiya e Whiteley (2000): Em um artigo mais teórico, os autores propõem uma sistemática para o desenvolvimento de um medidor inferencial utilizando técnicas de redes neurais e também destacam a importância deste tipo de sensor para medidas "on-line”. Detalham a metodologia empregada através da análise estatística para identificar o subconjunto das variáveis que apresentam interesse no esquema inferencial. Implementam a técnica em um processo de refinamento de uma torre de fracionamento de petróleo.

James et al. (2000): Neste artigo, cujo enfoque principal é sensores virtuais para bioreatores, os autores mostram os resultados de uma ampla pesquisa bibliográfica realizada, até a publicação do texto, no desenvolvimento de medidores inferenciais para processos bioquímicos, e os classificam em três categorias distintas em que situam todas as abordagens. Apresentam também um sumário dos analisadores com as respectivas técnicas utilizadas, data de desenvolvimento e aplicação, de modo que permite avaliar onde estão ocorrendo os avanços mais significativos e que técnicas utilizam.

Mejdell e Skogestad (1991a e 1991b): Dois artigos publicados em uma mesma revista. O primeiro propõe um sensor virtual para colunas de destilação contínuas (binárias ou multicomponentes), que utilizam modelos em espaço de estados que empregam técnicas de regressão de componentes principais 
(PCR - Principal Component Regression) e mínimos quadrados (PLS - Partial Least Squares). O artigo fornece ainda um procedimento para análise da dinâmica da coluna e possível simplificação do seu estudo para pseudobinária, sem perdas de generalizações. No segundo artigo, implementam o sensor em uma coluna piloto e utilizam medidas de temperaturas de todos os 11 pratos da mesma para efetuar a inferência.

Hong et al. (1999): Neste artigo os autores alertam para o perigo da perda de poder de predição de um sensor virtual que seja treinado com dados ruidosos ou de faixas de operação diferentes (dados heterogêneos). Propõem um procedimento para modelagem empírica de sistemas objetivando que o conjunto de dados utilizado seja homogêneo (através de seleção e classificação dos dados e modelagem por subclasses). A metodologia é ilustrada através de aplicação em um sensor virtual de composição para uma coluna de destilação binária simulada.

Martin e Gerhard (1997): Artigo com enfoque bastante operacional escrito por dois pesquisadores que atuam diretamente lidando com o ambiente industrial. Restringem-se ao desenvolvimento de analisadores virtuais através da modelagem empírica utilizando redes neurais. Descrevem a metodologia para desenvolvimento dos mesmos, bem como sua utilização para detecção de falhas. Por fim, relatam muitos exemplos de áreas de aplicação em que estão sendo instalados estes sensores.

Dong, Quian e Sun (1994): Apresentam um sensor virtual empregando redes neurais recorrentes do tipo Elman modificado (realimentação interna das saídas após atraso) e treinadas com o algoritmo recursivo GBP (Generalized Backpropagation). Mostram a boa capacidade deste tipo de redes para mapear sistemas dinâmicos de alta ordem (MIMO) e a vantagem do algoritmo recursivo para acompanhar variações temporais. 


\subsection{Estrutura da dissertação}

Nesta seção são apresentadas a estrutura da dissertação e uma breve descrição de cada um dos capítulos. O trabalho está dividido em 8 capítulos da seguinte forma:

Capítulo 1 - Introdução: Neste capítulo são descritos o objetivo do trabalho e a motivação que levou ao desenvolvimento do mesmo. A seguir, é complementado por uma revisão bibliográfica com as principais publicações encontradas relacionadas ao tema da dissertação e, por fim, uma explicação da estrutura geral desta.

Capítulo 2 - Sensores virtuais: Inicia-se com uma breve introdução aos sensores virtuais, sua importância e exemplos de áreas de aplicações industriais. Depois se passa a uma rápida exposição dos tipos de sensores encontrados e dos métodos mais utilizados.

Capítulo 3 - Coluna de destilação: Neste capítulo faz-se uma rápida introdução sobre colunas de destilação e sua importância. Em seguida descreve-se a coluna empregada e, finalmente, a caracterização do comportamento dinâmico da mesma para uma faixa próxima ao regime nominal de operação.

\section{Capítulo 4 - Projeto do experimento e coleta dos dados para identificação:} Aqui são apresentadas as várias etapas realizadas na definição do experimento e do conjunto de dados para treinamento, tais como: a seleção das variáveis de entrada e saída, a escolha do sinal de excitação a ser utilizado e a definição de período de amostragem. Além disso, também é realizada a coleta dos dados.

Capítulo 5 - Redes Neurais Artificiais: Aqui é apresentada uma breve introdução sobre as redes neurais e suas vantagens em identificação de processos. 
Em seguida, é apresentado um estudo comparativo para auxiliar a definir a arquitetura da rede a ser utilizada e a sua estrutura interna. Finalmente, analisam-se também os efeitos do acréscimo de regressores e estimadores no sensor.

Capítulo 6 - Sensor virtual com treinamento parcial: Neste capítulo é inicialmente mostrado um estudo dos efeitos do treinamento parcial em redes neurais. Em seguida, é apresentado um novo conjunto de dados diferentes para treinamento combinado do sensor desenvolvido e finalmente, é realizada uma comparação dos resultados finais obtidos.

Capítulo 7 - Sensor virtual com correção de erros: Este capítulo inicia-se com uma introdução sobre a importância da utilização dos conjuntos de dados simulado e real e, em seguida, descrevem-se os principais erros encontrados que são estudados neste projeto, bem como sua detecção e as propostas de correção.

Capítulo 8 - Considerações finais: Neste capítulo são consideradas as contribuições a respeito dos resultados do trabalho, as conclusões obtidas e sugestões de trabalhos futuros. 


\section{Capítulo 2}

\section{Sensores Virtuais}

\subsection{Introdução}

"Sensores virtuais são algoritmos matemáticos (modelos inferenciais) capazes de estimar, em tempo real, variáveis de interesse não medidas a partir de outras variáveis disponíveis, medidas instantaneamente" (JAMES et al., 2000).

A idéia de utilização de sensores virtuais já é bastante antiga e remonta à modelagem matemática de processos com enfoque na predição de propriedades a partir de dados da planta. Os primeiros sensores virtuais surgiram a partir de sistemas de controle indiretos, nos quais a variável a ser controlada (primária) era controlada através do comportamento de outras variáveis (secundárias), normalmente temperaturas. Um dos primeiros sensores desenvolvidos é o estimador inferencial de Brosilow, apresentado no final da década de 70 (JOSEPH; BROSILOW, 1978).

Com o passar do tempo, estes modelos inferenciais foram evoluindo com o objetivo de estimar uma variável difícil de ser medida. A partir de então, nota-se um grande esforço para se obterem estes estimadores com maior precisão e confi- 
abilidade, através do emprego de uma grande variedade de técnicas. No entanto, apenas nas últimas décadas, sua utilização industrial tem crescido bastante.

A denominação "sensor virtual" é um termo recente cuja origem do nome está relacionada a uma das principais aplicações desta técnica que é a substituição de sensores físicos pelo análogo via "software". Porém, são também encontrados sob diversos outros nomes, sendo que os mais comuns são: analisador virtual (bastante difundido principalmente no ambiente industrial), "soft sensor" (cuja patente foi requerida recentemente pela Pavilion Tecnologies Inc.), estimador virtual (ou “on-line”), ou ainda medidor inferencial.

O termo "sensor virtual" é ainda utilizado para uma ampla variedade de técnicas estimativas que são empregadas para inferirem estados e parâmetros de um processo. Estados referem-se às variáveis que definem o comportamento do processo e normalmente aparecem na forma diferencial, como, por exemplo, a concentração de um produto; já os parâmetros são as variáveis que descrevem o processo e normalmente aparecem na forma algébrica, como, por exemplo, coeficientes, taxas de crescimento ou propriedades físicas. Assim, faz-se uma última distinção, quando o sensor virtual é utilizado para estimar os estados é comumente chamado "observador de estados" e quando é empregado para inferir parâmetros é denominado "estimador de parâmetros" (JAMES et al., 2000).

\subsection{Importância}

A grande difusão que vem ocorrendo com os sensores virtuais em aplicações industriais ocorre devido às vantagens que estes apresentam frente a alguns problemas de medição dos sensores reais e principalmente pelas vantagens competitivas destes. A seguir, veremos mais detalhadamente algumas características que os têm valorizado. 
Mejdell e Skogestad (1991b) em seus trabalhos sobre controle de colunas de destilação relatam que uma das maiores dificuldades que enfrentam é a de medir a composição dos produtos. Dentre as alternativas existentes de analisadores físicos, uma das mais empregadas é a cromatografia gasosa, porém, esta apresenta algumas desvantagens, como grandes atrasos na obtenção das medidas e alto custo operacional. O tempo necessário de resposta para estes cromatógrafos é da ordem de 10 a 20 minutos, o que impossibilita sua utilização para controle. Além disso, ressaltam também a desvantagem econômica, uma vez que exigem altos investimentos na aquisição e instalação (inclusive dos sistemas de backup), como também para a manutenção e operação, na qual afirmam ser comum a necessidade de um funcionário para cada três cromatógrafos.

Em outro artigo, Choi e Park (2001), trabalhando com processos de tratamento de esgoto que necessitam de sensores para medir a concentração de nitrogênio e fósforo dissolvidos, apontam o sensor virtual como uma ferramenta capaz de solucionar o problema da carência de sensores no mercado para medir esse tipo de variável. E mesmo nos casos em que existam alternativas para estes sensores, normalmente estas apresentam baixa confiabilidade ou precisão, bem como seu alto custo torna desvantajoso o seu emprego quando comparados com a possibilidade de implantação de sensores virtuais, mais acessíveis. Esta opinião também é compartilhada por Jianxu e Huihe (2002) que preferem os sensores virtuais pela maior confiabilidade e precisão nas estimativas principalmente em faixas extremas de operação, como afirmam no trabalho de desenvolvimento de um sensor virtual para uma unidade de craqueamento catalítico de combustíveis para produção de diesel.

Por fim, Park e Han (2000) concluem que quando estão disponíveis sensores que superem as limitações de custo, confiabilidade e grandes atrasos de resposta, isto gera a possibilidade de implantação de sistemas mais eficientes de controle e monitoração das plantas industriais, o que acarreta redução nas perdas de produto e energia, além de produtos tóxicos e problemas de segurança. 
Uma constatação local deste fato pode ser percebida pela crescente popularização da aplicação de analisadores virtuais para medidas de índice de fluidez (MI) de polímeros em suas plantas produtoras. O que pode ser justificado pelo fato de que os modelos desenvolvidos para esta aplicação são bastante confiáveis e muito precisos e possuem custos de desenvolvimento, instalação e manutenção bem mais baixos que a utilização de um reômetro em linha (MARTIN; GERHARD, 1997).

\section{3 Áreas de aplicação em processos}

Os sensores virtuais possuem uma grande área de aplicação, pois atuam auxiliando na monitoração, controle e otimização de processos em geral, fornecendo medições mais precisas, mais rápidas e mais confiáveis a um custo mais baixo tanto para desenvolvimento e implantação como para manutenção. Além disso, deve-se ressaltar que estes podem atuar substituindo vários sensores físicos ou trabalhando em conjunto com estes e auxiliando na monitoração e controle de falhas e manutenção preventiva.

Martin e Gerhard (1997) fornecem vários exemplos de áreas de aplicação de importância para estes sensores, como em refinarias ou unidades petroquímicas (em processos de destilação para inferir composição e ponto de fulgor de determinados produtos, e monitorar o intemperismo no GLP), polímeros (na medição do índice de fluidez (MI) dos mesmos), papel e celulose (medição da resistência e porosidade do papelão), mineração (para medidas de $\mathrm{pH}$ na neutralização da lama de extração de ouro), além de vários outros processos como: alimentício, farmacêutico, química fina, semicondutores, têxteis e fibras. 


\subsection{Tipos de sensores}

James et al. (2000), após realizarem um estudo bastante abrangente sobre as tecnologias empregadas para desenvolvimento de sensores virtuais em processos bioquímicos, afirmam que são encontradas na literatura três classes distintas de sensores de acordo com os modelos empregados. A primeira classe é composta por sensores baseados em modelagem caixa branca, obtida através de equações que descrevem a física do processo; a segunda classe é composta por sensores baseados em modelagem (ou identificação) caixa preta ou modelagem empírica; e finalmente, a terceira classe é composta por sensores baseados em modelos híbridos, uma combinação destas duas primeiras classes.

$\mathrm{Na}$ primeira classe, um modelo matemático é obtido através de equações que descrevam a natureza do processo, como balanços de massa e energia. Esta abordagem exige que se esteja familiarizado e se conheça a fundo o sistema a ser modelado, bem como, conhecer as relações matemáticas que descrevam os fenômenos envolvidos (AGUIRRE, 2004).

Este tipo de estimador é bastante atraente quando se possui um modelo relativamente simples do processo e que apresente resultados realistas. Porém, para muitos processos, principalmente químicos e biológicos, o modelo necessário é muito complexo, pois envolve além de muitas variáveis, características não-lineares. Para estes processos, normalmente os modelos não apresentam um comportamento próximo ao real e os sensores apresentam resultados desapontadores (MARLIN, 1995).

$\mathrm{Na}$ segunda classe, estão os modelos obtidos através de modelagem (ou identificação) caixa preta ou modelagem empírica que fornecem uma descrição do processo através de um mapeamento dos dados de entrada-saída. Nesta modelagem, a necessidade de conhecimentos detalhados do processo é eliminada, e podem-se conseguir bons resultados com pouco ou nenhum conhecimento prévio 
do sistema. Porém, os requisitos necessários são bastante distintos dos análogos na modelagem pela física do processo (AGUIRRE, 2004).

Nesta abordagem, o algoritmo de estimação utiliza um modelo genérico para representar a dinâmica do sistema. Existem vários métodos de estimação comumente empregados para modelagem não-linear, dentre eles destacam-se: identificação estatística, redes neurais artificiais e sistemas neuro-fuzzy (PARK; HAN, 2000).

Algumas desvantagens desta segunda classe estão relacionadas às dificuldades para selecionar a estrutura mais apropriada para este tipo de modelo, as funções a serem utilizadas e a quantidade de termos necessários ao modelo. Além disso, os modelos da primeira classe podem ser utilizados para estimar coeficientes de crescimento ou de rendimento diretamente, uma vez que as variáveis aparecem explícitas no modelo, o que não é possível para os modelos caixa preta da segunda classe.

A terceira classe é composta pela modelagem híbrida que combina, em um mesmo modelo do processo, abordagens das duas classes anteriores. O objetivo dos estimadores híbridos é estimar tanto parâmetros como estados, através da combinação do conhecimento do modelo do processo com a habilidade e poder do mapeamento dos dados de entrada-saída.

$\mathrm{Na}$ prática, os modelos obtidos pelo enfoque empírico ( $2^{\mathrm{a}}$ classe) são os mais populares e serão preferidos neste trabalho em que serão empregadas técnicas de modelagem através de redes neurais artificiais. A determinação da topologia da rede neural a ser utilizada será descrita em detalhes no capítulo 5.

Independente de qual enfoque se utilize, uma preocupação que deve haver ao desenvolver-se um sensor virtual é determinar quais são as melhores variáveis a serem consideradas como entradas para o modelo inferencial. No caso de colunas de destilação, uma questão fundamental é determinar quais vazões, pressões e quais 
temperaturas (associadas a cada uma das bandejas) devem ser utilizadas para inferir a composição dos produtos de saída, além de conhecimento sobre a composição da alimentação.

Um último fato que deve ser mencionado é que os sensores virtuais que vêm sendo desenvolvidos nos últimos anos empregam, em sua ampla maioria, a tecnologia baseada em redes neurais artificiais, conforme pode ser observado em muitas publicações (BHARTIYA e WHITELEY 2001; CAMARGO, TAKESAKO 2003; CHOI e PARK 2001; FILETI, PEDROSA e PEREIRA 1999; PARK e HAN 2000; MEJDELL e SKOGESTAD 1991b; ZAMPROGNA, BAROLO e SEBORG 2001). Este fato pode ser explicado devido aos resultados superiores apresentados pelas redes neurais, tanto na maior precisão e acuidade na estimação dos valores, como pela capacidade superior no reconhecimento de padrões em sistemas complexos, não-lineares e com atrasos. Comparativamente com outras tecnologias como "fuzzy" e "neuro-fuzzy" as redes neurais apresentam resultados melhores e com um custo computacional equivalente, conforme trabalhos citados a seguir.

Em um trabalho recente, Murakami, Tanabe e Okamoto (2002) desenvolveram um sensor virtual para medição do pH de uma solução em uma planta de neutralização (CSTR - Continuous Stirred Tank Reactor). O objetivo era analisar comparativamente diferentes abordagens para o desenvolvimento do sensor virtual e definir as vantagens e desvantagens que cada tecnologia trazia para a solução do problema. Durante o desenvolvimento do sensor foram empregadas 3 tecnologias diferentes: "fuzzy", "neuro-fuzzy" e redes neurais artificiais. Para todos os conjuntos de teste apresentados, as redes neurais apresentaram sempre menor erro, o que os autores afirmam ser devido à sua "maior capacidade de generalização e uma maior imunidade ao ruído" (MURAKAMI; TANABE; OKAMOTO, 2002).

Em outro trabalho, Camargo e Takesako (2003) desenvolveram um sensor virtual empregando redes neurais para determinação da concentração de oxigênio dissolvido em um processo de tratamento de águas residuárias. Durante o projeto foram utilizadas duas abordagens diferentes para a implementação do sensor: lógi- 
ca fuzzy e redes neurais artificiais, porém as redes neurais mostraram-se melhores

“... tanto na abordagem inicial (geração dos dados de treinamento com distribuição normal), quanto na solução encontrada para reduzir o erro percentual máximo (misturar dados de distribuição normal com uniforme)...” (CAMARGO, TAKESAKO, 2003).

\subsection{Metodologia a ser empregada}

A seguir, descreve-se a abordagem realizada no desenvolvimento deste trabalho. Segundo Marlin (1995), há dois diferentes enfoques para gerar as variáveis que se deseja inferir. No primeiro, intitulado enfoque analítico, elas são determinadas através de modelos analíticos do processo. No outro, denominado enfoque empírico, as variáveis inferenciais são determinadas com base em dados experimentais ou simulados do processo. Na prática, os modelos obtidos pelo enfoque empírico são os mais populares e serão preferidos neste trabalho em que serão empregadas técnicas de modelagem através de redes neurais artificiais.

Independente de qual enfoque seja utilizado, uma preocupação que deve haver ao desenvolver um sensor virtual é determinar quais são as melhores variáveis a serem consideradas como entradas para o modelo inferencial.

Os procedimentos gerais para construir um sensor virtual empírico são (PARK; HAN, 2000):

\section{a) Compreensão preliminar do processo}

Deve-se considerar, neste caso, tanto as análises teóricas quanto a experiência dos operadores da planta para determinar quais são as melhores variáveis de 
entrada do modelo, as relações entre as variáveis de entrada e as variáveis inferidas, as correlações aproximadas, as características dinâmicas como tempos mortos, etc.

\section{b) Qualidade dos dados experimentais}

Visto que um modelo empírico é baseado em dados experimentais, seu sucesso depende totalmente da qualidade dos dados coletados. Portanto, aspectos como intervalo de amostragem e atenuação de ruído devem ser levados em conta.

Os ruídos nos dados são um dos fatores mais importantes para o bom funcionamento do sensor, o que justifica o emprego de filtros e proteções dos sinais aquisitados. Para o projeto aqui desenvolvido será empregado um modelo simulado para fornecer os dados ao sensor, o que garante a inexistência de ruídos externos ao processo.

\section{c) Determinação e validação do modelo}

A estrutura do modelo é de fundamental importância, bem como sua validação, na qual se verificam sua precisão e robustez, através da utilização de um novo conjunto de dados experimentais (validação cruzada).

Esta metodologia resumidamente apresentada será melhor desenvolvida no decorrer dos próximos capítulos da dissertação. 


\section{Capítulo 3}

\section{Coluna de Destilação}

\subsection{Introdução}

Segundo Luyben (1990), depois do CSTR (Continuous Stirred Tank Reactor), as colunas de destilação são provavelmente o processo mais importante e popular dentro da Engenharia Química.

De acordo com Skogestad (1997a), o comportamento de colunas de destilação tem sido extensivamente estudado nos últimos 70 anos, mas ainda permanece uma área ativa de pesquisa. Há um interesse renovado nos últimos anos no estudo de colunas de destilação por pesquisadores nas áreas de dinâmica e controle de processos (SKOGESTAD, 1997b).

De acordo com Nascimento et al. (1990), tanto o custo crescente de matéria-prima e energia, como a elevação da concorrência econômica a níveis mundiais, tem exigido que a operação e o controle das plantas industriais, de forma geral, sejam conduzidos de forma otimizada quanto à produtividade e lucratividade, atendendo às exigências cada vez maiores de qualidade dos produtos finais. 
A título de ilustração, na dissertação de Mestrado de Marco Antonio Spinelli (1997), ele modelou, de forma simplificada, uma coluna de destilação real da empresa em que trabalhava (Rhodia Paulínia) e, através desse modelo, ele testou 1232 diferentes combinações de sintonia de um controlador PID, selecionando então a melhor e implantando na planta real. O ganho total obtido foi avaliado em cerca de US\$270.000,00 ao ano, correspondente a uma redução no consumo de vapor de US\$30.000,00 e um aumento na capacidade de produção de US\$240.000,00. Percebe-se então, claramente, a importância do controle desenvolvido, ainda que o mesmo fosse simplificado e não baseado na composição dos produtos de interesse do processo, o que gera um controle limitado ao comportamento de outras variáveis que não refletem tão fielmente o comportamento real da coluna.

\subsection{Descrição do modelo utilizado}

A seguir faz-se uma rápida e resumida descrição do modelo da coluna de destilação que será utilizado no desenvolvimento do sensor virtual, bem como de suas condições de simulação.

A coluna de destilação a ser estudada é baseada em um modelo apresentado por Luyben (1990). Este modelo foi implementado em Matlab/Simulink ${ }^{\circledR}$ por Zanata (2002) a partir do qual serão gerados os dados da simulação dinâmica. Os resultados obtidos neste projeto serão analisados através da avaliação do desempenho do sensor virtual desenvolvido, isto é, comparando-se os dados de saída do sensor virtual de composição com os dados de saída de composição gerados pelo simulador da coluna.

O modelo trata de uma coluna multicomponente, não ideal, com sobrefluxo não-equimodal e pratos ineficientes. Estas considerações introduzem várias características não lineares que deixam o modelo mais realista, porém, este apresenta 
ainda algumas simplificações, por exemplo, no cálculo de entalpias e massas específicas.

A Figura 3.1 apresenta um desenho esquemático da coluna de destilação empregada.

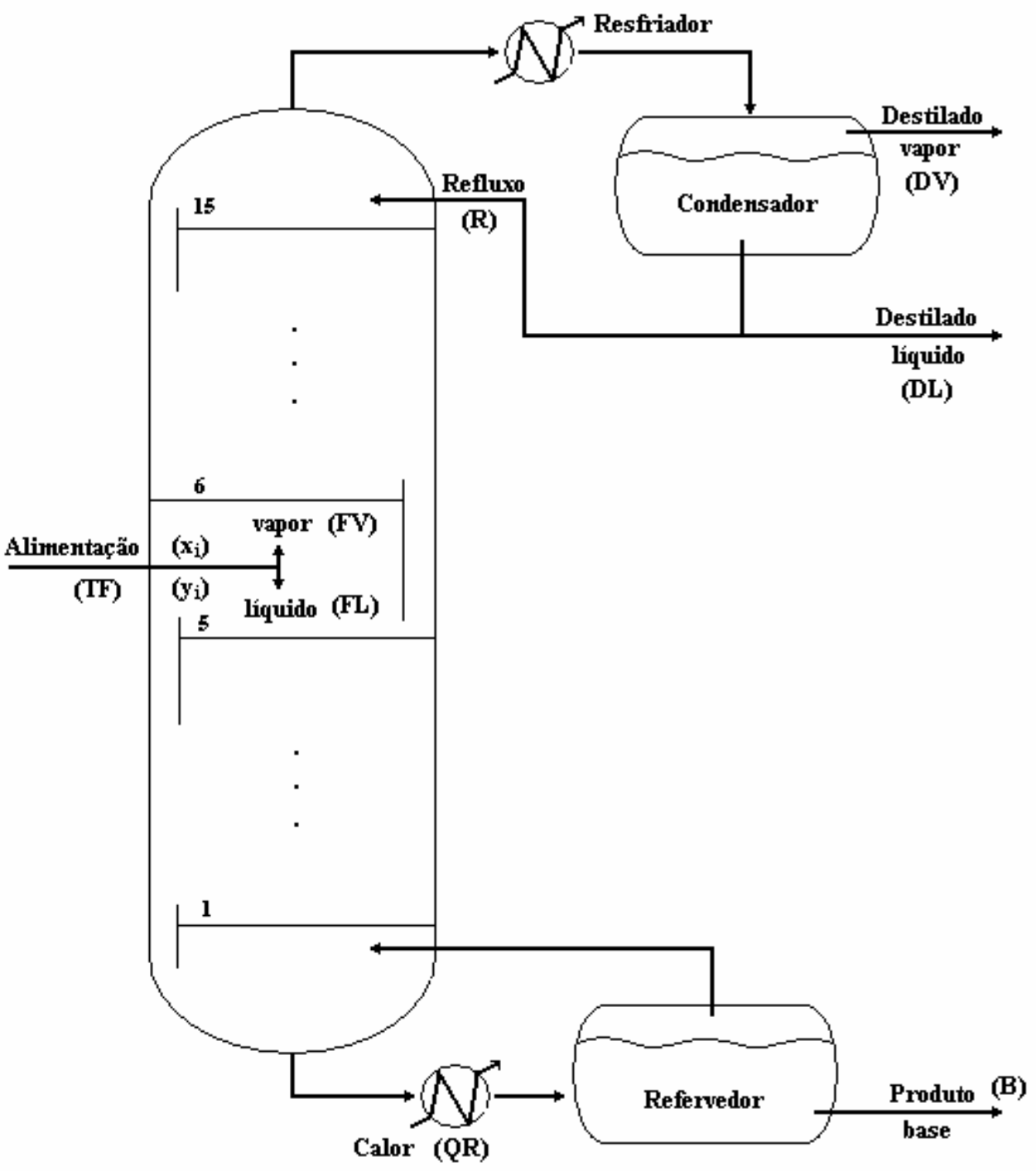

Figura 3.1: Esquema da coluna de destilação simulada dinamicamente 


\subsubsection{Especificações da coluna}

A coluna utilizada é composta de 15 pratos (ou bandejas), numerados de baixo para cima, além de um refervedor na base da coluna e um condensador parcial no topo da mesma, que são modelados como mais dois estágios. A alimentação é feita através de uma única entrada no prato 5 da coluna.

Esta unidade é dividida em duas seções: a seção "stripping" que engloba os estágios da base da coluna até o estágio de alimentação e a seção "rectifying" que engloba os estágios do prato de alimentação até o topo da coluna. Esta divisão é importante, pois deste modo o modelo pode representar mais eficientemente a dinâmica da coluna que possui maior nível de líquido nos pratos superiores.

As especificações da coluna utilizada, as dimensões e demais dados são fornecidos na Tabela 3.1.

Tabela 3.1: Especificações da coluna

Número de estágios total (condensador + refervedor) 17

Estágio de alimentação 6

\section{Diâmetro da coluna}

Seção "rectifying" $1,829 \mathrm{~m}$

Seção "stripping" $1,829 \mathrm{~m}$

\section{Comprimento do vertedouro no prato}

Seção "rectifying" $1,219 \mathrm{~m}$

Seção "stripping" $1,219 \mathrm{~m}$

\section{Altura do vertedouro no prato}

Seção "rectifying" $0,032 \mathrm{~m}$

Seção "stripping" $0,019 \mathrm{~m}$ 


\subsubsection{Alimentação}

A alimentação é composta por 5 componentes hipotéticos (mais pesado, pesado, intermediário, leve e mais leve) criados a partir de valores fornecidos por Luyben (1990). A alimentação fornecida à unidade de destilação é uma mistura nos estados líquido e vapor, por isto, é dita também mista, e que está em equilíbrio térmico.

A Tabela 3.2 apresenta, de forma resumida, as principais características da alimentação, na qual a composição é dada em fração molar para cada componente.

Tabela 3.2: Dados da alimentação

Número de componentes na alimentação: 5

\section{Alimentação}

Fase líquida

Temperatura: $322,04 \mathrm{~K}$

Fluxo: 362,84 kg.mol/h

Composição: $\left[\begin{array}{lllll}0,05 & 0,60 & 0,01 & 0,30 & 0,04\end{array}\right]$

\section{Fase vapor}

Temperatura: $322,04 \mathrm{~K}$

Fluxo: $90,72 \mathrm{~kg} \cdot \mathrm{mol} / \mathrm{h}$

Composição: $\left[\begin{array}{lllll}0,40 & 0,53 & 0,02 & 0,05 & 0\end{array}\right]$

Na Tabela 3.3 são fornecidos também os parâmetros e propriedades físicas para cada componente da mistura. 
Tabela 3.3: Propriedades dos componentes da alimentação

\section{Propriedades físicas}

Peso molecular: $\left[\begin{array}{lllll}30 & 50 & 90 & 130 & 300\end{array}\right] \mathrm{kg} / \mathrm{kg} \cdot \mathrm{mol}$

Massa específica: $\left[\begin{array}{lllllll}641 & 641 & 961 & 1121 & 1442\end{array}\right] \mathrm{kg} / \mathrm{m}^{3}$

Ponto de ebulição: $\left[\begin{array}{lllll}261 & 305 & 339 & 372 & 455\end{array}\right] \quad \mathrm{K}$

Capacidade térmica do vapor: $\left[\begin{array}{lllll}14 & 47 & 63 & 91 & 209\end{array}\right] \mathrm{kJ} / \mathrm{kg} \cdot \mathrm{mol} \cdot \mathrm{K}$

Capacidade térmica do líquido: $\left[\begin{array}{lllll}42 & 70 & 105 & 121 & 279\end{array}\right] \mathrm{kJ} / \mathrm{kg} \cdot \mathrm{mol} . \mathrm{K}$

\section{Pressão de vapor - Equação de Clapeyron}

Temperatura 1: $\left[\begin{array}{lllll}261 & 305 & 339 & 372 & 455\end{array}\right] \quad \mathrm{K}$

Pressão de vapor para temp. 1: $\left[\begin{array}{lllll}101 & 101 & 101 & 101 & 101\end{array}\right] \mathrm{kPa}$

Temperatura 2: $\left[\begin{array}{lllll}272 & 366 & 366 & 422 & 489\end{array}\right] \quad \mathrm{K}$

Pressão de vapor para temp. 2:

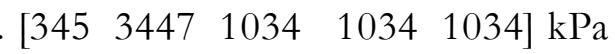

\subsubsection{Dados gerais da coluna}

As retiradas de produtos são realizadas em apenas dois locais, no condensador e no refervedor. Os componentes mais leves que chegaram ao topo da coluna, são resfriados por um trocador de calor e armazenados no condensador. Deste saem três fluxos: uma parte do líquido retorna para a coluna (refluxo), que possui fluxo constante; outra parte é retirada do destilado na forma de vapor, que também possui fluxo constante e, finalmente, uma retirada de destilado na forma líquida, cujo fluxo é controlado por uma válvula ideal que mantém o nível do reservatório constante (retira instantaneamente todo o líquido excedente).

Os componentes mais pesados que chegaram à base da coluna são armazenados no refervedor, onde são aquecidos. Deste sai um fluxo na forma de vapor que retorna a coluna, abaixo do primeiro prato e uma retirada de produto líquido da base da coluna, cujo fluxo é controlado por uma válvula ideal que mantém o nível do reservatório constante (retira instantaneamente todo o líquido excedente). 
Os dados apresentados na Tabela 3.4 resumem estas condições de operação.

Tabela 3.4: Valores de operação da coluna

Refluxo: $181,44 \mathrm{~kg} \cdot \mathrm{mol} / \mathrm{h}$

Destilado retirado na forma de vapor: $90,72 \mathrm{~kg} . \mathrm{mol} / \mathrm{h}$

Calor adicionado ao refervedor: $5,28 \cdot 10^{9} \mathrm{~J}$

Eficiência de Murphree: 0,5

\section{Pressão}

Condensador $135,83 \mathrm{kPa}$

Refervedor $146,17 \mathrm{kPa}$

\section{Acúmulo de líquido}

Condensador $0,2832 \mathrm{~m}^{3}$

Refervedor $0,2832 \mathrm{~m}^{3}$

Além disso, os pratos são modelados como não-ideais e a eficiência é considerada de acordo com a fórmula de Murphree.

$$
E_{N, J}=\frac{y_{N, J}-y_{N-1, J}^{T}}{y_{N, J}^{*}-y_{N-1, J}^{T}}
$$

Onde: $\boldsymbol{E}_{\boldsymbol{N}, J}$ é o coeficiente da eficiência de Murphree

$\boldsymbol{y}_{\boldsymbol{N}, J}$ é a composição atual do vapor no prato $\mathrm{N}$ do componente $\mathrm{J}$ $\boldsymbol{y}_{N, J}^{*}$ é a composição anterior do vapor no prato $\mathrm{N}$ do componente $\mathrm{J}$ $\boldsymbol{y}^{T}{ }_{N, J}$ é a composição do vapor no prato $\mathrm{N}$ do componente J, afetado pela alimentação 
Considera-se ainda que a coluna possua um gradiente linear de pressão entre o topo e a base da coluna. São fornecidos também os acúmulos de líquido (conhecidos como boldup) no condensador e refervedor.

A dinâmica dos fluxos em cada prato é expressa pela fórmula de Francis na qual se considera vertedouros retangulares.

$$
F_{L}=3,33 \cdot L_{W} \cdot\left(h_{O W}\right)^{1,5}
$$

Onde: $\boldsymbol{F}_{L}$ é a vazão de líquido acima do vertedouro $\left(\mathrm{ft}^{3} / \mathrm{s}\right)$

$\boldsymbol{L}_{W}$ é a altura do vertedouro $(\mathrm{ft})$

$\boldsymbol{h}_{\text {OW }}$ é a altura da coluna líquida acima do vertedouro (ft)

\subsection{Caracterização da coluna em regime}

Uma vez realizada a definição do problema a que vamos nos dedicar, seguese um primeiro estudo da coluna e da sua dinâmica de funcionamento no regime nominal de operação. Nesta seção, será analisado com mais detalhes o comportamento de cada variável.

Para a implementação do sensor virtual possui especial interesse as variáveis que serão monitoradas para delas se inferir a composição dos produtos de interesse. Estas variáveis devem ser de fácil medição, possuir precisão no valor medido e refletirem as variações das composições. Para o modelo visto, as variáveis de interesse podem ser: pressões (ao longo da coluna), temperaturas dos estágios (líquido e vapor estão submetidos à mesma temperatura) e fluxos de líquido e vapor que fluem pela coluna, principalmente nos estágios extremos. 


\subsubsection{Pressão}

Como visto na seção anterior a coluna de destilação do modelo possui um perfil de pressão linear entre o topo e a base da coluna. A Figura 3.2 mostra como se distribui o perfil das pressões na coluna quando se está em regime estacionário nas condições nominais de operação.

Para o objetivo da dissertação esta variável não gera interesse, pois uma vez que não sofre variações não é capaz de fornecer nenhuma informação extra sobre o comportamento do sistema, ou das alterações que ocorreram nas composições dos componentes nos pratos.

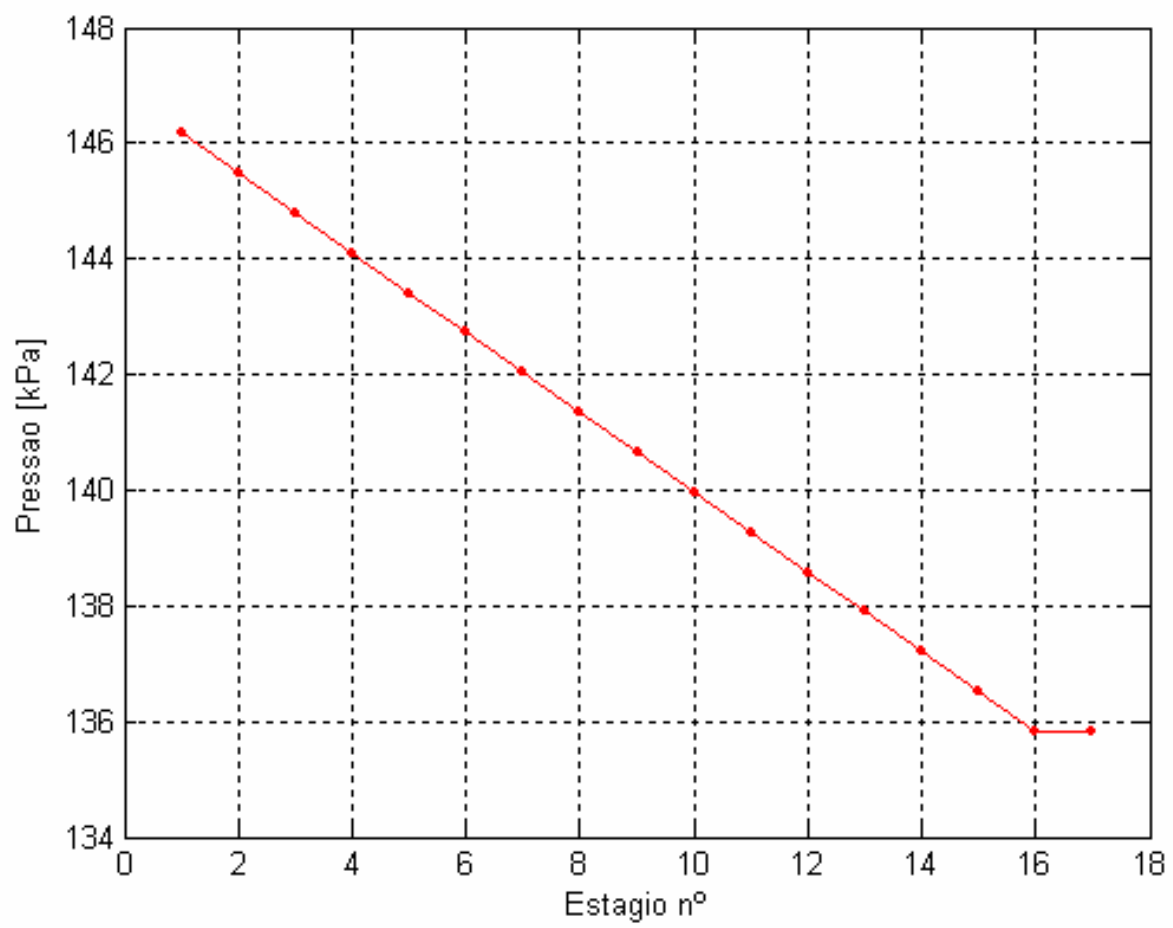

Figura 3.2: Perfil de pressão ao longo da coluna 


\subsubsection{Temperaturas}

As temperaturas são consideradas as variáveis mais importantes para inferência da composição dos produtos em uma coluna de destilação. Mejdell e Skogestad (1991a) afirmam que para misturas binárias à pressão constante, as temperaturas nos extremos da coluna são indicadores exatos das composições, mas não se pode garantir o mesmo para misturas multicomponentes, pois a presença dos componentes menos importantes afeta o comportamento da mesma.

A Figura 3.3 mostra como se distribuem as temperaturas nos vários pratos da coluna quando esta opera em regime estacionário nas condições nominais, sem perturbações externas. No estágio 6 pode-se observar um ponto que é referente ao valor da temperatura em que está a alimentação que a coluna está recebendo.

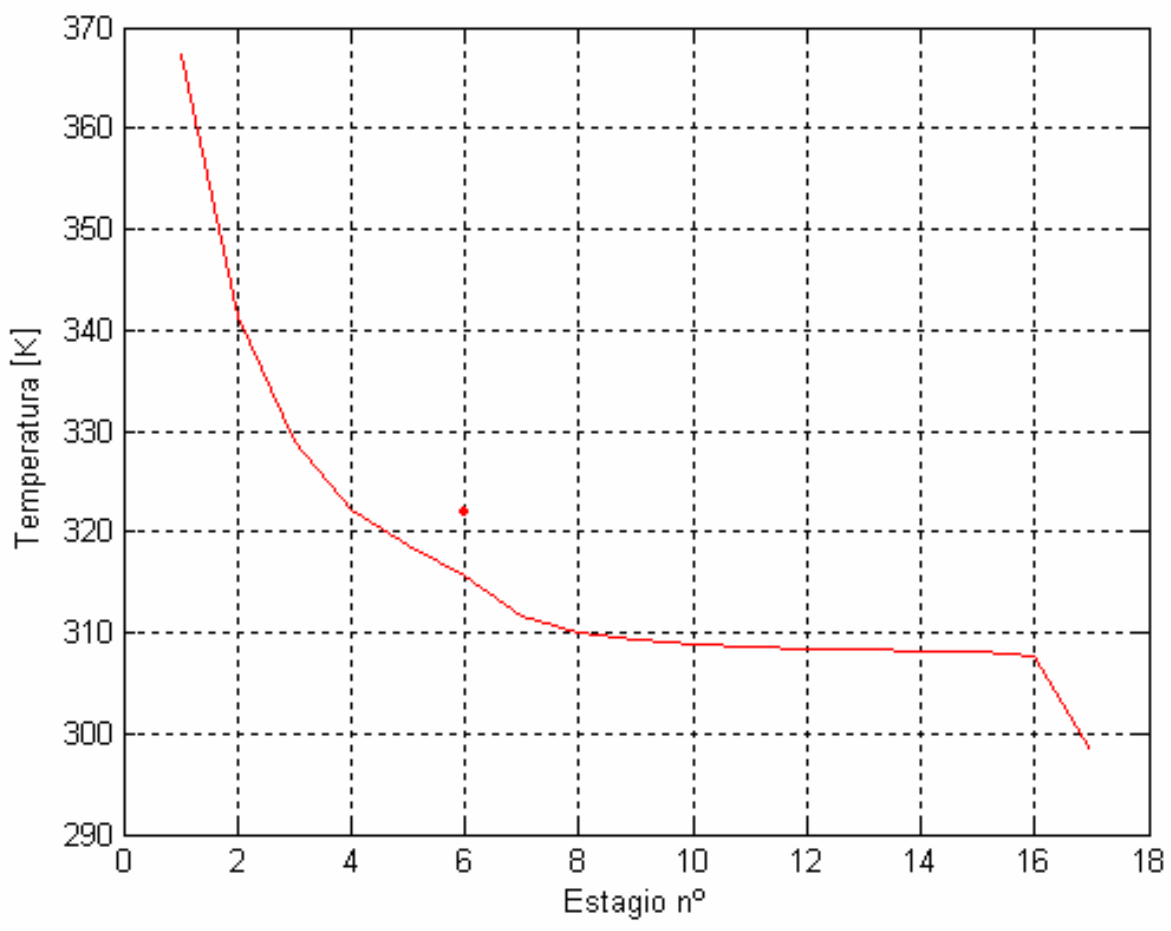

Figura 3.3: Perfil de temperaturas ao longo da coluna 
Várias abordagens para sensores virtuais foram feitas considerando como entradas do sistema apenas valores de temperatura em alguns pratos. Porém, para colunas multicomponentes utilizam-se medidas de temperatura em vários pratos para garantir uma estimação mais precisa. Assim, autores como Bozenhardt (1988) calculam as diferenças máximas de temperatura entre pratos para empregá-las na estimação do sistema; outros como Mejdell e Skogestad (1991b) utilizam diretamente as temperaturas de todos os pratos de uma coluna de alta pureza para inferirem sua composição.

\subsubsection{Fluxos líquido e vapor}

Os fluxos de líquido e de vapor são uma descrição da movimentação interna da coluna e refletem alterações que ocorram nas temperaturas, pressões e composições na mesma. As medições dos fluxos internos da coluna são difíceis de serem realizadas e não interessam para o escopo deste trabalho. Porém, na alimentação e nos extremos da coluna (condensador e refervedor) podem ser medidas e utilizadas para a identificação. Poucos artigos citam a utilização dessas vazões no projeto do sensor virtual, porém foi encontrada uma referência em que os autores referem-se à utilização destas variáveis no desenvolvimento do sensor e relatam um aumento na precisão da estimação (ZAMPROGNA, 2001).

A Figura 3.4 mostra o perfil dos fluxos de líquido e vapor que circulam pela coluna simulada quando esta opera em regime estacionário nas condições nominais de operação. A descontinuidade observada no estágio 6 para o líquido e 7 para o vapor referem-se ao fluxo de alimentação que a coluna recebe nestes pratos. Ainda, os dois pontos destacados no gráfico referem-se aos valores do fluxo de alimentação de líquido e vapor, respectivamente. 


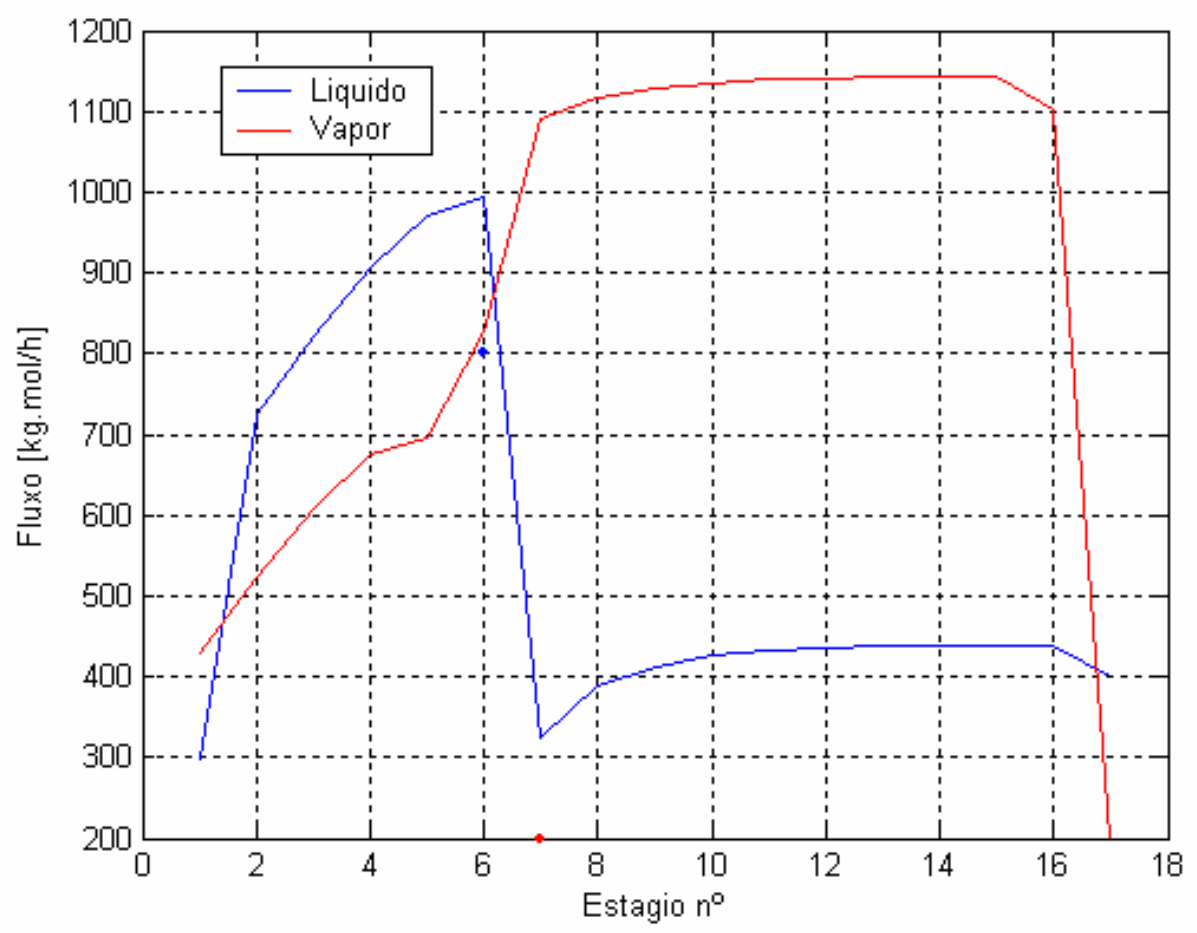

Figura 3.4: Perfil dos fluxos de líquido e vapor que circulam pela coluna

\subsubsection{Composição dos componentes}

A seguir faz-se uma análise das características da mistura multicomponente que está presente na coluna e de suas características particulares de comportamento.

A Tabela 3.5 apresenta de forma sucinta, a participação de cada componente na alimentação. 
Tabela 3.5: Participação de cada componente na alimentação da coluna

\begin{tabular}{|c|c|c|c|c|c|c|}
\hline & \multicolumn{2}{|c|}{ Composição [fm] } & \multicolumn{2}{|c|}{ Fluxo [kg/h] } & \multicolumn{2}{c|}{ Total } \\
\hline Componente & Líquido & Vapor & Líquido & Vapor & {$[\mathrm{kg} / \mathrm{h}]$} & {$[\mathbf{f m ]}$} \\
\hline $\mathbf{1}$ & 0,05 & 0,40 & 18,14 & 36,29 & 54,43 & 0,12 \\
\hline $\mathbf{2}$ & 0,60 & 0,53 & 217,70 & 48,08 & 265,79 & 0,59 \\
\hline $\mathbf{3}$ & 0,01 & 0,02 & 3,63 & 1,81 & 5,44 & 0,01 \\
\hline $\mathbf{4}$ & 0,30 & 0,05 & 108,85 & 4,54 & 113,39 & 0,25 \\
\hline $\mathbf{5}$ & 0,04 & 0 & 14,51 & 0,00 & 14,51 & 0,03 \\
\hline
\end{tabular}

$\mathrm{Na}$ tabela, as duas primeiras colunas, relativas à composição em fração molar, trazem os dados da composição do líquido e do vapor que compõem a alimentação. Depois, diante dos valores já fornecidos dos fluxos mássicos destas duas entradas $(362,84 \mathrm{~kg} / \mathrm{h}$ para o líquido e $90,72 \mathrm{~kg} / \mathrm{h}$ para o vapor), calcula-se o fluxo mássico de cada componente, nas colunas seguintes, e somam-se as duas parcelas na coluna intitulada total. Finalmente, a última coluna deixa claro que na alimentação há um predomínio dos componentes 2 e 4, com 59\% e $25 \%$ respectivamente, que coincide com os componentes que se deseja separar no processo.

A Figura 3.5 mostra o perfil das composições dos cinco componentes na coluna quando esta está submetida a regime estacionário nas condições nominais de operação. Pode-se observar que há predominância de dois componentes que possuem maior concentração ao longo desta. O componente 2, concentrado principalmente nos pratos superiores, e o componente 4, com predomínio nos pratos próximos à base, são exatamente as duas substâncias que se deseja separar no processo. Os outros componentes possuem relevância menor e podem ser considerados como impurezas. 


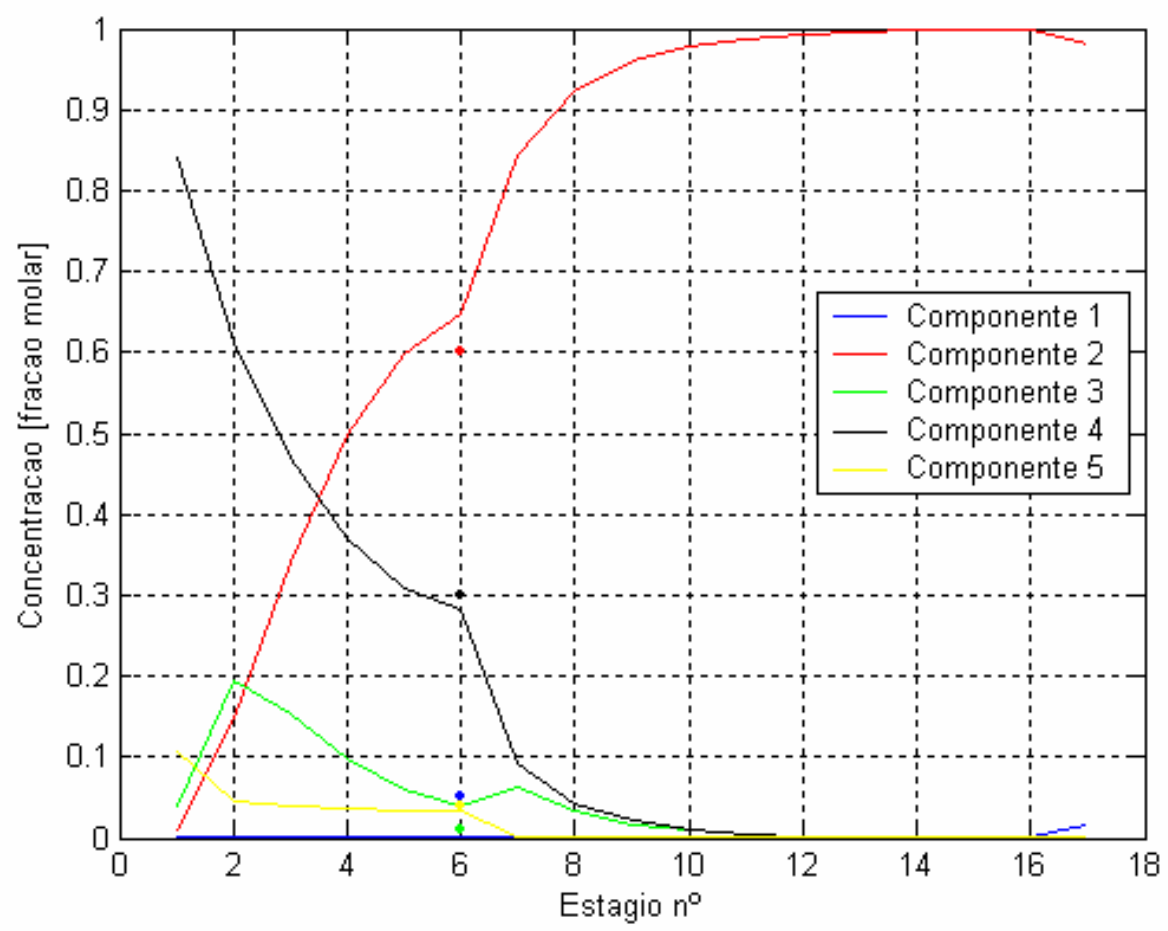

Figura 3.5: Perfil de composições do líquido ao longo da coluna

Outro fato que pode ser ressaltado é uma alteração da inflexão das curvas que o perfil apresenta no estágio 6 , o que pode ser explicado pela presença da alimentação neste local. Os pontos mostrados na Figura 3.5 referem-se à composição da alimentação líquida.

$\mathrm{Na}$ Figura 3.6 mostra-se o perfil da composição do vapor que flui pela coluna. Nestes, como era de se esperar, há predomínio dos componentes mais voláteis que se dirigem para os estágios superiores. Um fato interessante, que se pode ressaltar, é a retirada de destilado na forma de vapor realizada no condensador parcial que possui uma concentração bastante alta dos componentes 1 e 2 (aproximadamente 56\% e 44\% respectivamente). O predomínio do componente 1 nesta mistura pode ser explicado pelo fato de que no condensador a temperatura sofre uma queda, o que retira do vapor boa parte do componente 2 , deixando o componente 1 em maior concentração. 


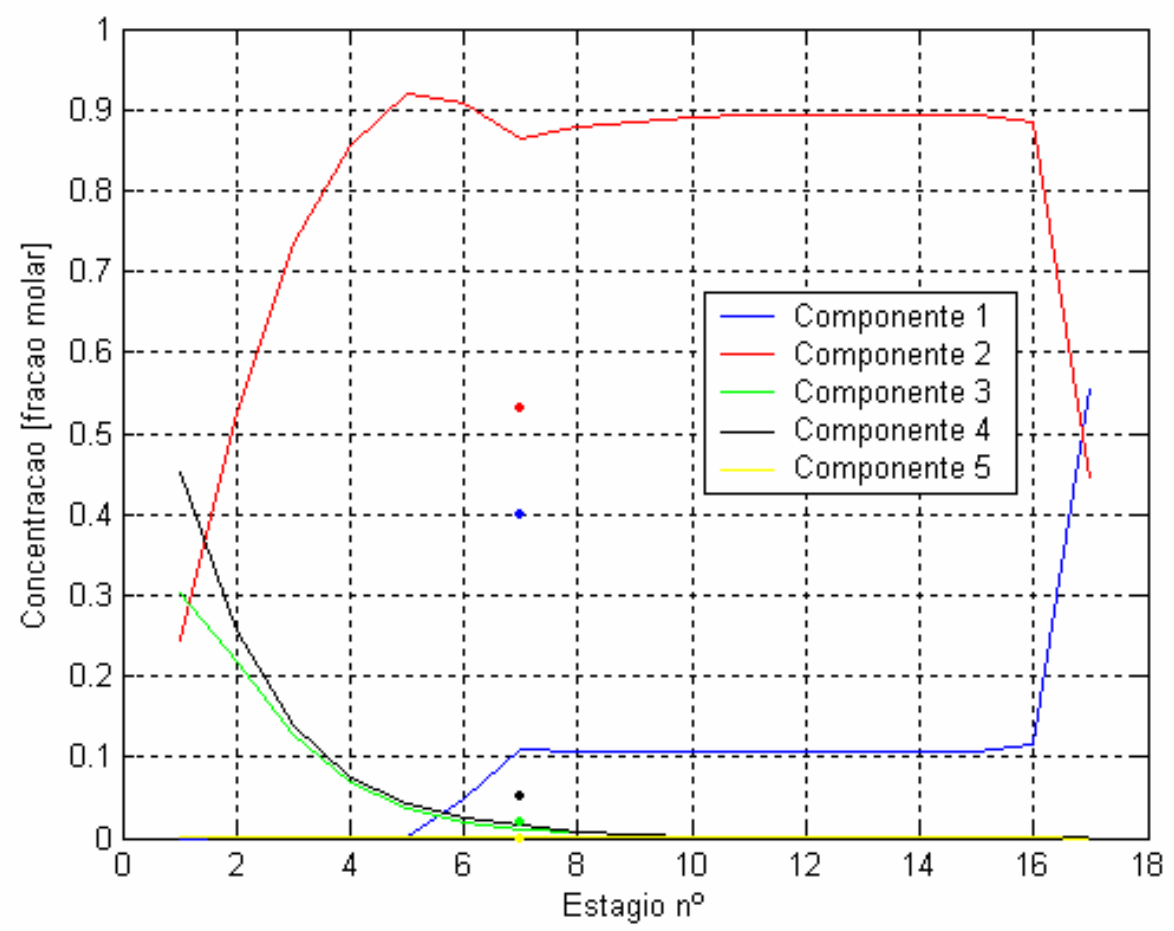

Figura 3.6: Perfil de composições do vapor ao longo da coluna

A Tabela 3.6 resume as composições obtidas pelo processo de destilação visto operando no regime nominal de operação para as retiradas de topo (condensador) de líquido e vapor e retirada de base (refervedor).

Tabela 3.6: Composição dos produtos para operação no regime nominal

\begin{tabular}{|c|c|c|c|}
\hline & \multicolumn{3}{|c|}{ Composição [fm] } \\
\hline Componente & Destilado Líquido & Destilado Vapor & Produto Base \\
\hline $\mathbf{1}$ & 0,02 & 0,56 & 0 \\
\hline $\mathbf{2}$ & 0,98 & 0,44 & 0,01 \\
\hline $\mathbf{3}$ & 0 & 0 & 0,04 \\
\hline $\mathbf{4}$ & 0 & 0 & 0,84 \\
\hline $\mathbf{5}$ & 0 & 0 & 0,11 \\
\hline
\end{tabular}




\subsection{Caracterização da coluna fora do regime}

Após ter sido realizada a descrição dos perfis das variáveis ao longo da coluna no regime nominal de operação para o qual ela foi projetada, segue-se uma análise do seu comportamento para as regiões próximas ao regime nominal. $\mathrm{O}$ intuito deste estudo é conhecer melhor o comportamento da coluna para uma faixa de operação em que ela poderá vir a operar na prática.

Primeiramente, é importante ressaltar que qualquer perturbação introduzida na coluna afeta o desempenho da mesma, levando-a a operar em uma nova condição de regime. Qualquer destas perturbações afetará conseqüentemente a composição no topo. Assim, a coluna pode apresentar dois efeitos na variação da composição do componente em estudo frente às perturbações: ou a coluna passa a operar mais próxima à separação dos componentes mais leves ou dos mais pesados.

Deste modo, se as perturbações afetarem a coluna no sentido de aumentar a temperatura interna ou diminuir o fluxo de líquido interno da mesma, esta passará a apresentar no topo maior concentração dos componentes mais pesados. Assim, se for aumentado a temperatura do fluxo de alimentação (TF) que entra na coluna o efeito será semelhante ao que ocorrerá caso seja aumentada a quantidade de calor inserida no refervedor (QR), que também será semelhante se for diminuída a vazão do fluxo de alimentação líquido (FL) ou vapor (FV) de entrada na coluna ou ainda do fluxo de reciclo $(\mathrm{R})$.

O mesmo ocorre caso a perturbação seja no sentido contrário, para diminuir a temperatura interna ou aumentar o nível de líquido nos pratos. Porém, é importante ressaltar que as variáveis perturbadas afetam com magnitude diferente o desempenho da coluna. Assim, uma diminuição na temperatura do fluxo de alimentação (TF) não afeta na mesma magnitude o desempenho da coluna que uma 
diminuição de mesma amplitude na quantidade de calor adicionado ao refervedor (QR), apesar das duas ações diminuírem a temperatura interna da coluna.

\subsubsection{Comportamento da coluna para degrau de $10 \%$}

A seguir faz-se uma análise das características da mistura multicomponente que está presente na coluna e de suas características particulares de comportamento quando a coluna é perturbada por um sinal do tipo degrau. Para esta situação foi considerada uma perturbação em degrau com amplitude de 10\% aplicada aumentando a quantidade de calor fornecida à coluna (QR), levando-a a operar no sentido de aumentar a separação para os componentes mais pesados, ou seja, houve um aumento na temperatura interna ou diminuição do fluxo de líquido interno da mesma.

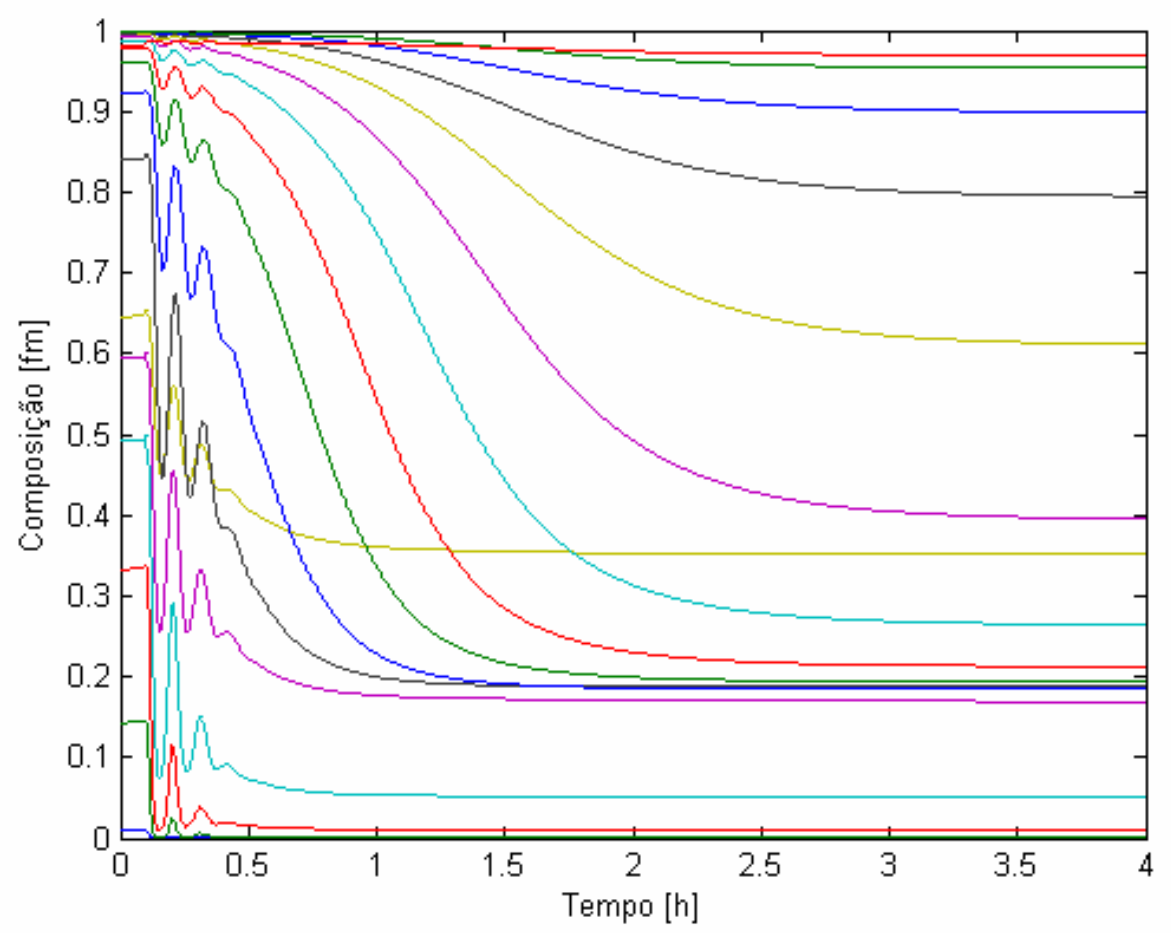

Figura 3.7: Perfil da composição do componente 2 antes e após degrau de 10\% 
Na Figura 3.7 a legenda com os números dos estágios não foi inserida, pois, ficaria praticamente ilegível devido à grande quantidade de cores (17) existentes. Porém, o gráfico foi apresentado deste modo para deixar clara a tendência que ocorre em todos os pratos da coluna de diminuir a concentração deste componente nos pratos. Ainda assim, os estágios podem ser identificados pela ordem no lado esquerdo (antes da perturbação), em que apresentavam ordem crescente.

A Figura 3.7 mostra a composição do componente 2 antes e depois do degrau de perturbação. Deve-se ressaltar que nos estágios próximos ao topo da coluna, que apresentavam concentração alta do componente 2 antes do degrau passam a apresentar uma concentração bem menor. Veja como exemplo o estágio 10 (em vermelho) que apresentava antes composição de 97\% do componente 2 e após o novo equilíbrio apresenta 21\%. Deve-se destacar ainda que a composição do componente de interesse no condensador no qual são realizadas as retiradas do destilado líquido sofreu pequena variação.

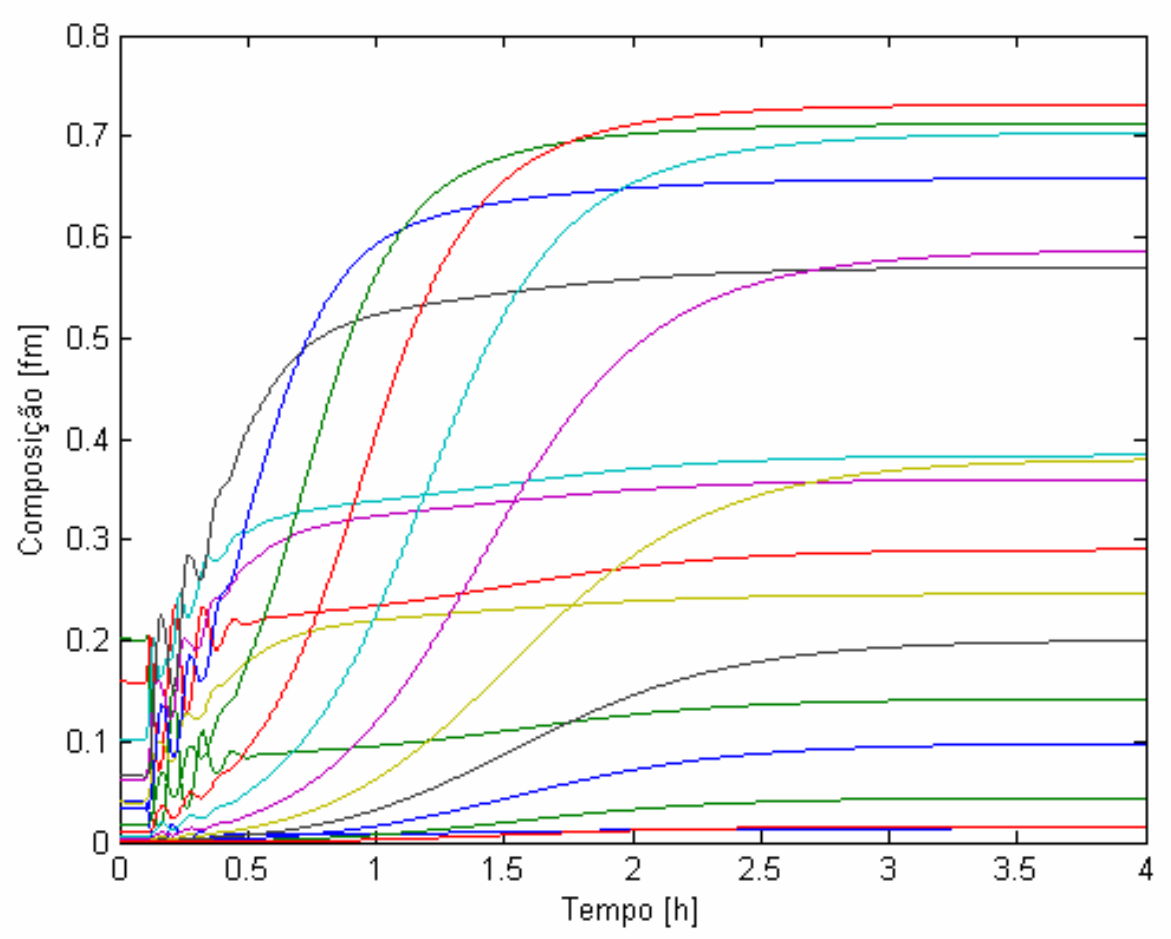

Figura 3.8: Perfil da composição do componente 3 em cada estágio 
$\mathrm{Na}$ Figura 3.8, que apresenta a composição do componente 3 nos mesmos estágios da coluna, pode-se observar um efeito similar ao anterior, pois também apresenta um novo regime de operação. Porém, a composição varia no sentido contrário, o que completa a Figura 3.7. Veja como exemplo o estágio 10 (em vermelho) que antes do degrau possuía aproximadamente 1\% de concentração do componente 3 e depois apresenta $74 \%$.

Destas duas figuras pode-se concluir que a coluna passa de uma operação binária de separação (componentes 2 e 4) para uma destilação ternária, em que o componente 3 pode ser isolado no estágio 10 com uma composição próxima de $74 \%$.

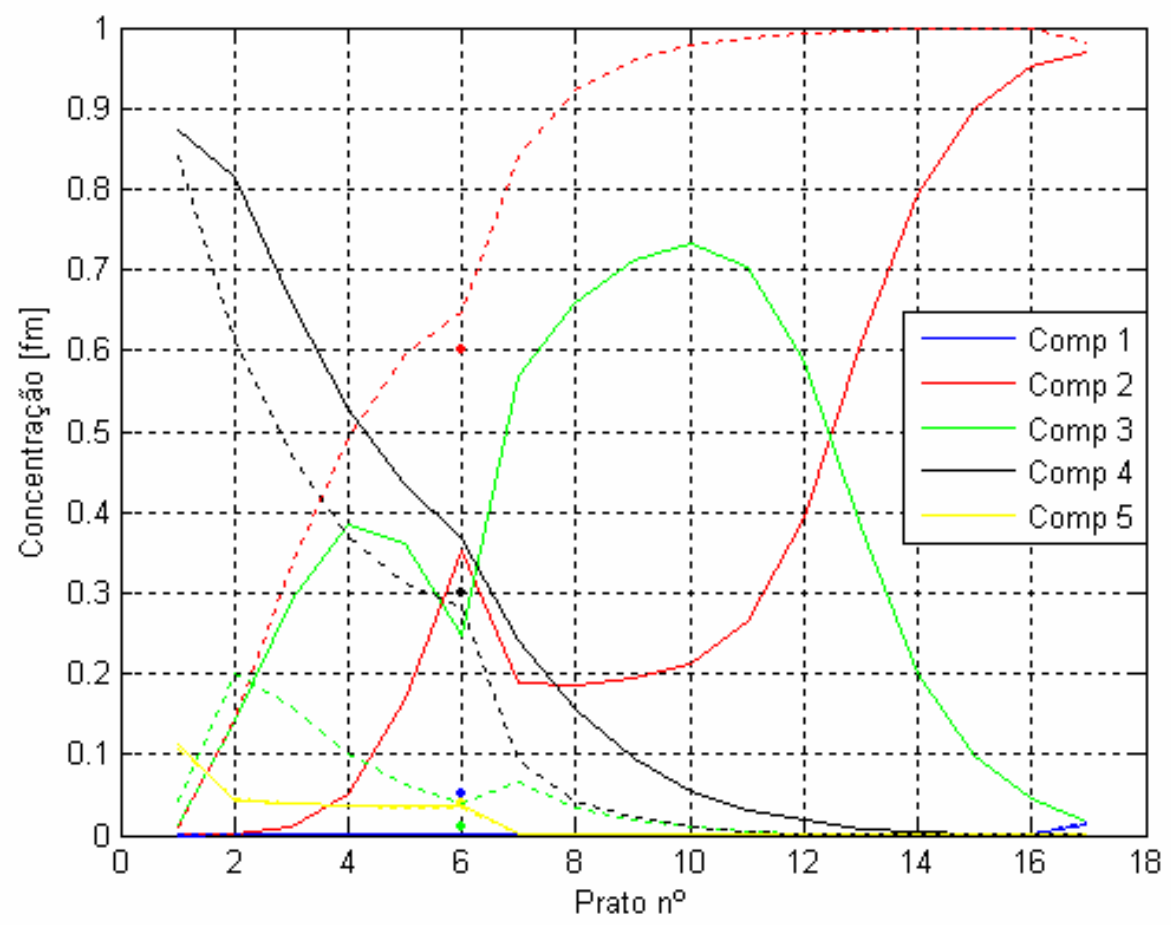

Figura 3.9: Composição dos componentes nos pratos antes e depois do degrau

A Figura 3.9 mostra a variação da composição de todos os componentes presentes na coluna antes e depois da perturbação em degrau de 10\%. A linha pontilhada é referente à Figura 3.5 (antes do degrau) e a linha contínua após o degrau. 


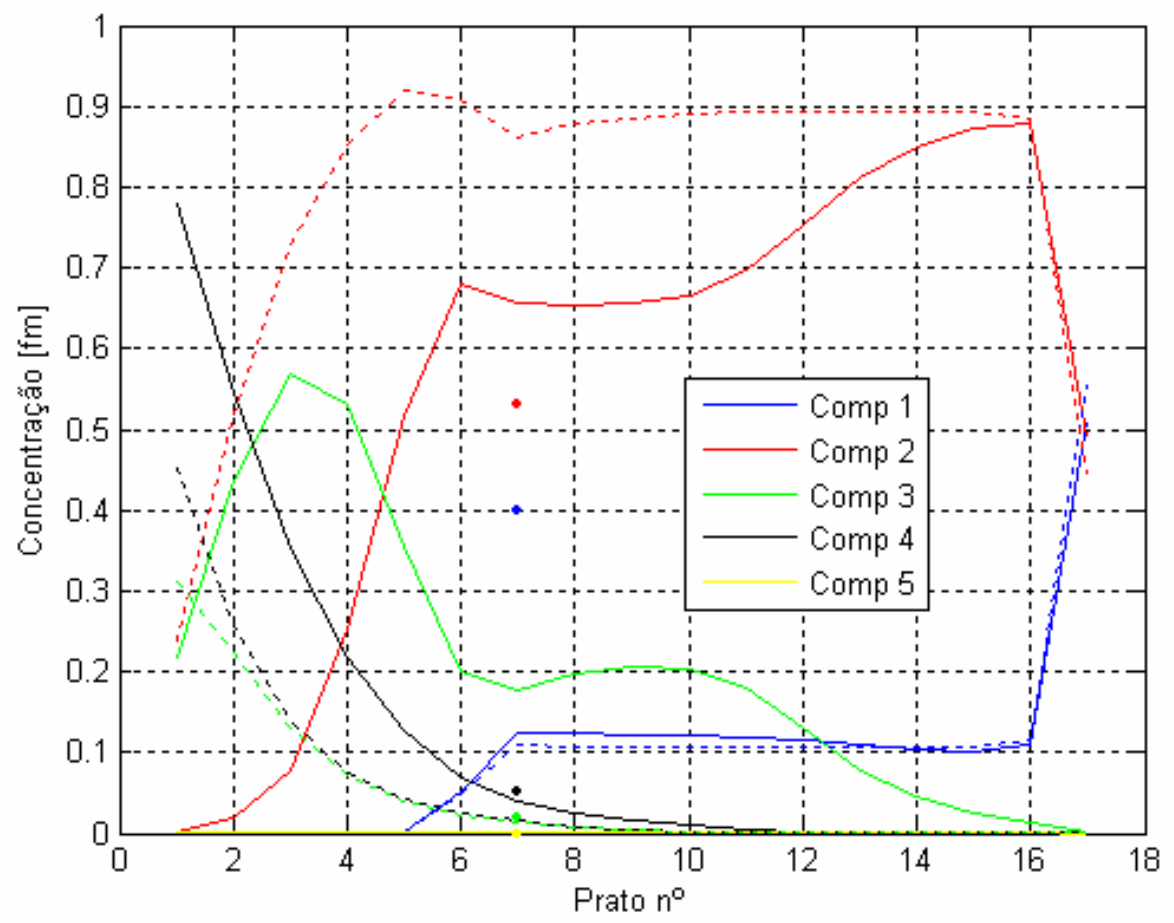

Figura 3.10: Composição dos componentes na fase vapor

Na Figura 3.10 pode-se ver o perfil da composição de todos os componentes presentes na coluna na fração vapor. Como era de se esperar há um aumento da concentração dos componentes mais pesados no vapor uma vez que há um aumento da temperatura interna com a perturbação em degrau.

Tabela 3.7: Composição dos produtos após degrau de 10\%

\begin{tabular}{|c|c|c|c|}
\hline & \multicolumn{3}{|c|}{ Composição [fm] } \\
\hline Componente & Destilado Líquido & Destilado Vapor & Produto Base \\
\hline $\mathbf{1}$ & 0,01 & 0,51 & 0 \\
\hline $\mathbf{2}$ & 0,97 & 0,49 & 0 \\
\hline $\mathbf{3}$ & 0,02 & 0 & 0,01 \\
\hline $\mathbf{4}$ & 0 & 0 & 0,87 \\
\hline $\mathbf{5}$ & 0 & 0 & 0,11 \\
\hline
\end{tabular}


Da Tabela 3.7 pode-se perceber que houve uma ligeira diminuição da qualidade do componente 2 retirado no topo da coluna, que é o de maior interesse. O componente 4 no produto de base teve uma ligeira melhora e o destilado vapor continua sendo uma mistura com apenas os dois mais leves, porém agora com menor diferença entre eles.

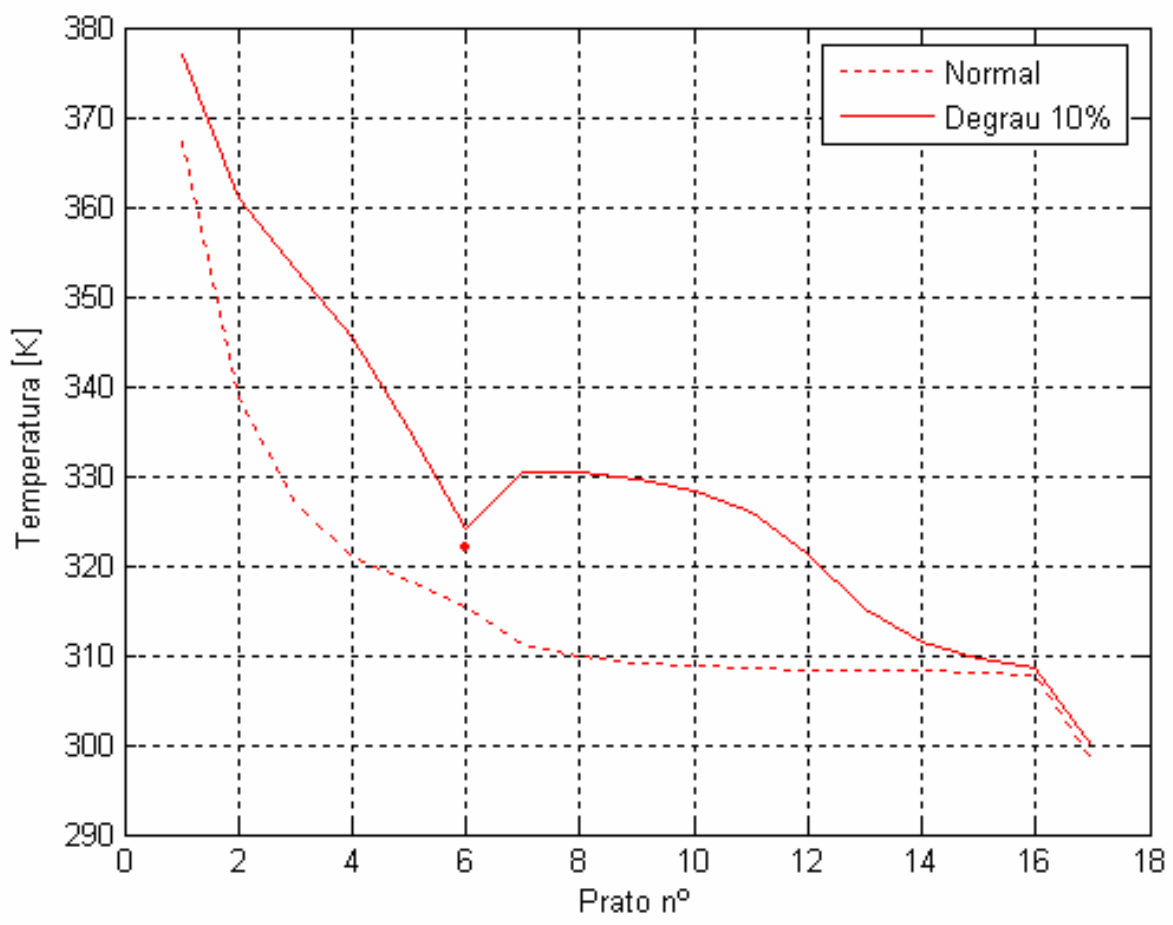

Figura 3.11: Perfil da temperatura ao longo da coluna antes e após o degrau

A Figura 3.11 exibe os perfis de temperaturas internas nos estágios da coluna antes, no regime nominal de operação e depois da perturbação em degrau. Deve-se destacar que as temperaturas nos estágios possuem realmente uma forte relação com as composições. Deste modo os pratos que tiveram maior variação de composição também tiveram de temperatura. 


\subsubsection{Comportamento da coluna para degrau de $-10 \%$}

A seguir faz-se uma análise das características particulares do comportamento da coluna quando perturbada por um sinal degrau contrário ao anterior. Para esta situação foi considerada uma perturbação na coluna com amplitude de $-10 \%$ (considerado em contraposição à perturbação aplicada no item anterior, mas de mesma magnitude) aplicada na quantidade de calor fornecido à coluna (QR), levando-a a operar no sentido de aumentar a separação dos componentes mais leves, ou seja, houve uma diminuição na temperatura interna ou aumento do fluxo de líquido da mesma.

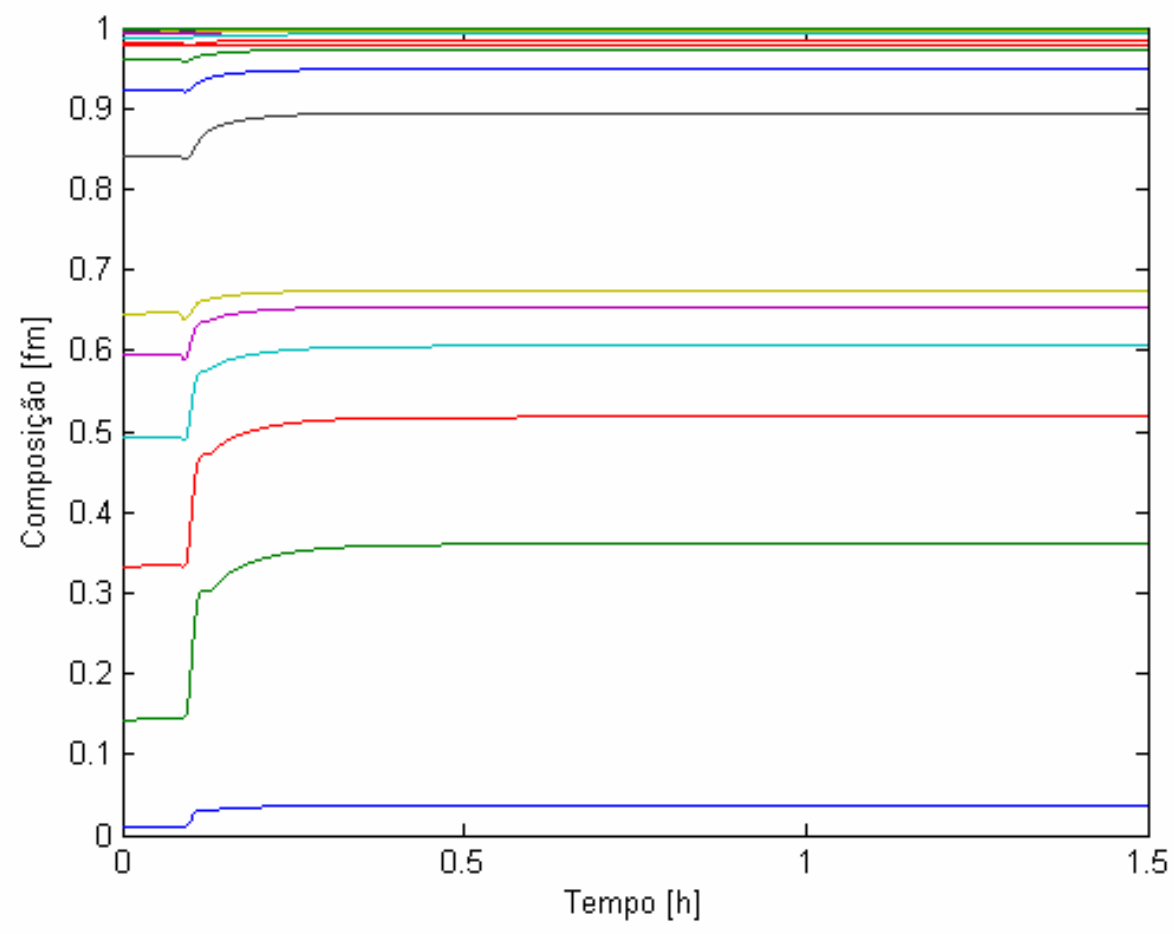

Figura 3.12: Perfil da composição do comp. 2 antes e após degrau de $-10 \%$

A Figura 3.12 mostra a composição do componente 2 antes e depois do degrau de perturbação. Deve-se ressaltar que houve um aumento da concentração deste componente no líquido dos pratos, principalmente nos pratos mais próximos à base da coluna onde possuíam menor participação. 


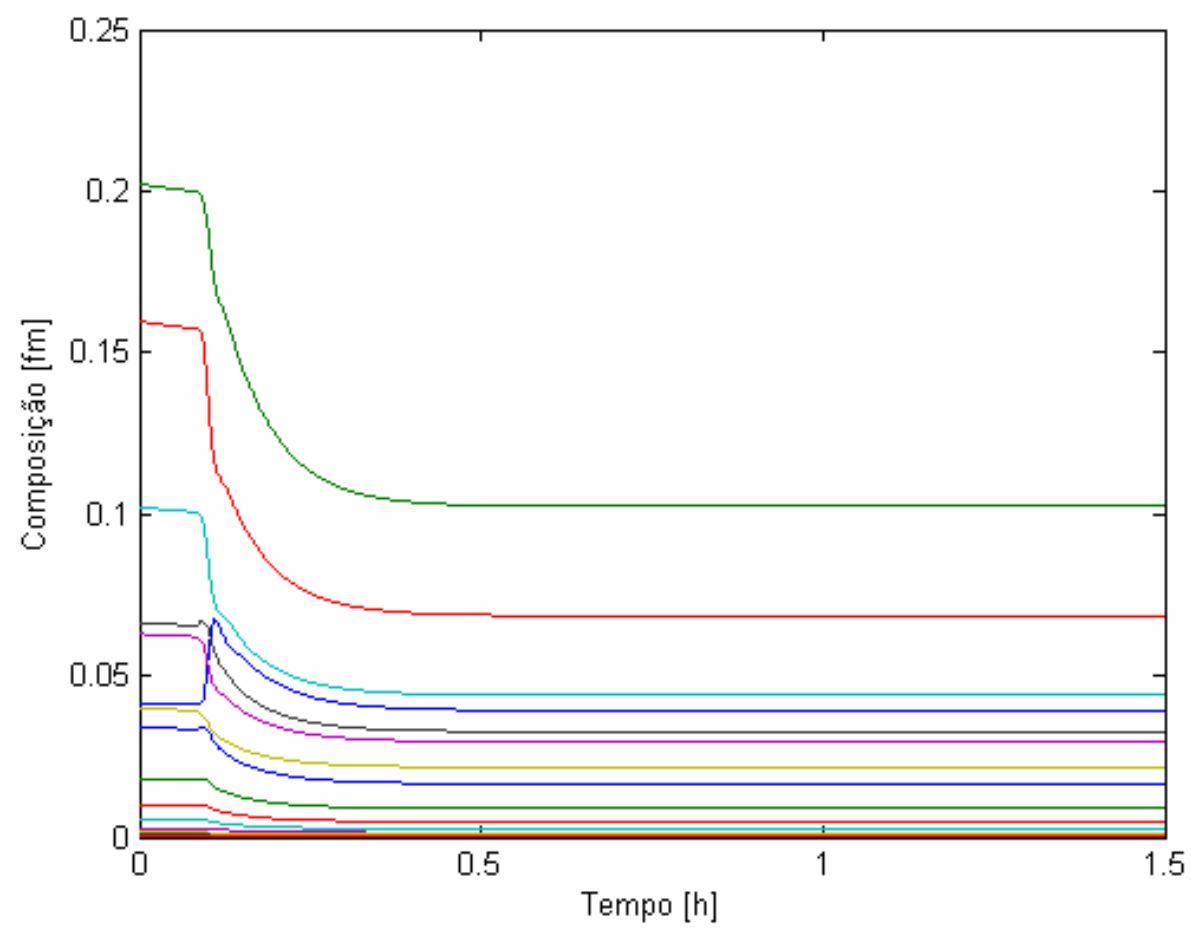

Figura 3.13: Perfil da composição do componente 3 em cada estágio

Na Figura 3.13 que apresenta a composição do componente 3 nos mesmos estágios da coluna pode-se observar que houve uma diminuição da composição nos pratos mais próximos à base, porém esta variação não compensa totalmente a variação do componente 2 , pois uma parcela será compensada pelo componente 4 .

A Figura 3.14 mostra a variação da composição do componente 4 ao longo da coluna antes e após o degrau de $-10 \%$. Destaca-se o fato de após o degrau a coluna chegar bem mais rapidamente ao novo ponto de regime de operação.

Destas três figuras pode-se concluir que não houve grandes mudanças na operação da coluna, apesar da perturbação degrau possuir a mesma magnitude com relação à perturbação anterior que apresentou alterações muito mais significativas. 


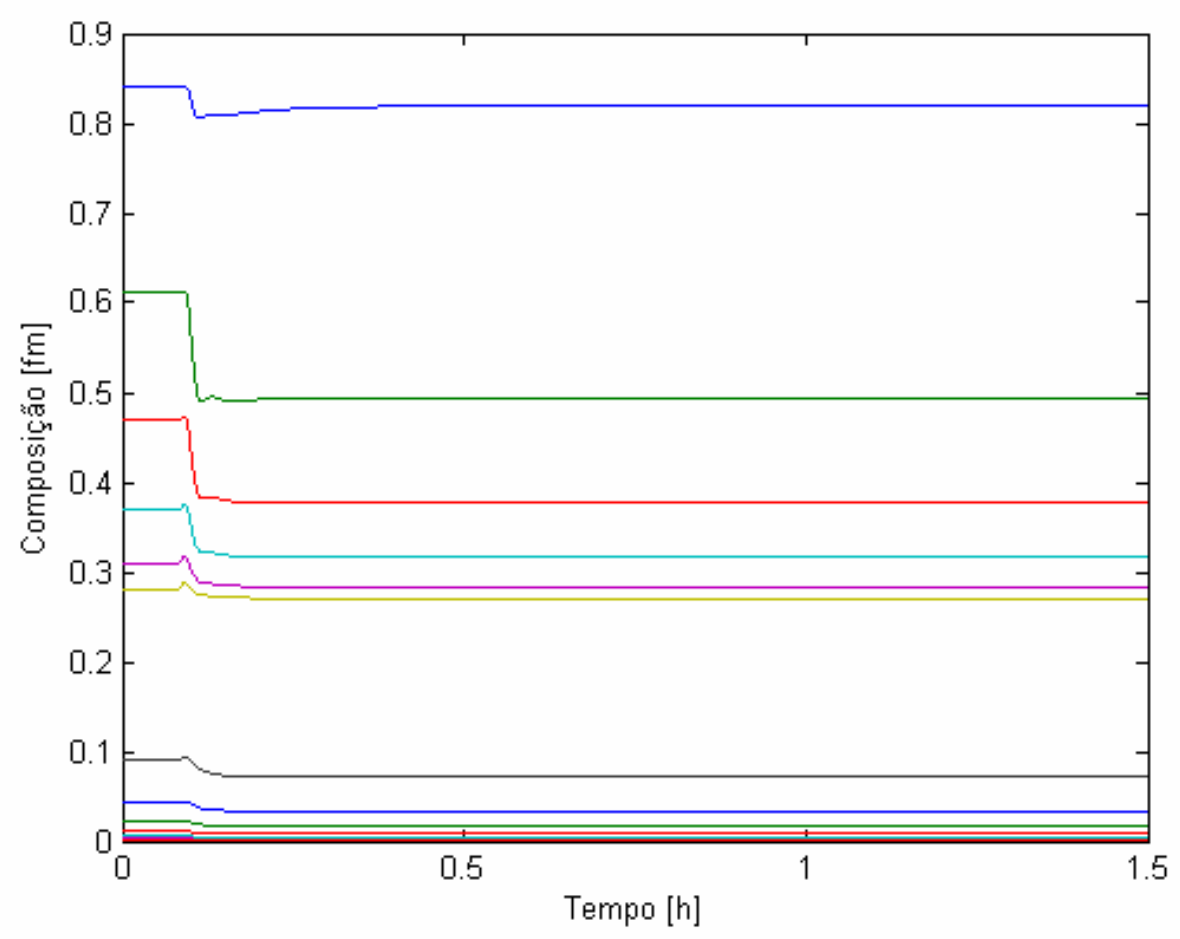

Figura 3.14: Perfil da composição do componente 4 em cada estágio

Outros fatos que chamam a atenção é que o comportamento da coluna praticamente não apresenta transitório nem sobressinal no momento de introdução da perturbação em degrau e o tempo de acomodação para o novo regime foi obtido em um intervalo de tempo bem menor $(0,5 \mathrm{~h})$ do que quando foi aplicado o degrau contrário (4h). Estes fatos podem significar que a coluna, quando em regime nominal, está operando de forma a maximizar a separação dos componentes 2 e 4. Assim, um aumento como o de 10\% do item anterior, altera as características de separação da coluna que passa a apresentar alta concentração do componente 3 nos estágios intermediários, além de uma redução da pureza do componente 2 no topo. Já a diminuição de 10\%, reduz a pureza do componente 4 na base, com uma melhora pequena na concentração do componente 2 no topo.

A Figura 3.15 mostra a variação da composição de todos os componentes presentes na coluna antes e depois da perturbação em degrau de $-10 \%$. A linha pontilhada é referente à operação da coluna em regime nominal (antes do degrau) e a linha contínua após a perturbação. 


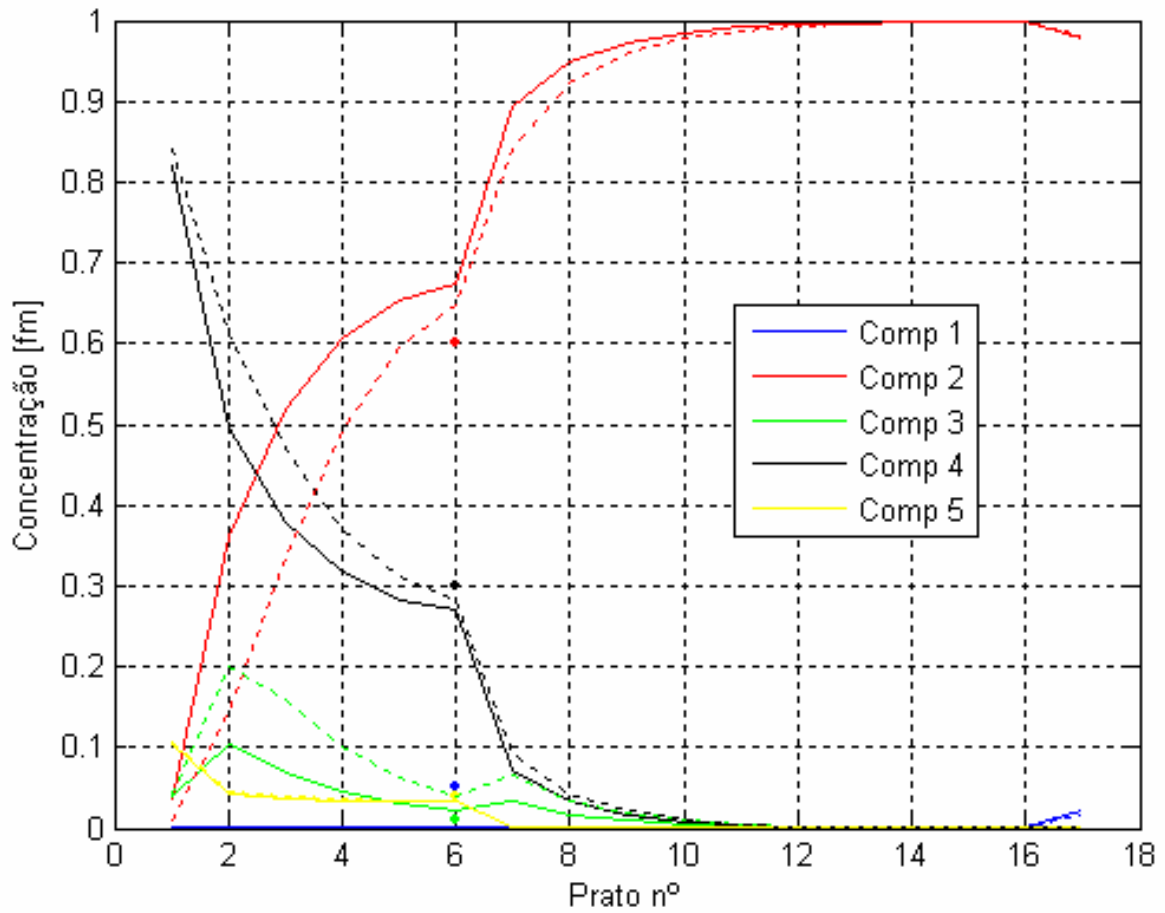

Figura 3.15: Composição dos componentes nos pratos antes e depois do degrau

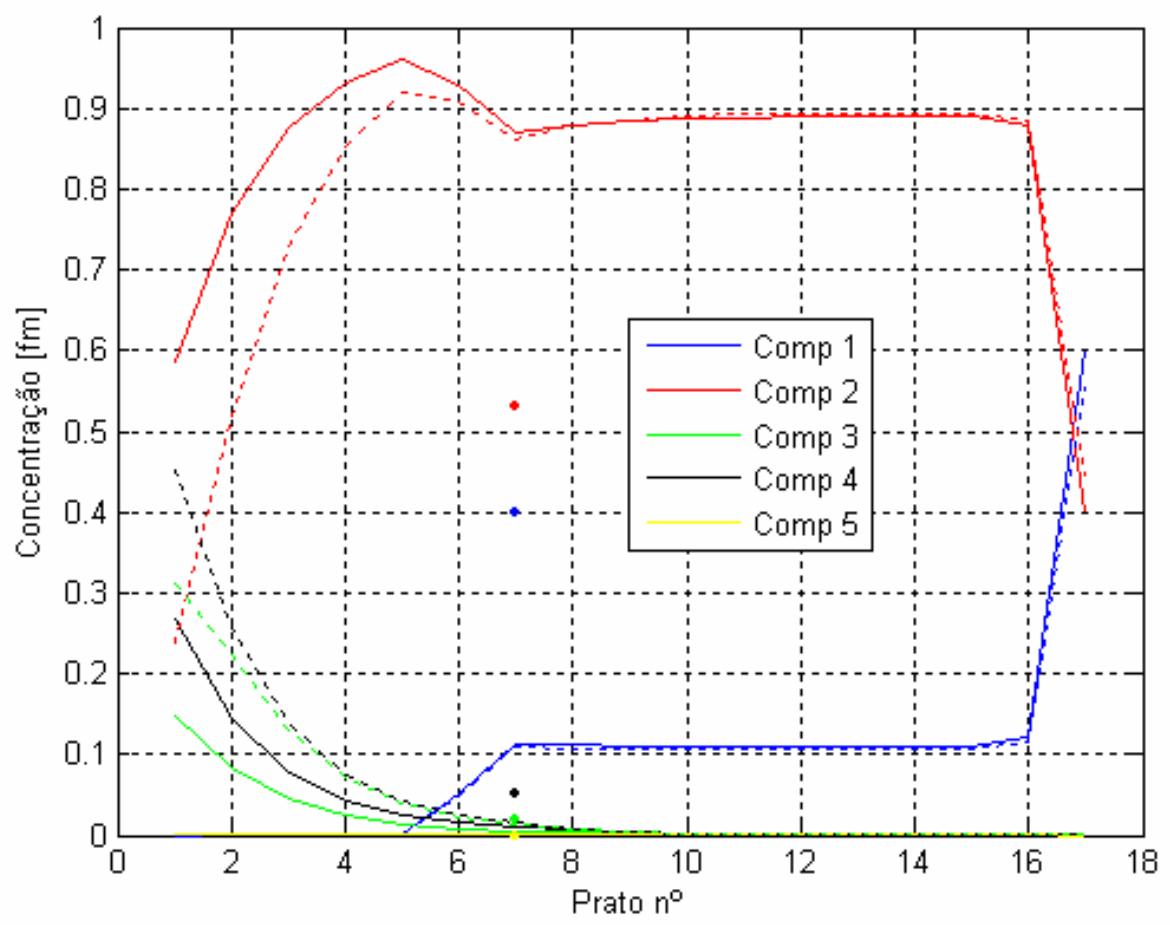

Figura 3.16: Composição dos componentes no vapor dos pratos 
Na Figura 3.16 pode-se ver o perfil da composição de todos os componentes presentes na coluna na fração vapor. Os pontos destacados nestas duas figuras são referentes às composições da alimentação da coluna.

Destas duas figuras podemos ver que as alterações nos pratos acima da alimentação da coluna são muito pequenas.

Tabela 3.8: Composição dos produtos após degrau de -10\%

\begin{tabular}{|c|c|c|c|}
\hline & \multicolumn{3}{|c|}{ Composição [fm] } \\
\hline Componente & Destilado Líquido & Destilado Vapor & Produto Base \\
\hline $\mathbf{1}$ & 0,02 & 0,60 & 0 \\
\hline $\mathbf{2}$ & 0,98 & 0,40 & 0,04 \\
\hline $\mathbf{3}$ & 0 & 0 & 0,04 \\
\hline $\mathbf{4}$ & 0 & 0 & 0,82 \\
\hline $\mathbf{5}$ & 0 & 0 & 0,10 \\
\hline
\end{tabular}

Da Tabela 3.8 pode-se perceber que a qualidade do componente 2 retirado no topo da coluna não sofreu alteração, como era esperado. O componente 4 no produto de base teve uma ligeira diminuição da sua concentração e o destilado vapor manteve os componentes mais leves, porém agora com uma maior diferença de concentração entre eles.

A Figura 3.17 exibe os perfis de temperaturas internas nos estágios da coluna antes, no regime nominal de operação, e depois da perturbação em degrau de menos 10\%. Pode-se observar que as alterações foram bem menores do que para o degrau no sentido oposto e nos estágios acima do de alimentação (6) praticamente não houve alterações no regime de operação. 


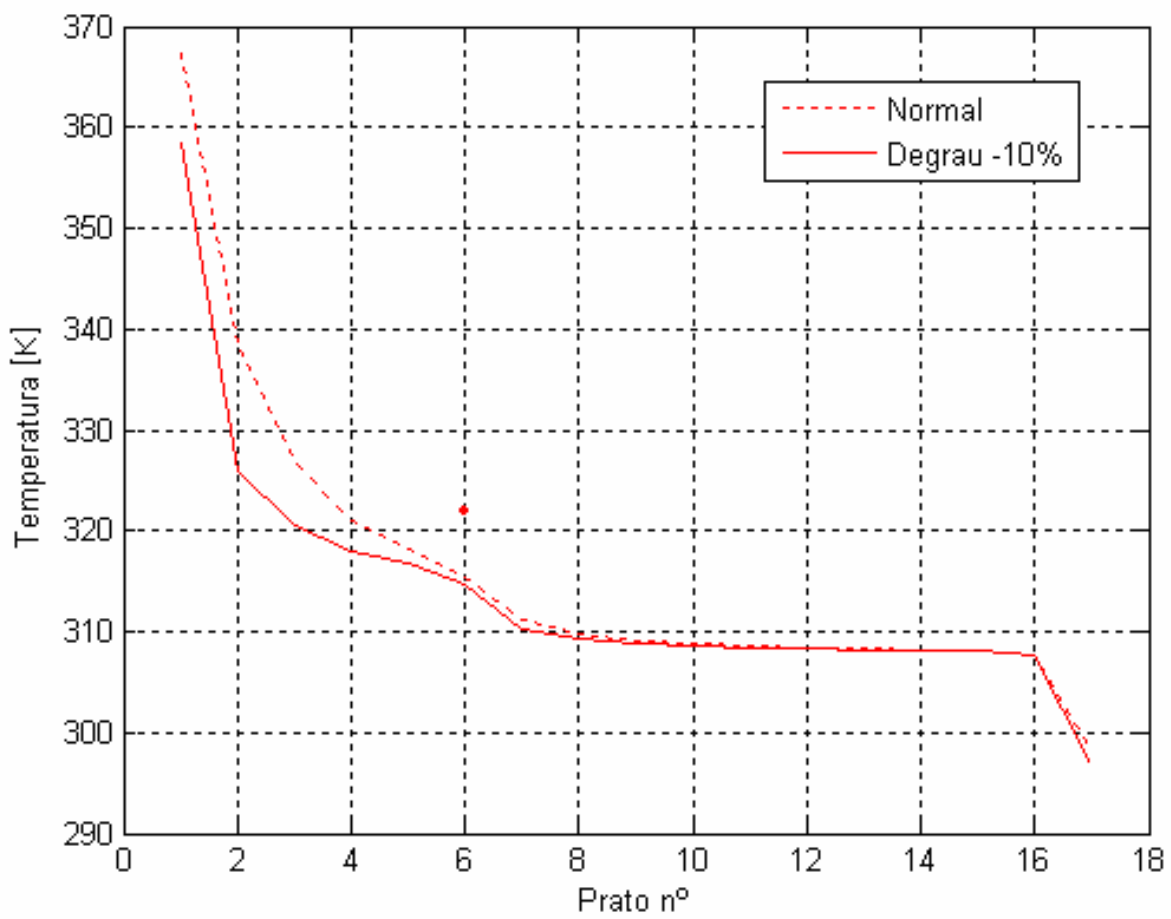

Figura 3.17: Perfil da temperatura ao longo da coluna antes e após o degrau

\subsubsection{Comportamento da coluna para rampa de $20 \%$}

A seguir, continuando a análise das características da mistura multicomponente que está presente na coluna e de suas características particulares de comportamento para uma faixa próxima à de operação, utilizou-se como perturbação para a coluna um sinal rampa com $20 \%$ de amplitude aplicada na quantidade de calor fornecido à coluna $(\mathrm{QR})$. Nos dois itens anteriores o sinal empregado como excitação foi um degrau, porém quando foi aplicado um degrau de $20 \%$ o sobressinal gerado na resposta ultrapassou os limites de operação da coluna. Então, para chegar a uma situação em que o regime fosse produzido por uma situação em torno de $20 \%$ maior, optou-se por aplicar o sinal rampa com $20 \%$ de amplitude e $0,5 \mathrm{~h}$ de duração. 
O sinal foi aplicado levando a coluna a operar no sentido de aumentar a separação para os componentes mais pesados, ou seja, houve um aumento na temperatura interna ou diminuição do fluxo de líquido interno da mesma. Esta rampa leva a coluna para um novo regime de operação no mesmo sentido do primeiro que foi aplicado (item 3.4.1), porém agora com uma amplitude maior.

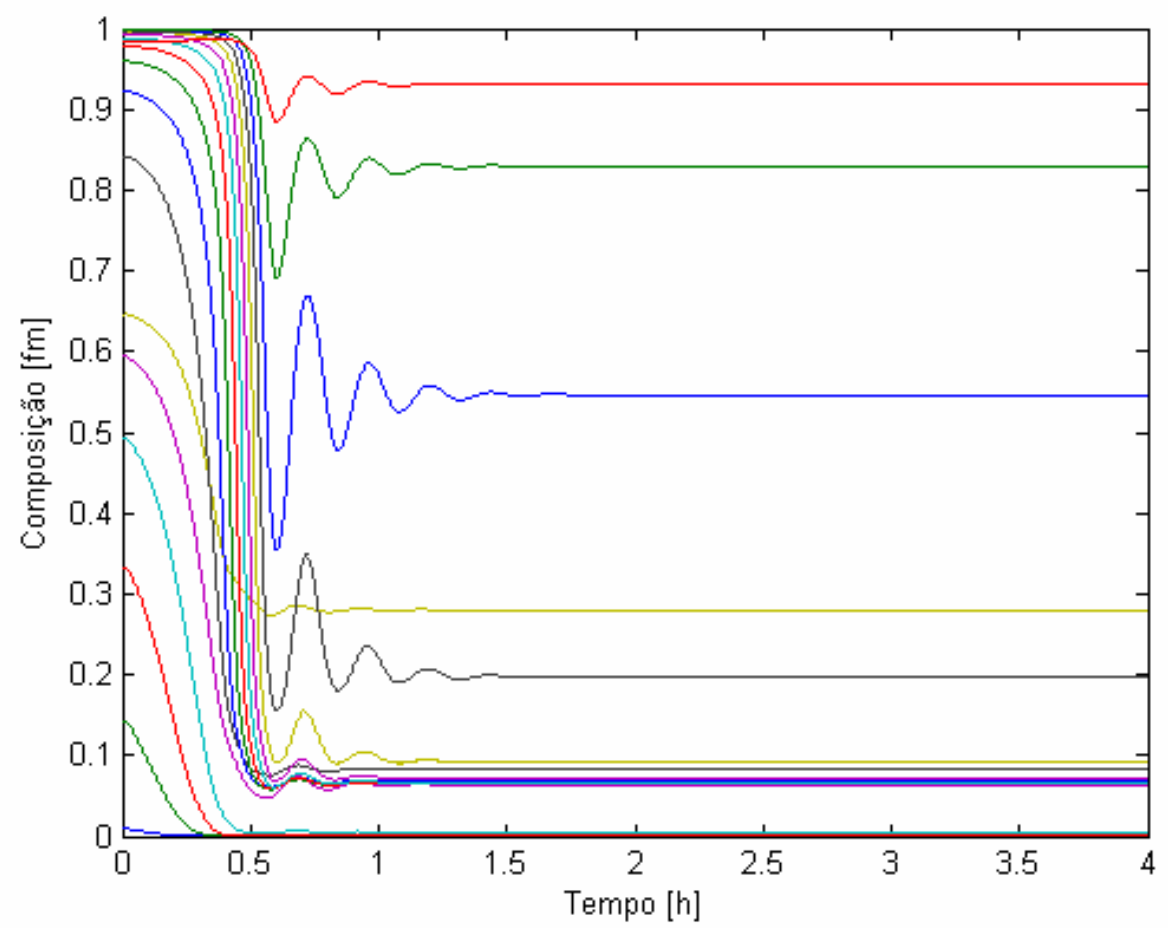

Figura 3.18: Perfil da composição do componente 2 antes e após rampa de $20 \%$

A Figura 3.18 mostra a composição do componente 2 antes e depois da perturbação em degrau de $20 \%$. Como era esperado houve uma grande variação das composições em todos os pratos. Proporcionalmente, a variação foi menor no condensador, onde é realizada a retirada do destilado líquido, que sofreu pequena variação.

Na Figura 3.19 que apresenta a composição do componente 3 nos mesmos estágios da coluna pode-se observar que após um conturbado transitório a composição sofre forte redução nos pratos mais baixos e aumento nos mais altos. 


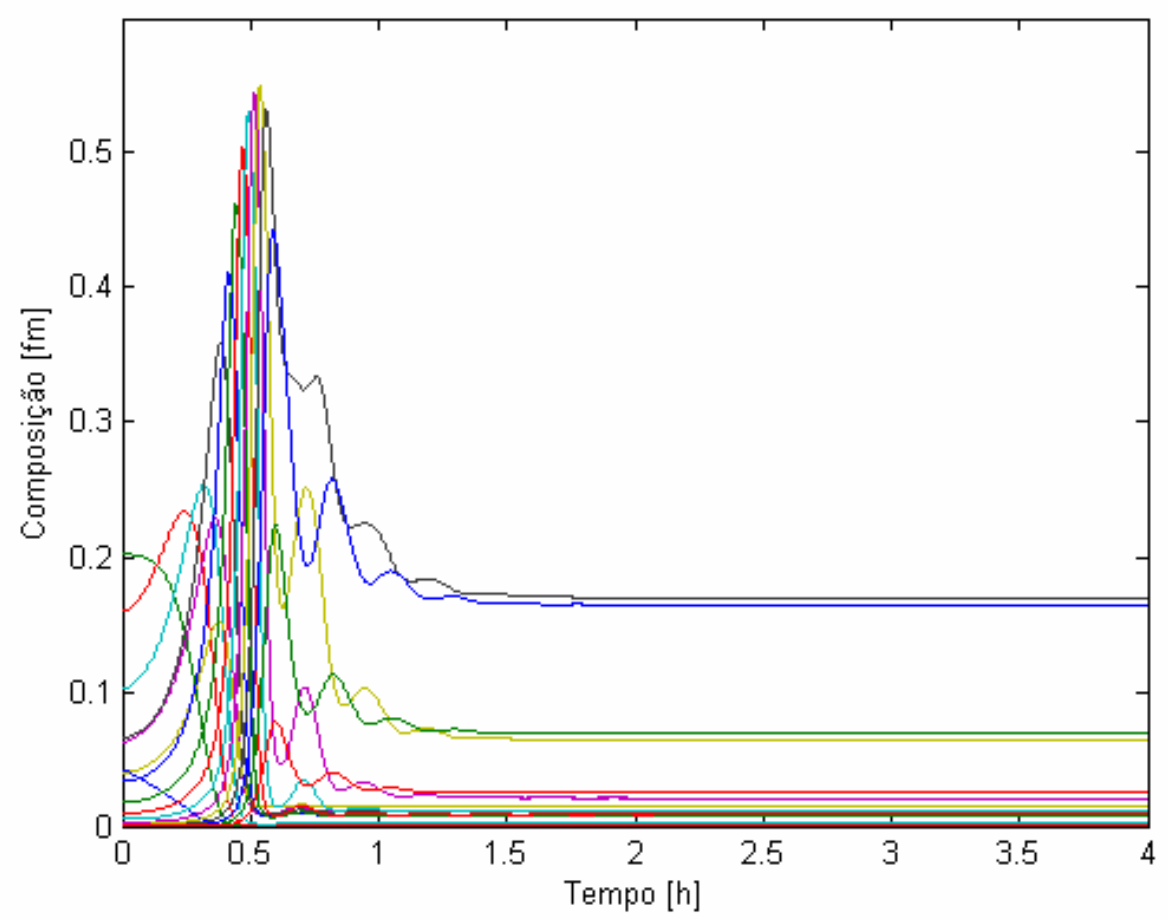

Figura 3.19: Perfil da composição do componente 3 em cada estágio

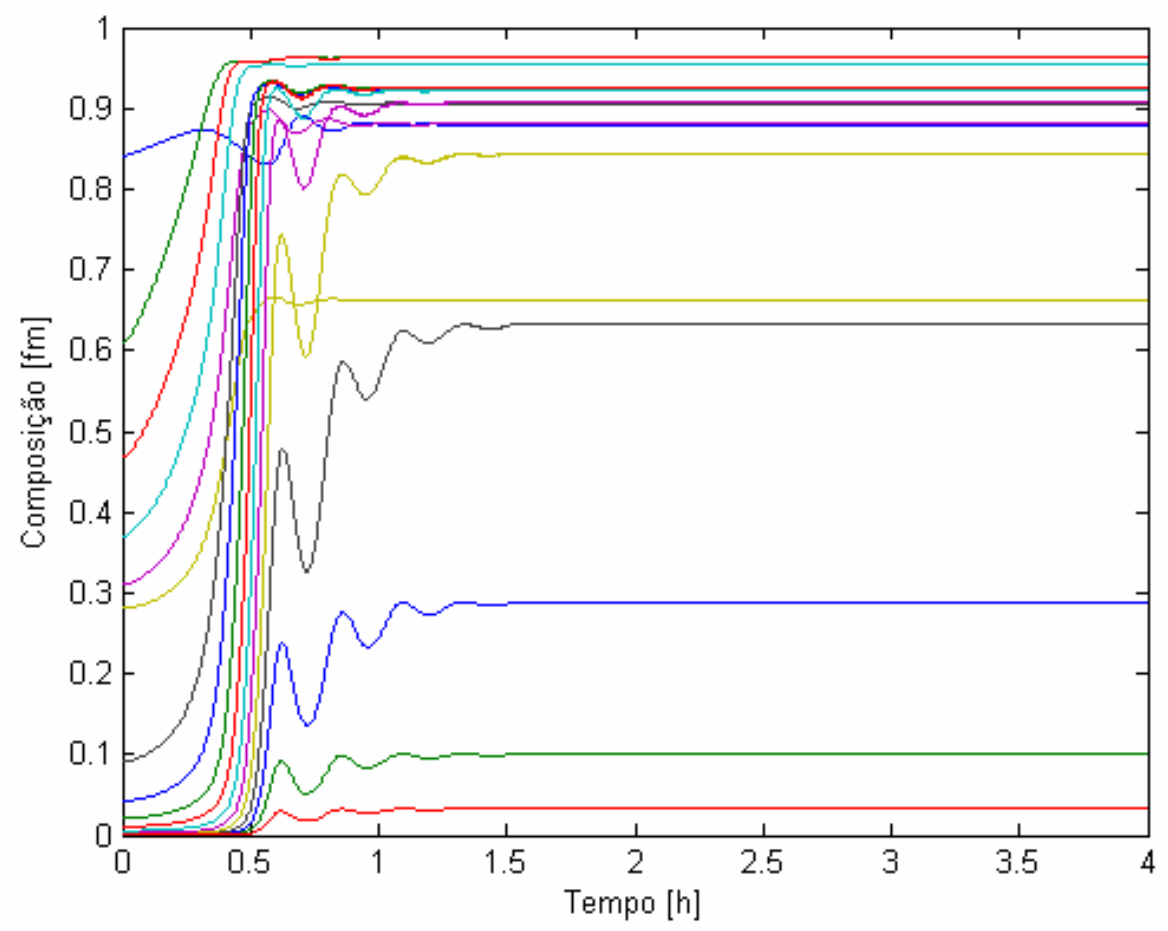

Figura 3.20: Perfil da composição do componente 4 em cada estágio 
$\mathrm{Na}$ Figura 3.20, que apresenta a composição do componente 4 nos estágios da coluna, pode-se observar que na maioria dos pratos que sofreram forte redução do componente 2 , este foi compensado pelo aumento da participação do componente 4.

Destas três figuras pode-se concluir que a coluna sofreu novamente grandes mudanças no regime de operação. Nesta nova configuração a coluna passa a separar o componente 4 como principal e o componente 2 como secundário, invertendo as condições nominais de operação.

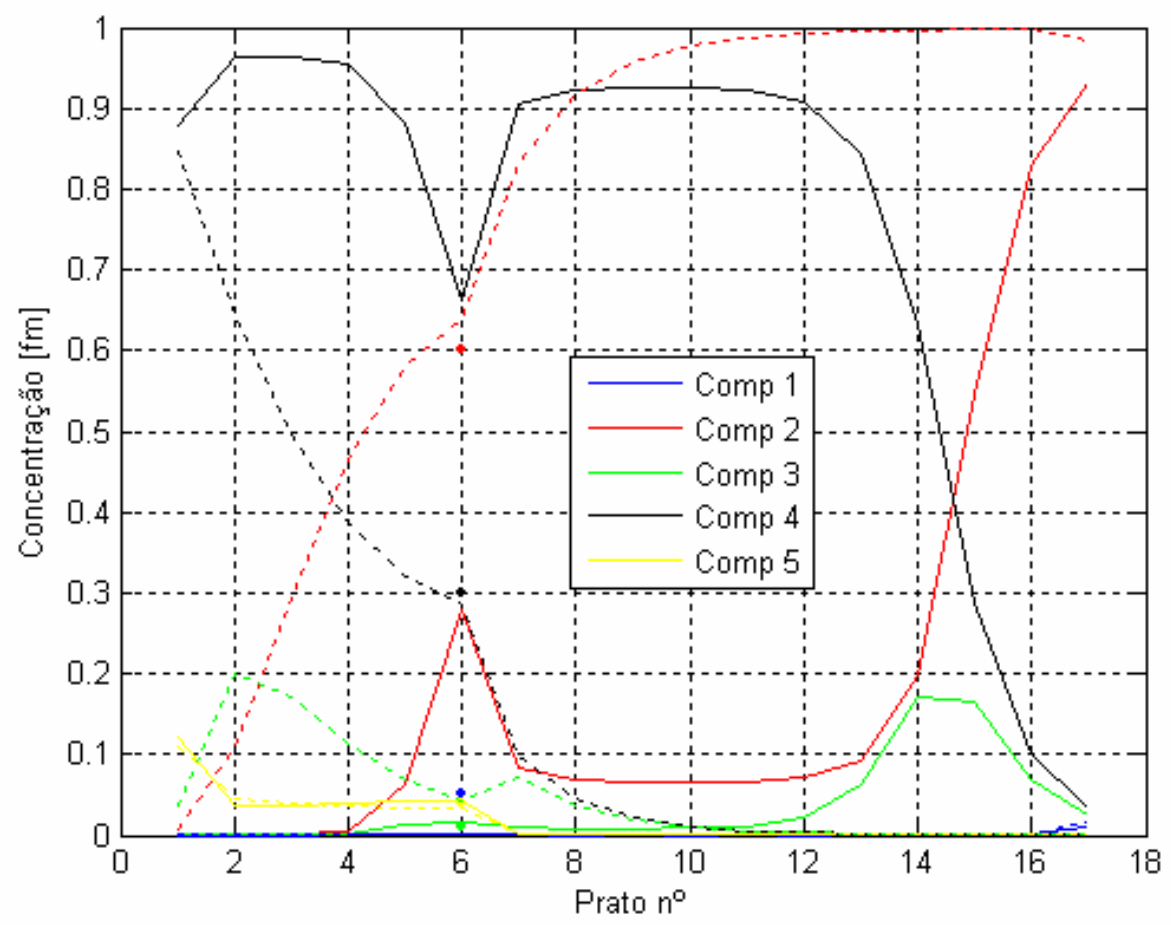

Figura 3.21: Composição dos componentes nos pratos antes e depois da rampa

A Figura 3.21 mostra a variação da composição de todos os componentes presentes na coluna antes e depois da perturbação em rampa de 20\%. A linha pontilhada é referente à operação em regime nominal conforme apresentado na Figura 3.5 e a linha contínua é o resultado da operação após obtenção do novo regime. 


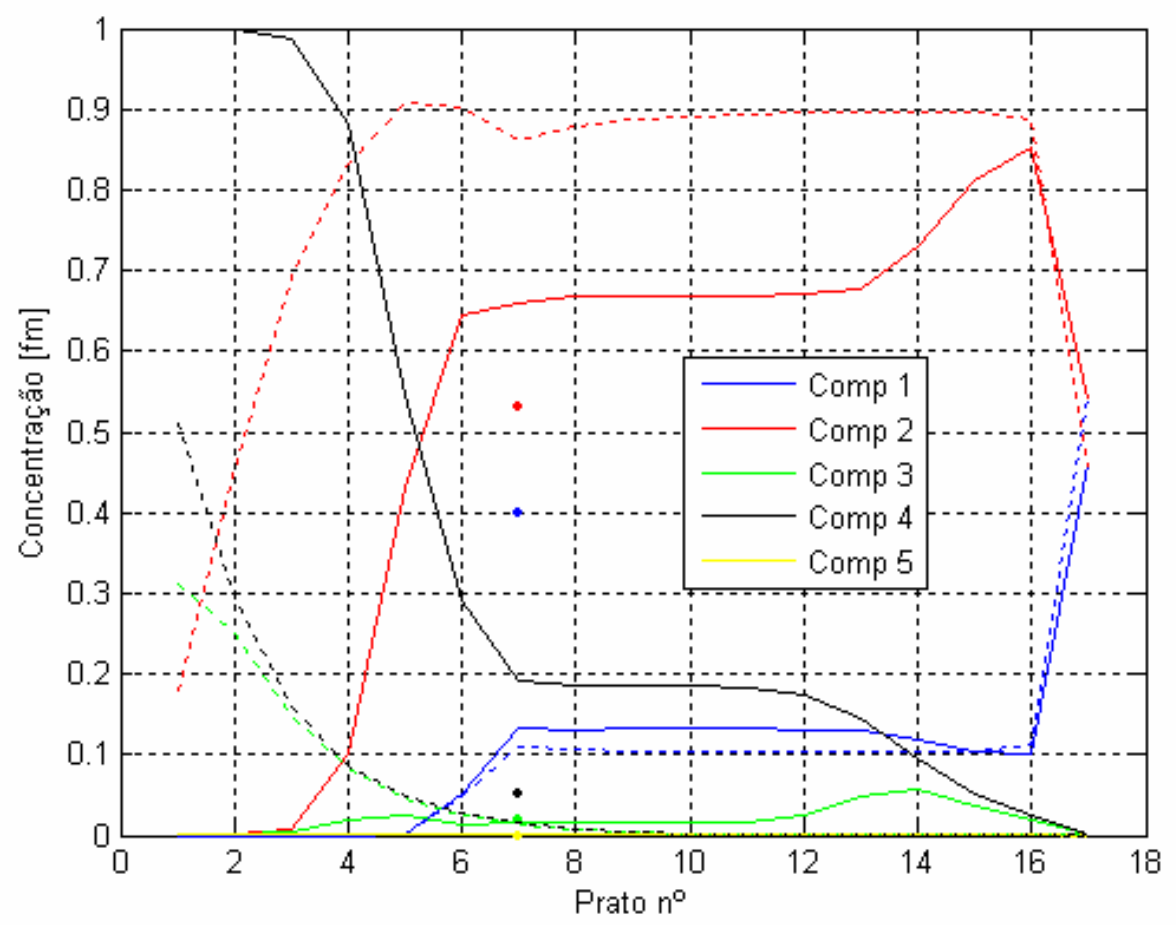

Figura 3.22: Composição dos componentes no vapor dos pratos

Na Figura 3.22 pode-se ver o perfil da composição de todos os componentes presentes no vapor da coluna. Como era de se esperar houve um aumento da concentração dos componentes mais pesados no vapor.

Tabela 3.9: Composição dos produtos após rampa de $20 \%$

\begin{tabular}{|c|c|c|c|}
\hline & \multicolumn{3}{|c|}{ Composição [fm] } \\
\hline Componente & Destilado Líquido & Destilado Vapor & Produto Base \\
\hline $\mathbf{1}$ & 0,01 & 0,46 & 0 \\
\hline $\mathbf{2}$ & 0,93 & 0,54 & 0 \\
\hline $\mathbf{3}$ & 0,03 & 0 & 0 \\
\hline $\mathbf{4}$ & 0,03 & 0 & 0,88 \\
\hline $\mathbf{5}$ & 0 & 0 & 0,12 \\
\hline
\end{tabular}


Da Tabela 3.7 pode-se perceber que houve uma redução considerável da qualidade do componente 2 retirado no topo da coluna, que é o de maior interesse. O componente 4 no produto de base teve uma ligeira melhora, porém há pratos em que apresenta uma composição mais alta do que a que possui no refervedor onde é retirado. Isto pode ser explicado pela presença do componente 5 que aparece apenas no refervedor. Finalmente, o destilado vapor continua apresentando uma mistura apenas com os componentes mais leves, porém agora com menor participação do componente 1 .

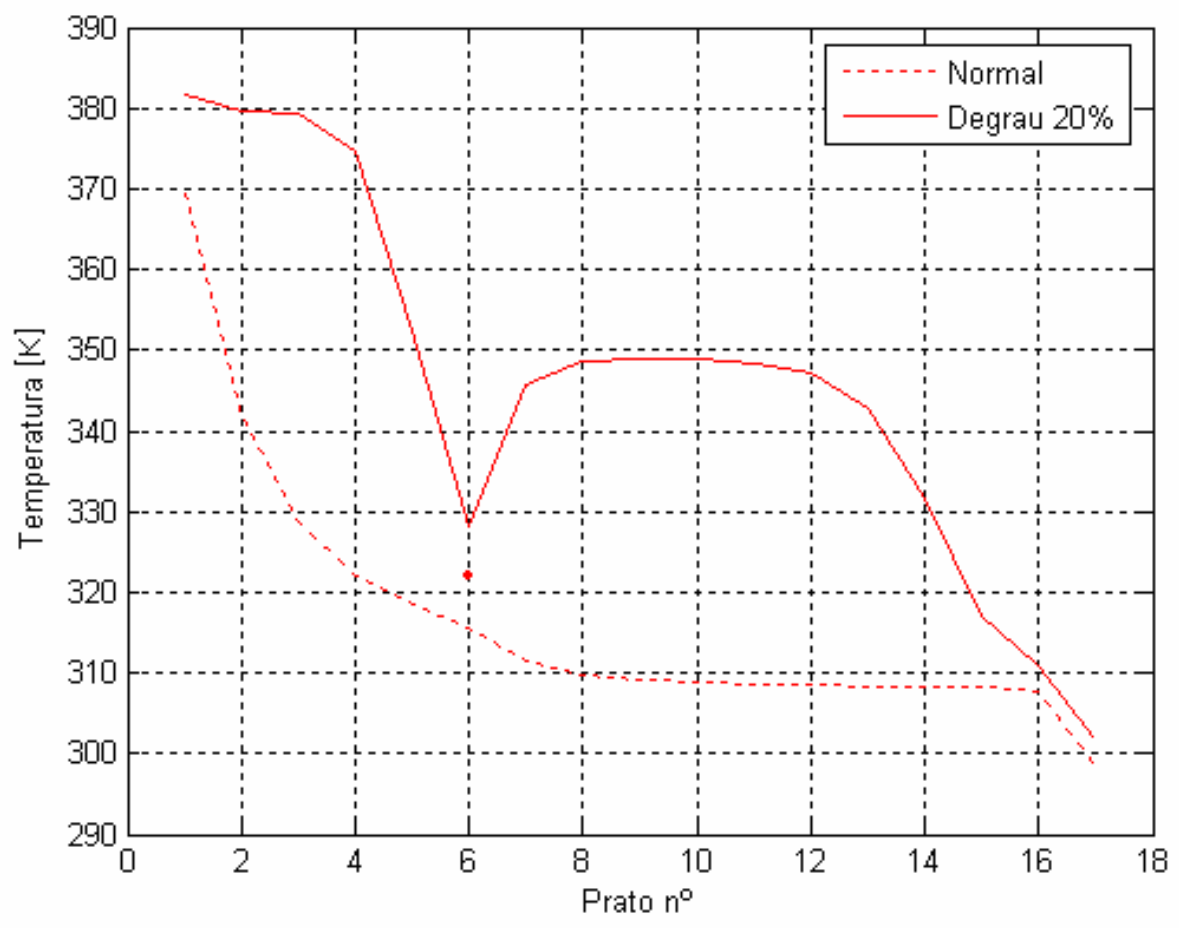

Figura 3.23: Perfil da temperatura ao longo da coluna antes e após o degrau

A Figura 3.23 exibe os perfis de temperaturas internas nos estágios da coluna antes, no regime nominal de operação e depois da perturbação em degrau. Deve-se destacar que houve uma grande variação da temperatura nos estágios intermediários da coluna. O ponto de inflexão observado no novo perfil de temperatura é devido ao efeito da alimentação que resfria o prato, o mesmo efeito da inflexão pode ser observado afetando também as composições como na Figura 3.21 . 


\section{Conclusões}

Após este estudo do comportamento da coluna de destilação para certa amplitude de operação pode-se concluir que:

- Na condição nominal de operação a coluna está operando no limite para maximizar a separação dos componentes 2 no topo e 4 na base. A aplicação do degrau de $-10 \%$ na quantidade de calor fornecida à coluna (QR), gerou uma melhora quase imperceptível na qualidade do produto 2 no topo, e a aplicação do degrau de 10\% levou a coluna a reduzir a composição do mesmo.

- A aplicação do degrau de 10\% alterou significativamente o modo de operação da coluna, introduzindo sobressinal elevado e maior tempo de acomodação, do que quando comparado com a aplicação do degrau de menos $10 \%$. Estas alterações podem auxiliar na determinação dos parâmetros de amostragem das respostas da coluna

- A aplicação de um degrau com $20 \%$ de amplitude gera um sobressinal muito alto e provoca erros no modelo, isto sugere que devemos limitar as excitações nas variáveis, para que somadas não ultrapassem este valor.

- Pode-se observar que a temperatura possui de fato uma grande influência na composição do componente 2 no topo da coluna, resta ainda descobrir em quais pratos ela possui uma influência mais significativa, o que será abordado mais adiante. 


\section{Capítulo 4}

\section{Projeto do Experimento e Coleta dos Dados para Identificação}

Neste capítulo descreve-se a obtenção do conjunto de dados que será utilizado para o treinamento da rede neural do sensor virtual. Esta é uma das etapas mais importantes para o desempenho do sensor. A seguir serão apresentados os detalhes da determinação e aquisição do conjunto de dados para a realização dos treinamentos.

\subsection{Projeto do experimento para identificação}

Para a obtenção do sensor virtual para medições inferenciais da composição dos produtos da coluna de destilação é necessário que se tenha primeiramente um conjunto de dados bastante abrangente. Para isto o processo simulado será submetido a uma excitação externa, na forma de um sinal que perturba determinadas variáveis. 
Tipicamente em identificação de sistemas há 3 tipos de variáveis de entrada (variáveis que aferem a saída), todas elas independentes entre si, que são:

- Variáveis manipuladas

- Perturbações medidas

- Perturbações não-medidas

No entanto, no caso do modelo da coluna de destilação, sabe-se que há variáveis internas (como, por exemplo, a temperatura nos pratos) que influenciam fortemente a composição dos produtos destilados. É comum que os sensores virtuais para colunas de destilação empreguem esta temperatura nos pratos como variável de entrada (KANO et al., 2000, FILETI et al., 1999 MEJDELL e SKOGESTAD 1991a e b).

Entretanto, não se consegue manipular diretamente as temperaturas nos pratos, muito embora seja fácil medi-las. Suas variações são conseqüência de alterações nas variáveis manipuladas. Elas, portanto, não são independentes das variáveis manipuladas não caracterizando uma perturbação medida. Desta forma, para designar este tipo de variável, foi adotada neste trabalho a notação variável de entrada não diretamente manipulável.

Nesta fase do projeto, inclui-se a seleção das variáveis de entrada e saída da planta (variáveis manipuladas, variáveis de entrada não diretamente manipuláveis e variáveis de saída) e das variáveis coletadas que devem refletir a situação momentânea da planta. Também será escolhido o sinal que será empregado para a realização da excitação (tipo de sinal, amplitude e freqüência) e definido o intervalo de amostragem.

Os dados coletados serão separados em duas categorias: dados de treinamento, que serão utilizados para o treinamento da rede e dados de teste, que serão utilizados para avaliar o desempenho do sensor sob condições reais de utilização. Além dessa divisão, será feita uma subdivisão do conjunto de treinamento, criando além dos 
dados para treinamento propriamente dito, um outro subconjunto de validação, utilizado para verificar a eficiência da rede quanto à sua capacidade de generalização durante o treinamento e podendo ser empregado como critério de parada do treinamento.

Deve-se enfatizar que durante a coleta dos dados para treinamento da rede não foram introduzidos ruídos, tanto nas variáveis de entrada como nas de saída. Porém, ressalta-se que um ruído deste tipo será utilizado nos dados de entrada para a validação final do sensor virtual no capítulo 6 .

A seguir serão descritas as principais etapas seguidas para a realização do projeto do experimento e a coleta do conjunto de dados.

\subsubsection{Seleção das variáveis de entrada e saída}

Nesta seção é apresentada a seleção das variáveis do modelo, na qual se distinguem: variáveis manipuladas, variáveis de entrada não diretamente manipuláveis e variáveis de saída.

\section{Seleção das variáveis de saída}

As variáveis de saída são os valores fornecidos como resposta do modelo dinâmico da coluna. Estas variáveis revelam a situação atual da coluna e os efeitos desencadeados pelas variáveis de entrada. Assim, têm-se como variáveis de saída:

- Composição de cada componente da mistura no estado líquido em cada estágio $\left(\mathrm{x}_{\mathrm{i}, \mathrm{j}}\right)$

- Composição de cada componente da mistura no estado de vapor em cada estágio $\left(\mathrm{y}_{\mathrm{i}, \mathrm{j}}\right)$ 
Será coletada apenas a composição do componente 2 na fase líquida no estágio de topo da coluna $\left(\mathrm{x}_{2,17}\right)$, pois esta é a variável que se deseja que o sensor estime. Esta variável será fornecida à rede neural durante o treinamento da mesma e será obtida depois durante a operação do sensor como variável estimada pelo sensor virtual.

\section{Seleção das variáveis de entrada}

Há dois tipos de variáveis de entrada para o sensor virtual: aquelas diretamente manipuláveis pelo usuário e aquelas que são conseqüência da manipulação (não diretamente manipuláveis), mas que afetam as saídas e que serão medidas e empregadas como variáveis de entrada do sensor. Como exemplo da primeira categoria pode-se citar o calor fornecido ao refervedor $(\mathrm{QR})$ e o fluxo de alimentação (FL) e como exemplo da segunda categoria pode-se citar as temperaturas nos pratos $(\mathrm{T})$.

Um esclarecimento que deve ser feito é que o calor fornecido ao refervedor (QR) não é diretamente manipulado, mas sim a temperatura ou a vazão do fluido que fornece calor ao refervedor. Como este fato não altera a variável manipulada será mantida a nomenclatura utilizada anteriormente no resto do trabalho.

\section{Seleção das variáveis manipuladas}

Estas variáveis podem ser perturbadas por um sinal de entrada forçado pelo usuário do sistema para levar a planta a diferentes condições de operação. Da análise destas variáveis serão selecionadas algumas que serão efetivamente manipuladas através de um sinal de excitação.

A seguir, apresenta-se uma lista das variáveis manipuladas que poderiam ser escolhidas. Não aparecem na relação algumas variáveis que são manipuláveis, mas 
que não poderiam ser excitadas, como as variáveis que são controladas durante a operação da planta. Neste caso, citam-se as variáveis manipuladas pelos controladores, como o nível de fluido no condensador e no refervedor.

$\begin{array}{ll}\text { Alimentação: } & \text { Fluxo de líquido }(\mathrm{FL}) \\ & \text { Fluxo de vapor }(\mathrm{FV}) \\ & \text { Temperatura }(\mathrm{TF}) \\ & \text { Composição do líquido }\left(\mathrm{x}_{\mathrm{i}}\right) \\ & \text { Composição do vapor }\left(\mathrm{y}_{\mathrm{i}}\right) \\ & \text { Vazão de refluxo }(\mathrm{R}) \\ \text { Condensador: } & \text { Quantidade fornecida de calor }(\mathrm{QR}) \\ \text { Refervedor: } & \end{array}$

Dentre estas variáveis foram escolhidas para serem manipuladas: na alimentação, o fluxo de líquido e de vapor que entram na coluna (FL e FV) e a temperatura deste fluxo (TF). A composição da alimentação, tanto do líquido como do vapor, não serão alteradas por dois motivos: primeiro, por se supor que a alimentação é homogênea no reservatório da qual provém e segundo, que as composições desta mistura são difíceis de serem medidas em linha.

No condensador será manipulada a vazão de refluxo $(\mathrm{R})$ que retorna para a coluna, sendo que esta variável possui papel relevante na pureza do produto de topo. Colabora com isto o fato de que alguns autores propõem esta variável como meio para controlar a concentração do destilado (KANO et al., 2003, MEJDELL e SKOGESTAD, 1993).

No refervedor será considerada a quantidade fornecida de calor (QR) à coluna, pois esta variável é a principal fonte de calor da coluna, juntamente com a temperatura da alimentação.

Portanto, serão manipuladas as seguintes variáveis: TF, FL, FV, R e QR. 


\section{Seleção das variáveis de entrada não diretamente manipuláveis}

As variáveis de entrada não diretamente manipuláveis refletem alterações oriundas das variáveis manipuladas e possuem uma grande influência nas variáveis de saída.

As variáveis de entrada não diretamente manipuláveis da coluna e que são passíveis de medição empregando sensores convencionais são:

- Temperatura nos estágios $\left(\mathrm{T}_{\mathrm{i}}\right)$

- Pressão nos estágios $\left(\mathrm{P}_{\mathrm{i}}\right)$

Destacam-se também outras variáveis de entrada não diretamente manipuláveis da coluna, mas de medição muito difícil:

- Fluxos de líquido interno nos estágios $\left(\mathrm{L}_{\mathrm{i}}\right)$

- Fluxos de vapor interno nos estágios $\left(\mathrm{V}_{\mathrm{i}}\right)$

- Composição do líquido em cada estágio $\left(\mathrm{x}_{\mathrm{i}}\right)$

- Composição do vapor em cada estágio $\left(\mathrm{y}_{\mathrm{i}}\right)$

Dentre estas variáveis serão escolhidas apenas as temperaturas $\left(T_{i}\right)$ nos estágios, pois possuem forte dependência com a composição da mistura no prato e são de medição relativamente fácil. A medida da pressão nos estágios não será utilizada, apesar de conhecido os seus valores, pois o modelo empregado considera pressão constante no tempo.

Quanto às demais variáveis: os fluxos internos de líquido e de vapor serão desprezados, uma vez que sua medição é muito difícil de ser realizada (estão disponíveis no simulador apenas para cálculos internos) e as composições também não serão consideradas pela dificuldade de medi-las em linha em cada prato. 
Ainda assim, tem-se que a temperatura interna possui 17 diferentes valores, sendo um para cada estágio da coluna. A utilização de todas estas informações pode deixar o conjunto de dados demasiadamente grande, o que traz maior lentidão para a rede, e principalmente pelo fato de que as temperaturas em todos os pratos é um volume de informação repetitiva e desnecessária para o treinamento da rede.

Portanto, serão coletados dados apenas dos pratos cujos valores das temperaturas sejam mais representativos para a estimação da composição do componente 2 no topo da coluna. A Figura 4.1 mostra o comportamento das temperaturas nos 17 estágios da coluna, quando se excita as cinco variáveis manipuladas mostradas anteriormente com sinais aleatórios cuja variação máxima na amplitude é de $\pm 5 \%$ e independentes entre si.

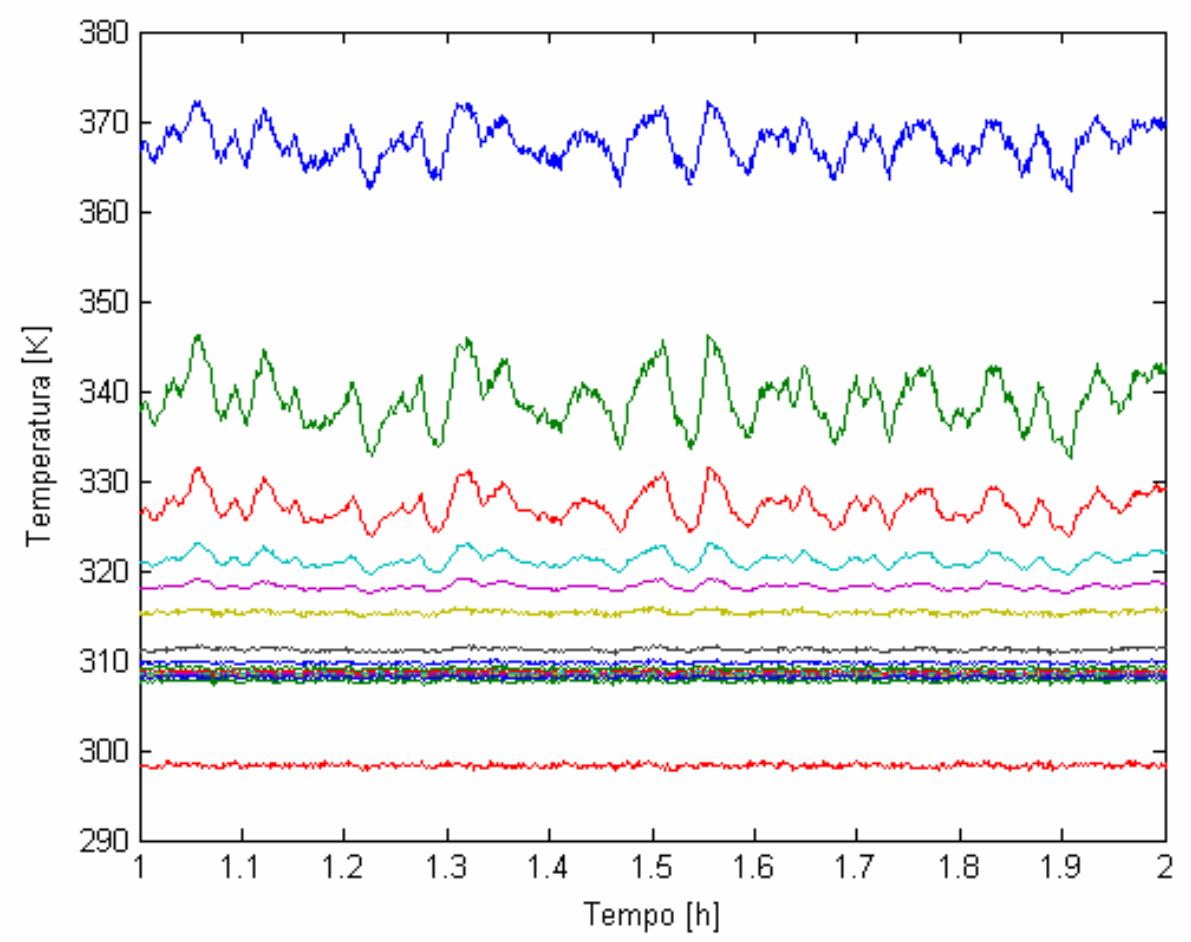

Figura 4.1: Perfil de temperaturas na coluna durante excitação aleatória

A Figura 4.2 mostra em detalhes o comportamento da temperatura nos pratos inferiores da coluna, que na Figura 4.1 aparecem muito próximos e difíceis de 
serem visualizados. Pode-se observar que o comportamento da temperatura nestes pratos possui uma grande semelhança entre si, sendo, portanto repetitivo e desnecessário a utilização dos valores em todos os estágios.

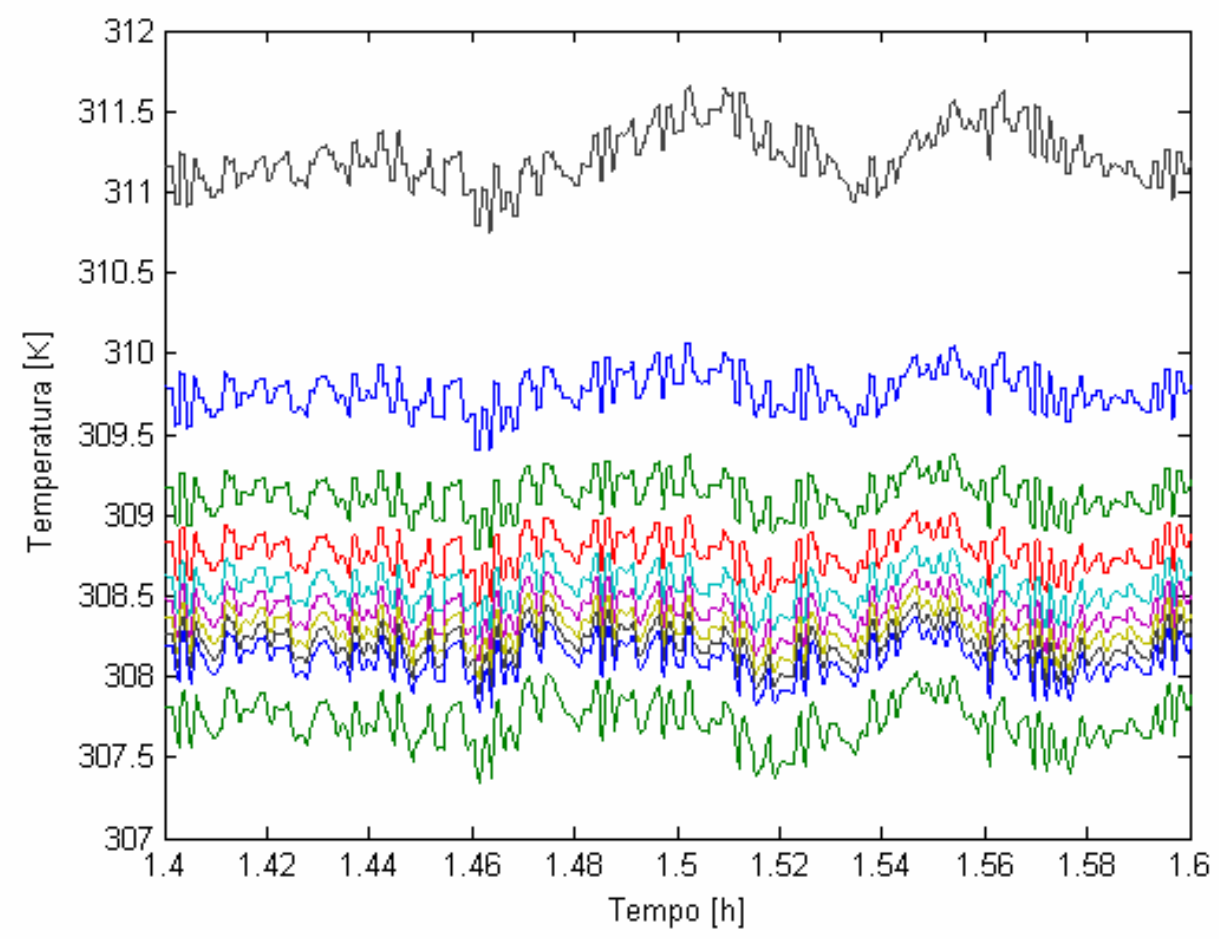

Figura 4.2: Detalhe do perfil de temperaturas nos pratos inferiores da coluna

A fim de se reduzir o número de variáveis selecionadas que serão utilizadas para o treinamento da rede, fez-se um estudo comparativo baseado na covariância destas variáveis (temperatura em cada prato $-\mathrm{T}_{\mathrm{i}}$ ) com relação à variável de saída que se quer estimar (composição do componente 2 no condensador $-\mathrm{x}_{2,17}$ ).

Esta análise é conhecida como covariância cruzada e pode ser obtida através da utilização da seguinte equação: 


$$
\operatorname{Cov}_{x, y}(\zeta)=\frac{1}{N} \cdot \sum_{k=1}^{N}[(x(k)-\bar{x}) \cdot(y(k-\zeta)-\bar{y})]
$$

Onde: $\boldsymbol{N}$ é o número de elementos dos vetores (x e y mesmo tamanho). $\boldsymbol{x}$ e $\boldsymbol{y}$ são respectivamente os vetores de entrada e saída. $\bar{x}$ e $\bar{y}$ são os valores médios dos respectivos vetores. $\zeta$ é o número de atrasos analisados para o sinal.

Analisando-se a covariância cruzada entre as temperaturas nos pratos e a composição do produto 2 no estado líquido no estágio 17 (condensador), para um tempo de amostragem de 1,5 segundos, resultam os valores mostrados nas figuras a seguir. Com base em um trabalho de Kano et al (2000), decidiu-se por selecionar os 5 pratos cujas temperaturas apresentem maior correlação com $x_{2,17}$.

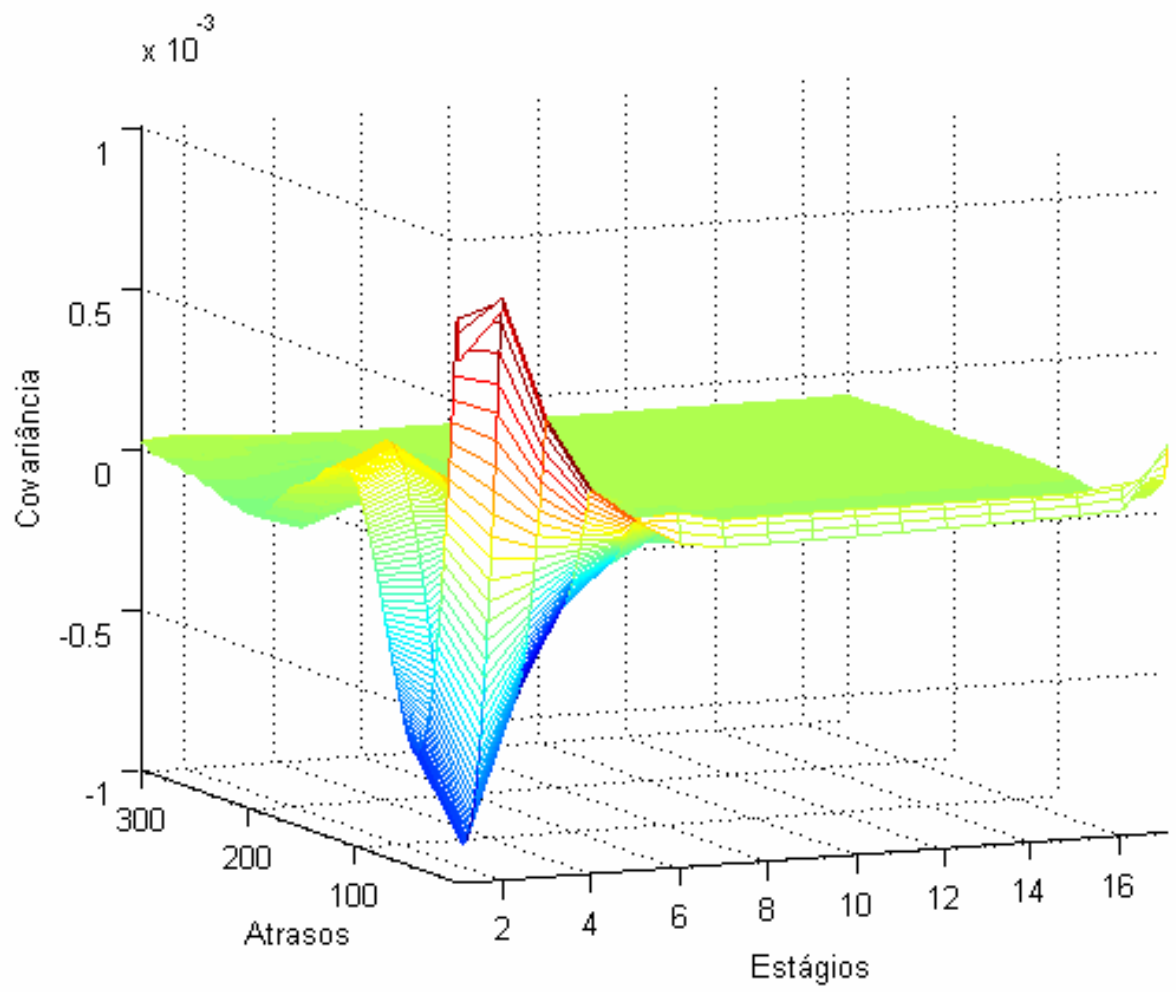

Figura 4.3: Covariância cruzada das temperaturas nos pratos $\left(\mathrm{T}_{\mathrm{i}}\right)$ e $\mathrm{x}_{2,17}$ 
$\mathrm{Na}$ Figura 4.3 pode-se observar no eixo dos estágios que os 5 estágios que apresentam maior correlação da temperatura com a composição do produto destilado no topo da coluna são os de número: 1, 2, 3, 4 e 17. Portanto, serão utilizados os valores das temperaturas nestes 5 pratos como entrada da coluna.

A Figura 4.4 mostra a covariância cruzada resultante entre as temperaturas nos 5 estágios selecionados (maior correlação) atrasados em até 300 períodos de amostragem antes do valor atual da composição do líquido no condensador $\left(\mathrm{x}_{2,17}\right)$.

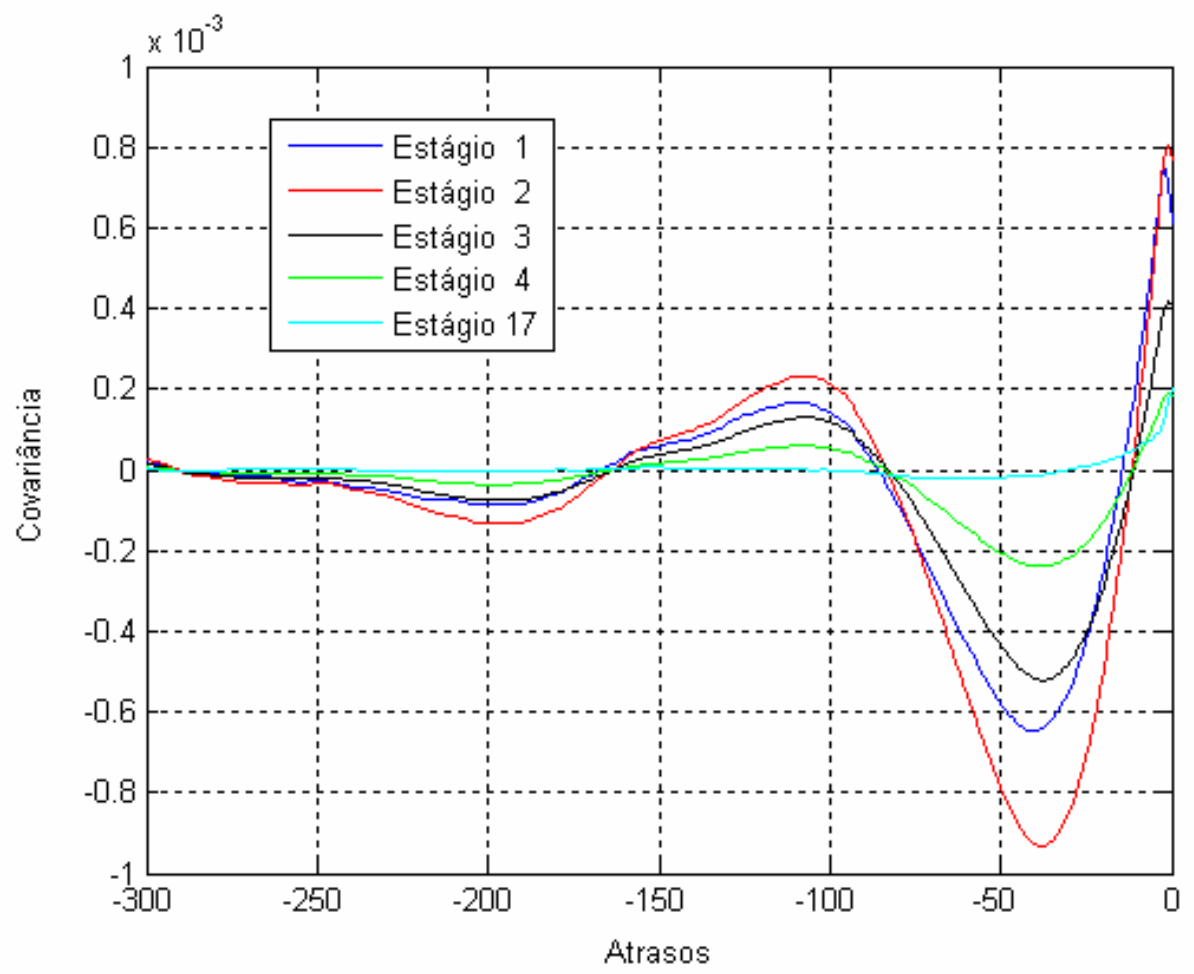

Figura 4.4: Covariância cruzada das temperaturas nos estágios $\left(\mathrm{T}_{\mathrm{i}}\right)$ e $\mathrm{x}_{2,17}$

Pode-se observar na Figura 4.4 que a temperatura nos 5 estágios selecionados apresenta um alto valor de covariância para os valores amostrados com poucos atrasos, o que mostra a influência que esta temperatura nos instantes anteriores terá na composição do líquido no condensador $\left(\mathrm{x}_{2,17}\right)$. Com o aumento dos atrasos a correlação diminui indicando a perda desta influência. 
A Figura 4.5 mostra em detalhes os instantes amostrados que apresentam maior correlação entre a temperatura e a composição do destilado no topo da figura anterior.

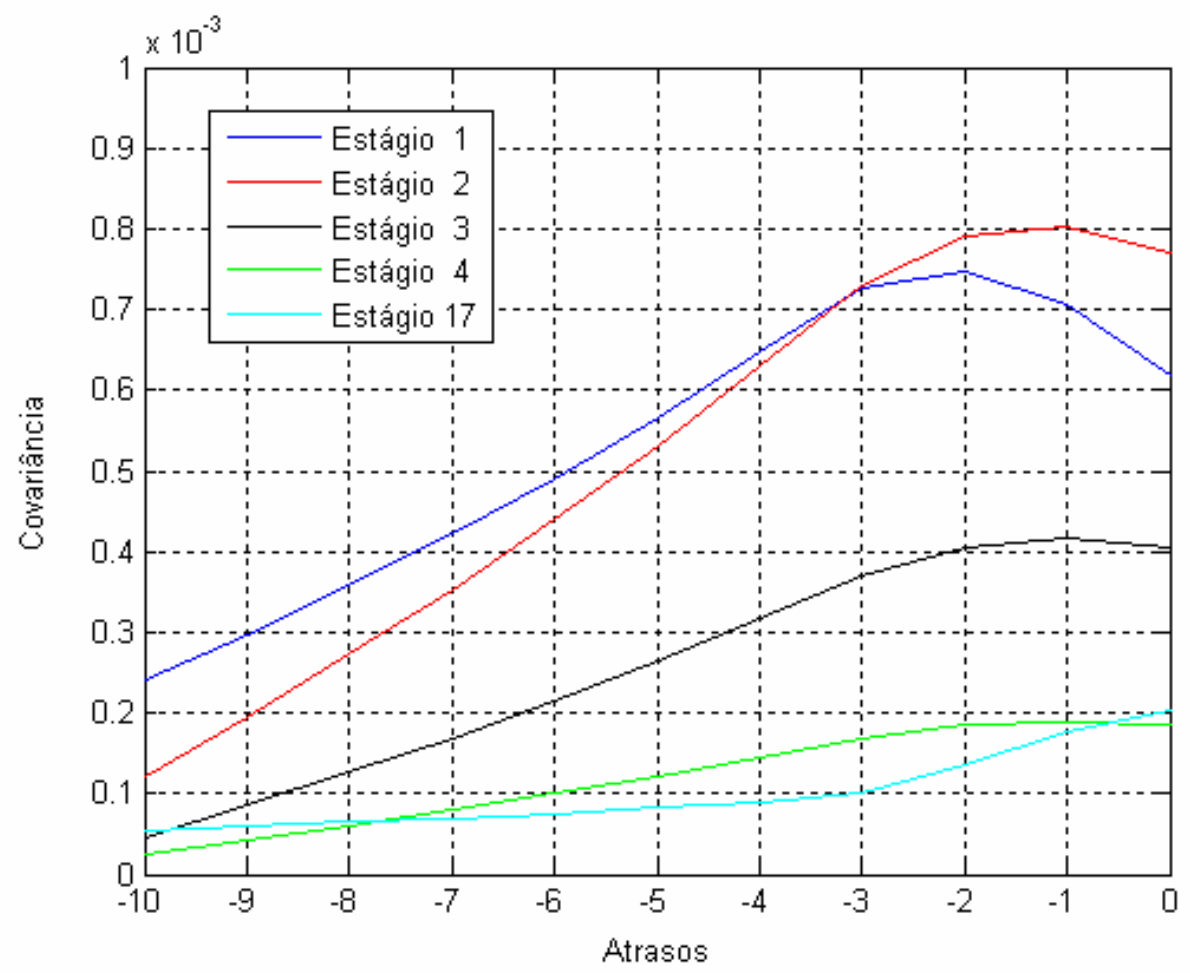

Figura 4.5: Detalhe da Covariância cruzada de $\mathrm{T}_{\mathrm{i}}$ e $\mathrm{x}_{2,17}$

Pode-se observar da Figura 4.5 que os instantes amostrados que apresentam maior correlação com a composição da saída são respectivamente: -2 para o estágio 1; -1 para os estágios 2, 3 e 4; e sem atraso para o estágio 17. Isto mostra claramente que os pratos mais distantes do topo influenciam-no com um atraso maior que é fruto do tempo necessário para a sua propagação coluna acima. Deve-se destacar que a amostragem realizada coleta pontos a cada 40 passos de integração realizados pelo simulador (ou seja, 1,5 s).

Portanto, temos que os estágios mais significativos escolhidos são os de número: 1, 2, 3, 4, e 17. Destaca-se que estes estágios referem-se ao refervedor (1), ao condensador (17), e aos três estágios mais próximos à base da coluna (2, 3 e 4). 
Finalmente, temos que as temperaturas a serem consideradas como entradas não diretamente manipuláveis para o modelo do sensor virtual são: $\mathrm{T}_{1}, \mathrm{~T}_{2}, \mathrm{~T}_{3}, \mathrm{~T}_{4}$, e $\mathrm{T}_{17}$.

\section{Conjunto das variáveis coletadas para treinamento da rede}

O conjunto de dados será composto pelas seguintes variáveis que serão coletadas para treinamento da rede neural: variáveis manipuladas - fluxo de líquido e de vapor da alimentação (FL e FV), temperatura da alimentação (TF), refluxo do condensador $(\mathrm{R})$ e quantidade de calor adicionado $(\mathrm{QR})$ - variáveis de entrada não diretamente manipuláveis - temperaturas nos pratos escolhidos $\left(\mathrm{T}_{1}, \mathrm{~T}_{2}, \mathrm{~T}_{3}, \mathrm{~T}_{4} \mathrm{e}\right.$ $\mathrm{T}_{17}$ ) - e a variável de saída - composição do componente 2 na fase líquida no topo $\left(\mathrm{x}_{2,17}\right)$.

\subsubsection{Escolha do sinal de excitação}

Para a realização do treinamento do sensor o conjunto de dados deve ser tal que contenha dados representativos de toda a amplitude em que se espera que o sensor venha a operar e que estes dados estejam representados em número suficiente para a rede gerar um padrão para reconhecimento futuro.

Para satisfazer as duas condições anteriores, durante a aquisição dos dados a coluna deve apresentar comportamento variável passando por situações diferentes de operação. Para induzir este efeito na simulação dinâmica serão utilizados sinais de excitação em todas as variáveis manipuladas para perturbar o regime de operação da coluna.

$\mathrm{Na}$ identificação de sistemas não-lineares, como é o caso das redes neurais, tipicamente utiliza-se como sinal de excitação o sinal aleatório ou ruído branco (AGUIRRE, 2004), aplicado simultaneamente em todas as variáveis manipuladas. 
Para a excitação serão utilizados sinais aleatórios (ruído branco) com distribuição normal de probabilidade e com amplitude máxima de $\pm 20 \%$, o que garante uma boa faixa de operação para o sensor, levando-se em conta as possíveis variações que pode enfrentar na prática.

Destaca-se também que o sinal aleatório com distribuição normal foi preferido ante as outras distribuições (uniforme, por exemplo) por gerar um conjunto de dados mais parecido com a realidade, uma vez que se espera que as flutuações ocorram em torno dos valores nominais de operação.

Quanto ao período de variação da excitação, este será igual a três vezes o período de amostragem. Este valor foi escolhido com base na freqüência comumente utilizada em identificação de sistemas e por se assumir que as perturbações que chegam à coluna possuem uma freqüência próxima à taxa de amostragem sugerida.

Finalmente, destaca-se que para cada uma das 5 variáveis manipuladas a semente utilizada para o sinal aleatório é diferente, caracterizando assim, 5 sinais aleatórios independentes.

\subsubsection{Período de amostragem}

O período de amostragem ou "sampling time" é o intervalo de tempo com o qual é realizada a coleta de cada amostra de dados. Este intervalo de tempo deve ser pequeno o suficiente para que sejam coletados dados capazes de acompanhar a evolução temporal das variáveis do sistema, com o menor volume de dados possível (GUSTAVSSON, 1975). 
Neste trabalho, o tempo de amostragem a ser considerado será calculado de três maneiras distintas e o menor deles será empregado. A primeira estimativa é feita considerando-se o período de amostragem como sendo um décimo da menor constante de tempo associada com a composição do componente 2 na fase líquida no estágio $17\left(\mathrm{x}_{2,17}\right)$, quando excitada por um degrau em cada uma das variáveis manipuladas. A segunda estimativa é calculada empregando o método de análise das autocovariâncias linear e não-linear do sinal de saída $\left(\mathrm{x}_{2,17}\right)$, conforme proposto em (AGUIRRE, 2004). A terceira estimativa é calculada como um décimo do tempo de acomodação associada com a composição do componente 2 na fase líquida no estágio $17\left(\mathrm{x}_{2,17}\right)$ do sistema, após aplicação do degrau.

\section{Primeiro método}

Para se determinar a menor constante de tempo, analisou-se o gráfico da resposta da composição do componente 2 na fase líquida no estágio 17 (condensador) após a aplicação de um degrau em cada variável manipulada (QR, TF, R, FL e FV).

A Figura 4.6 mostra os resultados obtidos na variação da composição de $\mathrm{x}_{2,17}$ após aplicação individual de um degrau de $+5 \%$ ou $-5 \%$ em cada uma das variáveis manipuladas. O critério para se aplicar $+5 \%$ ou $-5 \%$ visa ao aumento da temperatura nos pratos. 


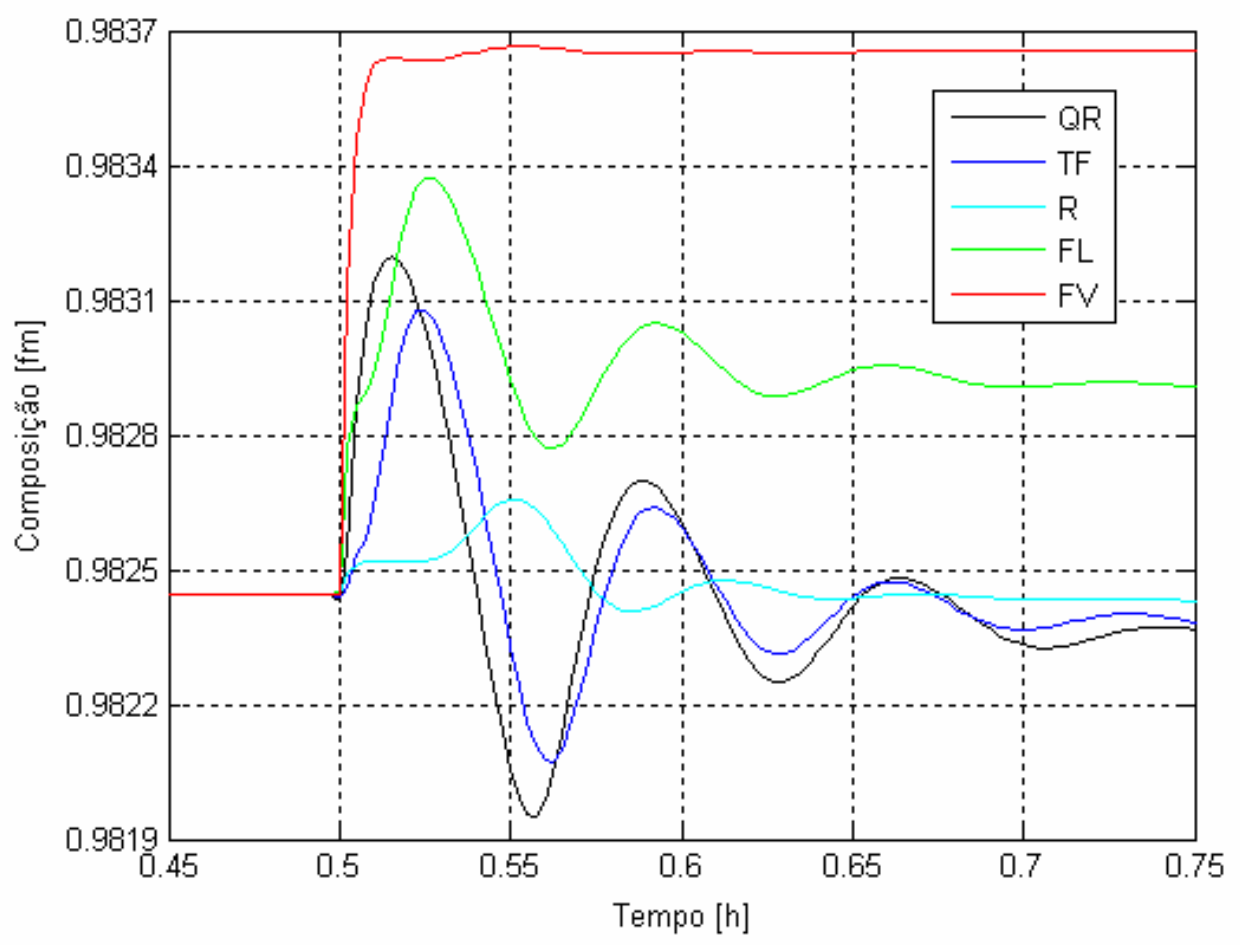

Figura 4.6: Comparação da composição de $\mathrm{x}_{2,17}$ após degrau

A fim de se determinar qual curva apresenta a menor constante de tempo fez-se uma análise comparativa das curvas apresentadas na figura anterior. Dentre as curvas obtidas escolheu-se a que apresenta resposta mais rápida (menor constante de tempo), que foi a curva para a excitação com degrau de - 5\% aplicada na variável FV.

A Figura 4.7 mostra em detalhe a variação da resposta fornecida pela curva selecionada anteriormente, bem como os valores determinados para o cálculo do período de amostragem. 


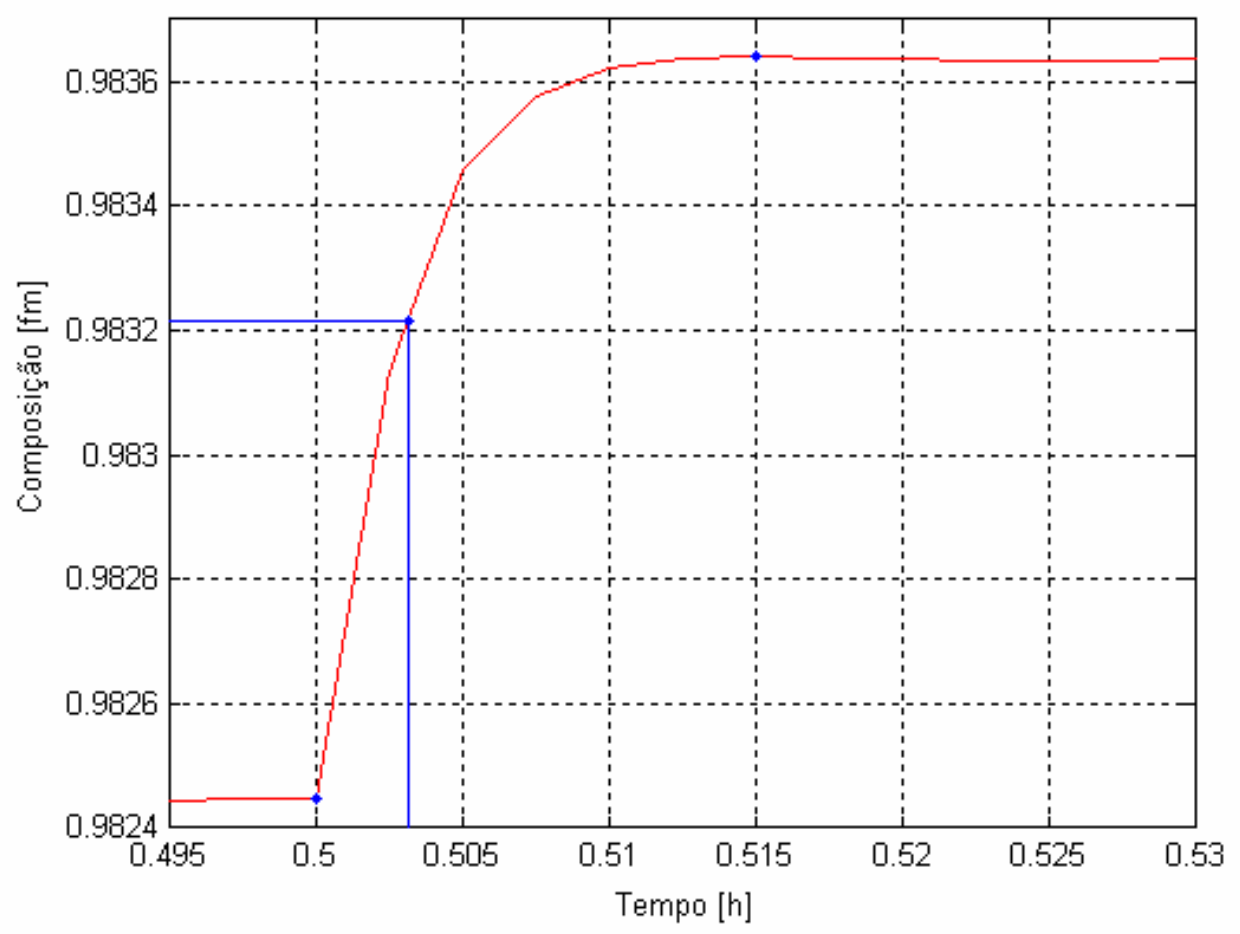

Figura 4.7: Detalhe da obtenção da menor constante de tempo do sistema

Da diferença entre os patamares de estabilização calculamos a amplitude para uma variação de 63\% (0,63 da diferença entre os patamares) e coletamos do gráfico o tempo necessário para esta variação acontecer. Este valor é a constante de tempo mais rápida do sistema. A seguir podem-se ver os cálculos realizados:

Antes da aplicação do degrau: $\quad \mathrm{x}_{2}(0,500)=0,98245$

Estabilização após degrau: $\quad \mathrm{x}_{2}(0,515)=0,98365$

$$
\text { Delta }=\mathrm{x}_{2}(0,515)-\mathrm{x}_{2}(0,500)=0,00120
$$

Temos 63\% do delta $=0,000756$

No gráfico corresponde ao valor de 0,98321, o instante de tempo de: $0,5035 \mathrm{~h}$

Logo a menor constante de tempo é: $\quad \tau_{m}=0,0035 \mathrm{~h}$

Finalmente, o período de amostragem escolhido é: $\mathrm{T}=0,0004 \mathrm{~h} \mathrm{ou} 1,5 \mathrm{~s}$ 


\section{Segundo método}

O método heurístico é um critério simples para avaliação do período de amostragem, que tem apresentado boas indicações em casos práticos (AGUIRRE, 2004). O método consiste em encontrar uma taxa (número inteiro) com o qual o sinal deve ser decimado. Deve-se considerar que quanto mais superamostrado estiver o sinal, maior será a redundância entre duas observações consecutivas.

Para quantificar estes efeitos da sobre-amostragem do sinal são utilizadas as funções de autocovariância linear e não-linear.

Neste caso temos que o sinal foi primeiramente amostrado a uma taxa de $0,0001 \mathrm{~h}$, ou seja, $0,36 \mathrm{~s}$.

Como era esperado, pode-se observar que a curva é simétrica em torno do atraso zero, o que pode ser explicado pelo fato de que o processo é estacionário.

Linear:

$$
\operatorname{Cov}_{x, y}(\zeta)=\frac{1}{N} \cdot \sum_{k=1}^{N}[(x(k)-\bar{x}) \cdot(y(k-\zeta)-\bar{y})]
$$

Não-linear: $\quad \operatorname{Cov}_{x, y}^{*}(\zeta)=\frac{1}{N} \cdot \sum_{k=1}^{N}\left[\left(x^{2}(k)-\bar{x}^{2}\right) \cdot\left(y^{2}(k-\zeta)-\bar{y}^{2}\right)\right]$

Onde: $\boldsymbol{N}$ é o número de elementos dos vetores (x e y mesmo tamanho). $\boldsymbol{x}$ e $\boldsymbol{y}$ são respectivamente os vetores de entrada e saída.

$\bar{x}$ e $\bar{y}$ são os valores médios dos respectivos vetores. $\zeta$ é o número de atrasos analisados para o sinal. 


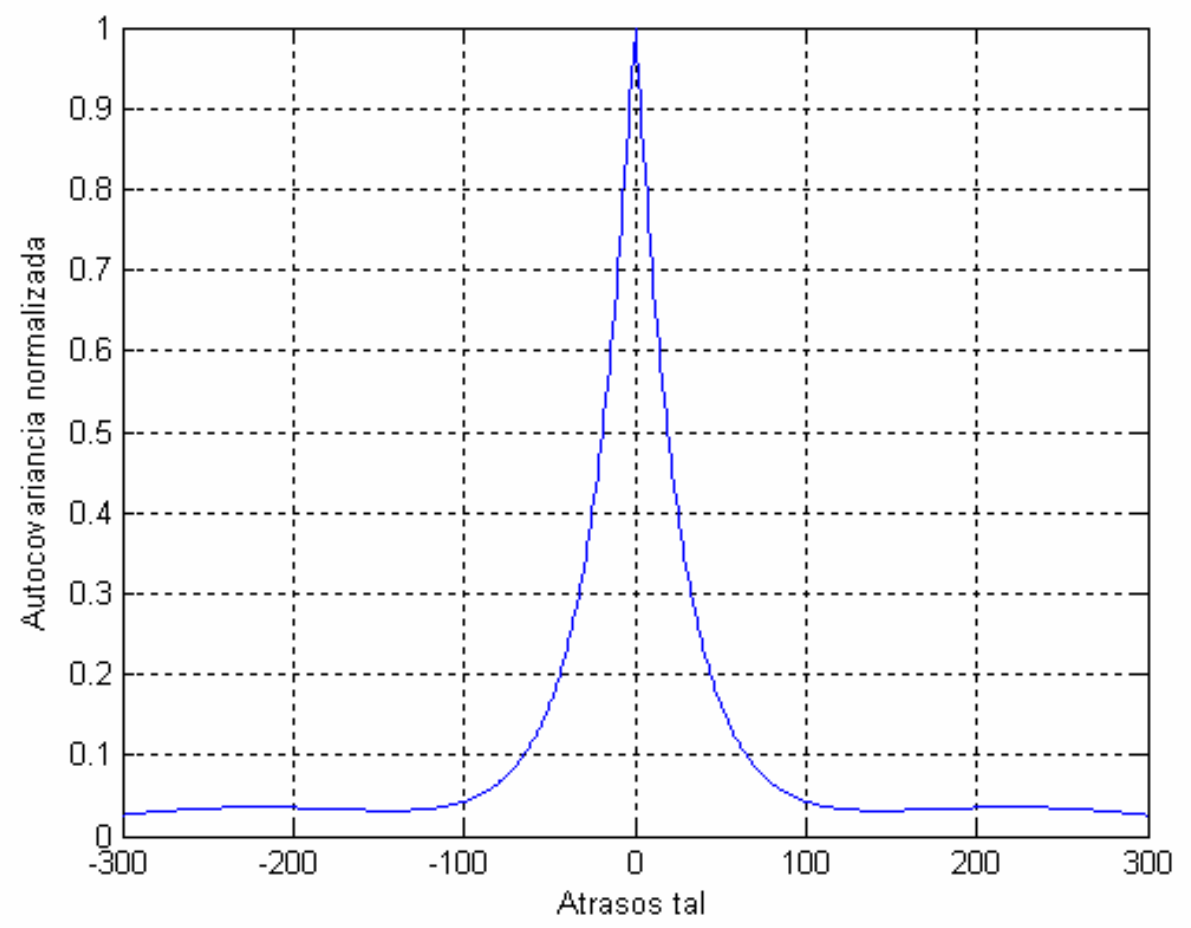

Figura 4.8: Auto-covariância das composições $\mathrm{x}_{2,17}$ com atraso

Analisando-se a Figura 4.8 percebe-se que o primeiro mínimo aparece na função autocovariância para o atraso de 143.

Mínimo ocorre para: $\quad \tau_{\mathrm{m}}=143$

Logo, temos que: $\quad 10 . \Delta \leq \tau_{\mathrm{m}} \leq 20 . \Delta \quad \rightarrow \quad 8 \leq \Delta \leq 14$

Escolheu-se: $\quad \Delta=11$

Portanto, tem-se que o novo período será: $\quad T=0,0001 . \Delta$

Finalmente, o período de amostragem escolhido é: $\quad \mathrm{T}=0,0011 \mathrm{~h} \mathrm{ou} 4 \mathrm{~s}$ 


\section{Terceiro método}

Uma regra prática bastante utilizada e de fácil obtenção é a que considera o tempo de amostragem como $10 \%$ do menor tempo de acomodação de $2 \%$ da resposta ao degrau do sistema. Neste caso, resulta que o menor tempo de acomodação da composição do componente 2 na fase líquida no estágio $17\left(\mathrm{x}_{2,17}\right)$, ocorre quando a excitação é um degrau na variável manipulada FV.

A Figura 4.9 mostra a variação da composição do componente 2 na fase liquida no condensador.

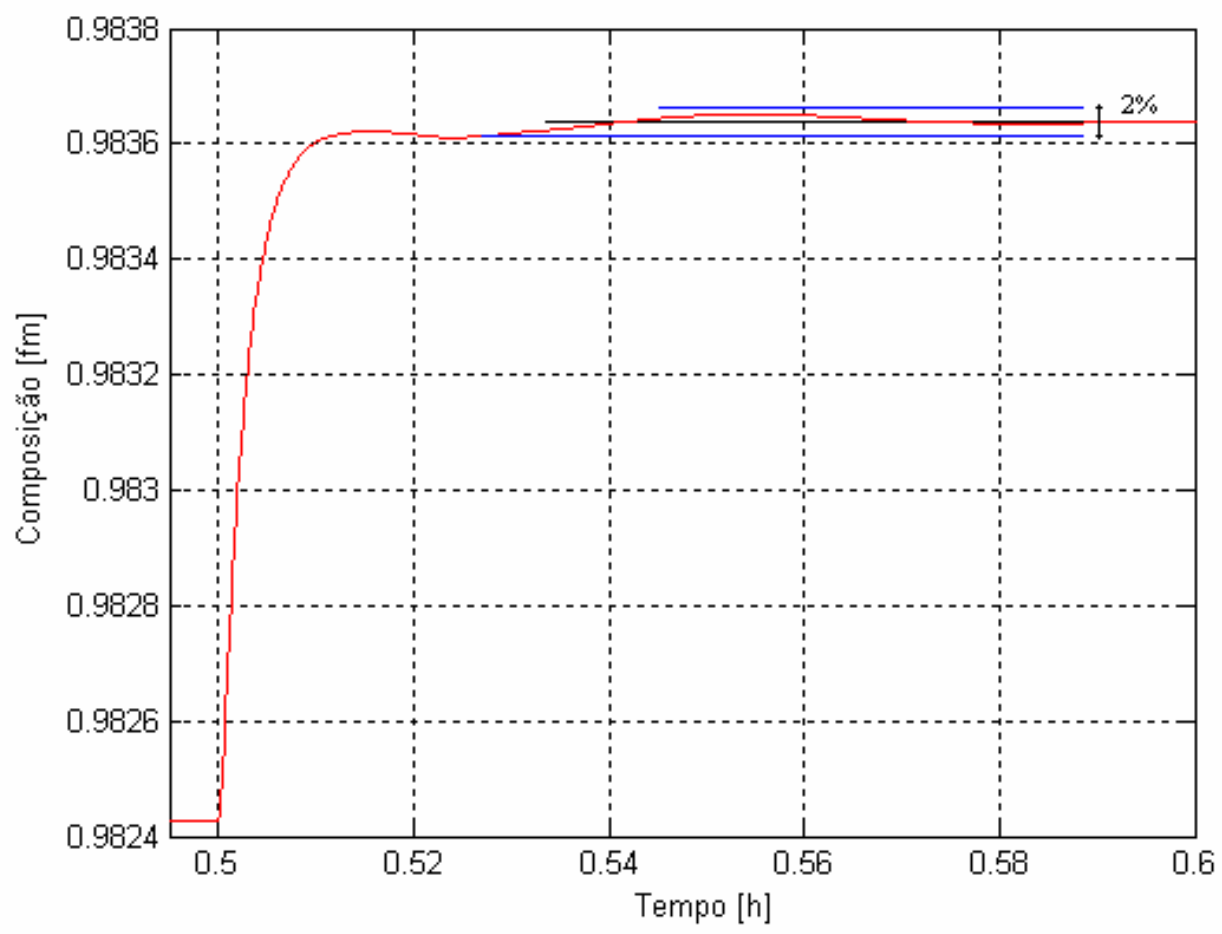

Figura 4.9: Detalhe da obtenção do menor tempo de acomodação do sistema

Na Figura 4.9 pode-se observar que o sinal entra na faixa de $2 \%$ de variação no instante $0,525 \mathrm{~h}$, sendo que o degrau foi aplicado em $\mathrm{t}=0,5 \mathrm{~h}$. Portanto, o tempo de acomodação é de 0,025 h. 
Finalmente, o período de amostragem resultante é: $\mathrm{T}=0,0025 \mathrm{~h} \mathrm{ou} 9 \mathrm{~s}$

Comparando-se os resultados apresentados pelos três métodos anteriores, optou-se pelo de $1,5 \mathrm{~s}$, por ser o menor dentre os três.

Este valor será utilizado na decimação que aparece nos blocos do Simulink ${ }^{\circledR}$ para aquisição dos dados.

O sinal aleatório será mantido constante por um período equivalente a 3 períodos de amostragem:

Logo o período da excitação aleatória é: $\quad$ Rand $=0,0012$ h ou $4,5 \mathrm{~s}$

\subsubsection{Implantação da perturbação no sistema}

Uma vez definido o tipo de sinal que será utilizado como excitação do processo foi feita a implantação deste sinal nas variáveis manipuladas.

Para isto, foi anexado um bloco funcional gerador do sinal aleatório desejado ao modelo do simulador dinâmico. A Figura 4.10 mostra este bloco funcional anexado à variável manipulada entrada de calor no refervedor (QR). Para as demais variáveis manipuladas o procedimento é o mesmo. 


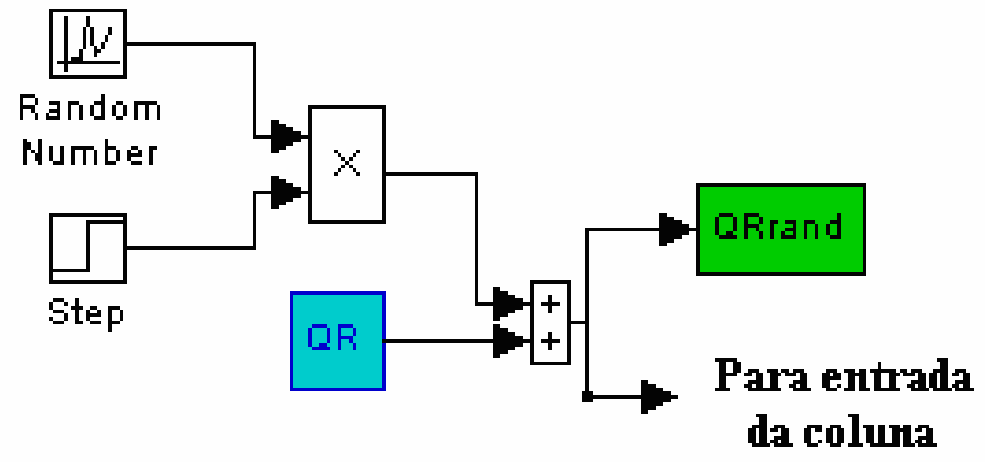

Figura 4.10: Bloco funcional gerador do sinal aleatório para a variável QR

Pode ser observado um degrau junto ao sinal aleatório utilizado como critério de permissão para iniciar a perturbação após o sistema entrar em regime de operação. O tempo de espera de entrada do sistema em regime estacionário foi de $1 \mathrm{~h}$. Este período de espera não será utilizado para o treinamento da rede, pois apresenta variações muito pequenas, conforme mostrado na Figura 4.11.

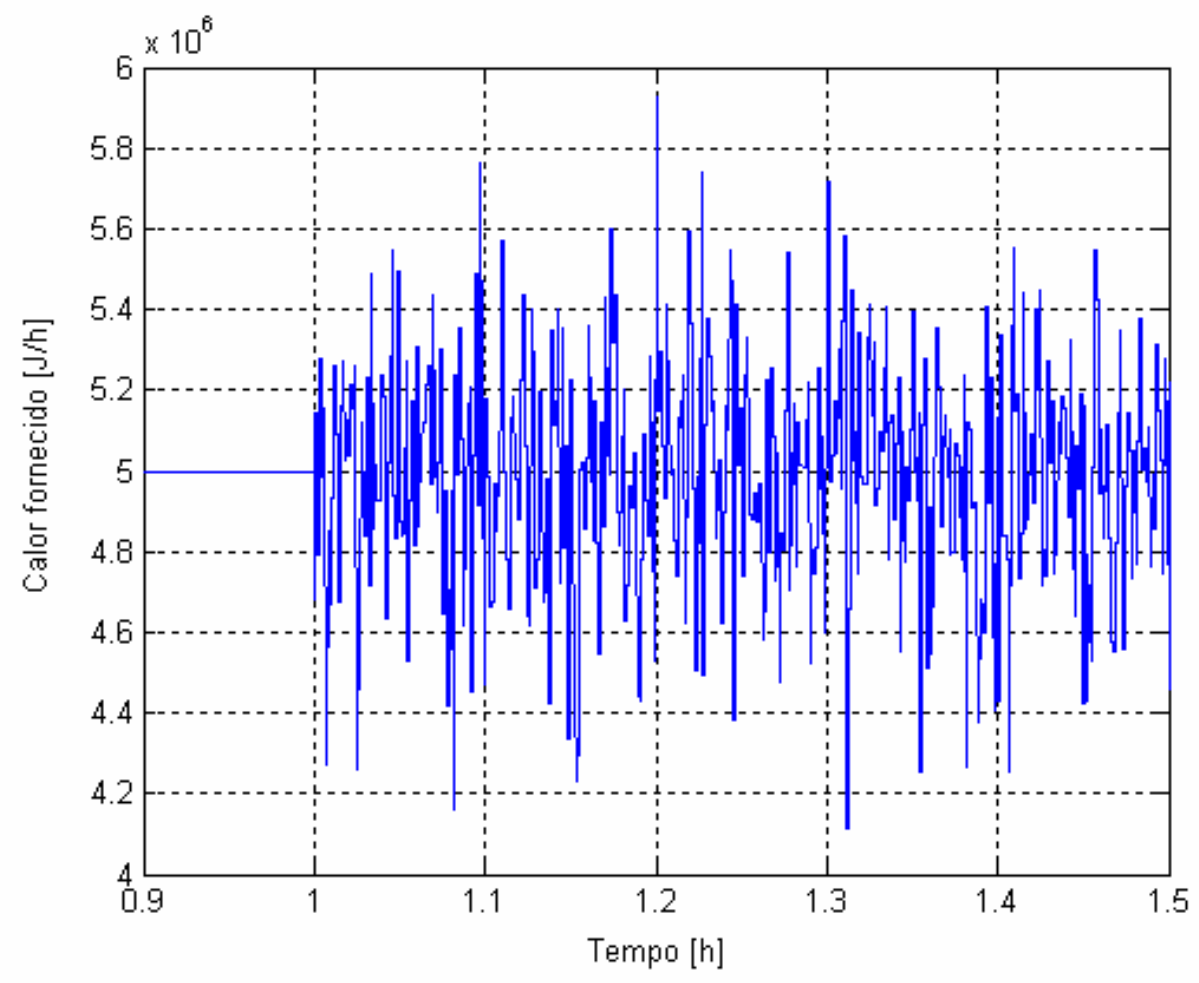

Figura 4.11: Exemplo da perturbação no fluxo de vapor da alimentação 
A amplitude da excitação máxima foi implementada com $\pm 20 \%$ de variação para cada variável, como pode ser observado na Figura 4.11.

\subsection{Coleta dos dados}

Resumindo, foram excitadas as variáveis: TF, FL, FV, QR e R de modo aleatório e com sementes diferentes, ou seja, sinais aleatórios em todas estas variáveis estatisticamente independentes entre si e com período de variação de 3 intervalos de amostragem (4,5 segundos).

Para a aquisição dos dados para treinamento foi realizada uma coleta inicial com 37.500 pontos referentes a $15 \mathrm{~h}$ de funcionamento da coluna, sendo $1 \mathrm{~h} \mathrm{o}$ tempo de espera, com coleta das 10 variáveis de entrada (TF, FL, FV, QR, R, T 1 , $\left.\mathrm{T}_{2}, \mathrm{~T}_{3}, \mathrm{~T}_{4}, \mathrm{~T}_{17}\right)$ e da variável de saída $\mathrm{x}_{2,17}$. Este conjunto de dados foi dividido em dois: um para o treinamento da rede e outro para validação cruzada e teste do desempenho do sensor.

Os dados coletados foram gravados em arquivo pelo Matlab ${ }^{\circledR}$ para utilização futura no treinamento como será visto nos próximos capítulos. 


\section{Capítulo 5}

\section{Redes Neurais Artificiais}

\subsection{Introdução}

O desenvolvimento das redes neurais artificiais (RNA) foi motivado pelo reconhecimento de que o cérebro humano processa informações de uma forma inteiramente diferente do computador digital convencional. O cérebro é um computador (sistema de processamento de informação) altamente complexo, não-linear e paralelo. Ele tem a capacidade de organizar seus constituintes estruturais, conhecidos por neurônios, de forma a realizar certos processamentos muito mais rapidamente que o mais rápido computador digital hoje existente (HAYKIN, 1999).

As redes neurais tentam, de alguma forma, mimetizar este funcionamento. Estima-se que haja aproximadamente 10 bilhões de neurônios no córtex cerebral e 50 trilhões de sinapses (ou conexões entre neurônios). A função de um neurônio isolado é relativamente bem conhecida, porém, o seu comportamento coletivo e interações no conglomerado de elementos cerebrais são pouco claros e carentes de postulados. Conseqüentemente, a arquitetura das redes neurais atuais é baseada em um conhecimento primitivo das funções de um sistema nervoso biológico (WILLIS et al., 1992). 


\subsection{Importância}

Segundo Haykin (1999), a rede neural artificial funciona como um processador paralelo distribuído, constituído de unidades simples de processamento, que possui uma propensão natural para armazenar conhecimento de experiências. Ela imita o cérebro em dois aspectos: conhecimento é adquirido do ambiente pela rede através do processo de aprendizado e o conhecimento adquirido é armazenado através da definição de pesos internos, análogos às conexões sinápticas dos neurônios.

A Figura 5.1 mostra um exemplo de uma rede neural simples.

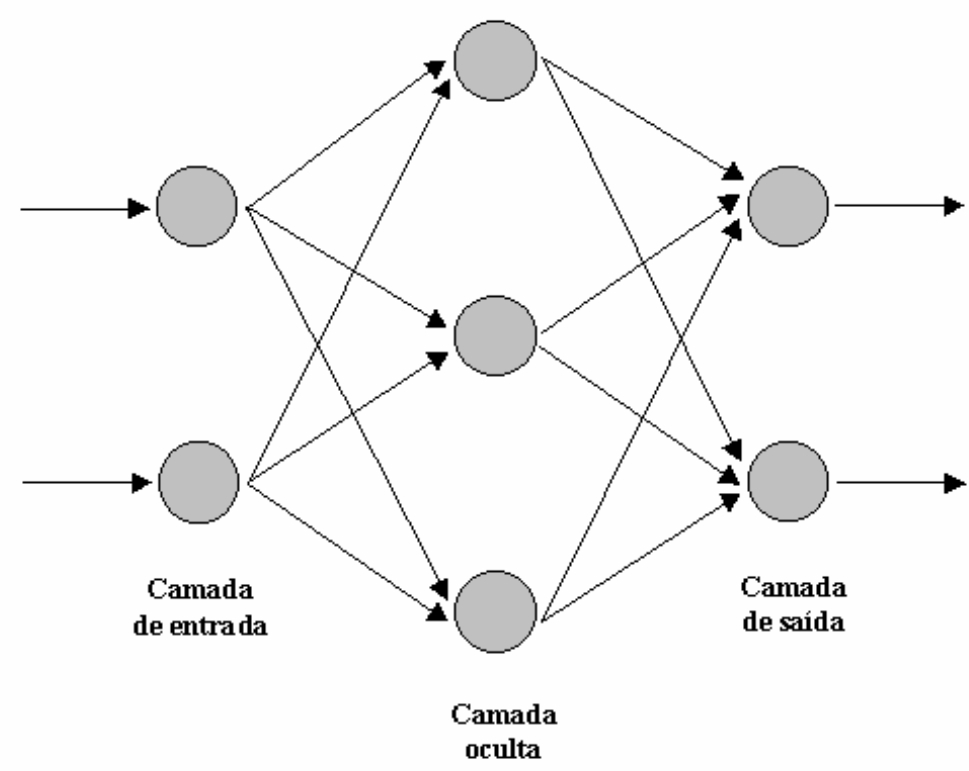

Figura 5.1: Rede neural com uma camada oculta

A capacidade de aprender através de exemplos e de generalizar a informação aprendida são, sem dúvida, os atrativos principais da solução de problemas através de redes neurais. A generalização, que está associada à capacidade da rede aprender através de um conjunto reduzido de exemplos e posteriormente dar respostas coerentes para dados não conhecidos, é uma demonstração de que a 
capacidade das redes neurais vai muito além do que simplesmente mapear relações de entrada e saída. Elas são capazes de extrair informações não-apresentadas de forma explícita através dos exemplos. As redes neurais são capazes de atuar como mapeadores universais de funções multivariáveis, com custo computacional que cresce apenas linearmente com o número de variáveis. Outras características importantes são a capacidade de auto-organização e de processamento temporal que, aliadas àquelas citadas anteriormente, fazem das redes neurais uma ferramenta computacional extremamente poderosa e atrativa para a solução de problemas complexos (BRAGA; CARVALHO; LUDERMIR, 1998).

A solução de problemas através de redes neurais é bastante atrativa, já que a forma como estes são representados internamente pela rede e o paralelismo natural inerente à arquitetura das redes neurais criam a possibilidade de um desempenho superior ao dos modelos convencionais. As principais propriedades e capacidades que as tem tornado tão difundidas são: não-linearidade (a rede neural é inerentemente não-linear e esta característica é distribuída por toda a rede), tolerância a falhas (devido a sua natureza redundante e distribuída a rede pode sofrer perdas de neurônios locais que o comportamento geral é pouco afetado), adaptabilidade (uma rede neural pode facilmente adaptar seus pesos sinápticos para uma situação e assim acompanhar alterações do ambiente em que foi treinada) e mapeamento de entradasaída (através dos exemplos de entrada-saída a rede é capaz de aprender a reconhecer padrões, em um processo que lembra a inferência estatística não-paramétrica).

A idéia de se utilizar uma rede neural artificial como estratégia para resolver problemas que requeriam análise complexa de dados não é nova. Nos últimos 60 anos, centenas de cientistas têm se empenhado para desenvolver uma estrutura semelhante ao cérebro humano e algoritmos equivalentes ao nosso processo de aprendizagem. Recentemente, métodos de modelagem, identificação e estimação de parâmetros utilizando técnicas de redes neurais artificiais têm sido aplicados com êxito a uma variedade de processos reais (WILLIS et al., 1990). 
A abordagem mais comum adotada para o desenvolvimento de modelos não-lineares de um processo é baseada no conhecimento e emprego das equações que descrevem a física do sistema. Porém, para processos mais complexos é necessário um tempo maior para a modelagem, além de que muitas vezes as simplificações introduzidas em algumas etapas para tornar a modelagem do problema mais tratável, acabam por introduzir imprecisões nos resultados.

Quando a relação entre medida de qualidade e variações do processo pode ser obtida "on-line", então o modelo resultante pode ser utilizado dentro de um sistema de controle digital para regular o processo. A habilidade de representar efetivamente sistemas não-lineares complexos é um dos aspectos mais atraentes da utilização de redes neurais artificiais em sistemas de sensoriamento virtual (FILETI et al., 1999).

Neste trabalho se pretende empregar redes neurais artificiais para desenvolver o sensor virtual, por ser ela uma técnica que tem sido bastante utilizada nos últimos anos nesse tipo de aplicação e apresentado resultados acima da média comparado com outras técnicas de identificação de sistemas.

\subsection{Metodologia empregada}

A metodologia utilizada neste trabalho segue os passos típicos para a identificação de um modelo. Esta metodologia é constituída por 4 etapas principais: projeto do experimento e coleta dos dados, definição da estrutura do modelo, cálculo dos parâmetros e validação do modelo.

Após uma breve visão geral sobre as redes neurais artificiais, sua importância e utilização em identificação de sistemas, veremos a seguir, mais detalhes da metodologia que será utilizada no desenvolvimento deste trabalho para a obtenção 
do sensor virtual e os principais pontos que foram levados em consideração na execução destas etapas.

\subsubsection{Projeto do experimento e coleta dos dados}

Esta etapa foi apresentada no capítulo anterior e é de fundamental importância, pois possui grande influência nas principais determinações realizadas sobre o modelo a ser desenvolvido. Dentre estas escolhas destacam-se: a seleção das variáveis de entrada e saída, a escolha do sinal de excitação, incluindo sua forma, amplitude e freqüência, taxa de amostragem e coleta dos dados. Deve-se considerar também como condicionar os sinais antes de amostrá-los, através de filtros de préamostragem e como (eventualmente) refinar os dados coletados, por exemplo, removendo tendências (LJUNG, 1999).

\subsubsection{Determinação da estrutura da rede neural}

Esta etapa consta de três passos: seleção do paradigma neural apropriado à aplicação, determinação da topologia da rede a ser utilizada - o número de camadas, o número de unidades em cada camada, a escolha das funções de ativação, etc - e a determinação de parâmetros do algoritmo de treinamento. Este passo possui um grande impacto nas capacidades e limitações do desempenho do sistema resultante.

A fim de reduzir o tempo necessário nesta fase de determinação da estrutura da rede neural - seleção do paradigma neural, topologia da rede e algoritmo de treinamento - será inicialmente realizada uma escolha com base teórica sobre um estudo das capacidades e vantagens de cada tipo. Este estudo visa reduzir o espectro de opções que serão em uma segunda fase implementadas, com os dados obtidos do modelo, para avaliação dos resultados apresentados. 


\subsubsection{Treinamento da rede}

Nesta fase, seguindo o algoritmo de treinamento escolhido, serão ajustados os pesos das conexões. É importante considerar, nesta fase, alguns aspectos tais como a inicialização da rede, o modo de treinamento e o tempo de treinamento.

Uma boa escolha dos valores iniciais dos pesos da rede pode diminuir o tempo necessário para o treinamento. Normalmente, os valores iniciais dos pesos da rede são números aleatórios uniformemente distribuídos, em um intervalo definido. A escolha errada destes pesos pode levar a uma saturação prematura. Nguyen e Widrow (2000) encontraram uma função que pode ser utilizada para determinar valores iniciais melhores que valores puramente aleatórios.

Quanto ao modo de treinamento, na prática é mais utilizado o modo seqüencial padrão devido ao menor armazenamento de dados, além de ser menos suscetível ao problema de mínimos locais, devido à pesquisa de natureza estocástica que realiza. Por outro lado, no modo "batch" se possui uma melhor estimativa do vetor gradiente, o que torna o treinamento mais estável. A eficiência relativa dos dois modos de treinamento depende do problema que está sendo tratado.

Quanto ao tempo de treinamento, vários fatores podem influenciar a sua duração, porém sempre será necessário utilizar algum critério de parada. O critério de parada do algoritmo "backpropagation" não é bem definido, e geralmente é utilizado um número máximo de ciclos. Mas deve ser considerada a taxa de erro médio por ciclo e a capacidade de generalização da rede. Pode ocorrer que em um determinado instante do treinamento a generalização comece a degenerar, causando o problema de "over-training", ou seja, a rede se especializa no conjunto de dados do treinamento e perde a capacidade de generalização.

O treinamento deve ser interrompido quando a rede apresentar uma boa capacidade de generalização e quando a taxa de erro for suficientemente pequena, 
ou seja, menor que um erro admissível. Assim, deve-se encontrar um ponto ótimo de parada com erro mínimo e capacidade de generalização máxima.

\subsubsection{Validação do modelo obtido e análise do desempe- nho do sensor virtual}

Durante esta fase o conjunto de teste será utilizado para determinar o desempenho da rede com dados que não foram previamente utilizados. A performance da rede, medida nesta fase, é uma boa indicação de seu desempenho real. Devem ser considerados ainda outros testes como análise do comportamento da rede utilizando entradas especiais e análise dos pesos atuais da rede, pois se existirem valores muito pequenos, as conexões associadas podem ser consideradas insignificantes e assim serem eliminadas ("prunning”). De modo inverso, valores substancialmente maiores que os outros poderiam indicar que houve "overtraining" da rede.

Ao final desta etapa, o sensor virtual deverá estar implementado, treinado e pronto para operar, apresentando boa precisão.

Destas 4 etapas para a identificação de um modelo, a primeira (projeto do experimento e coleta dos dados) já foi apresentada no capítulo anterior. As três etapas seguintes (determinação da rede, treinamento e validação) serão apresentadas a seguir, juntas, neste mesmo capítulo.

Estas três últimas etapas, apesar de claramente distintas serão realizadas de forma sucessiva para as topologias de redes selecionadas e a sua validação servirá como método para seleção da melhor estrutura a ser utilizada no sensor virtual. 


\subsection{Determinação da topologia da RNA}

Uma vez obtido o conjunto de dados passamos agora à determinação da arquitetura e dos parâmetros que serão utilizados pela rede neural.

\subsubsection{Arquitetura da rede neural}

Para proceder a uma melhor escolha da rede neural que poderia vir a fornecer os melhores resultados para o sistema em questão, foi realizado inicialmente um estudo teórico sobre as características e peculiaridades dos principais tipos de redes neurais disponíveis no Matlab $^{\circledR}$ (versão 7.0), tais como:

\footnotetext{
Redes Feedforward

- Linear

- Perceptron e Adaline

- MLP - Multi-Layer Perceptron

- Backpropagation

- Algoritmos avançados

- RBF - Radial Basis Function

- Redes Probabilísticas
}

\section{Redes Recorrentes}

- Rede de Elman

- Rede de Hopfield

Optou-se por selecionar dois tipos diferentes de arquiteturas e avaliá-las segundo o seu desempenho com os dados do problema. As redes selecionadas foram: rede feedforward MLP com algoritmo backpropagation e rede recorrente de Elman. 
Esta seleção teve como intuito permitir a comparação de uma rede considerada padrão para problemas de identificação de sistemas, a feedforward MLP, com uma rede muito utilizada em processos dinâmicos, a rede recorrente de Elman. A seguir são apresentadas mais características destas redes que fundamentam melhor o porquê da seleção delas.

\section{Rede feedforward MLP backpropagation}

A rede feedforward MLP (Multi-layer perceptron) backpropagation (comando "newff" no Matlab), como o próprio nome sugere, é um tipo de rede sem realimentação, ou seja, a informação é distribuída pela rede em um só sentido, com várias camadas (normalmente 2 camadas ocultas) e treinada com um dos mais poderosos algoritmos que é o backpropagation. A Figura 5.2 mostra um esquema de uma rede feedforward com 2 camadas ocultas.

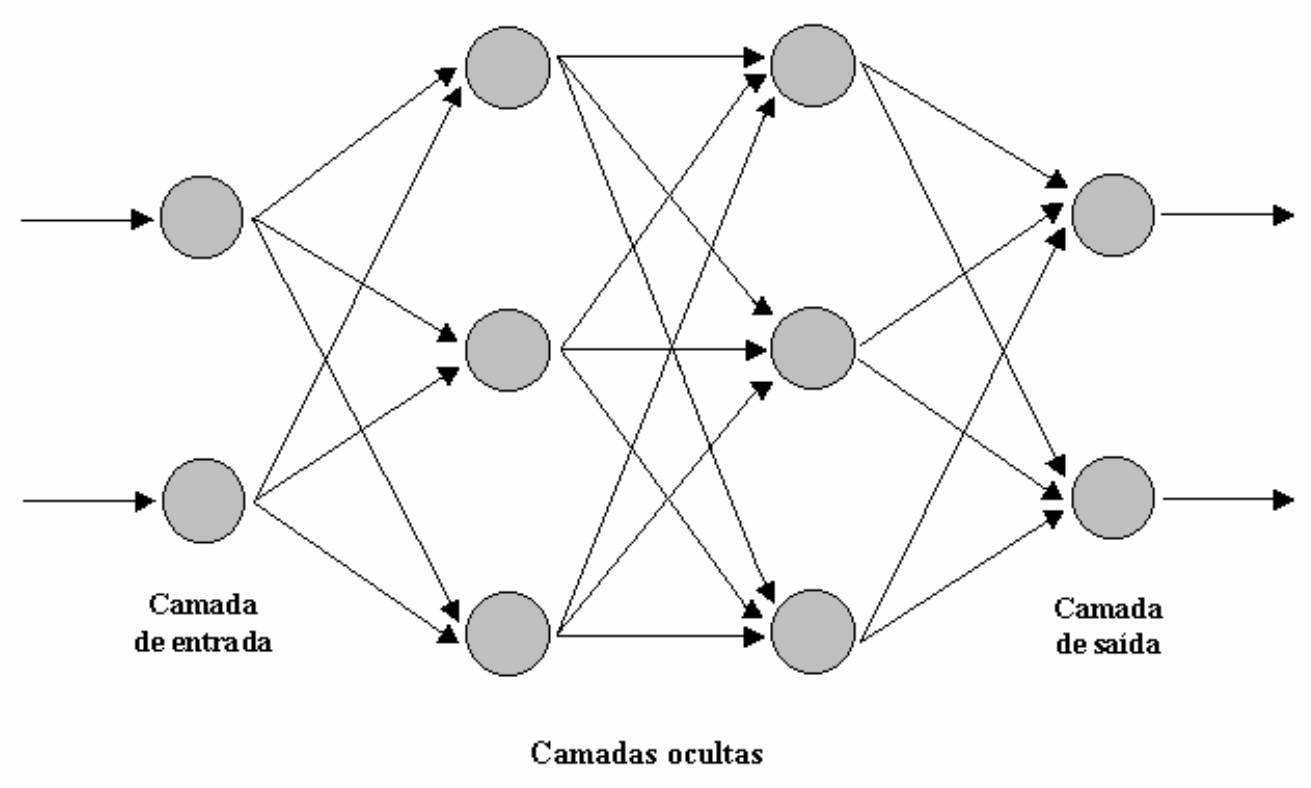

Figura 5.2: Esquema de rede neural MLP feedforward

Este tipo de rede é o mais difundido e utilizado tanto pela sua simplicidade como pela alta capacidade de aproximar funções. A rede MLP é capaz de aproxi- 
mar qualquer função com um número finito de descontinuidades, desde que possua o número suficiente de neurônios nas camadas ocultas.

O algoritmo backpropagation é capaz de treinar redes MLP feedforward com diferentes funções de transferência e permite o mapeamento de relações lineares e não-lineares entre os vetores de dados de entrada e saída, na aproximação de funções, reconhecimento e classificação de padrões. (Outros tipos de redes também podem ser utilizados, porém as redes MLP são as mais freqüentemente empregadas).

O termo backpropagation refere-se ao processo pelo qual derivadas do erro apresentado pela rede são utilizadas na correção dos pesos internos, de forma retroativa. Este processo pode ser utilizado com várias estratégias de otimização diferentes.

A arquitetura da rede neural MLP não é completamente determinada pelo problema a ser resolvido. Assim, o número de neurônios na camada de entrada da rede e na camada de saída da rede são requeridos e determinados pelo problema. Entretanto, o número de camadas ocultas entre a entrada e a saída da rede e o tamanho destas camadas são escolhas realizadas pelo projetista da rede e baseadas principalmente na análise e experiência do mesmo. Existem algumas regras que tentam abordar o melhor ajuste destes valores, porém as teorias são muitas vezes contraditórias e pouco práticas.

O treinamento backpropagation pode ser realizado por vários algoritmos diferentes. Há, entre eles, grande variedade de requisitos computacionais e de exigências de armazenamento de dados. Porém, nenhum deles pode ser considerado como melhor do que os demais, mas sim o mais adaptado para uma situação específica. É preciso analisar dentre estes quais apresentam melhor resultado e não comprometem a estrutura do sistema de desenvolvimento. A análise e escolha do melhor algoritmo de treinamento da rede serão realizadas posteriormente. 


\section{Rede recorrente de Elman}

A rede recorrente de Elman (comando "newelm" no Matlab) é normalmente composta por 3 ou 4 camadas (entrada, uma ou duas ocultas e saída). Na camada oculta há a adição de uma realimentação das saídas desta camada para a entrada da mesma. A Figura 5.3 mostra um esquema simplificado de uma rede típica de Elman.

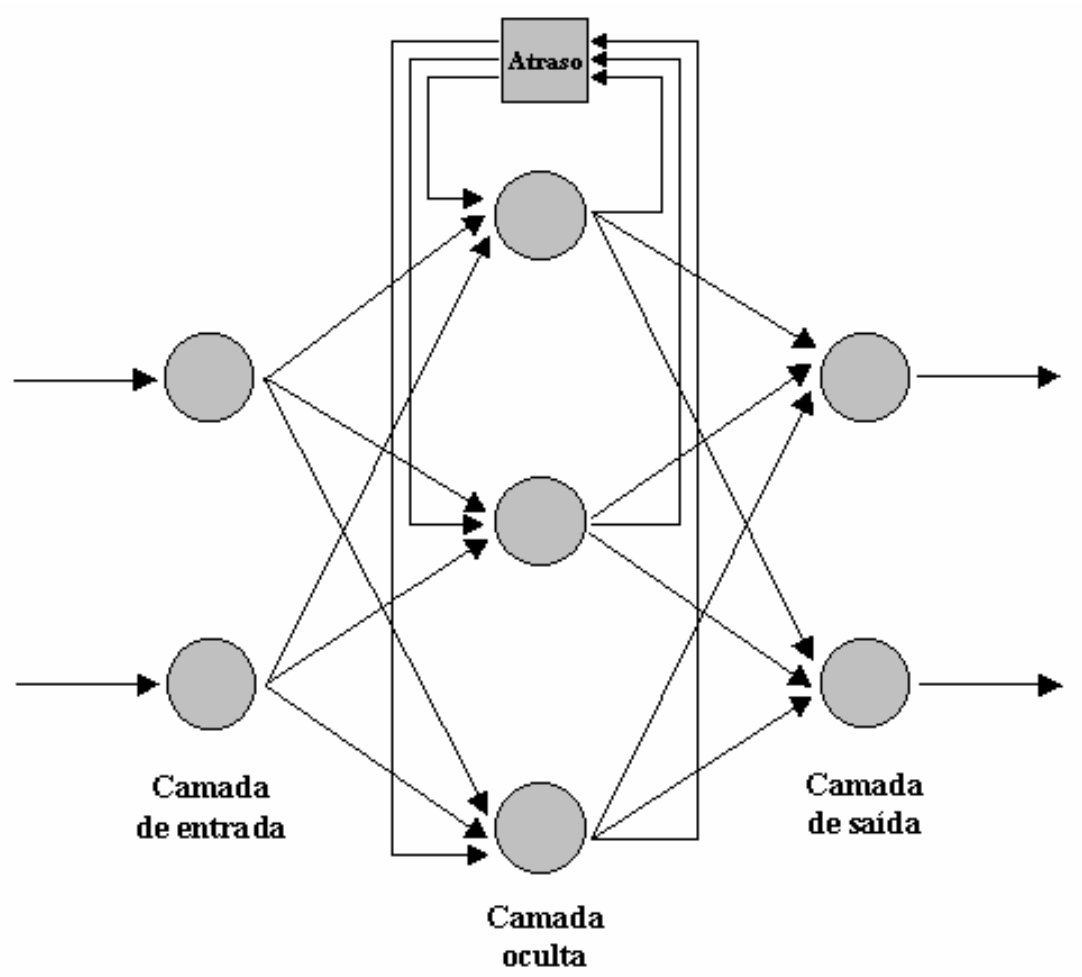

Figura 5.3: Esquema simplificado de uma rede recorrente de Elman

O atraso na conexão e a realimentação dos valores internos em um passo seguinte fazem com que esta rede seja capaz de armazenar informações do passo anterior e utilizá-las em um momento futuro. Devido a esta capacidade a rede é capaz de inferir e reconhecer padrões temporais e espaciais, sendo que pode ser treinada para responder a ambos os tipos de padrões. 
Esta rede foi uma das escolhidas, pois se espera que por possuir a capacidade de armazenar informações passadas ela seja capaz de apresentar um desempenho superior às outras, principalmente pelo fato de reconhecer padrões variantes no tempo.

\subsubsection{Definição da topologia}

A seguir descreve-se a abordagem realizada para obter o ajuste da escolha da topologia que será utilizada pelas redes, dentre eles destaca-se: escolha do número de camadas ocultas, número de neurônios por camada, função de transferência empregada e algoritmo de treinamento.

Porém, para se comparar os resultados obtidos é necessária a definição de um modo de cálculo do erro de cada rede. Para a avaliação das redes serão utilizados 3 critérios:

Erro Máximo: é o maior pico de erro apresentado pela rede após o treinamento, confrontando os resultados obtidos com os esperados fornecidos pelo simulador. Este erro permite visualizar o quão fora da média está o ponto de maior erro na avaliação.

$$
\text { Máx }=\max \left(\left|\frac{\hat{Z}(i)-Z(i)}{\hat{Z}(i)}\right|\right) .100[\%]
$$

Média do Erro Absoluto (MAE): é a média aritmética do valor do módulo do erro obtido entre o valor estimado pelo sensor e o valor esperado, fornecido pelo simulador. Este erro apresenta a magnitude da dispersão dos erros com pesos equivalentes. 


$$
M A E=\frac{\sum_{i=1}^{N}(|Z(i)-\hat{Z}(i)|)}{N}
$$

Média do Erro Quadrático (MSE): é a média dos quadrados das diferenças entre o valor estimado pelo sensor e o valor esperado, fornecido pelo simulador. Este valor é utilizado como medida do desempenho da rede durante o seu treinamento. Esta função pondera com maior peso (quadrático) os pontos em que o erro apresentado pela rede for maior.

$$
M S E=\frac{\sum_{i=1}^{N}(Z(i)-\hat{Z}(i))^{2}}{N}
$$

\section{Inicialização dos pesos}

A determinação dos valores iniciais dos pesos da rede neural pode representar uma alteração significativa no tempo necessário para o treinamento da rede e para a melhor convergência dos resultados apresentados, sem levar o treinamento a ser interrompido após convergir para algum mínimo local.

Normalmente, a inicialização da rede é realizada com números aleatórios uniformemente distribuídos. Porém, existem outras possibilidades para esta condição, e algumas já incorporadas à programas específicos. Dentre elas há funções que realizam um melhor ajuste destes valores iniciais dos pesos da rede através da relação entre amplitudes dos valores de entrada, saída, tipo da arquitetura da rede, etc.

Para a realização dos treinamentos que são mostrados a seguir, utilizou-se uma função disponibilizada pelo Matlab ${ }^{\circledR}$ que se baseia em um algoritmo desenvolvido por Nguyen e Widrow (comando “initnw”). A principal vantagem de uma 
escolha mais apropriada para a inicialização dos pesos da rede refere-se principalmente ao tempo de treinamento necessário e à melhor acuidade dos resultados finais apresentados.

A função de inicialização Nguyen-Widrow atribui valores iniciais aos pesos das camadas de neurônios de acordo com um algoritmo que visa distribuir a região ativa de cada neurônio na camada, de maneira aproximadamente regular através do espaço de entrada da camada. As principais vantagens deste algoritmo sobre uma inicialização puramente aleatória dos pesos é que menos neurônios são desperdiçados (desde que todos estejam no espaço de entrada) e a convergência do treinamento é mais rápida.

\section{Função de transferência (ou ativação)}

A função de transferência ou de ativação determina o valor de saída de cada neurônio em função do valor local induzido.

O primeiro grupo compreende as funções de transferência tipo degrau, que permitem que os neurônios de um perceptron escolham uma dentre 2 possíveis saídas. Este tipo de função é largamente empregado em problemas de classificação.

As funções de transferência lineares com ou sem saturação apresentam um espectro de saída maior para o neurônio. São bastante utilizadas em problemas que exigem aproximadores lineares, como em filtros lineares.

As funções de transferência sigmóides são contínuas em todo o intervalo e apresentam sempre valores diferentes para o espectro de entrada do neurônio. São comumente utilizadas nas redes que empregam o algoritmo backpropagation, principalmente pelo fato de serem diferenciáveis. Quando empregadas permitem à rede respostas mais velozes. 
A Figura 5.4 apresenta de forma resumida os tipos mais comuns de funções de transferência utilizados em redes neurais.

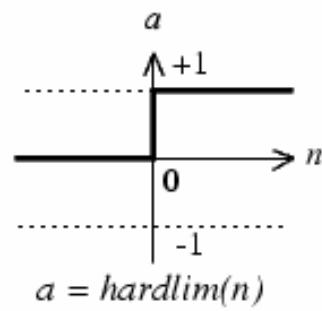

Hard-Limit Transfer Function

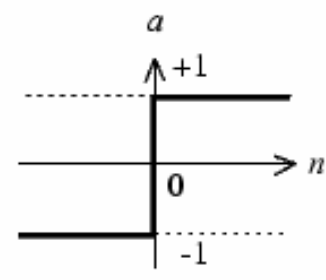

$a=\operatorname{hardlims}(n)$

Symmetric Hard-Limit Trans. Funct.
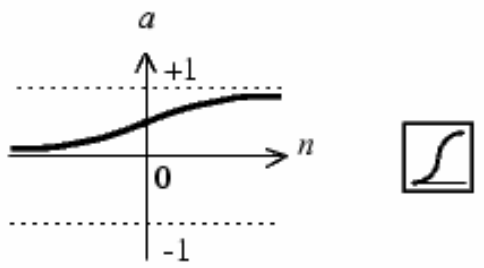

$$
a=\log \operatorname{sig}(n)
$$

Log-Sigmoid Transfer Function
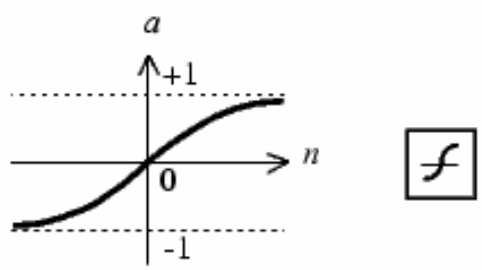

$$
a=\operatorname{tansig}(n)
$$

Tan-Sigmoid Transfer Function

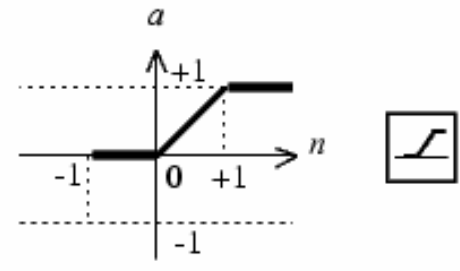

$a=\operatorname{satlin}(n)$

Satlin Transfer Function

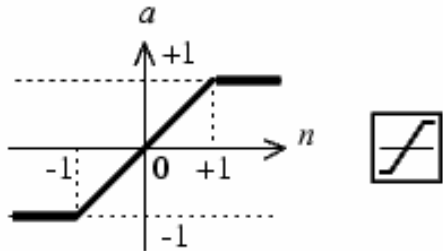

$$
a=\operatorname{satlins}(n)
$$

Satlins Transfer Function

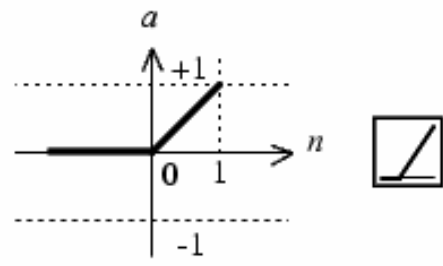

$a=\operatorname{poslin}(n)$

Positive Linear Transfer Funct.

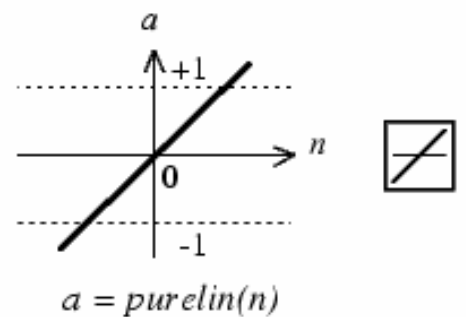

Linear Transfer Function

Figura 5.4: Funções de transferência 
No presente trabalho será empregado na rede neural para todos os neurônios das camadas ocultas a função de transferência tangente-sigmóide (comando "tansig"), pois apresentam o melhor resultado na transferência dos pesos ponderados. Para a camada de saída da rede será utilizada a função de transferência linear com saturação não-simétrica (comando "satlin"), pois apresenta saída linear para o intervalo 0 e 1 , que equivale ao intervalo válido esperado para a composição dos componentes na coluna de destilação.

\section{Algoritmos de treinamento}

Existem vários tipos de algoritmos para treinamento por backpropagation das redes neurais. Em geral, eles diferem entre si e possuem uma grande variedade de requisitos computacionais e de memória disponível e não há um algoritmo que possa ser considerado superior aos demais para todas as situações.

Os algoritmos de treinamento existentes no Matlab podem ser divididos em três grupos: aprendizagem pelo gradiente conjugado, pelo gradiente descendente e algoritmos quasi-Newton. Dar-se-á maior ênfase aos algoritmos de gradiente descendente (Gradient descent with momentum, Variable learning rate e Resilient backpropagation) e quasi-Newton (BFGS e Levenberg-Marquardt). Cada um destes algoritmos difere entre si, basicamente pela estratégia de otimização utilizada para realizar os ajustes nos pesos e bias da rede neural.

O gradient descent with momentum (comando do Matlab "traingdm") corrige os pesos e bias da rede neural, reajustando estes valores na direção oposta ao da função gradiente e, simultaneamente, considera como parâmetro para realizar o ajuste, uma fração do valor dos pesos da iteração anterior, denominado momentum. Com este fator momentum, este algoritmo consegue convergir mais rapidamente e responder não somente ao gradiente local, mas também às tendências recentes na superfície de erro, sem que se tenha de aumentar a taxa de aprendizado, evitando com isto, uma eventual instabilidade que este aumento po- 
deria causar. Como pode ser observado na Figura 5.5, este método pode apresentar uma grande oscilação e também apresenta convergência lenta.

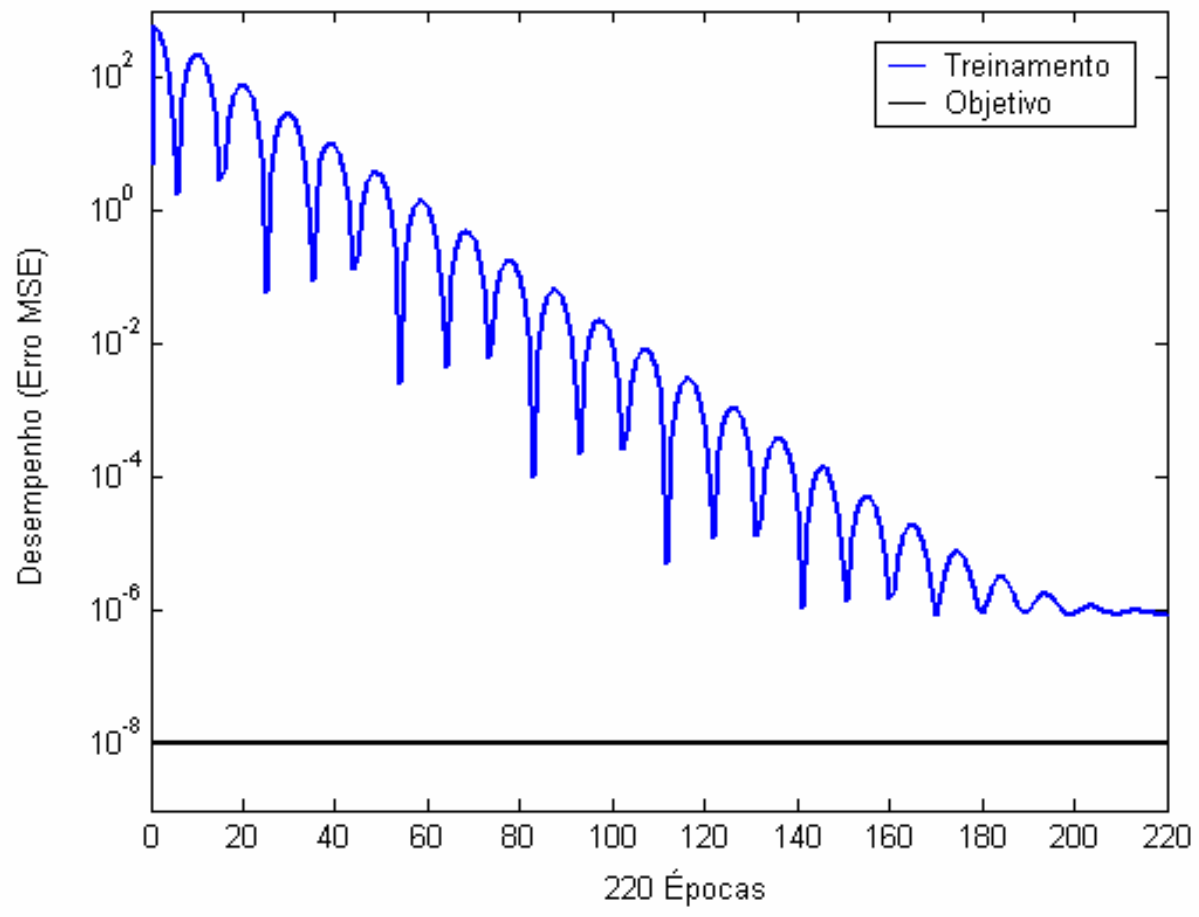

Figura 5.5: TrainGDM

O variable learning rate (comando do Matlab "traingdx" ou "traingda") utiliza os mesmos princípios do gradient descent with momentum para corrigir os pesos da rede, mas tendo como diferencial, o fato da taxa de aprendizagem ser variável, fazendo com que se tenha um aprendizado mais rápido do que com taxa fixa e evitando a instabilidade e oscilações no processo de aprendizagem, como pode ser observado na Figura 5.6. 


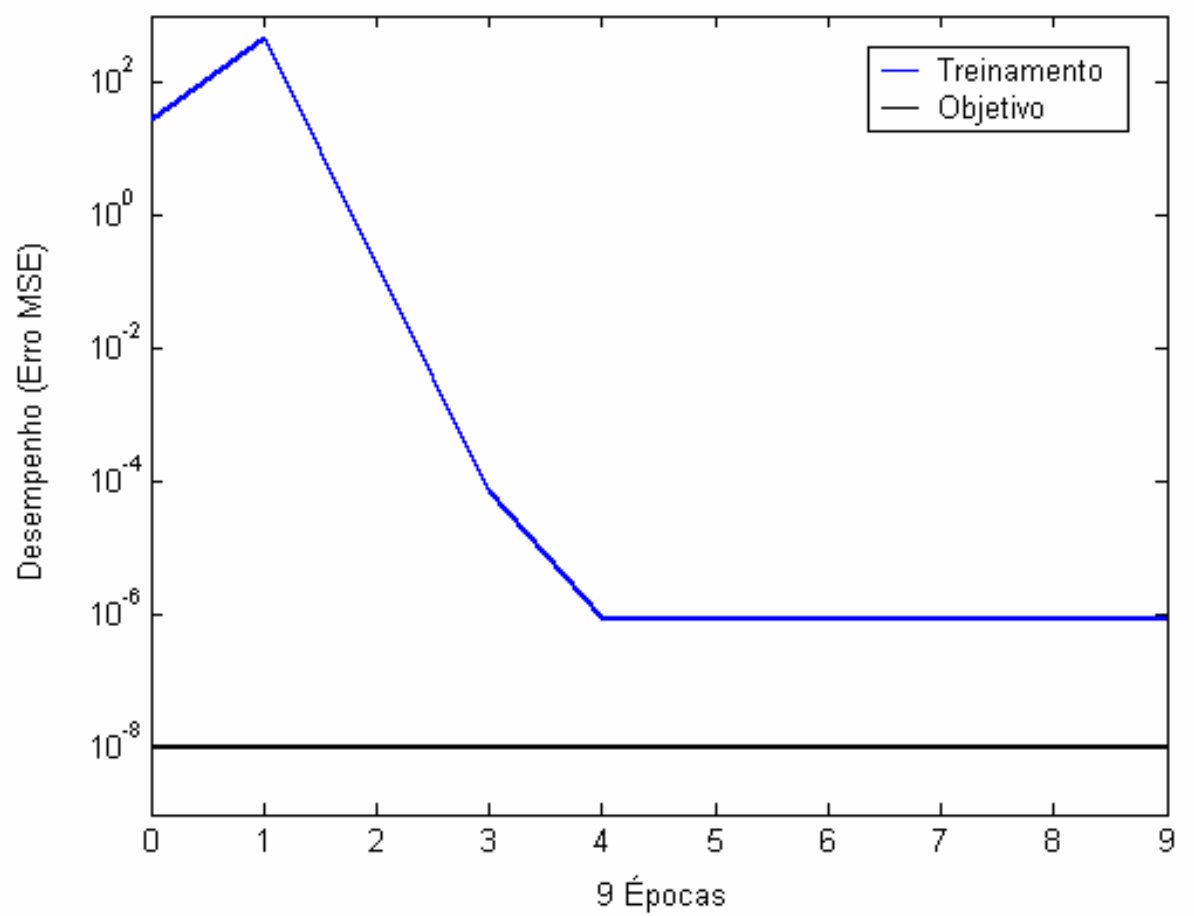

Figura 5.6: TrainGD

O resilient backpropagation (comando do Matlab “trainrp”), utiliza os mesmos princípios do gradient descent with momentum, porém neste caso, não utiliza a magnitude do gradiente como referência para a correção dos pesos, mas fia-se apenas na direção do gradiente como referência para os ajustes dos pesos da rede. Este algoritmo é considerado um dos mais rápidos do Matlab, porém é ainda mais lento do que os quasi-Newton, e tem como uma das suas principais vantagens o fato de requerer pouca memória para ser executado. No entanto, deve-se observar que caso o treinamento seja interrompido por um motivo qualquer, não é aconselhável retreinar a rede utilizando este algoritmo, pois todo o treinamento anterior será perdido, uma vez que o treinamento sempre se inicia com um aumento significativo do erro. Caso seja necessário um treinamento maior, deve-se alterar o método de treinamento. O seu comportamento pode ser observado na Figura 5.7 


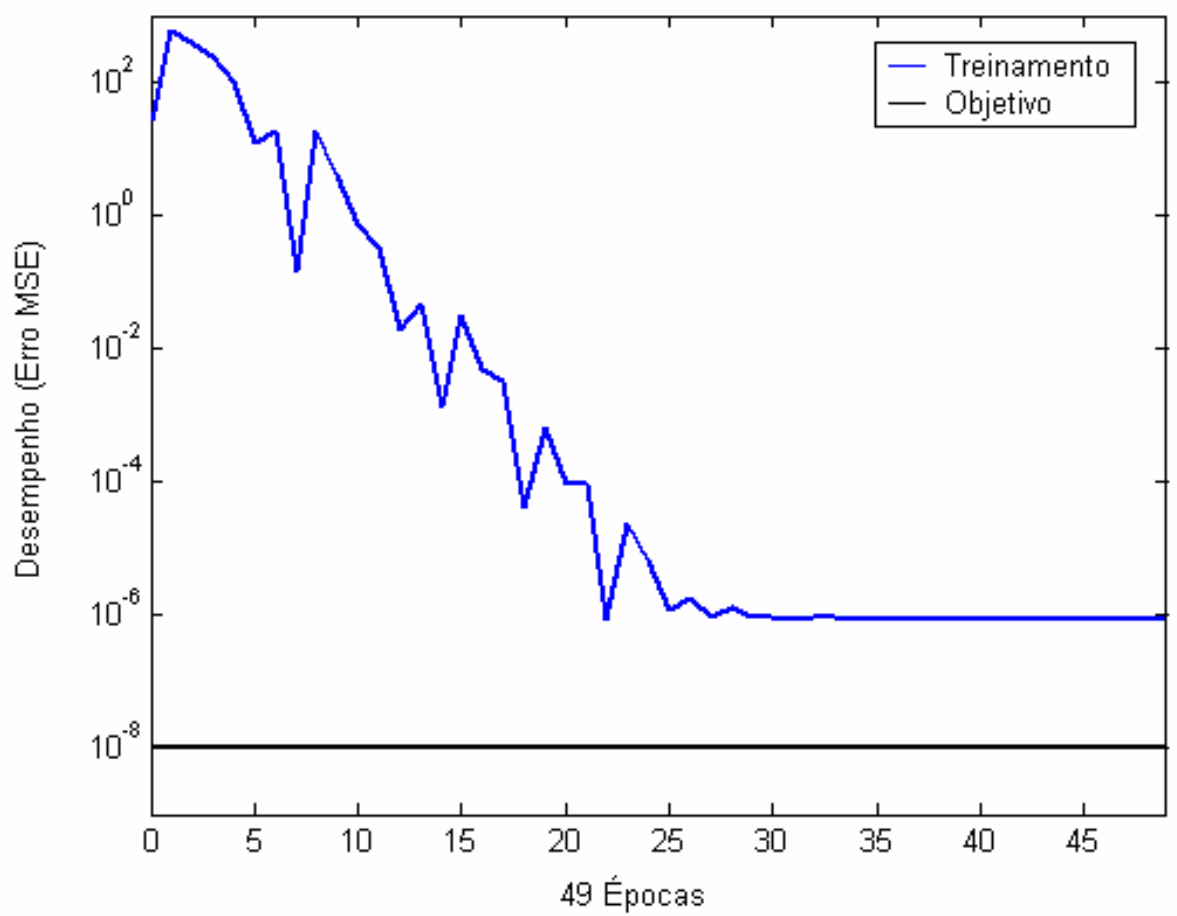

Figura 5.7: TrainRP

O BFGS (comando do Matlab "trainbfg") e o Levenberg-Marquardt (comando do Matlab “trainlm”) são métodos alternativos aos métodos de gradiente conjugado para se obter um treinamento rápido. Possuem como base para os ajustes dos pesos o método de Newton, ou seja, utilizam a matriz Hessiana para fazer a correção dos pesos e bias da rede. Devido ao fato do cálculo desta matriz para redes MLP ser muito complexo, utiliza-se uma aproximação da matriz Hessiana, o que confere ao algoritmo o nome de método quasi-Newton (ou secante). O método BFGS é resultado de estudos de Broyden, Fletcher, Goldfab e Shanno, que lhe conferiram este nome. Deve-se observar, que este método utiliza rotinas de Line Search para sua implementação (no Matlab há diversas rotinas, mas foi utilizado apenas a Backtracking - cujo nome no Matlab é "srchbac").

Tanto o BFGS, quanto o Levenberg-Marquardt, apresentam uma convergência muito rápida, porém o algoritmo de Levenberg-Marquardt mostrou-se muito mais eficiente. Este método é recomendado como padrão para redes MLP no Matlab. De acordo com o manual de referências sobre redes neurais do Matlab, 
isto costuma ser verdade apenas para redes que apresentem poucas centenas de pesos e esta vantagem é especialmente notável se precisão no treinamento for requerida. Dentre as principais desvantagens do método de Levenberg-Marquardt está a necessidade de uma grande quantidade de memória para que ele possa ser executado e o fato do treinamento de cada época ser demorado por exigir uma grande capacidade de processamento (quando comparado com os demais algoritmos). Para resolver o problema de memória, pode-se utilizar uma melhoria introduzida na versão 6.1 do Matlab que é treinar a rede com uma redução da memória requerida (propriedade "mem_reduc" para este tipo de treinamento no Matlab). Para fazer esta redução de memória divide-se a matriz Hessiana em tantas vezes quanto for especificado, mas isto acarretará em um tempo muito maior durante a fase de treinamento. Nas Figura 5.8 e Figura 5.9 pode-se observar o comportamento do treinamento utilizando-se estes dois métodos.

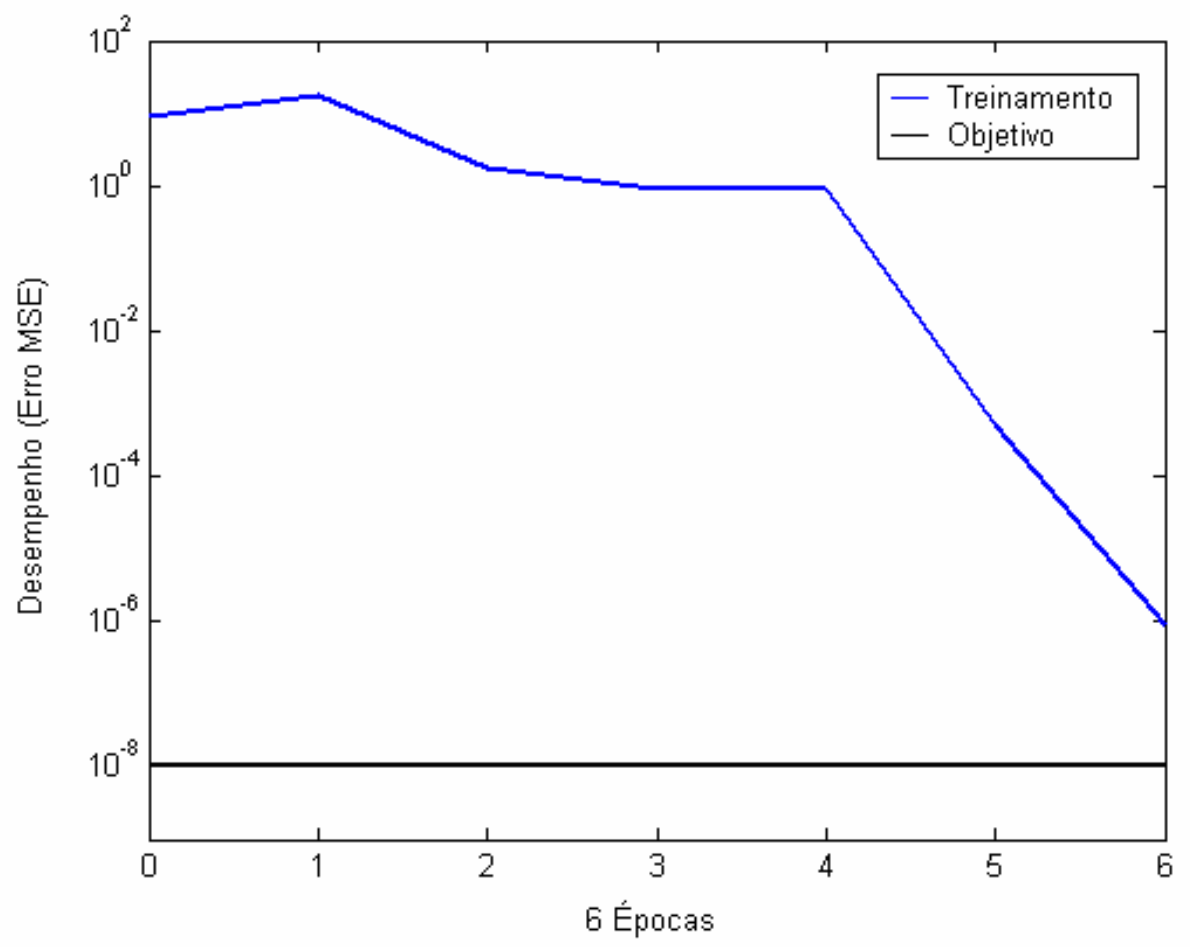

Figura 5.8: BFGS 


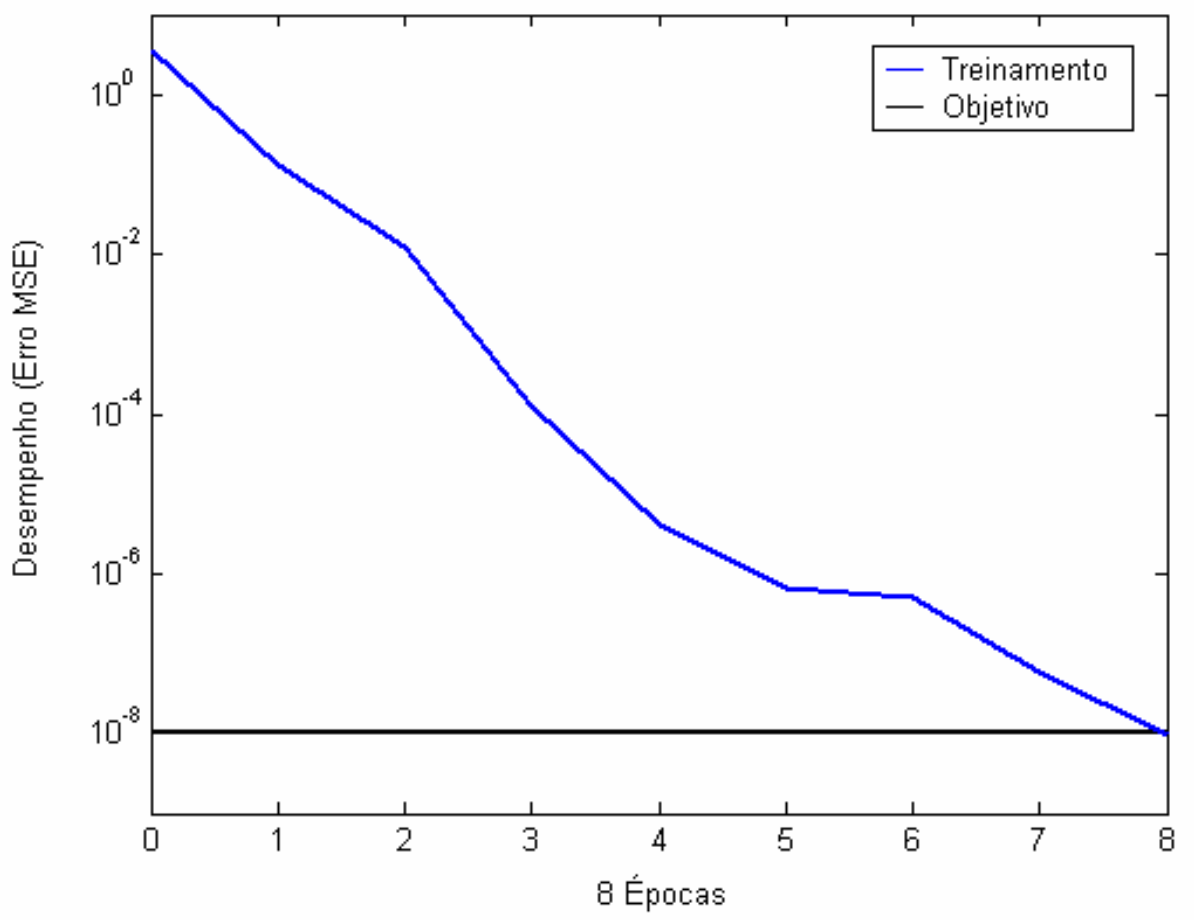

Figura 5.9: TrainLM

Uma recomendação fornecida pelo manual técnico do Matlab é para inicialmente utilizar-se o algoritmo Levenberg-Marquardt, e no caso de requerer muita memória (mesmo utilizando-se a redução de memória), tentar o emprego do algoritmo BFGS, ou um dos métodos de gradiente conjugado. Ou utilizar o resilient backpropagation que é rápido e necessita de pouca memória.

A Tabela 5.1 exibe uma lista completa dos principais algoritmos para treinamento das redes neurais disponíveis no Matlab ${ }^{\circledR}$. 
Tabela 5.1: Lista dos algoritmos de treinamento disponíveis no Matlab ${ }^{\circledR}$

\begin{tabular}{|c|c|}
\hline Função & Descrição \\
\hline traingd & $\begin{array}{l}\text { Gradiente descendente básico. Apresenta resposta lenta e pode ser } \\
\text { utilizado em treinamentos de modo incremental. }\end{array}$ \\
\hline traingdm & $\begin{array}{l}\text { Gradiente descendente com momento. Geralmente é mais rápido do } \\
\text { que o traingd. Pode ser utilizado em treinamentos de modo incremen- } \\
\text { tal. }\end{array}$ \\
\hline traingdx & $\begin{array}{l}\text { Taxa de aprendizado adaptativa. Convergência mais rápida do que } \\
\text { traingd, porém só pode ser utilizado em treinamentos por batelada. }\end{array}$ \\
\hline trainrp & $\begin{array}{l}\text { Resilient backpropagation. Algoritmo simples de treinamento batelada } \\
\text { com rápida convergência e pouca memória requisitada. }\end{array}$ \\
\hline traincgf & $\begin{array}{l}\text { Algoritmo de gradiente conjugado de Fletcher-Reeves. Possui os me- } \\
\text { nores requisitos de memória dentre os algoritmos de gradiente } \\
\text { conjugado. }\end{array}$ \\
\hline traincgp & $\begin{array}{l}\text { Algoritmo de gradiente conjugado de Polak-Ribiére. Requer um pou- } \\
\text { co mais de memória do que o traincgf., porém apresenta convergência } \\
\text { rápida para alguns problemas específicos. }\end{array}$ \\
\hline traingb & $\begin{array}{l}\text { Algoritmo de gradiente conjugado de Powell-Beale. Requer um pouco } \\
\text { mais de memória do que traincgp, mas geralmente apresenta uma } \\
\text { convergência mais rápida. }\end{array}$ \\
\hline trainscg & $\begin{array}{l}\text { Algoritmo de gradiente conjugado em escala. O único algoritmo de } \\
\text { gradiente conjugado que não necessita da função line search. Adapta- } \\
\text { se com facilidade a uma grande variedade de problemas. }\end{array}$ \\
\hline trainbfg & $\begin{array}{l}\text { Método quasi-Newton BFGS. Necessita o armazenamento da apro- } \\
\text { ximação da matriz Hessiana e requer mais recurso computacional a } \\
\text { cada iteração do que os algoritmos de gradiente conjugado, porém } \\
\text { geralmente converge em poucas iterações. }\end{array}$ \\
\hline trainoss & $\begin{array}{l}\text { One step secant method. Meio-termo entre métodos de gradiente } \\
\text { conjugado e métodos quasi-Newton. }\end{array}$ \\
\hline trainlm & $\begin{array}{l}\text { Algoritmo de Levenberg-Marquardt. É o algoritmo de treinamento } \\
\text { mais rápido para redes de tamanho moderado. Possui a função de } \\
\text { redução de memória para ser utilizada quando possuir muitos dados } \\
\text { para treinamento. }\end{array}$ \\
\hline trainbr & $\begin{array}{l}\text { Regularização de Bayesian. É uma modificação do algoritmo de trei- } \\
\text { namento de Levenberg-Marquardt para gerar redes com melhor } \\
\text { generalização. Reduz a dificuldade de se determinar a arquitetura de } \\
\text { rede otimizada. }\end{array}$ \\
\hline
\end{tabular}




\section{Número de camadas e neurônios por camada}

O número de neurônios na camada de entrada e de saída da rede é definido pelo conjunto de dados que será fornecido à rede e pela resposta que se deseja, respectivamente. Deste modo, a rede definida possuirá 10 neurônios na camada de entrada, referentes aos valores das respectivas variáveis coletadas; e 1 neurônio na camada de saída, que será a estimação da composição do componente 2 no topo da coluna. Resta ainda definir as camadas ocultas.

Da teoria temos que as redes MLP feedforward com 1 camada oculta são capazes de aproximar qualquer função contínua; já as redes com 2 camadas ocultas conseguem aproximar qualquer função não-linear. Redes com mais de duas camadas não apresentam acréscimo nenhum à capacidade estimativa da rede, porém podem fornecer maior segurança para perdas localizadas (redundância de neurônios) e maior precisão (BRAGA; CARVALHO; LUDERMIR, 1998).

A determinação do número de camadas ocultas da rede, bem como do número de neurônios em cada camada que maximizam os resultados não são obtidos de modo determinístico. Alguns autores após estudos empíricos propuseram algumas regras para auxílio na determinação inicial da estrutura da rede (como utilizar um terço do número de entradas na camada oculta, ou um número fixo).

Porém, os próprios autores alertam que estas regras são apenas auxiliares, e que devido à grande variedade de problemas que podem ser apresentados às redes neurais é difícil o estabelecimento de regras. Finalmente, Haykin (1999) em seu livro sobre redes neurais alerta que "não há teoria para otimizar a arquitetura das redes neurais" e recomenda como solução para este problema que "deve-se realizar um estudo experimental exaustivo" em busca da melhor combinação.

A fim de se determinar a estrutura da rede neural que será utilizada foram realizados vários ensaios, variando progressivamente o número de camadas e de neurônios por camadas e comparando-se os resultados obtidos. 
Sabe-se que as redes neurais são fortemente influenciadas pelas condições iniciais utilizadas no treinamento e que para determinadas condições a rede não converge ou apresenta convergência para uma solução com erro maior que o esperado (mínimo local). Para se realizar a comparação das diferentes arquiteturas foi realizado o treinamento de aproximadamente 15 redes com diferentes condições iniciais para cada estrutura (combinação de número de camadas e neurônios), pois isto aumenta a probabilidade de surgirem redes com boa convergência e redes que convergirão para mínimo locais.

Como é o intuito deste capítulo, serão apresentados os resultados para as redes recorrentes de Elman e para as redes feedforward MLP e comparados ao final. Vale ainda ressaltar que o conjunto de dados utilizado para o treinamento contém 2.000 pontos de dados.

\section{Redes de Elman}

Após o treinamento das 15 redes com diferentes condições iniciais selecionou-se a melhor metade das redes treinadas, ou seja, especificamente as 7 redes que apresentavam os melhores resultados. As demais foram desprezadas (na sua maioria redes que não convergiram ou apresentaram erro muito grande). Destes valores selecionados calculou-se a média, que foi denominado de "média da metade melhor" (MMM) e estes resultados foram comparados, como pode ser visto na Tabela 5.2.

Quanto à nomenclatura das redes apresentada têm-se que o número de camadas e neurônios por camada é apresentado como o nome que identifica a rede neural. Deste modo, as redes com 2 camadas ocultas e com 20 neurônios na primeira camada e 10 neurônios na segunda camada oculta são representadas com o nome "20 10", e assim sucessivamente. 
Tabela 5.2: Cálculo dos erros médios apresentados pela rede

\begin{tabular}{|c|c|c|c|}
\hline & \multicolumn{3}{|c|}{ Rede de Elman com 1 camada oculta de 10 neurônios } \\
\hline & Erro MSE & Erro $M A E$ & Erro Máx \\
\hline \multirow{5}{*}{ 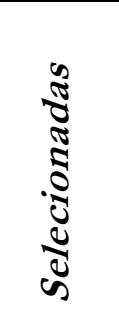 } & $2,2394 \cdot 10^{-10}$ & $1,1251 \cdot 10^{-5}$ & 0.0096 \\
\hline & $2,3951 \cdot 10^{-10}$ & $1,1407 \cdot 10^{-5}$ & 0.0137 \\
\hline & $3,0967 \cdot 10^{-10}$ & $1,1658 \cdot 10^{-5}$ & 0.0272 \\
\hline & $3,3034 \cdot 10^{-10}$ & $1,1825 \cdot 10^{-5}$ & 0.0226 \\
\hline & $3,4216 \cdot 10^{-10}$ & $1,3938 \cdot 10^{-5}$ & 0.0136 \\
\hline \multirow{3}{*}{$\frac{8}{8}$} & $3,4782 \cdot 10^{-10}$ & $1,2828 \cdot 10^{-5}$ & 0.0305 \\
\hline & $3,5327 \cdot 10^{-10}$ & $1,3496 \cdot 10^{-5}$ & 0.0152 \\
\hline & $3,6210 \cdot 10^{-10}$ & $1,1809 \cdot 10^{-5}$ & 0.0312 \\
\hline \multirow{4}{*}{$\begin{array}{l}0 \\
\frac{\pi}{0} \\
\mathbb{N} \\
\mathbb{5} \\
0 \\
0 \\
0\end{array}$} & $4,3709 \cdot 10^{-10}$ & $1,3268 \cdot 10^{-5}$ & 0.0427 \\
\hline & $4,4732 \cdot 10^{-10}$ & $1,5606 \cdot 10^{-5}$ & 0.0158 \\
\hline & $7,3436 \cdot 10^{-10}$ & $1,5591 \cdot 10^{-5}$ & 0.0612 \\
\hline & $7,3736 \cdot 10^{-10}$ & $1,4496 \cdot 10^{-5}$ & 0.0558 \\
\hline \multirow{3}{*}{$\sum_{\substack{0 \\
\hdashline}}^{\infty}$} & $3,1789 \cdot 10^{-7}$ & $4,4741 \cdot 10^{-4}$ & 0.2725 \\
\hline & $5,2912 \cdot 10^{-7}$ & $5,7736 \cdot 10^{-4}$ & 0.2985 \\
\hline & $9,3309 \cdot 10^{-7}$ & $7,9134 \cdot 10^{-4}$ & 0.3792 \\
\hline$M M M$ & $3,0067 \cdot 10^{-10}$ & $1,2343 \cdot 10^{-5}$ & 0,0189 \\
\hline
\end{tabular}

Destaca-se que dentre os treinamentos anteriores, três redes não convergiram apresentando erro MSE de aproximadamente mil vezes superior às demais. Outras apresentaram erros maiores que o esperado, pois convergiram para mínimos locais. E a grande maioria convergiu para uma região de erro MSE pequeno de aproximadamente $3 \cdot 10^{-10}$.

A seguir são apresentados os valores calculados para as médias das melhores metades de várias estruturas de redes com 1,2 e 3 camadas ocultas, com diferentes quantidades de neurônios por camada como mostrado na Figura 5.10.

A Figura 5.11 apresenta, de forma comparativa, a melhor rede obtida após o treinamento para cada estrutura avaliada. Estes valores auxiliam a completar a análise da média da metade melhor, porém isoladamente não permitem conclusões sólidas. 


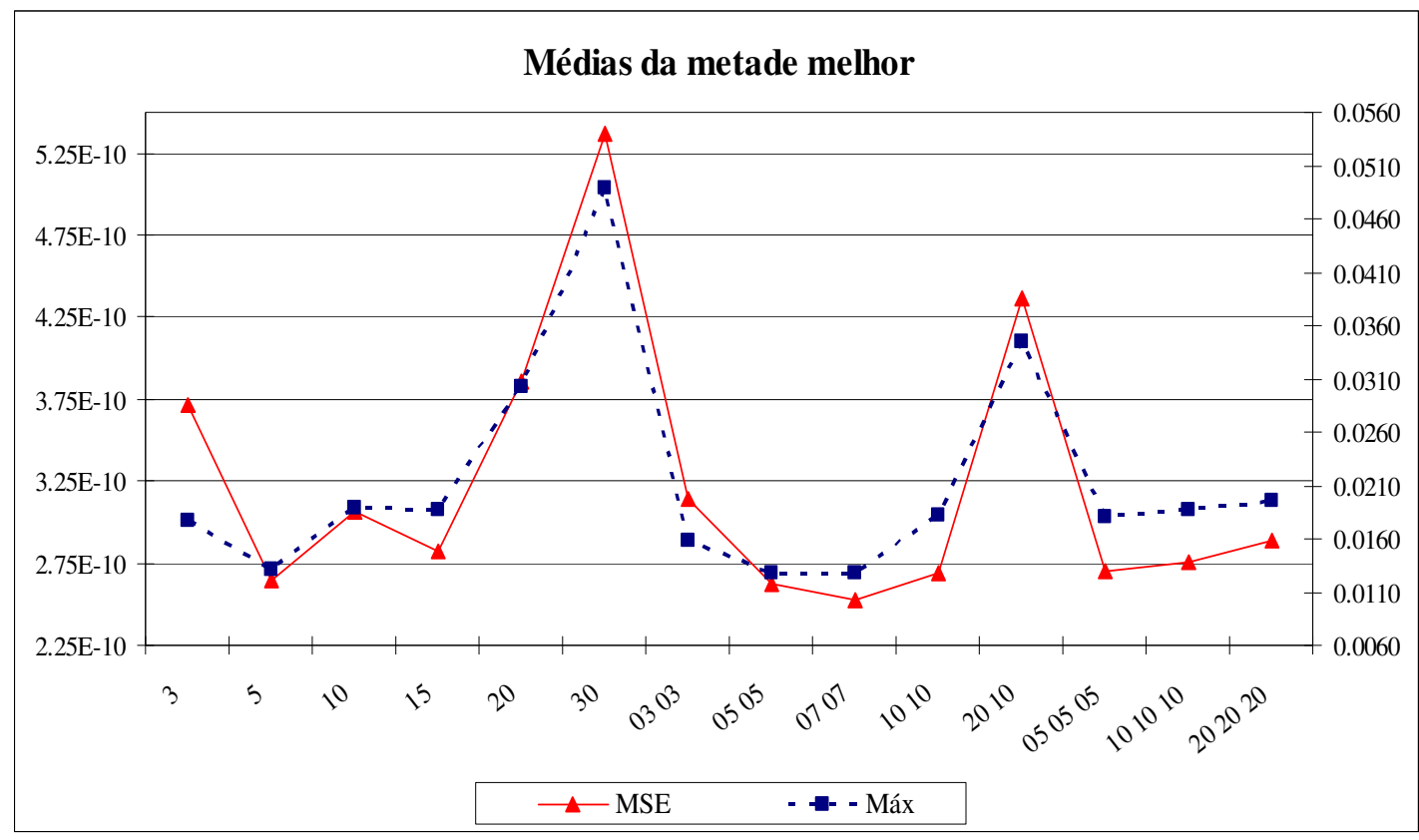

Figura 5.10: Média do erro obtido para a melhor metade das redes de Elman

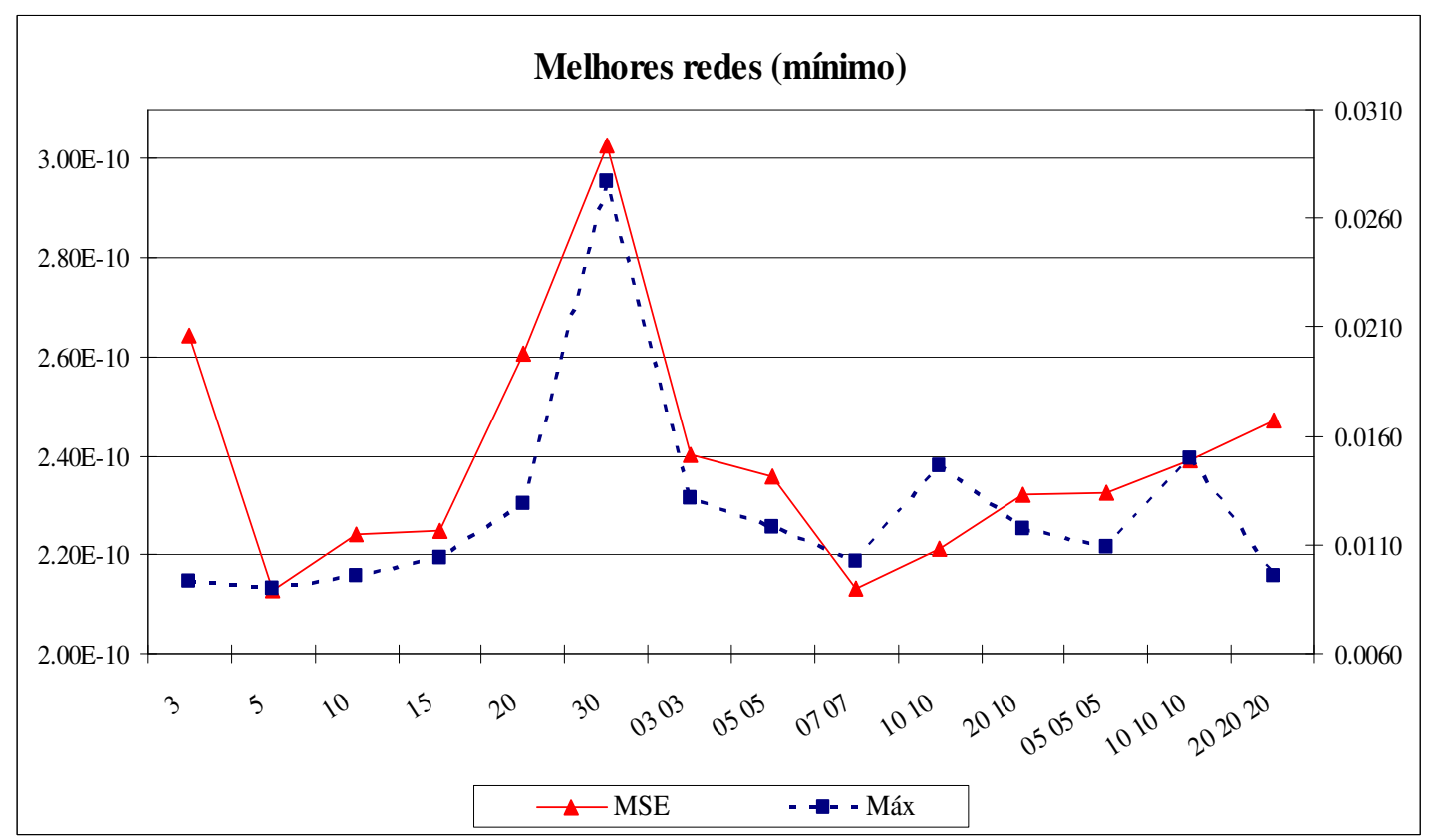

Figura 5.11: Erro mínimo apresentado pelas melhores redes de Elman 
Analisando-se a Figura 5.10 pode-se observar que para cada número de camadas há um ponto ótimo no número de neurônios por camada. Deste modo temos que os melhores resultados devem ser obtidos para: rede com apenas uma camada oculta a melhor opção será com 5 neurônios, para duas camadas a melhor é com 7 neurônios em cada e para três neurônios a melhor opção é com 5 neurônios em cada uma.

Porém, as melhores redes obtidas podem estar em uma mesma camada. A Tabela 5.3 apresenta os dados das quatro melhores redes ordenando-se de acordo com o menor erro MSE para a média da metade melhor.

Tabela 5.3: Quadro resumo das 4 melhores redes obtidas após treinamento

\begin{tabular}{|c|c|c|c|c|}
\cline { 2 - 5 } \multicolumn{1}{c|}{} & \multicolumn{2}{c|}{ Média da melhor metade } & \multicolumn{2}{c|}{ Melhor rede obtida } \\
\hline Redes & Erro MSE & Erro Máx & Erro MSE & Erro Máx \\
\hline $\mathbf{0 7} \mathbf{0 7}$ & $2,5298 \cdot 10^{-10}$ & 0,0128 & $2,1315 \cdot 10^{-10}$ & 0,0094 \\
\hline $\mathbf{0 5} \mathbf{0 5}$ & $2,6291 \cdot 10^{-10}$ & 0,0128 & $2,3570 \cdot 10^{-10}$ & 0,0103 \\
\hline $\mathbf{5}$ & $2,6433 \cdot 10^{-10}$ & 0,0132 & $2,1275 \cdot 10^{-10}$ & 0,0090 \\
\hline $\mathbf{1 0} \mathbf{1 0}$ & $2,6952 \cdot 10^{-10}$ & 0,0182 & $2,2131 \cdot 10^{-10}$ & 0,0104 \\
\hline
\end{tabular}

A rede escolhida como a melhor opção foi a rede com 2 camadas ocultas e com 7 neurônios em ambas as camadas. De fato, pode-se observar que esta rede apresenta o menor erro MSE médio, o que indica que varias redes convergem para resultados bons, e o maior pico de erro obtido é pequeno comparativamente aos demais, confirma a seleção o fato da melhor rede obtida estar entre as melhores. 


\section{Redes Feedforward}

Em seguida, foram realizados os mesmos ensaios para as redes feedforward. Os valores calculados para as médias das melhores metades das várias estruturas de redes com nenhuma, 1, 2 e 3 camadas ocultas, com diferentes quantidades de neurônios por camada como pode ser visto na Figura 5.12.

A Figura 5.13 apresenta, de forma comparativa, as melhores redes obtidas após o treinamento para cada estrutura avaliada.

Pode-se observar dentre as redes testadas uma denominada " 0,1 " que refere-se à rede sem camadas ocultas, ou seja, as entradas são ponderadas diretamente no neurônio da camada de saída. Esta rede foi incluída apesar dos resultados fracos apresentados, devido ao fato de que para esta arquitetura as redes com poucos neurônios estavam apresentando resultados muito bons.

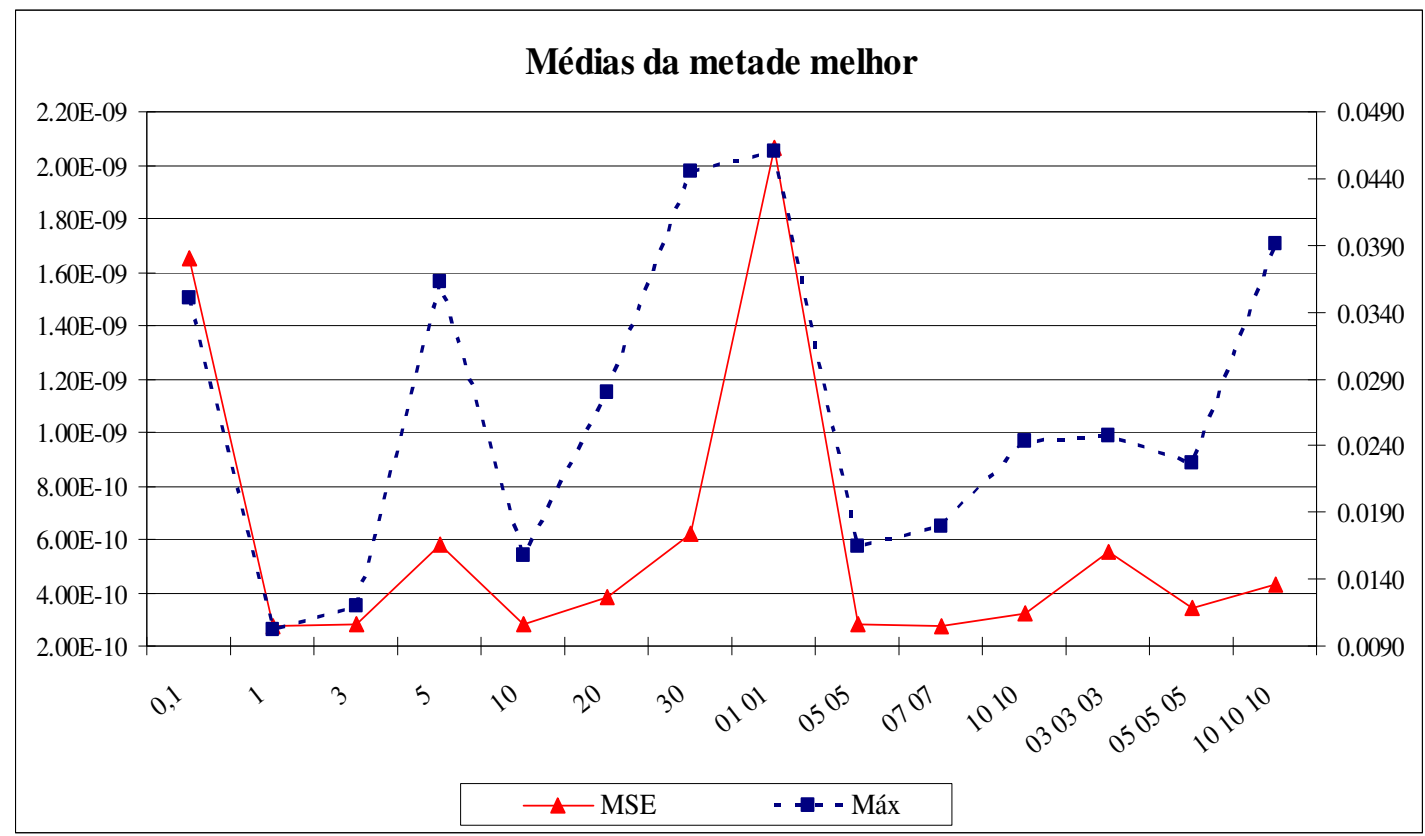

Figura 5.12: Erro obtido para a melhor metade das redes Feedforward 


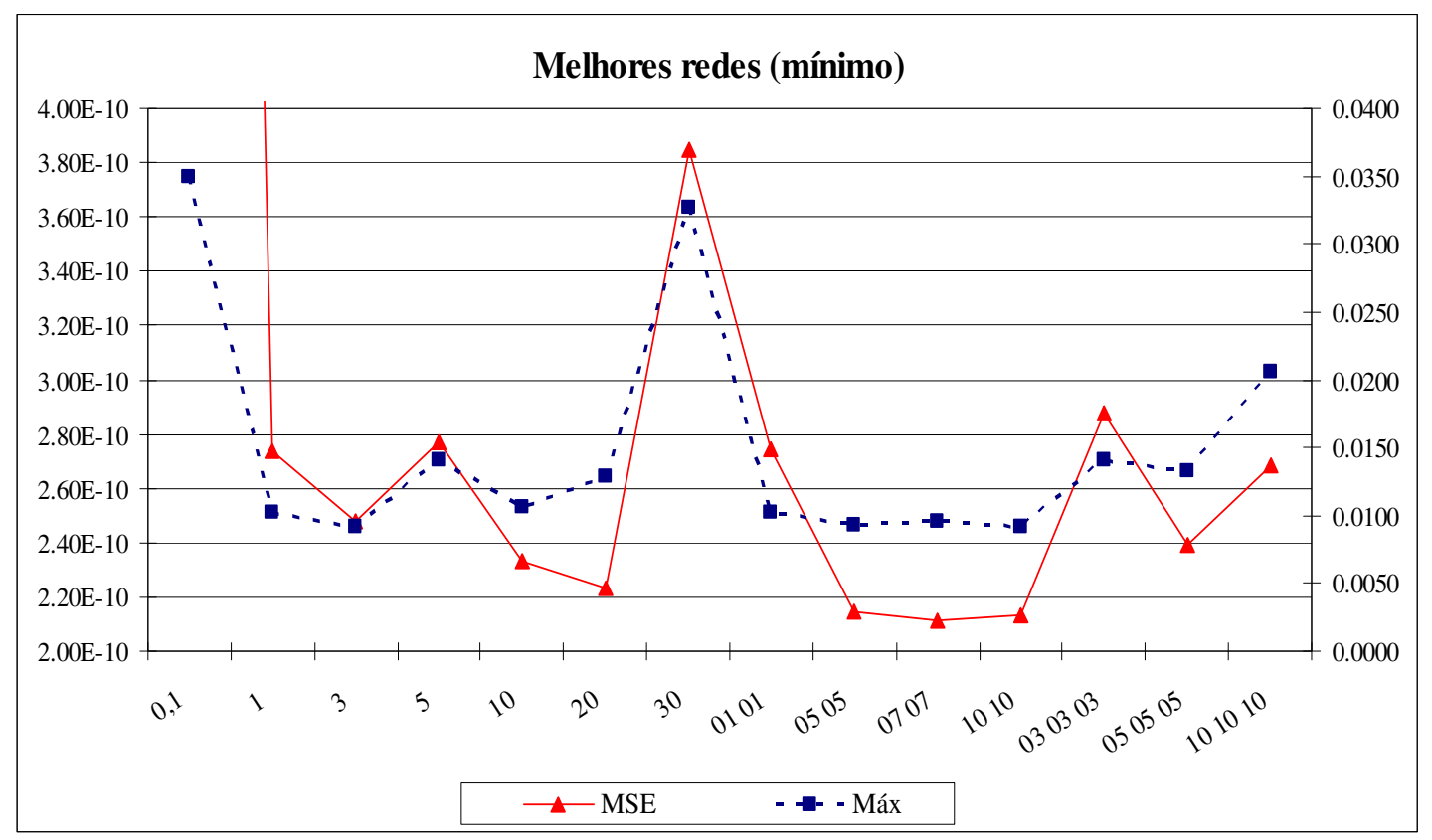

Figura 5.13: Erro mínimo apresentado pelas melhores redes Feedforward

Analisando-se a Figura 5.12 pode-se observar que para cada número de camadas há um ponto ótimo no número de neurônios por camada. Deste modo temos que os melhores erros MSE foram obtidos para: rede com apenas uma camada oculta as melhores opções foram com 1, 3 e 10 neurônios, para duas camadas as melhores foram com 7 neurônios em cada e 5 em cada e para três neurônios a melhor opção é com 5 neurônios em cada uma.

Porém, confrontando os dados com a Figura 5.13 pode-se perceber que as redes com uma só camada apresentam valores ruins para a melhor rede obtida (valor próximo ao do erro MSE obtida na figura anterior), o que indica que há uma grande homogeneidade nas respostas (erro MSE médio pequeno). Portanto, as redes com duas camadas são mais uma vez a melhor opção e coincidentemente com os resultados obtidos para as redes de Elman, a melhor opção é também uma rede com 7 neurônios em cada camada oculta.

A Tabela 5.4 apresenta os dados das quatro melhores redes considerando-se por ordem de menor erro MSE para a média metade melhor. 
Tabela 5.4: Quadro resumo das 4 melhores redes obtidas após treinamento

\begin{tabular}{|c|c|c|c|c|}
\cline { 2 - 5 } \multicolumn{1}{c|}{} & \multicolumn{2}{c|}{ Média da melhor metade } & \multicolumn{2}{c|}{ Melhor rede obtida } \\
\hline Redes & Erro MSE & Erro Máx & Erro MSE & Erro Máx \\
\hline $\mathbf{0 7} \mathbf{0 7}$ & $2,7338 \cdot 10^{-10}$ & 0,0180 & $2,1111 \cdot 10^{-10}$ & 0,0096 \\
\hline $\mathbf{1}$ & $2,7582 \cdot 10^{-10}$ & 0,0103 & $2,7344 \cdot 10^{-10}$ & 0,0102 \\
\hline $\mathbf{1 0}$ & $2,8187 \cdot 10^{-10}$ & 0,0158 & $2,3328 \cdot 10^{-10}$ & 0,0106 \\
\hline $\mathbf{3}$ & $2,8282 \cdot 10^{-10}$ & 0,0120 & $2,4795 \cdot 10^{-10}$ & 0,0091 \\
\hline
\end{tabular}

A rede escolhida como a melhor opção foi coincidentemente a rede com 2 camadas ocultas e com 7 neurônios em ambas as camadas. De fato, pode-se observar que esta rede apresenta o menor erro MSE, além de que se pode encontrar uma rede ótima com erros pequenos e picos de erro comparativamente mais baixos.

Comparando-se as duas estruturas de redes (Elman e Feedforward) pode-se observar que os resultados apresentados são muito semelhantes. Porém, a rede recorrente de Elman apresentou resultados ligeiramente melhores.

Tabela 5.5: Quadro resumo das 2 melhores redes obtidas após treinamento

\begin{tabular}{|c|c|c|c|c|}
\cline { 2 - 6 } \multicolumn{1}{c|}{} & \multicolumn{2}{c|}{ Média da melhor metade } & \multicolumn{2}{c|}{ Melhor rede obtida } \\
\hline Redes & Erro MSE & Erro Máx & Erro MSE & Erro Máx \\
\hline Elman $\mathbf{0 7 0 7}$ & $2,5298 \cdot 10^{-10}$ & 0,0128 & $2,1315 \cdot 10^{-10}$ & 0,0094 \\
\hline Feedforward $\mathbf{0 7} \mathbf{0 7}$ & $2,7338 \cdot 10^{-10}$ & 0,0180 & $2,1111 \cdot 10^{-10}$ & 0,0096 \\
\hline
\end{tabular}




\section{Tempo de treinamento e validação}

Outro fato importante que precisa ser definido é o critério de parada do treinamento. Conforme vimos anteriormente, há vários fatores que podem afetar o tempo de treinamento, porém sempre é necessário determinar um critério de parada.

Normalmente, o critério utilizado é o erro mínimo apresentado pela rede na sua adequação ao conjunto de dados apresentado para seu treinamento. Este erro indiretamente afeta a capacidade de generalização da rede, sendo que pode ocorrer que em um determinado instante do treinamento, a generalização comece a degenerar, causando o problema de "over-training", ou seja, a rede especializa-se no conjunto de dados do treinamento e perde a capacidade de generalização.

O treinamento deve ser interrompido quando a rede apresentar uma boa capacidade de generalização e quando a taxa de erro for suficientemente pequena, ou seja, menor que um erro admissível. Assim, deve-se encontrar um ponto ótimo de parada com erro mínimo e capacidade de generalização máxima. Para encontrar este ponto foi utilizado um outro subconjunto dos dados para realizar a cada época do treinamento uma avaliação do erro para este conjunto de validação.

No Matlab ${ }^{\circledR}$ pode-se visualizar a convergência da rede conforme prossegue o treinamento para o conjunto de dados de treinamento e o de validação. O critério de parada dá-se assim que for detectado algum aumento no erro para o conjunto de validação.

A Figura 5.14 mostra a convergência do erro apresentado pela rede durante o treinamento. Observa-se uma ligeira diferença entre as duas curvas fruto de uma adaptação melhor da rede para os dados de treinamento, porém sem comprometer a sua capacidade de generalização (mínimo também para o conjunto de validação). 


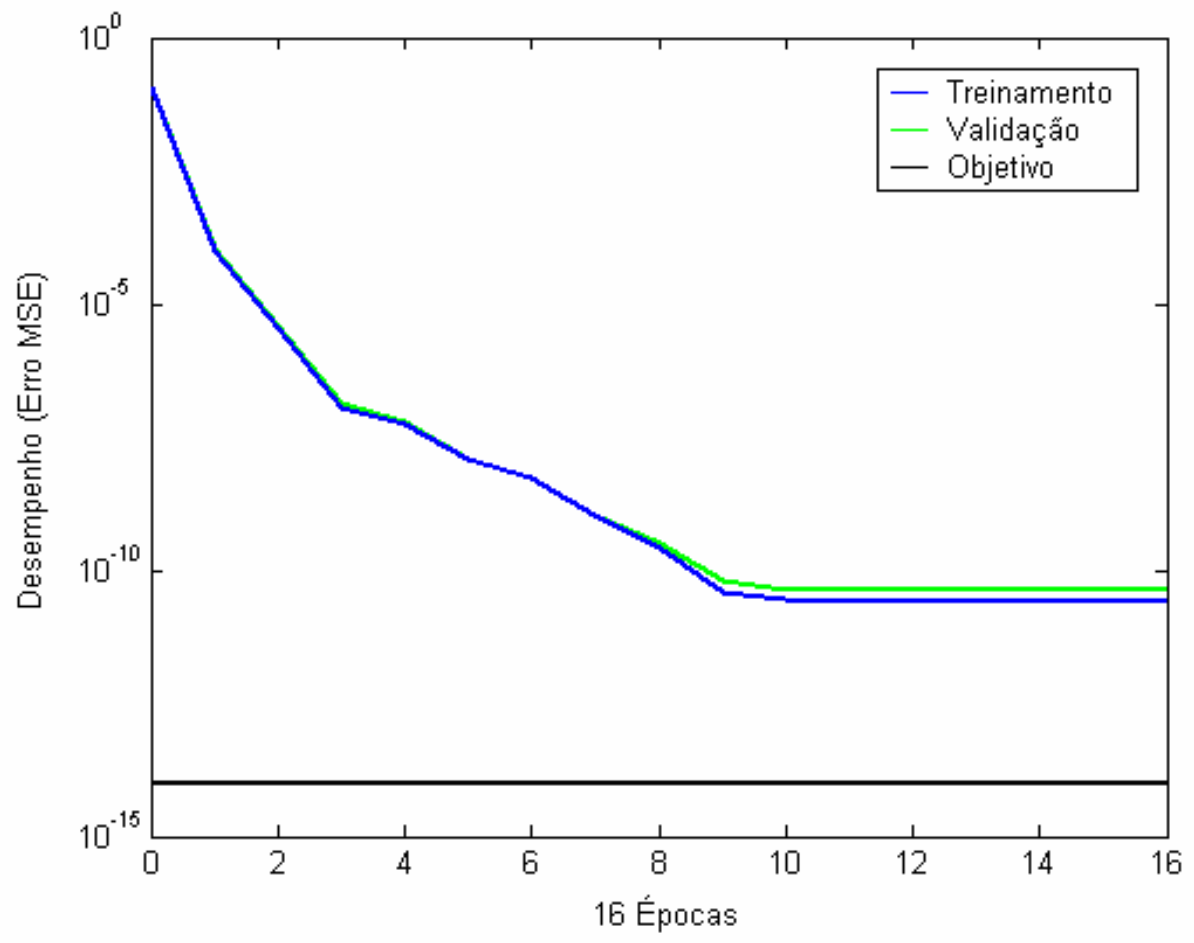

Figura 5.14: Convergência dos erros de treinamento da rede Elman

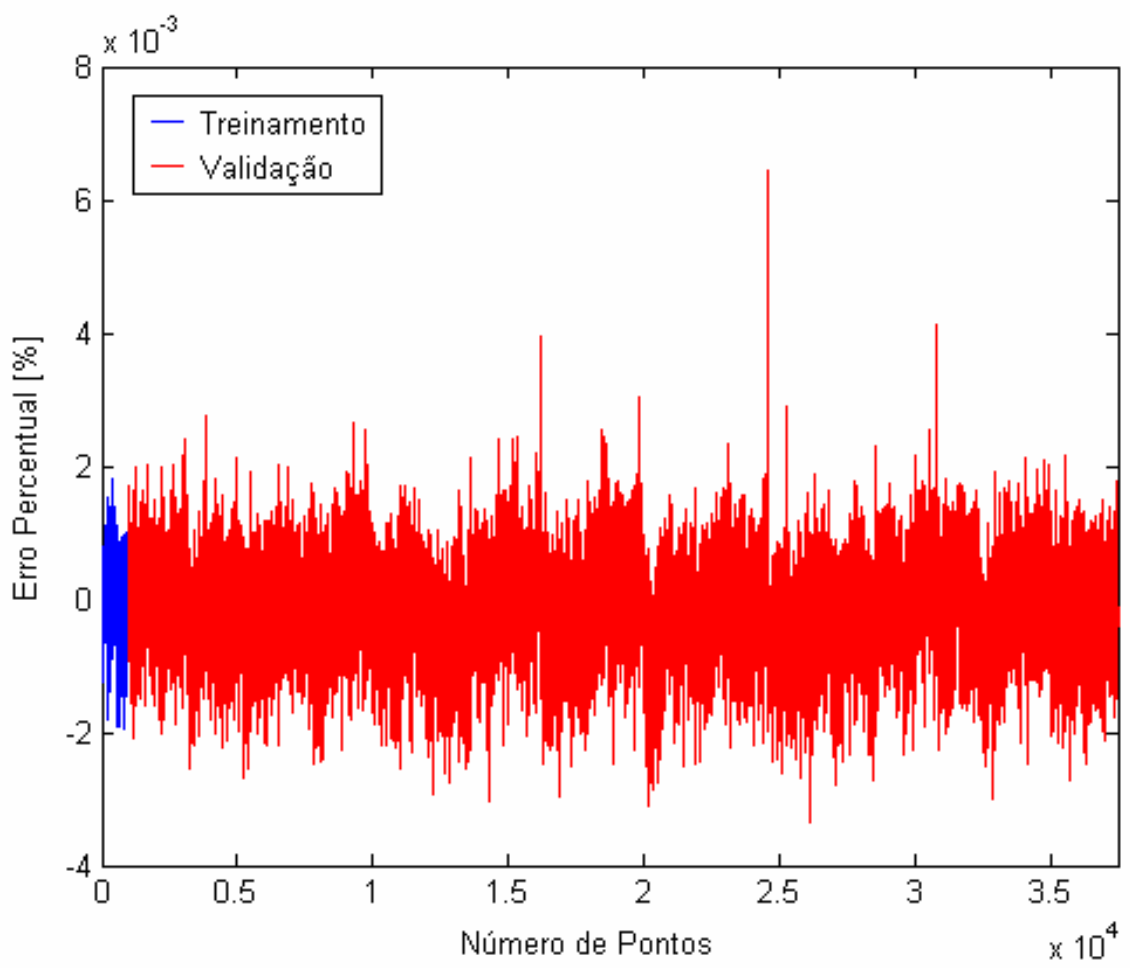

Figura 5.15: Erro apresentado para conjuntos de treinamento e validação 
A Figura 5.15 mostra o erro da rede para o conjunto de treinamento (azul) e de teste (vermelho). Destaca-se que o erro apresenta grande uniformidade, com apenas três picos mais relevantes, nos quais o erro é maior.

A Figura 5.16 mostra a sobreposição dos valores fornecidos pelo simulador e pelo sensor (estimado) para a composição do componente 2 no topo da coluna. Repara-se que o erro é bastante pequeno.

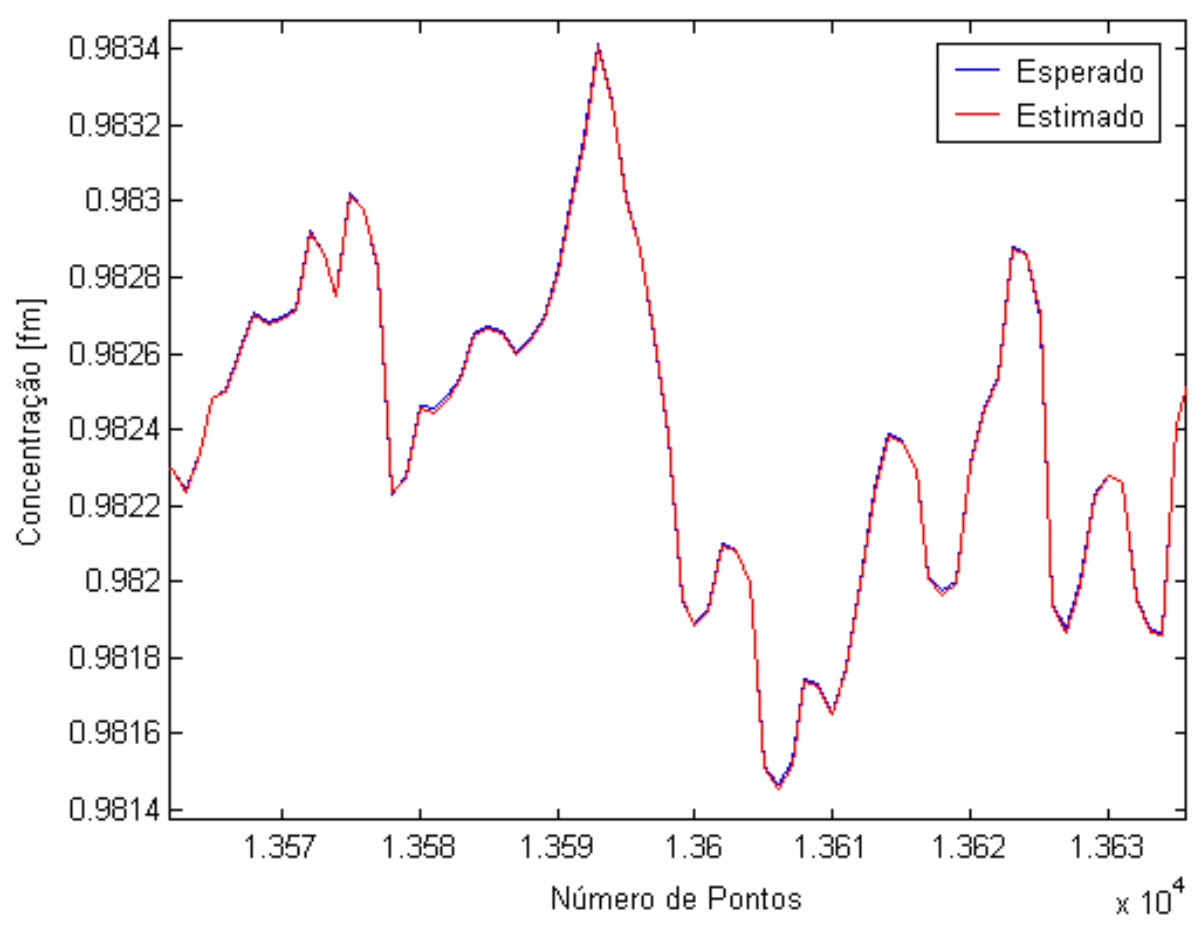

Figura 5.16: Comparação da estimação obtida do sensor e esperada 


\subsection{Treinamento com Regressores e Estimadores}

A seguir, é apresentado um estudo realizado visando conhecer o comportamento da rede neural do sensor virtual frente ao acréscimo de regressores e estimadores dos parâmetros utilizados.

Por regressores entende-se a utilização das variáveis coletadas defasadas (regredidas) no tempo como entradas para o sensor virtual, ou seja, serão fornecidas como entrada da rede neural além das variáveis coletadas anteriores, os valores destas mesmas em instantes anteriores, com o intuito de melhorar a estimação futura. Deste modo, foram realizados ensaios considerando-se as 10 entradas do sensor regredidas para até 3 períodos de amostragem.

Já por estimadores compreende-se a utilização das respostas fornecidas (estimadas) pela rede para cada instante do conjunto de dados, apresentadas como entrada para a rede em um passo de estimação futuro. O objetivo é que este valor da composição estimado pela rede em um instante anterior possa ajudar a melhorar a próxima estimação, uma vez que esta pode basear-se nesta memória das estimações.

A fim de se conhecer o comportamento da rede neural com relação a cada um desses parâmetros, foram realizados três grupos de testes. Assim, no primeiro, para conhecer melhor a influência dos regressores, foram treinadas três redes. Uma com as 10 entradas normais (TF, FL, FV, QR, R, T $, T_{2}, T_{3}, T_{4}$ e $T_{17}$ ) instantâneas, outra com 20 entradas (sendo o valor das 10 atuais, mais as mesmas 10 medidas no instante de amostragem anterior) e uma última com 30 entradas (10 atuais, 10 na amostragem anterior e mais $10 \mathrm{da}$ amostragem 2 intervalos antes).

No segundo grupo de testes, foi realizado algo análogo com os estimadores. Também foram treinadas três redes neurais. Uma com 11 entradas (sendo as 10 normais e mais a variável estimada pelo sensor no instante de amostragem anteri- 
or), outra com 12 entradas (variável estimada no instante anterior e ante-anterior) e outra com 13 entradas (3 estimações defasadas).

O terceiro grupo de testes foi realizado para avaliar o comportamento destes dois parâmetros conjuntamente. Para isto foram treinadas três redes: uma com 21 (10 atuais +10 do instante anterior +1 estimação no instante anterior), outra com 22 entradas (igual a anterior e +1 estimação dois instantes anteriores) e outra com 33 entradas (10 entradas para até 2 instantes anteriores e mais três estimações anteriores da rede).

Este estudo foi motivado pelo fato de que as redes de Elman, por serem recorrentes, possuem armazenadas informações passadas, ao passo que as redes feedforward não apresentam estes dados. Deste modo, com o acréscimo de entradas com funções de regressores, esperava-se que as redes feedforward apresentassem resultados ainda melhores.

A seguir são apresentadas as respostas obtidas para o treinamento das redes neurais com um conjunto de treinamento com 2.000 pontos, para as diversas combinações de entradas utilizadas e a seguir serão comparadas as duas arquiteturas selecionadas no item anterior.

A Figura 5.17 e a Figura 5.19 trazem o erro MSE médio e o erro máximo médio obtidos para a metade melhor dos resultados obtidos. A Figura 5.18 e a Figura 5.20 mostram o erro MSE e o maior pico de erro obtido para a melhor rede obtida para cada caso (combinação do número de entradas) estudado.

Os resultados obtidos para as duas arquiteturas de redes selecionadas no item anterior são realmente muito semelhantes. 
Resultados obtidos para redes recorrentes de Elman:

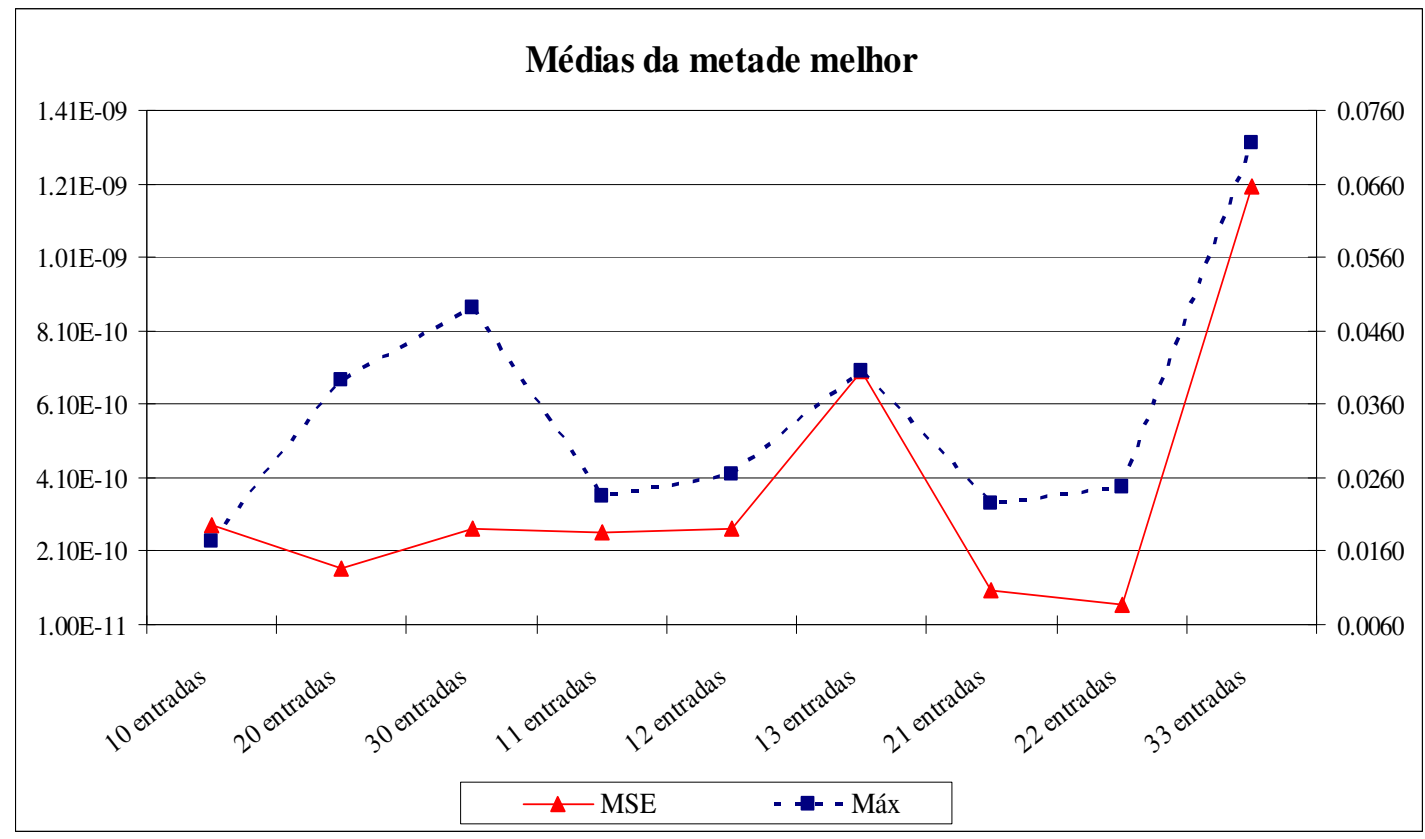

Figura 5.17: Média do erro obtido para a melhor metade das redes Elman

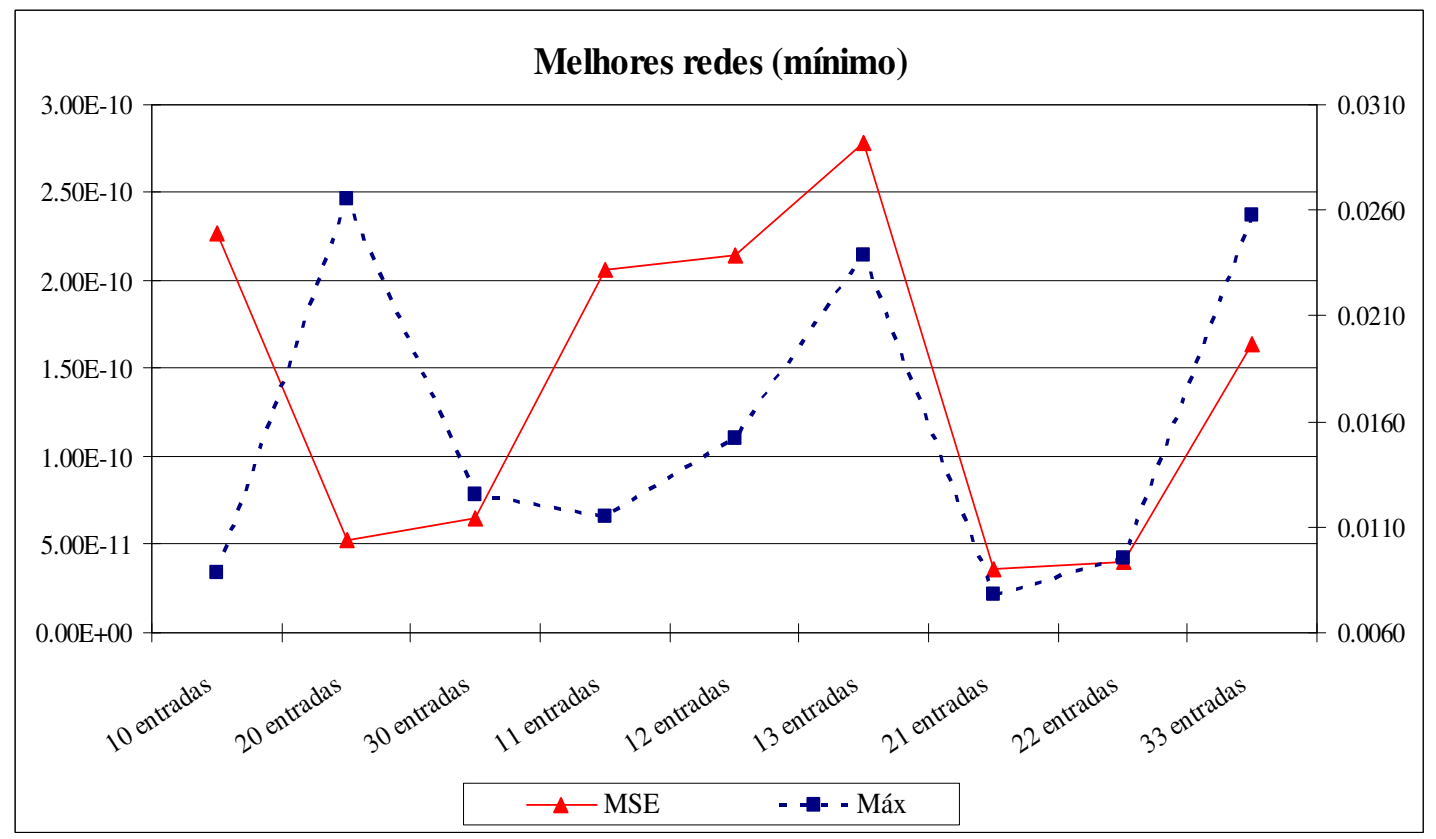

Figura 5.18: Erro mínimo apresentado pelas melhores redes Elman 
Resultados obtidos para redes feedforward MLP:

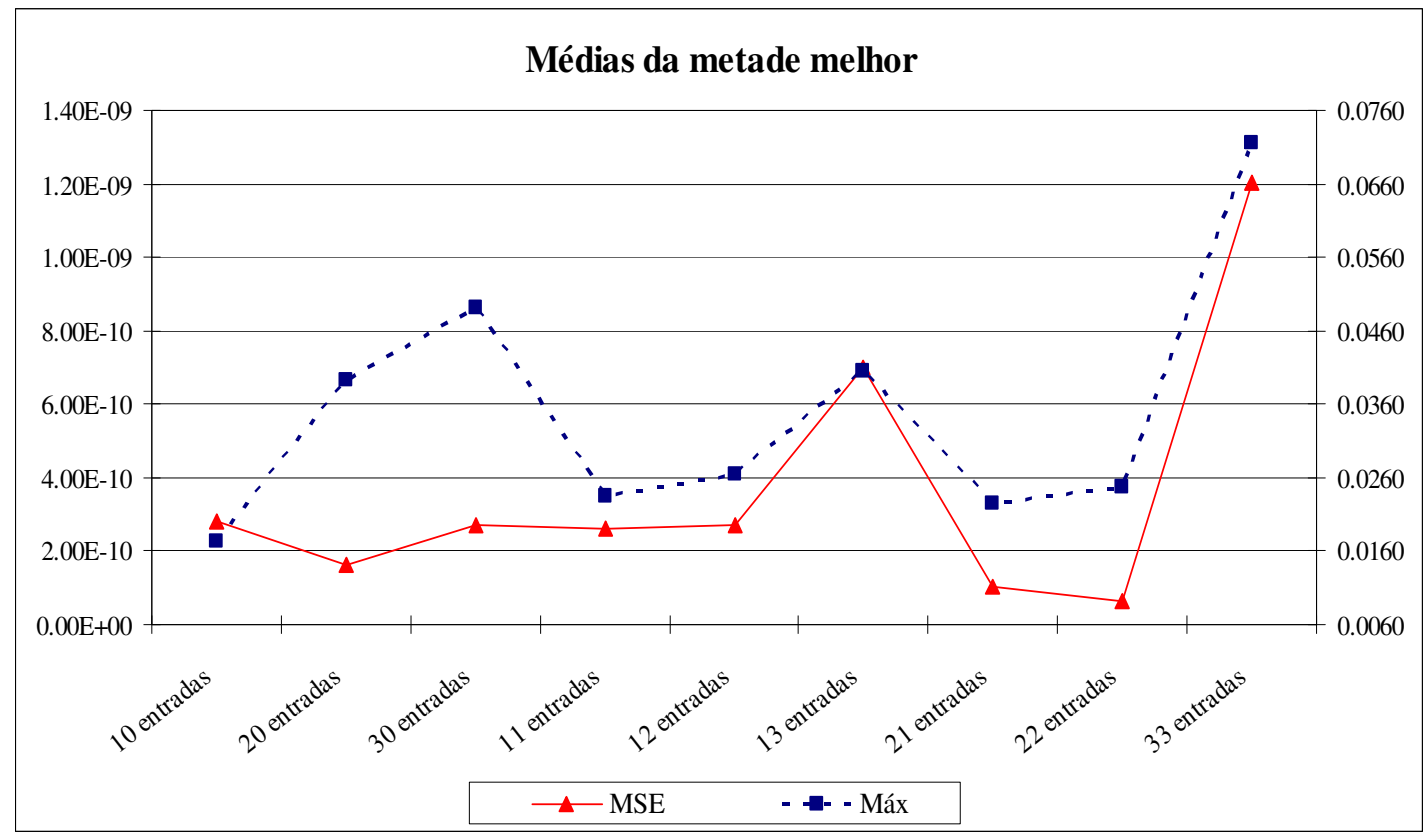

Figura 5.19: Erro obtido para a melhor metade das redes Feedforward

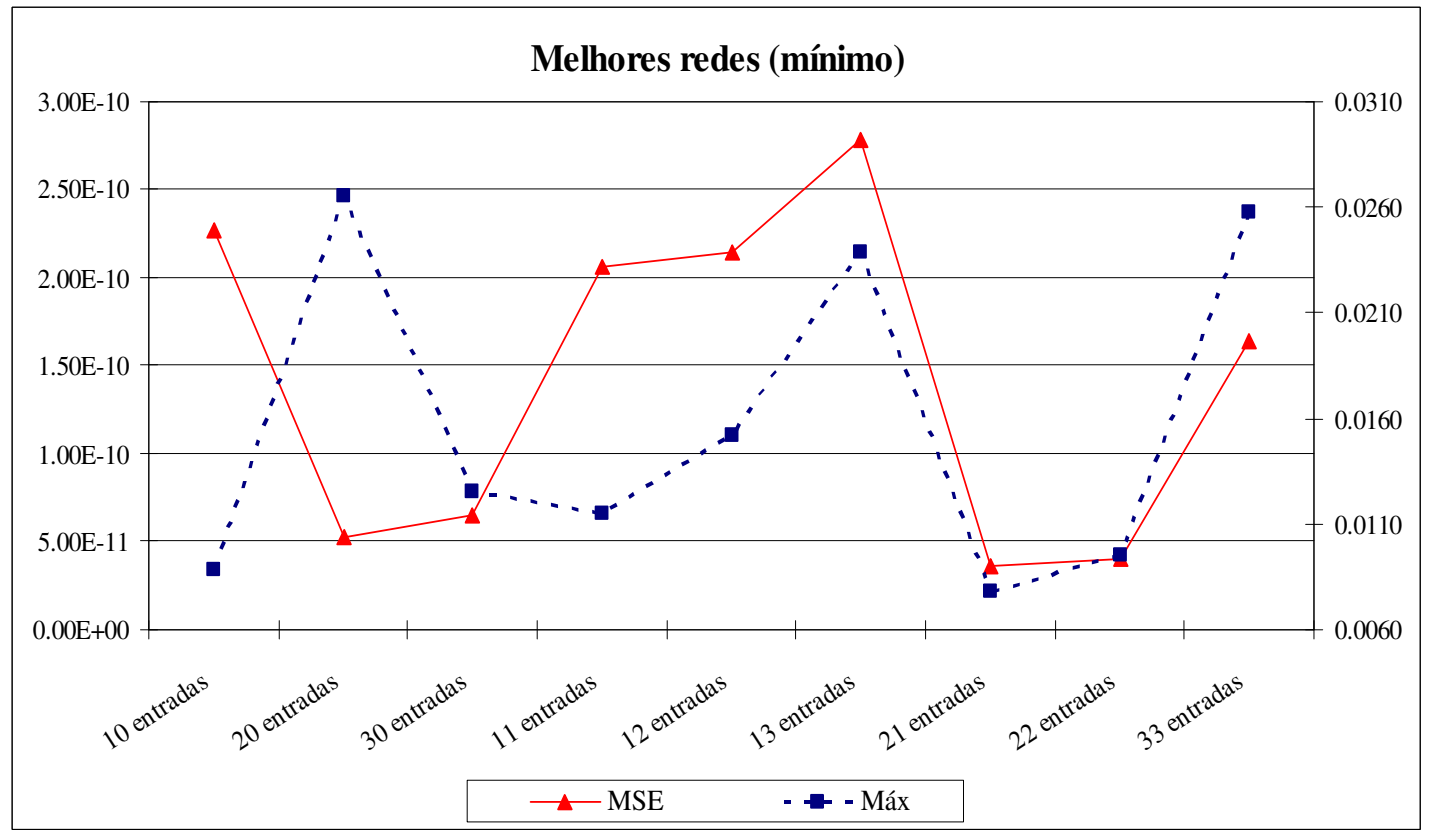

Figura 5.20: Erro mínimo apresentado pelas melhores redes Feedforward 
Analisando-se a Figura 5.17 e Figura 5.19 pode-se observar que o acréscimo dos regressores (redes com 20, 30, 21, 22 e 33 entradas) apresentou grande melhora nos resultados obtidos. Isto pode ser explicado pelo fato de que com o acréscimo dos valores regredidos o sensor passa a receber mais informações sobre o processo, que demoram a propagar-se pela coluna de destilação.

Repara-se também que o acréscimo de um conjunto de medidas regredidas (redes com 20, 21 e 22 entradas) apresenta resultados muito melhores; ao passo que o acréscimo de dois conjuntos regredidos gera resultados melhores que os originais, porém piores que os obtidos com apenas um conjunto regredido. Isto pode ser explicado pelo fato de que as variáveis que sofrem alteração retardada são coletadas apenas na amostragem seguinte, e não mais nas outras que a seguem. Este fato havia sido detectado já durante o estudo da análise correlacional dos dados coletados, realizada no capítulo 4 desta dissertação.

Quanto aos estimadores pode-se observar que o acréscimo de até dois deles gera resultados mais precisos, porém o acréscimo de mais estimadores piora a acuidade do sensor. Este fato pode ser explicado pelo fato de que as variáveis de entrada do sensor perdem rapidamente a correlação com a saída desejada, uma vez que o simulador está sendo submetido a um regime de grande variação das suas variáveis de entrada manipuladas e medidas para simular um longo período de operação real da coluna de destilação.

Comparando-se os resultados vistos com os das Figura 5.18 e Figura 5.20 pode-se confirmar a análise anterior, uma vez que as melhores redes obtidas estão de acordo com o número de regressores e estimadores. Finalmente, o erro máximo não segue sempre o erro MSE e para algumas redes cresce bastante. Porém, observando as melhores redes obtidas, pode-se identificar que estas apresentam também os menores picos de erro. 
Portanto, podemos concluir que os melhores resultados são obtidos para as redes neurais com regressores amostrados no instante anterior ao atual e com 1 ou 2 estimadores da composição. Para as análises do próximo capítulo será utilizada a rede neural recorrente de Elman com 2 camadas ocultas com 7 neurônios em cada uma, além de 22 entradas (10 atuais +10 regredidas +2 estimadores).

Destaca-se finalmente que a introdução de regressores aumenta o volume de dados de entrada da rede, o que torna o seu treinamento um pouco mais lento. Porém, a rede torna-se mais robusta a perturbações nos dados, uma vez que há maior quantidade de informação sobre um mesmo estado. Quanto ao acréscimo dos estimadores espera-se que estes auxiliem a rede a apresentar um erro menor, porém, há o perigo associado à utilização destas variáveis que é o fato da rede fiarse demasiadamente nestes e se houver um erro de estimação este pode ser propagado e amplificado.

No próximo capítulo será tratada a influência do treinamento parcial com diferentes tamanhos de conjuntos de treinamento no qual será utilizada esta rede de Elman. 


\section{Capítulo 6}

\section{Sensor Virtual com Treinamento Parcial}

\subsection{Introdução}

Neste capítulo descreve-se a obtenção do sensor virtual para estimação da composição do produto na coluna e apresenta-se uma análise da utilização de treinamentos parciais para a obtenção do mesmo.

O intuito é desenvolver um sensor capaz de operar em uma coluna real sem ter sido treinado com dados coletados diretamente desta planta, mas treinado com dados de um simulador dinâmico. Em seguida, conforme estejam disponíveis dados da coluna real será realizado um retreinamento do sensor para melhorar o seu desempenho.

O capítulo se inicia com um estudo dos efeitos do treinamento parcial sucessivo em redes neurais, analisando sua viabilidade e vantagens. Depois se analisa a precisão e a confiabilidade dos resultados obtidos na utilização de um sensor treinado unicamente com dados de um simulador para operar em uma coluna real. 
Finalmente, o capítulo se encerra com uma análise das vantagens de se utilizar este tipo de sensor e retreiná-lo para melhorar a qualidade da sua estimação.

\subsection{Treinamentos parciais}

Como já foi dito no início deste trabalho, pretende-se estudar o comportamento das redes neurais frente a um treinamento intervalado, ou seja, conhecer os resultados que podem ser obtidos através de um treinamento inicial com um determinado conjunto de dados e depois aperfeiçoar o desempenho desta rede com novos treinamentos sobre os anteriores.

Uma das aplicações deste método é para o caso de não se possuir um conjunto significativo de dados reais de um processo, mas sim um conjunto de dados simulados obtido de um modelo matemático (simulador dinâmico). Nesta situação, o sensor seria treinado com um conjunto de dados oriundo das simulações e depois, conforme estivessem disponíveis dados da planta real, realizar-se-ia um novo treinamento para o sensor apresentar melhor adaptação à planta. $\mathrm{O}$ mesmo pode dar-se com um processo lentamente variante no tempo, que seria de tempos em tempos retreinado.

Para a análise dos resultados obtidos e avaliação das redes, foram realizados vários treinamentos sucessivos, com diferentes tamanhos iniciais e de incremento, para serem comparados e conhecer-se o comportamento deste tipo de treinamento.

Para realizar a análise dos efeitos do treinamento parcial na configuração final do sensor foram realizados quatro grupos de teste. O primeiro grupo, denominado "direto", consiste em um único treinamento com todo o conjunto de dados realizado para cada rede com diferentes tamanhos dos conjuntos de dados. Assim, foram treinadas redes com conjunto de dados desde 500 até 6.000 pontos. 
O segundo grupo analisado consiste no treinamento parcial da rede com retreinamentos de 500 pontos cada. Deste modo, a rede é inicialmente treinada com 500 pontos, depois esta rede é retreinada com um conjunto contendo mais 500 pontos (ou seja, retreinada com 1.000 pontos). Estes retreinamentos vão-se repetindo sempre com um aumento de 500 pontos sobre o treinamento anterior.

O terceiro e quarto grupos realizam-se de modo análogo, com treinamentos parciais através de conjuntos de dados com acréscimo respectivamente de 1.000 e 2.000 pontos cada.

A Tabela 6.1 apresenta os resultados obtidos para o treinamento parcial. 
Tabela 6.1: Quadro resumo dos resultados para treinamento intervalado

\begin{tabular}{|c|c|c|c|}
\hline & MSE_test & MAE_test & MAX_test \\
\hline \multicolumn{4}{|c|}{ Treinamento Direto } \\
\hline 0500 dir & $6.8856 \mathrm{E}-10$ & $1.7720 \mathrm{E}-05$ & 0.0291 \\
\hline 1000 dir & $4.7939 \mathrm{E}-10$ & $1.4830 \mathrm{E}-05$ & 0.0331 \\
\hline 1500 dir & $5.0117 \mathrm{E}-10$ & $1.3822 \mathrm{E}-05$ & 0.0460 \\
\hline 2000 dir & $2.8423 \mathrm{E}-10$ & $1.1336 \mathrm{E}-05$ & 0.0199 \\
\hline $2500 \mathrm{dir}$ & $5.6024 \mathrm{E}-10$ & $1.2222 \mathrm{E}-05$ & 0.0429 \\
\hline 3000 dir & $2.1727 \mathrm{E}-10$ & $1.1249 \mathrm{E}-05$ & 0.0093 \\
\hline 3500 dir & $2.8778 \mathrm{E}-10$ & $1.3051 \mathrm{E}-05$ & 0.0094 \\
\hline 4000 dir & $2.3539 \mathrm{E}-10$ & $1.1662 \mathrm{E}-05$ & 0.0097 \\
\hline 4500 dir & $1.8168 \mathrm{E}-10$ & 1.0103E-05 & 0.0091 \\
\hline 5000 dir & $1.6745 \mathrm{E}-10$ & 9.6483E-06 & 0.0091 \\
\hline 5500 dir & $1.7672 \mathrm{E}-10$ & $9.8438 \mathrm{E}-06$ & 0.0092 \\
\hline 6000 dir & $1.8210 \mathrm{E}-10$ & 9.9817E-06 & 0.0092 \\
\hline \multicolumn{4}{|c|}{ Parciais de 500 } \\
\hline 05001 & $6.8856 \mathrm{E}-10$ & $1.7720 \mathrm{E}-05$ & 0.0291 \\
\hline 10001 & $4.3133 \mathrm{E}-10$ & $1.4340 \mathrm{E}-05$ & 0.0288 \\
\hline 15001 & $3.4044 \mathrm{E}-10$ & $1.2227 \mathrm{E}-05$ & 0.0276 \\
\hline 20001 & $3.5180 \mathrm{E}-10$ & $1.2370 \mathrm{E}-05$ & 0.0276 \\
\hline 25001 & $3.6495 \mathrm{E}-10$ & $1.2514 \mathrm{E}-05$ & 0.0276 \\
\hline 30001 & $2.4008 \mathrm{E}-10$ & 1.1779E-05 & 0.0098 \\
\hline 35001 & $2.3563 \mathrm{E}-10$ & $1.1540 \mathrm{E}-05$ & 0.0098 \\
\hline 40001 & $2.3770 \mathrm{E}-10$ & $1.1605 \mathrm{E}-05$ & 0.0098 \\
\hline 45001 & $1.8536 \mathrm{E}-10$ & $1.0241 \mathrm{E}-05$ & 0.0097 \\
\hline 50001 & $1.6651 \mathrm{E}-10$ & $9.7822 \mathrm{E}-06$ & 0.0093 \\
\hline 55001 & $1.7278 \mathrm{E}-10$ & $9.9173 \mathrm{E}-06$ & 0.0094 \\
\hline 60001 & $1.6432 \mathrm{E}-10$ & $9.5434 \mathrm{E}-06$ & 0.0092 \\
\hline \multicolumn{4}{|c|}{ Parciais de 1.000 } \\
\hline 10002 & $4.7939 \mathrm{E}-10$ & $1.4830 \mathrm{E}-05$ & 0.0331 \\
\hline 20002 & $2.6859 \mathrm{E}-10$ & $1.1687 \mathrm{E}-05$ & 0.0368 \\
\hline 30002 & $2.0658 \mathrm{E}-10$ & $1.1146 \mathrm{E}-05$ & 0.0089 \\
\hline 40002 & $1.9693 \mathrm{E}-10$ & $1.0642 \mathrm{E}-05$ & 0.0093 \\
\hline 50002 & $1.7035 \mathrm{E}-10$ & 9.8649E-06 & 0.0089 \\
\hline 60002 & $1.7200 \mathrm{E}-10$ & 9.8181E-06 & 0.0089 \\
\hline \multicolumn{4}{|c|}{ Parciais de 2.000 } \\
\hline 20003 & $2.8423 \mathrm{E}-10$ & $1.1336 \mathrm{E}-05$ & 0.0199 \\
\hline 40003 & $1.8719 \mathrm{E}-10$ & $1.0336 \mathrm{E}-05$ & 0.0102 \\
\hline 60003 & $1.7732 \mathrm{E}-10$ & $9.9680 \mathrm{E}-06$ & 0.0099 \\
\hline
\end{tabular}

A Figura 6.1 e a Figura 6.2 apresentam os mesmos resultados da tabela anterior, porém de um modo mais fácil de visualizar e comparar os dados. 
118

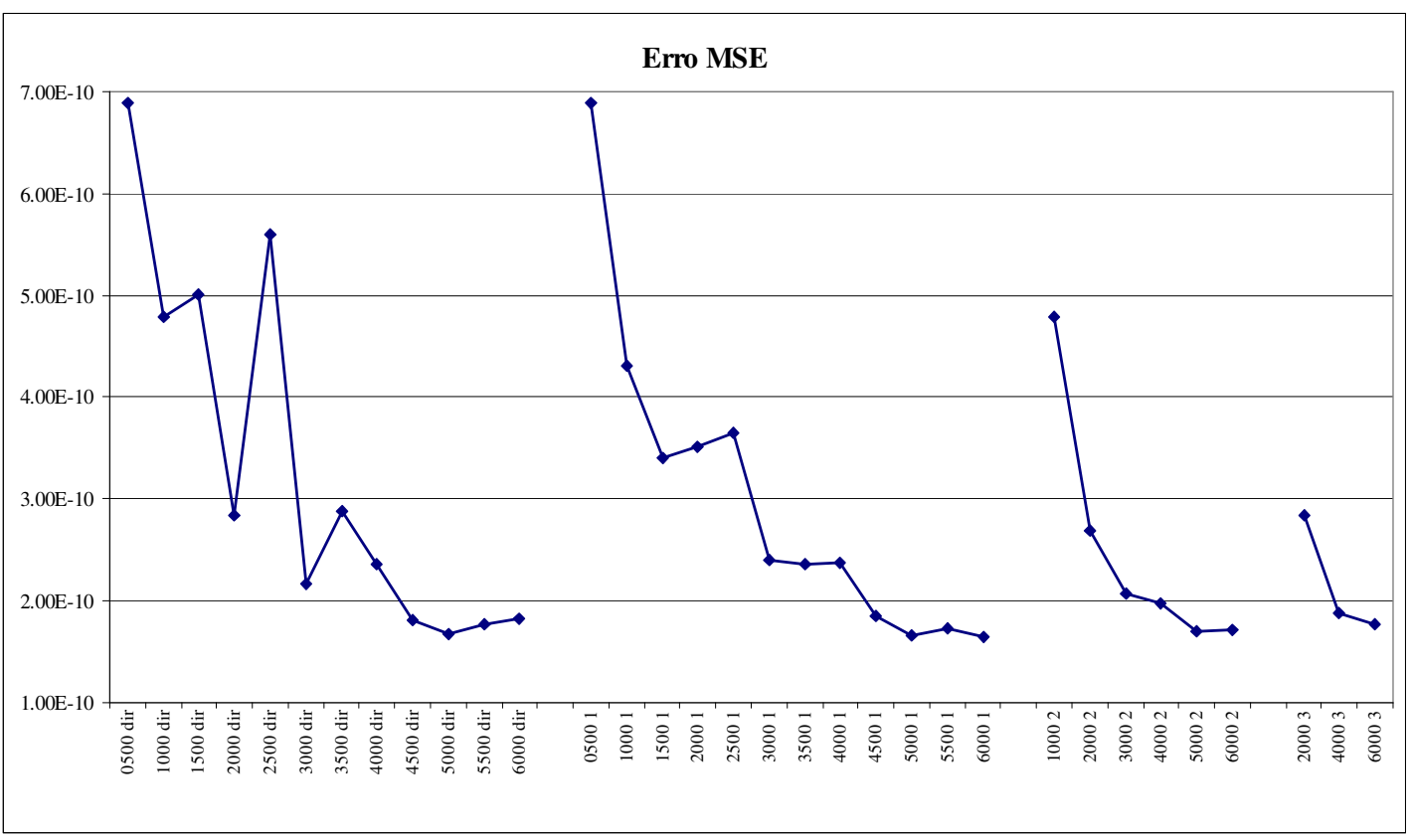

Figura 6.1: Erro MSE apresentado pela rede para treinamento parcial

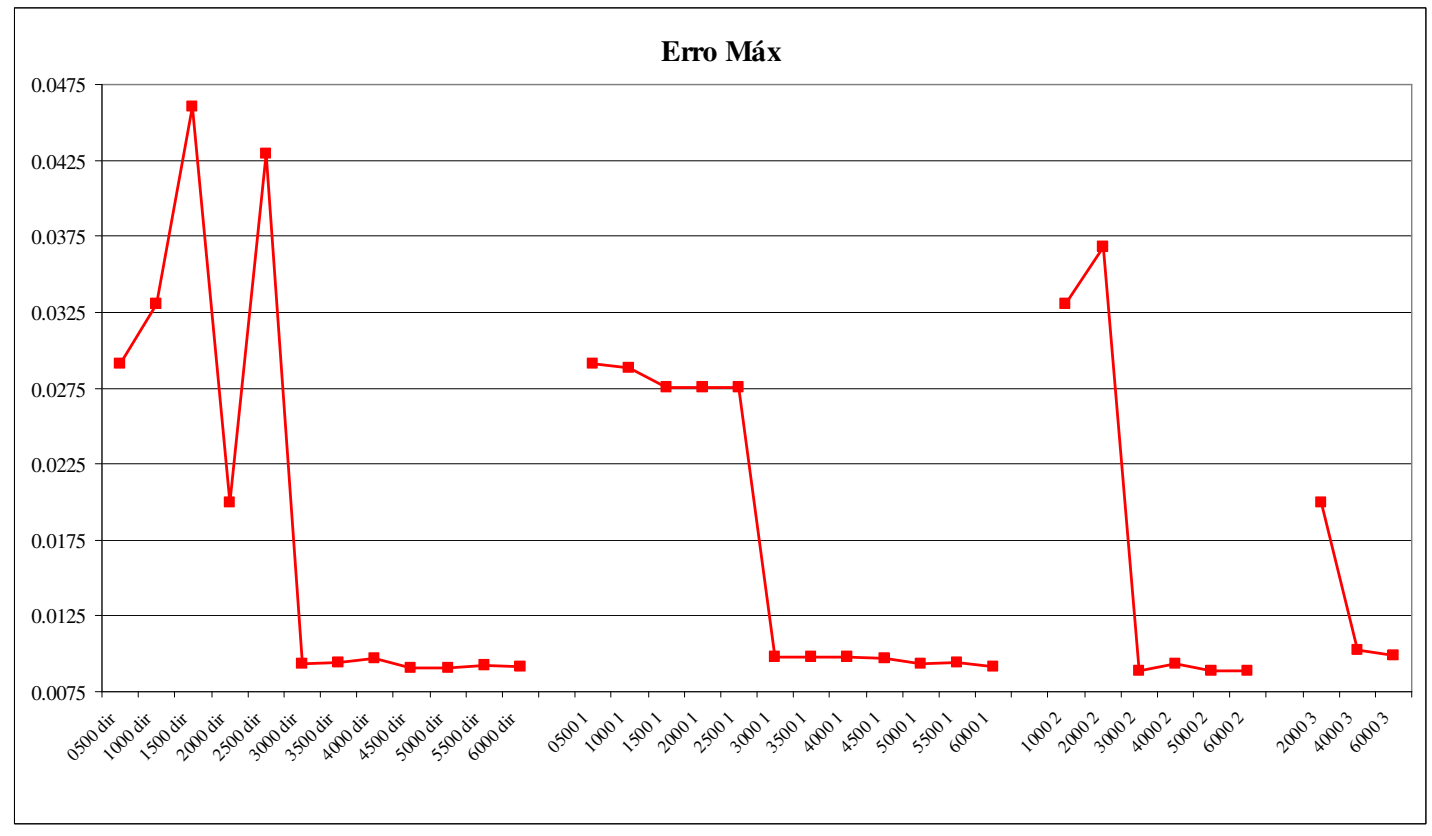

Figura 6.2: Erro Máximo apresentado pela rede para treinamento parcial 
Analisando-se os dados das tabelas e figuras anteriores pode-se perceber que:

Em geral, para cada série de treinamentos sucessivos com um mesmo tamanho de conjunto de dados os resultados vão ficando melhor conforme se aumenta o número de dados utilizados para o treinamento. Este fato pode ser explicado pela razão de que quanto mais pontos são apresentados à rede, melhor será sua capacidade de apreender os padrões.

Porém, observando-se a Figura 6.1 pode-se observar que a partir de um determinado número de pontos o sensor apresenta pequena melhora nos resultados frente ao aumento do conjunto de treinamento. Isto se deve ao fato de que os treinamentos realizados com conjuntos de dados com pelo menos 4.500 pontos já apresentam as situações que a rede precisa conhecer para identificar os parâmetros necessários. O mesmo ocorre para os picos de erro, como pode ser observado na Figura 6.2, porém a estabilização ocorre para um conjunto de pontos menor, com aproximadamente 3.000 pontos.

Daqui pode-se concluir que para o treinamento apresentar um bom resultado é necessário treinar a rede inicialmente com um número não muito pequeno de dados, o valor escolhido para as próximas etapas é de 5.000 pontos. Após isto, podem-se realizar novos treinamentos com conjuntos menores de dados.

Ainda, analisando-se a Figura 6.1 pode-se perceber que o treinamento realizado com os dados de forma direta apresenta maior variabilidade. Ou seja, a rede pode convergir pouco e parar em um mínimo local com um erro maior do que o que poderia ter sido alcançado se o treinamento houvesse sido realizado por etapas parciais, como pode ser observado para o conjunto com 2.500 pontos. Porém, o contrário também pode ocorrer. Assim a rede treinada diretamente pode também convergir rapidamente para uma situação de erro pequeno, que no treinamento parcial teria sido mais difícil de ser alcançado, como pode ser visto para o conjunto com 2.000 pontos. 
Tabela 6.2: Quadro resumo ordenado do treinamento intervalado

\begin{tabular}{|c|c|c|c|}
\hline & Erro MSE & Erro MAE & Erro Máx \\
\hline 05001 & $6.8856 \mathrm{E}-10$ & $1.7720 \mathrm{E}-05$ & 0.0291 \\
\hline 0500 dir & $6.8856 \mathrm{E}-10$ & $1.7720 \mathrm{E}-05$ & 0.0291 \\
\hline 10001 & $4.3133 \mathrm{E}-10$ & $1.4340 \mathrm{E}-05$ & 0.0288 \\
\hline 10002 & $4.7939 \mathrm{E}-10$ & $1.4830 \mathrm{E}-05$ & 0.0331 \\
\hline 1000 dir & $4.7939 \mathrm{E}-10$ & $1.4830 \mathrm{E}-05$ & 0.0331 \\
\hline 15001 & $3.4044 \mathrm{E}-10$ & $1.2227 \mathrm{E}-05$ & 0.0276 \\
\hline 1500 dir & $5.0117 \mathrm{E}-10$ & $1.3822 \mathrm{E}-05$ & 0.0460 \\
\hline 20001 & $3.5180 \mathrm{E}-10$ & $1.2370 \mathrm{E}-05$ & 0.0276 \\
\hline 20002 & $2.6859 \mathrm{E}-10$ & $1.1687 \mathrm{E}-05$ & 0.0368 \\
\hline 20003 & $2.8423 \mathrm{E}-10$ & $1.1336 \mathrm{E}-05$ & 0.0199 \\
\hline 2000 dir & $2.8423 \mathrm{E}-10$ & $1.1336 \mathrm{E}-05$ & 0.0199 \\
\hline 25001 & $3.6495 \mathrm{E}-10$ & $1.2514 \mathrm{E}-05$ & 0.0276 \\
\hline 2500 dir & $5.6024 \mathrm{E}-10$ & $1.2222 \mathrm{E}-05$ & 0.0429 \\
\hline 30001 & $2.4008 \mathrm{E}-10$ & $1.1779 \mathrm{E}-05$ & 0.0098 \\
\hline 30002 & $2.0658 \mathrm{E}-10$ & $1.1146 \mathrm{E}-05$ & 0.0089 \\
\hline 3000 dir & $2.1727 \mathrm{E}-10$ & $1.1249 \mathrm{E}-05$ & 0.0093 \\
\hline 35001 & $2.3563 \mathrm{E}-10$ & $1.1540 \mathrm{E}-05$ & 0.0098 \\
\hline 3500 dir & $2.8778 \mathrm{E}-10$ & $1.3051 \mathrm{E}-05$ & 0.0094 \\
\hline 40001 & $2.3770 \mathrm{E}-10$ & $1.1605 \mathrm{E}-05$ & 0.0098 \\
\hline 40002 & $1.9693 \mathrm{E}-10$ & $1.0642 \mathrm{E}-05$ & 0.0093 \\
\hline 40003 & $1.8719 \mathrm{E}-10$ & $1.0336 \mathrm{E}-05$ & 0.0102 \\
\hline 4000 dir & $2.3539 \mathrm{E}-10$ & $1.1662 \mathrm{E}-05$ & 0.0097 \\
\hline 45001 & $1.8536 \mathrm{E}-10$ & $1.0241 \mathrm{E}-05$ & 0.0097 \\
\hline 4500 dir & $1.8168 \mathrm{E}-10$ & $1.0103 \mathrm{E}-05$ & 0.0091 \\
\hline 50001 & $1.6651 \mathrm{E}-10$ & $9.7822 \mathrm{E}-06$ & 0.0093 \\
\hline 50002 & $1.7035 \mathrm{E}-10$ & $9.8649 \mathrm{E}-06$ & 0.0089 \\
\hline 5000 dir & $1.6745 \mathrm{E}-10$ & $9.6483 \mathrm{E}-06$ & 0.0091 \\
\hline 55001 & $1.7278 \mathrm{E}-10$ & $9.9173 \mathrm{E}-06$ & 0.0094 \\
\hline 5500 dir & $1.7672 \mathrm{E}-10$ & $9.8438 \mathrm{E}-06$ & 0.0092 \\
\hline 60001 & $1.6432 \mathrm{E}-10$ & $9.5434 \mathrm{E}-06$ & 0.0092 \\
\hline 60002 & $1.7200 \mathrm{E}-10$ & $9.8181 \mathrm{E}-06$ & 0.0089 \\
\hline 60003 & $1.7732 \mathrm{E}-10$ & $9.9680 \mathrm{E}-06$ & 0.0099 \\
\hline $6000 \mathrm{dir}$ & $1.8210 \mathrm{E}-10$ & $9.9817 \mathrm{E}-06$ & 0.0092 \\
\hline
\end{tabular}

A Figura 6.3 e a Figura 6.4 apresentam de forma gráfica os dados reordenados da tabela anterior. 

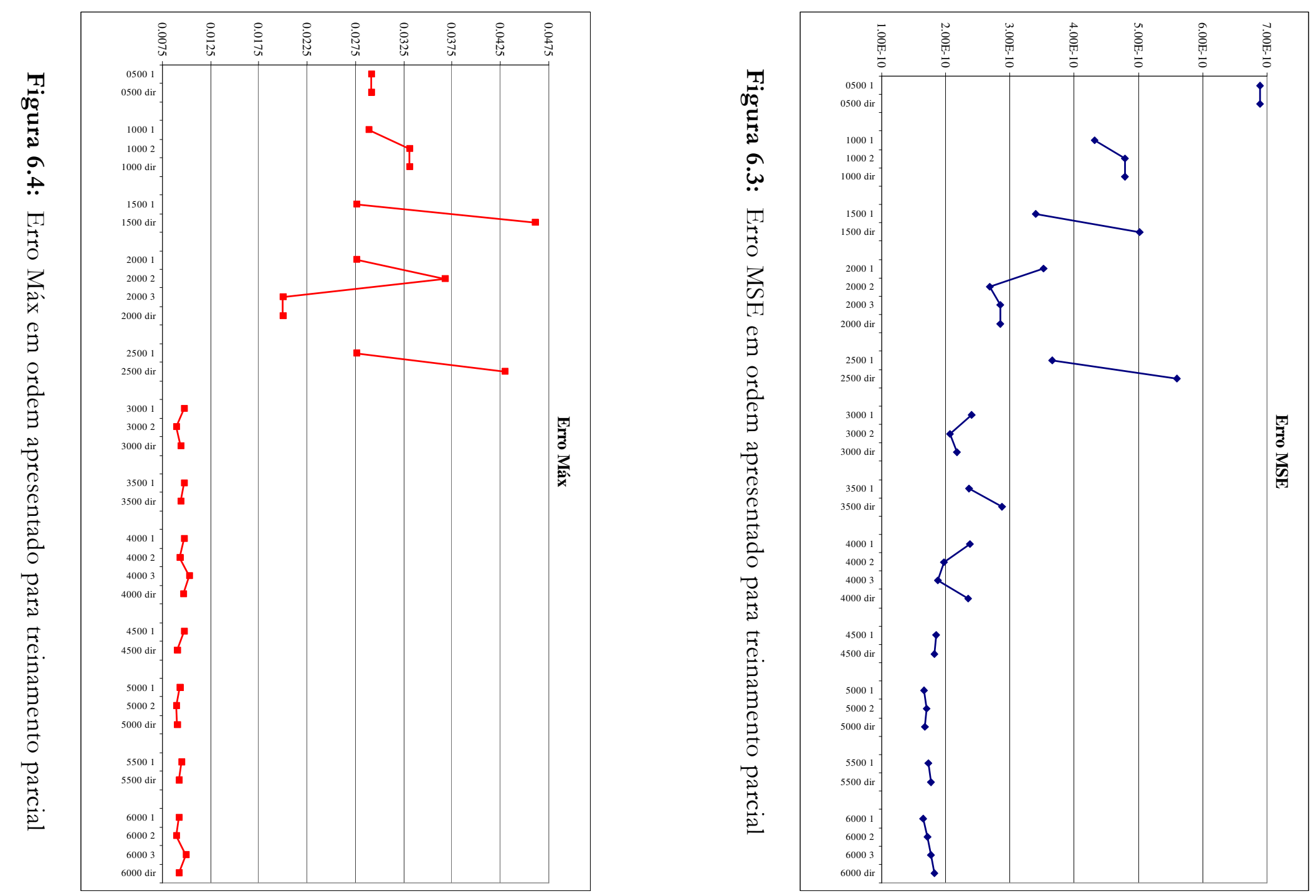
Analisando-se a Figura 6.3 e a Figura 6.4 pode-se observar claramente a redução exponencial do erro apresentado pela rede com o aumento do número de pontos e também a saturação deste valor para os conjuntos superiores a 5.000 pontos.

Porém, comparando-se os resultados obtidos para os treinamentos realizados com a mesma quantidade de pontos, mas de formas diferentes (diretamente ou em parciais de tamanhos diferentes) pode-se perceber que há grande variação do responsável pelo melhor resultado. Assim, pode-se dizer que para o treinamento realizado com 5.000 e 6.000 pontos os melhores resultados foram obtidos com o treinamento com parciais de 500, para o conjunto com 4.000 pontos a rede treinada com parciais de 2.000 apresenta resultados em muito superiores aos demais, para o conjunto com 5.500 pontos o melhor é o treinamento direto, e assim sucessivamente.

Deve-se ressaltar que todos estes treinamentos foram realizados em uma mesma rede neural cuja disposição inicial (inicialização) dos pesos foi armazenada. Isto evita o erro que se poderia ter se para algumas inicializações o erro obtido fosse menor em função de uma inicialização melhor.

Este fato de que não há um modo de treinamento melhor que os demais, adicionado ao de que a diferença entre estes resultados é, em geral, muito pequena reforça a idéia de que o treinamento parcial apresenta resultados tão bons quanto o treinamento direto. $\mathrm{O}$ que derruba o temor de que este treinamento poderia ficar preso em mínimos locais e perder frente ao treinamento direto que seria capaz de mover-se com maior liberdade em busca do mínimo global no espaço de erro.

Portanto, deste estudo pode-se concluir que: primeiro que o treinamento parcial apresenta resultados satisfatórios, o que será importante nas etapas futuras, e segundo que a rede utilizada a partir daqui será treinada com 5.000 pontos (o que garante boa precisão) e treinada de forma direta, pois é mais rápido e apresenta resultado semelhante aos parciais. 


\subsection{Dados "reais" para validação}

Até o presente momento, dedicou-se esforços para a obtenção de um sensor capaz de estimar a composição do segundo componente mais leve de uma coluna de destilação real, baseando seu treinamento unicamente em dados de um simulador dinâmico (modelo matemático) da mesma coluna.

Este estudo tem como objetivo principal o desenvolvimento de um sensor que poderia operar em um processo no qual não está disponível um conjunto significativo de dados histórico de operação da unidade. Outra possibilidade poderia ser no caso de uma unidade nova, em que o sensor de composição precisa estar disponível para operar junto com o início da nova planta. Para ambos os casos justifica-se o desenvolvimento do sensor baseado apenas em dados de um modelo simulado e depois, com o passar do tempo e conforme estiverem disponíveis dados reais da planta, seria realizado o retreinamento do mesmo.

Entretanto, deve-se garantir que o sensor desenvolvido apresente boa precisão e confiabilidade para a operação. Além de que haja em paralelo algum sistema tradicional de avaliação da composição, mesmo com intervalo de medição de periodicidade bem maior, para permitir aferir o funcionamento do sensor neste começo de operação.

Uma vez que tenha sido obtido o sensor de composição com precisão de acordo com o esperado, com relação aos dados do simulador, passa-se ao passo seguinte que será a validação do mesmo para um conjunto de dados da operação real.

Para levar em conta os erros que um simulador dinâmico pode apresentar optou-se por coletar os dados para a identificação do simulador de coluna disponível, mas foram feitas pequenas alterações, explicadas a seguir, quando se coletam os dados como se fossem de uma planta real. 
Para simular os dados reais de uma unidade foram realizadas quatro alterações no simulador, com o intuito de alterar um pouco o modo de operação do mesmo. Uma das alterações introduzidas foi um aumento do coeficiente de eficiência da troca de calor entre líquido e vapor nos pratos, conhecido como coeficiente de Murphree. Foi realizado um aumento de 20\% nesta variável considerando que seu valor é de difícil estimação e depende fortemente da estrutura da coluna e do modo de realização das trocas líquido-vapor. Esta alteração afeta o modo de variação da composição nos pratos, alterando a forma da curva de resposta da coluna.

Outra alteração introduzida foi na composição da alimentação de entrada. Foi realizada uma diminuição de $5 \%$ na concentração do componente 2 na fase líquida que entra na coluna e aumentada a do componente 3; para a fase vapor também foi realizada uma diminuição da concentração do componente 2 e aumentada a do componente 1. Esta alteração tem efeito no sentido de diminuir a concentração do componente 2 por toda a coluna, alterando a média do sinal de forma diferente para cada prato.

Esta segunda alteração baseou-se no fato de que o sensor desenvolvido não recebe informações sobre a composição da mistura que entra na coluna. Considera-se que este valor varia pouco ao longo do tempo, uma vez que o produto a ser destilado é considerado bastante homogêneo, por estar armazenado em grandes reservatórios e é relativamente uniforme devido à origem comum. Porém, o sensor será testado recebendo um produto com composição diferente daquela com que foi treinado.

Finalmente, a terceira alteração foi a introdução de ruído com distribuição normal nos sinais coletados. Para deixar os dados mais realistas foram introduzidos dois tipos de ruídos nos dados: ruído de medição e do processo. O primeiro deles simula a imprecisão no sensor de coleta dos dados e foi introduzido nas variáveis medidas (temperaturas, vazões e quantidade de calor). Este ruído introduzido possui amplitude diferente para cada variável, de acordo com a precisão de cada tipo 
de medidor. Sendo, portanto, maior para os medidores de vazão (1\%) e menor para os medidores de temperatura $(0,5 \%)$.

Também foi introduzido ruído com distribuição normal na variável de saída da coluna, isto é, a composição do componente 2 no topo. Este ruído visa simular as variações que ocorrem no processo durante a sua operação. Deste modo, tem-se que a resposta da planta para uma variação na condição de operação não é isenta de ruído, mas sim cheia de pequenas variações. O ruído utilizado possui média zero e variância de $1,45 \cdot 10^{-4}$.

Uma última alteração realizada foi quanto à amplitude da variação das entradas medidas. Durante a coleta dos dados impõe-se um regime forçado de variação nas variáveis manipuladas buscando fazer com que o simulador opere em diversas condições em um tempo reduzido. Para a coleta dos dados nesta etapa foi realizada uma variação equivalente a $50 \%$ da amplitude do sinal no conjunto de dados coletados para o treinamento do sensor.

A Figura 6.5 apresenta o histograma dos dados utilizados para o treinamento do sensor e os dados coletados para a sua validação após as alterações. 


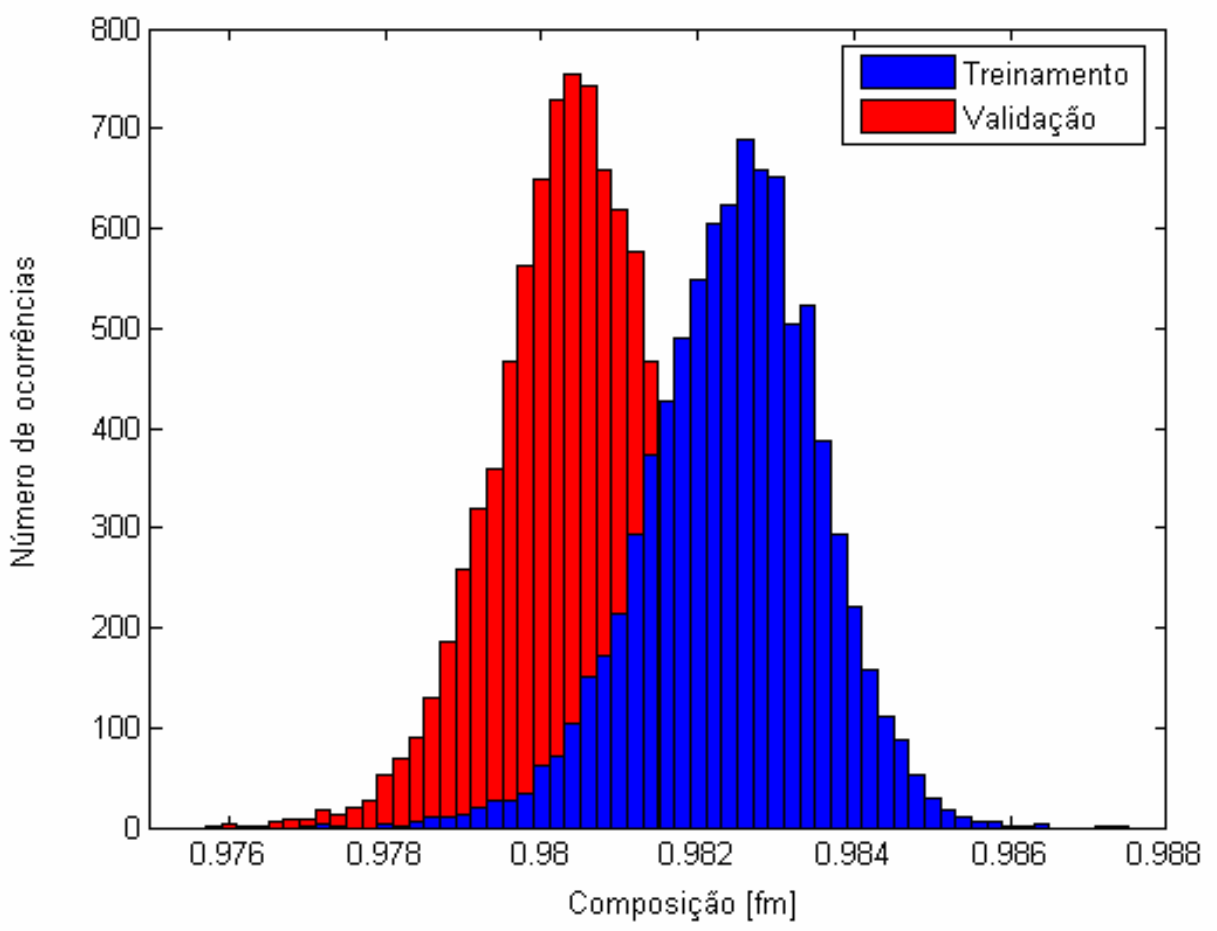

Figura 6.5: Histogramas da composição do componente 2 no topo

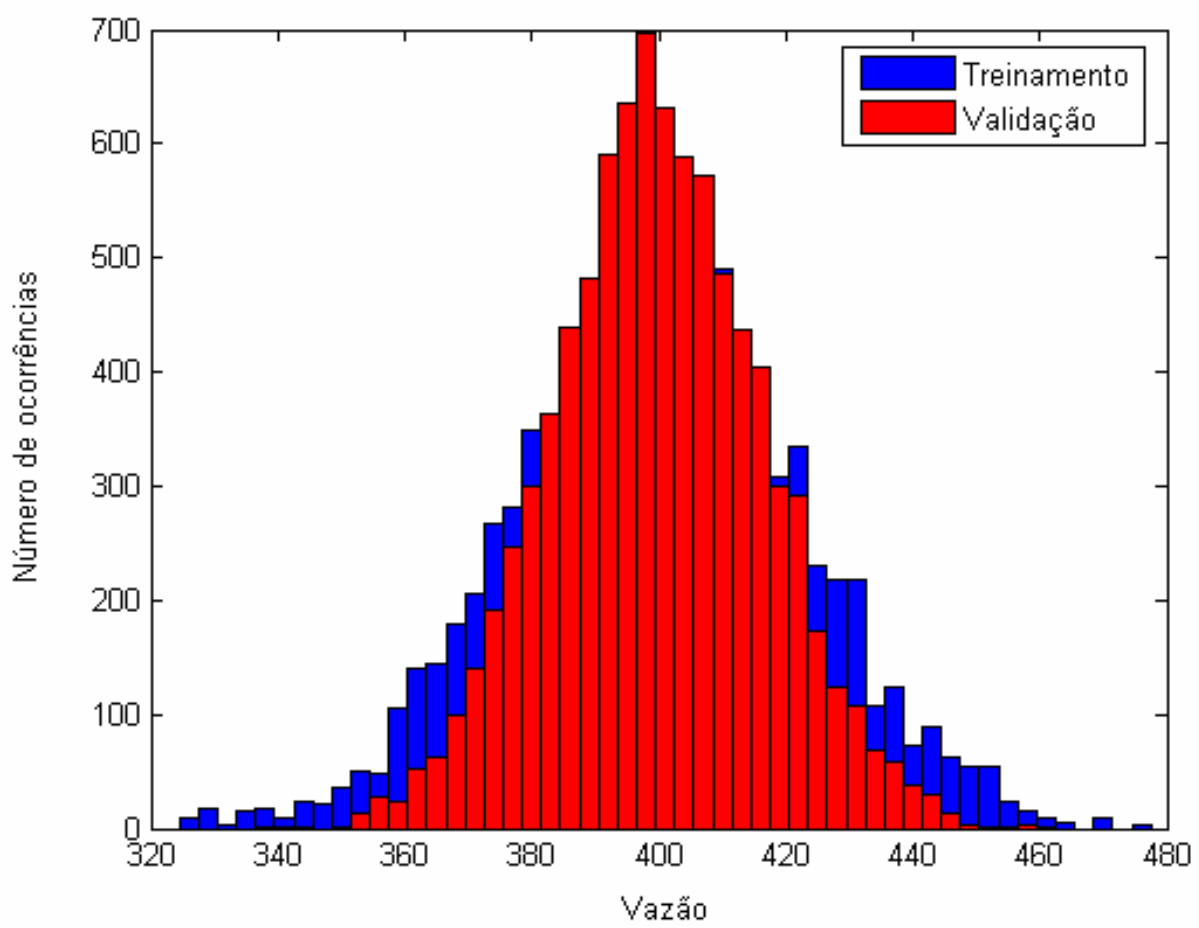

Figura 6.6: Histogramas da vazão de refluxo na coluna 


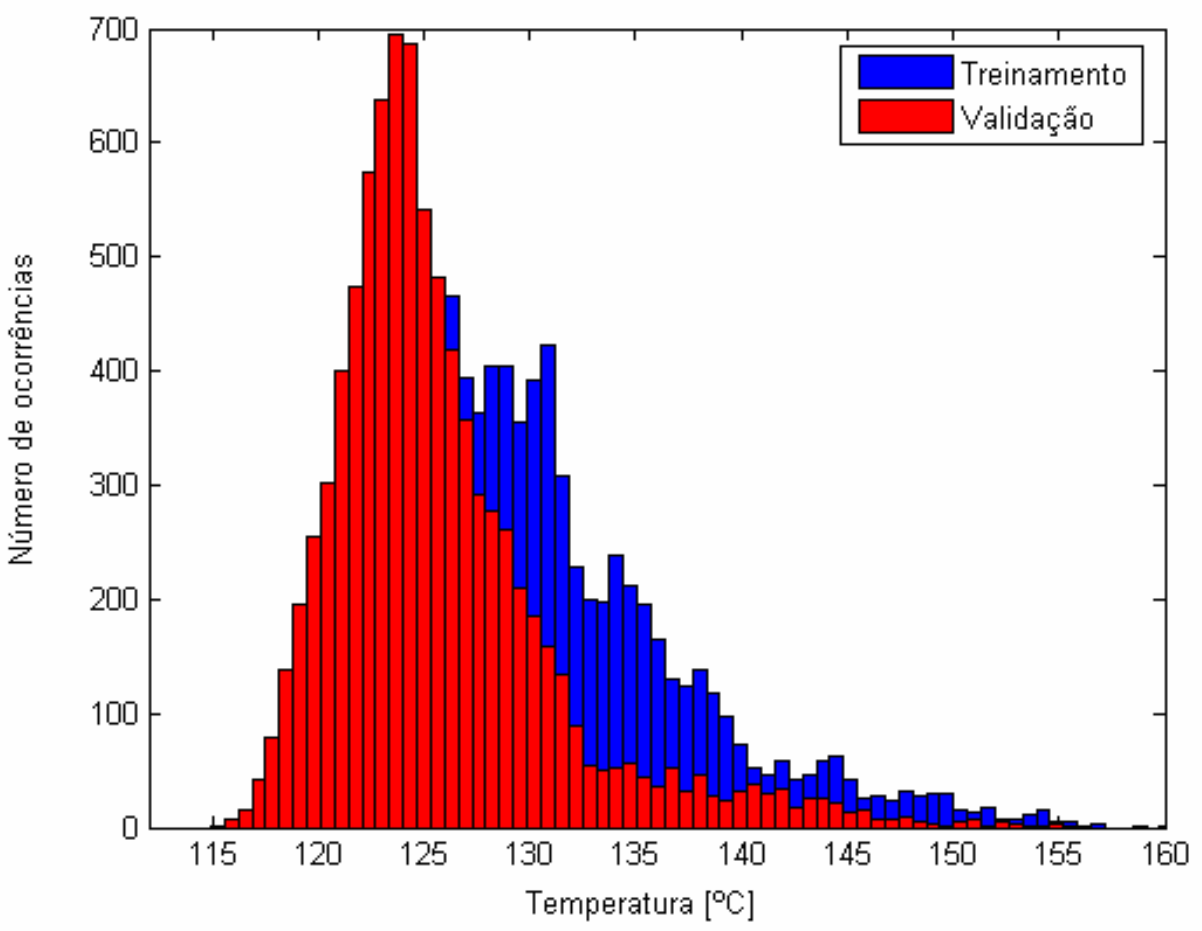

Figura 6.7: Histogramas da temperatura no prato 3

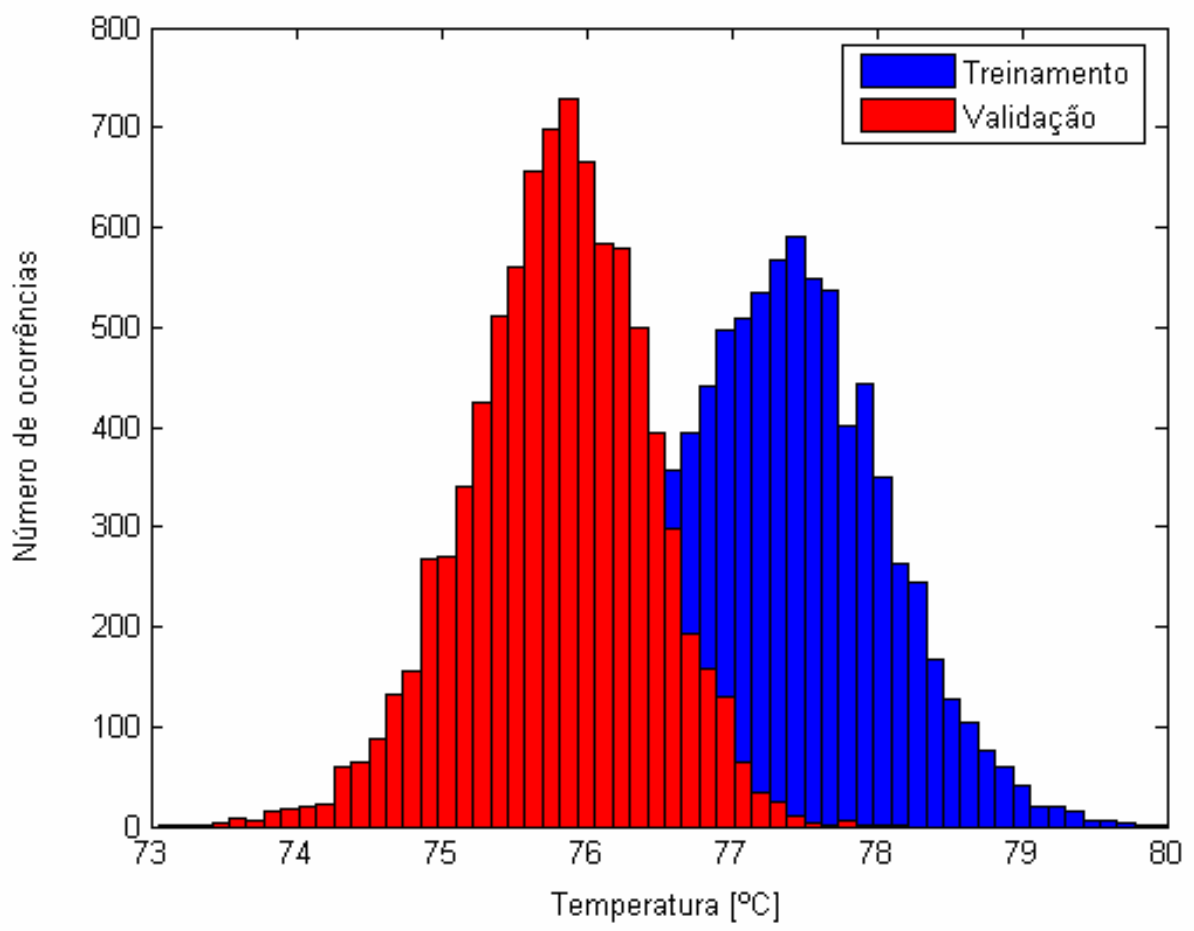

Figura 6.8: Histogramas da temperatura no condensador 


\subsection{Operação do sensor com dados "reais"}

Após toda a pesquisa realizada nos capítulos anteriores, chegou-se a um sensor que após o treinamento com 5.000 pontos oriundos de um simulador dinâmico apresenta um erro bastante pequeno para os dados de simulação. Pode-se concluir, portanto, que foi alcançado o objetivo de desenvolver um sensor virtual capaz de estimar a composição futura para uma coluna de destilação simulada.

Porém, qual será o funcionamento deste sensor quando o conjunto de dados apresentado for diferente do qual foi treinado? E se estes dados contiverem ruído? Estas questões serão esclarecidas nesta seção.

Como critério de comparação vejamos primeiro os resultados obtidos para o treinamento do sensor com o conjunto de 5.000 pontos oriundos do simulador dinâmico inicial e depois compará-los com os dados do novo conjunto gerados na seção anterior.

A Figura 6.9 mostra a convergência do desempenho do sensor durante o treinamento. O erro apresenta grande redução saindo de uma condição de erro da ordem de $10^{-1}$ e chegando a um erro MSE de $10^{-11}$. 


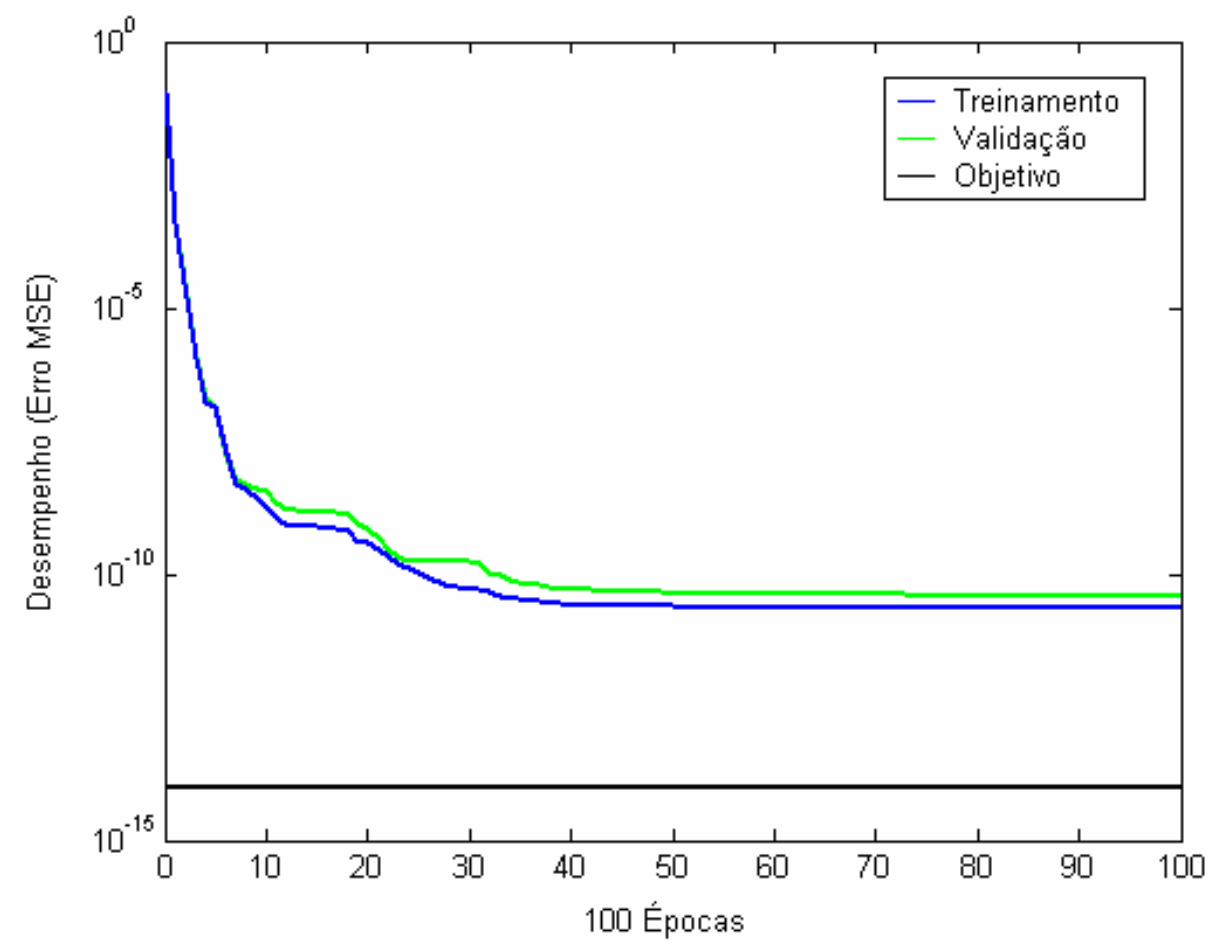

Figura 6.9: Gráfico do desempenho durante o treinamento do sensor virtual

Dois fatos devem ser ressaltados: o primeiro é que esta rede foi escolhida como mostrado anteriormente, e onde se priorizou a busca por uma rede com erro MSE pequeno após o treinamento. Lembrando que algumas redes podem não convergir ou convergir para mínimos locais não satisfatórios devido a uma má combinação dos pesos na inicialização da rede.

O segundo fato é que esta rede e seus pesos iniciais foram armazenados antes do treinamento ocorrer. Mais à frente será treinada com os dados modificados, porém, sem o treinamento prévio com os dados do simulador dinâmico.

A Figura 6.10 mostra o erro percentual apresentado pelo sensor após o treinamento com os dados do simulador. Esta diferença foi obtida entre o valor estimado pelo sensor após o treinamento e o valor esperado, fornecido pelo simulador. 


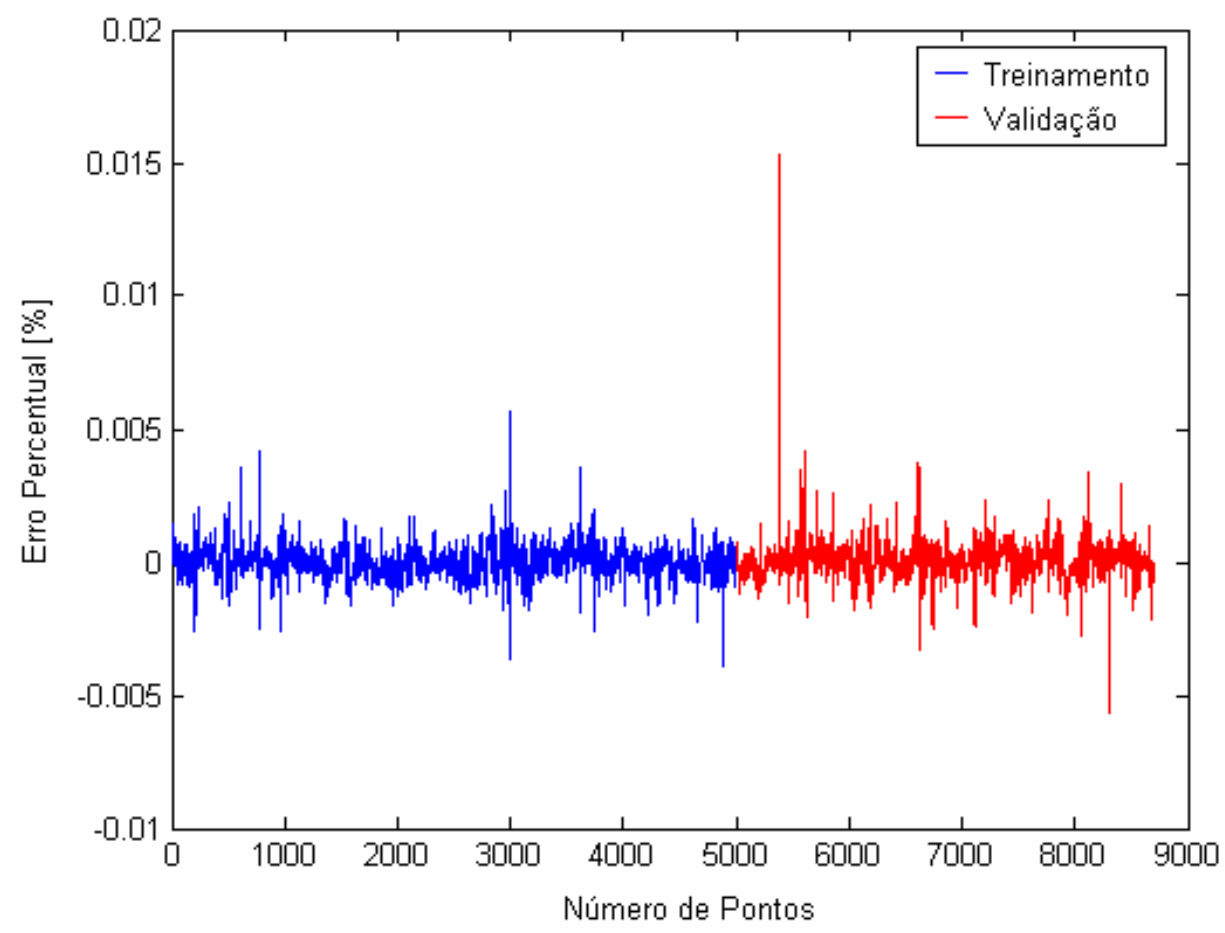

Figura 6.10: Erro percentual entre os valores estimado e esperado

Na Figura 6.10 pode-se ver que a primeira região (em cor azul), é o erro obtido pela diferença entre os dados utilizados no treinamento e os estimados pelo sensor para o mesmo conjunto. $\mathrm{Na}$ segunda região (em cor vermelha), os dados não foram apresentados ao sensor durante o seu treinamento (validação cruzada).

A Figura 6.11 e a Figura 6.12 apresentam as curvas das composições, nas quais aparece o erro visto na figura anterior para cada uma das regiões de dados. 


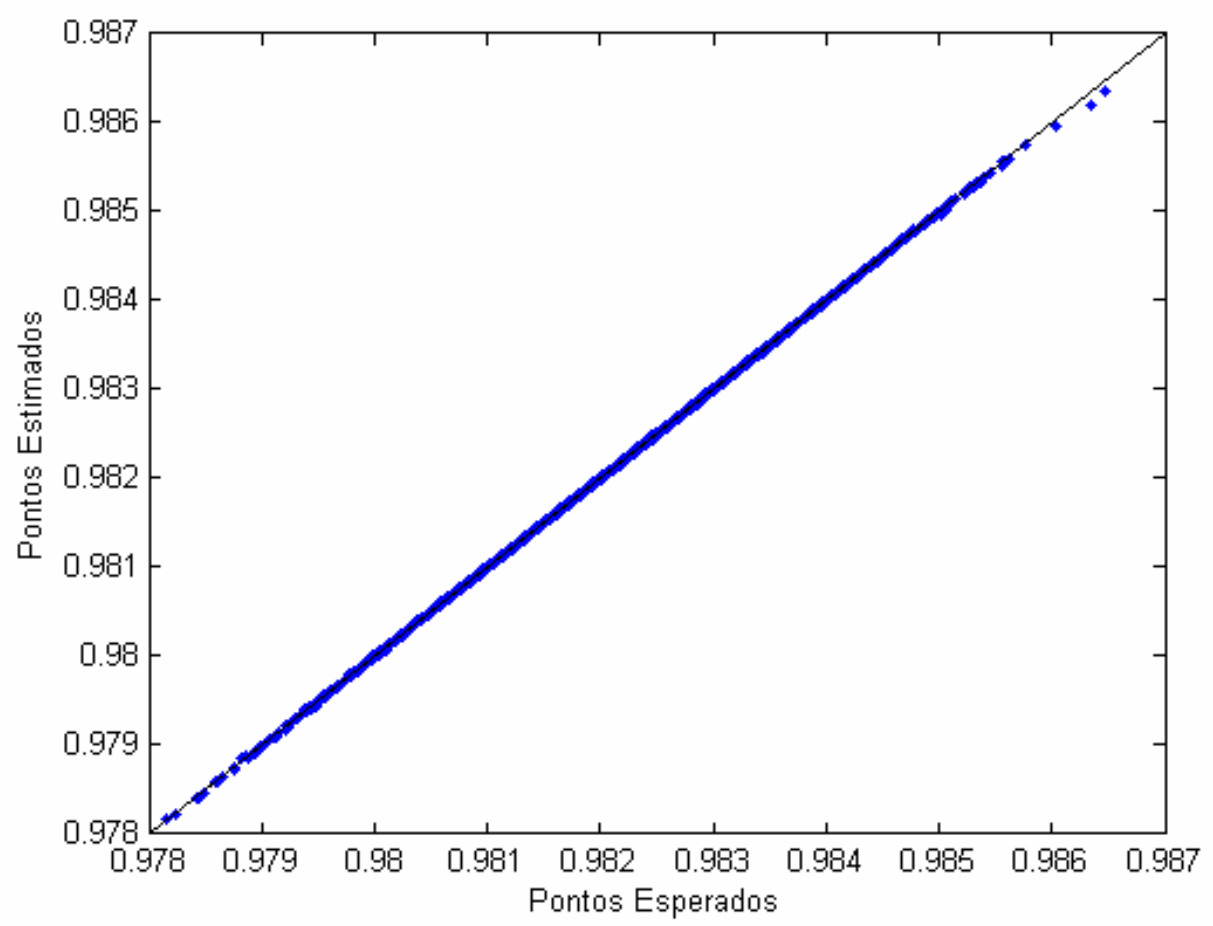

Figura 6.11: Dispersão dos dados estimados pelo sensor e esperados

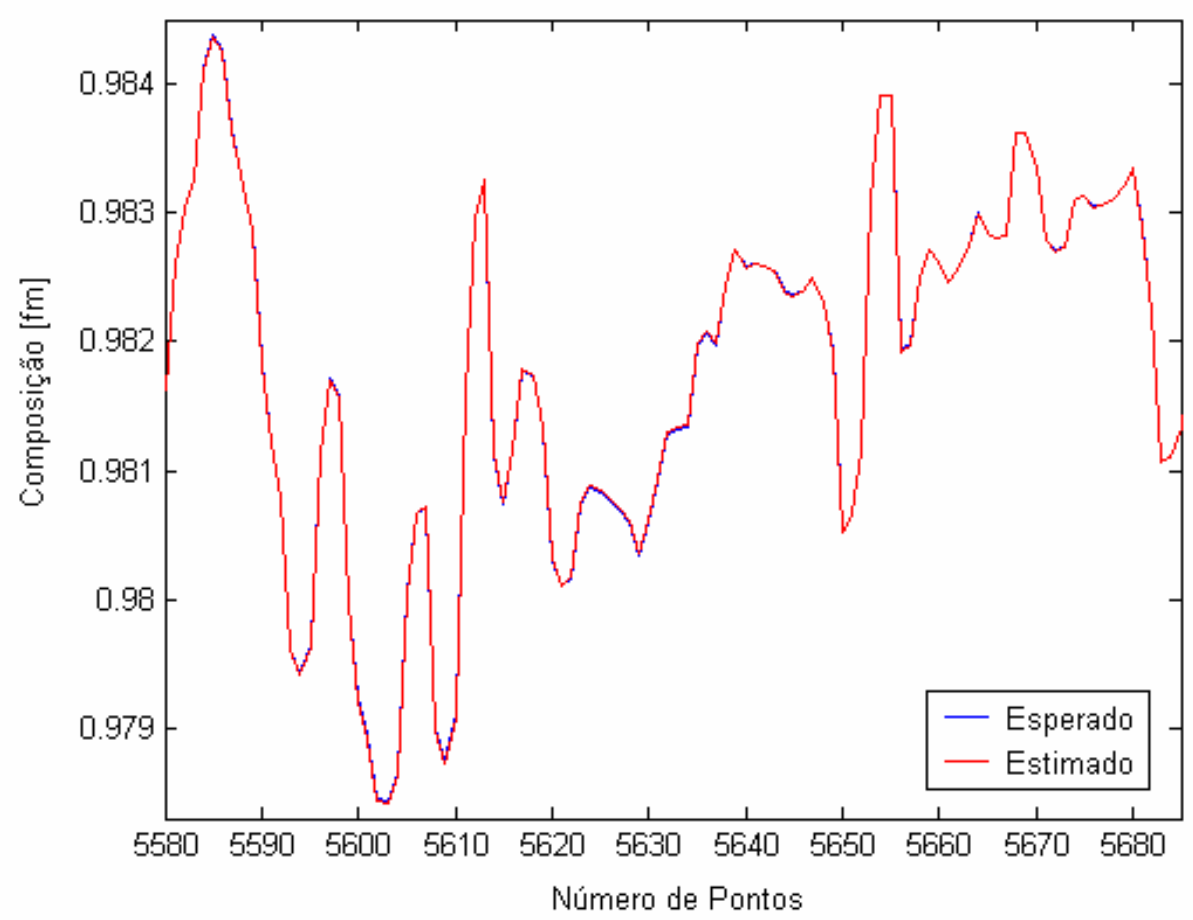

Figura 6.12: Valor estimado pelo sensor e esperado fornecido pelo simulador 
Comparando-se as diferenças entre as curvas na figura anterior pode-se observar que a diferença é mínima, o que mostra que o treinamento apresentou ótima convergência (erro MSE de 2,8.10 $0^{-11}$ ) para os dados de treinamento e também para

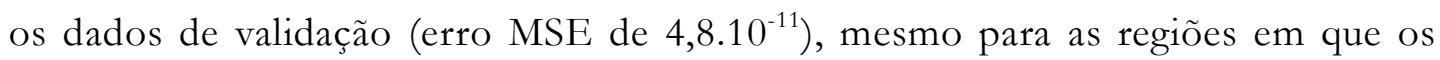
erros são maiores. Este fato mostra que o treinamento foi muito bem sucedido, a rede apreendeu os padrões necessários e não houve especialização no conjunto de treinamento.

Agora, vejamos o desempenho do sensor treinado quando lhe são apresentados dados de um processo ligeiramente diferente.

A Tabela 6.3 apresenta de forma comparativa os erros calculados para as respostas do sensor durante a validação cruzada para os dados provenientes da mesma fonte de treinamento (porém, não apresentados no treinamento) e dados originados de um processo diferente.

Tabela 6.3: Quadro resumo dos erros para as duas avaliações

\begin{tabular}{|c|c|c|c|}
\cline { 2 - 4 } \multicolumn{1}{c|}{} & Erro MSE & Erro MAE & Erro Máx \\
\hline Dados Simulador & $4,8243 \cdot 10^{-11}$ & $4,3631 \cdot 10^{-6}$ & 0,0153 \\
\hline Dados Modificados & $2,3569 \cdot 10^{-8}$ & $1,2231 \cdot 10^{-4}$ & 0,0701 \\
\hline
\end{tabular}

Analisando-se a tabela pode-se perceber que houve um aumento significativo (da ordem de $10^{3}$ para o erro MSE e de $10^{2}$ para o erro MAE), o que mostra que o sensor ainda consegue uma boa capacidade estimativa, porém bem inferior à apresentada anteriormente.

A Figura 6.13 mostra as curvas dos valores estimados pelo sensor e esperados gerados pelo simulador dinâmico modificado. A Figura 6.14 resume os valores do erro entre as duas curvas para mais de 37.000 dados. 


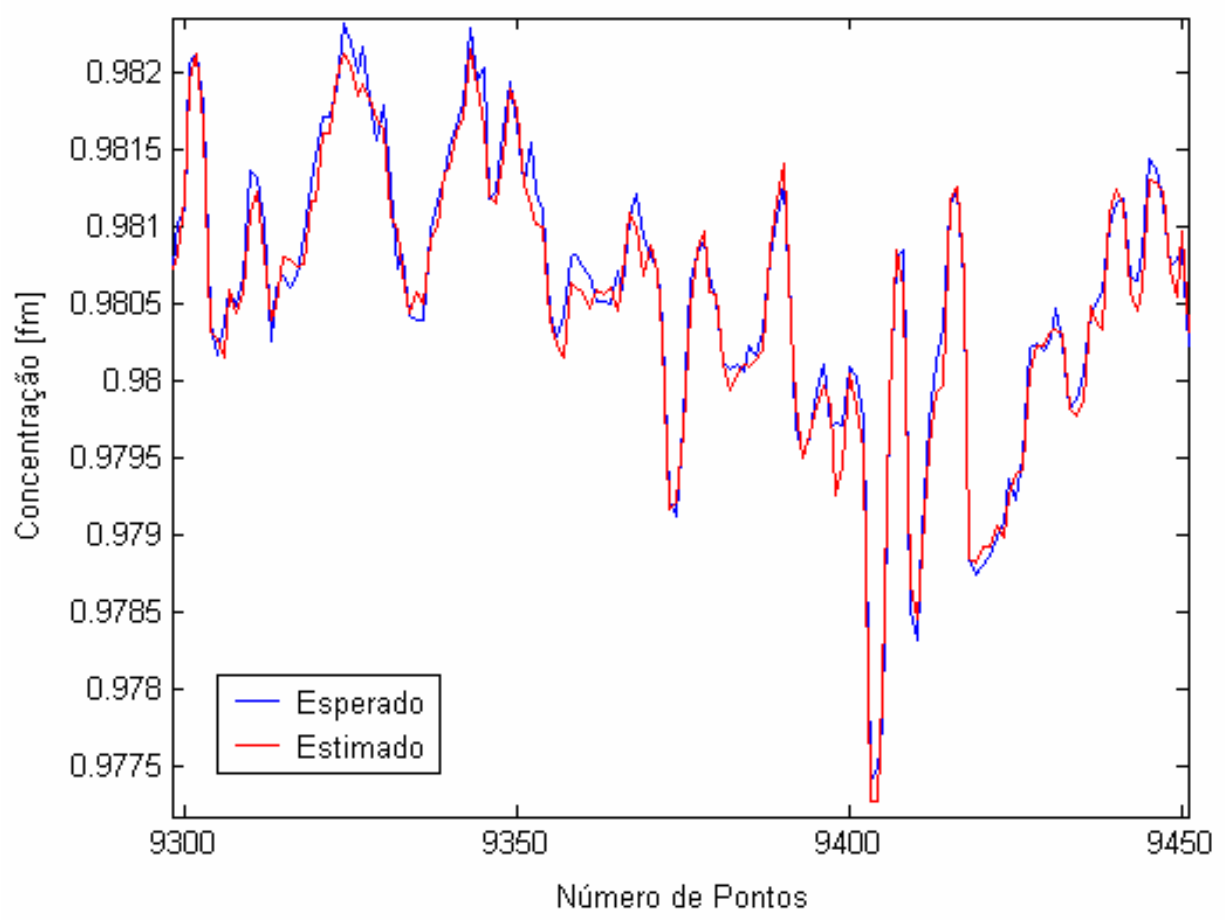

Figura 6.13: Valor estimado pelo sensor e esperado

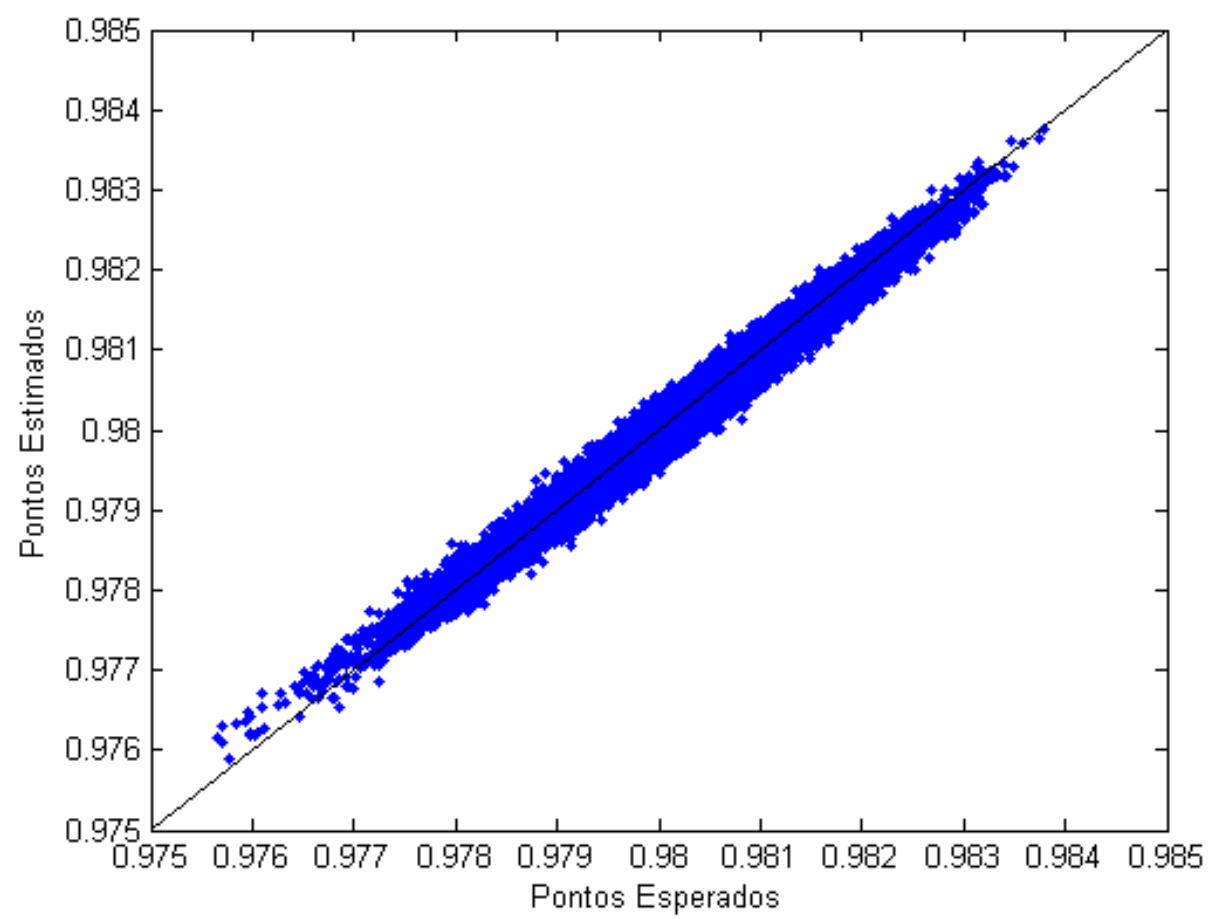

Figura 6.14: Erro percentual entre os valores estimado e esperado 
Observando-se a Figura 6.13 pode-se reparar que o sensor acompanha muito bem as tendências apresentadas pelo simulador, porém apresenta erro maior nos limites extremos. Pode-se observar da Figura 6.14 que o erro apresentado é bastante homogêneo, não havendo regiões onde este seja maior, mesmo para uma grande faixa de tempo (número de pontos). Isto mostra que o treinamento realizado anteriormente foi bastante abrangente.

A proposta é que este sensor já possa ser utilizado para estimação na planta sendo treinado apenas com os dados oriundos de um simulador dinâmico do processo. Porém, com o passar do tempo pode haver disponibilidade de um histórico de dados de situações conhecidas em que se coletaram dados confiáveis do processo e estes podem ser utilizados para melhorar o desempenho do sensor, como será visto no próximo item.

\subsection{Retreinamento da rede}

A última etapa acrescentada é um aperfeiçoamento do sensor, no sentido de ajustá-lo com maior precisão às condições reais da coluna de destilação com a qual está operando.

Para realizar este ajuste a rede neural será treinada novamente com um pequeno conjunto de dados proveniente do histórico de operação do processo que se busca identificar. Espera-se com isto que o sensor reduza o erro gerado, aumentando a sua acuidade, pois apreenderá padrões ligeiramente diferentes daqueles com que foi treinado.

Paralelamente a isto, um outro ensaio será realizado, em que a mesma rede neural também será treinada a partir de uma condição em que não foi previamente treinada com nenhum conjunto de dados proveniente do simulador dinâmico da 
coluna. Com isto espera-se comparar os dois métodos de treinamento de modo mais eficiente.

Destaca-se ainda um problema que pode vir a ocorrer, que é o fato da rede neural nova (não treinada com dados do simulador) apresentar uma combinação dos pesos iniciais deficiente que a faria convergir para um mínimo local com erro alto. Para resolver este problema e aumentar a qualidade da comparação dos resultados será utilizada a mesma rede neural com os mesmos valores de inicialização.

Em seguida foram realizados os treinamentos, que podem ser vistos na Tabela 6.4. Três situações foram contempladas. A primeira consiste em retreinar o sensor após um breve tempo de operação, quando estiverem disponíveis apenas 100 pontos coletados do processo, e repetir o treinamento a cada 100 novos pontos disponibilizados, até os primeiros 600 pontos. O erro calculado leva em consideração mais de 37.000 pontos do processo, o que equivale a aproximadamente 15 horas da operação com perturbações impostas nos sinais de entrada.

A segunda situação consiste em retreinar o sensor a cada conjunto de 250 pontos. Aumentando-se o conjunto de pontos do treinamento inicial, melhora o desempenho da rede treinada a partir do zero, pois esta possuirá um maior conjunto de dados para apreender os padrões. Finalmente, foi repetido o processo para conjuntos de 500 pontos. Estas duas últimas situações foram repetidas até 2.000 pontos, o que deve ser suficiente para que a rede sem treinamento convirja para um erro pequeno. A coleta de um maior número de pontos torna-se menos praticável, uma vez que há grande dificuldade, como vimos no capítulo 1, para coletarmos estes dados, sendo necessário normalmente a utilização de análises laboratoriais. 
Tabela 6.4: Quadro comparativo dos retreinamentos do sensor

\begin{tabular}{|c|c|c|c|}
\hline Pontos & Erro MSE & Erro MAE & Erro Máx \\
\hline \multicolumn{4}{|c|}{ Treinamento Parciais 100} \\
\hline 100 & $2.2121 \mathrm{E}-08$ & $1.1786 \mathrm{E}-04$ & 0.0762 \\
\hline 200 & 2.2134E-08 & 1.1789E-04 & 0.0762 \\
\hline 300 & $2.2140 \mathrm{E}-08$ & $1.1791 \mathrm{E}-04$ & 0.0762 \\
\hline 400 & 2.1001E-08 & $1.1535 \mathrm{E}-04$ & 0.0697 \\
\hline 500 & 2.0875E-08 & $1.1525 \mathrm{E}-04$ & 0.0674 \\
\hline 600 & 2.0648E-08 & $1.1460 \mathrm{E}-04$ & 0.0654 \\
\hline \multicolumn{4}{|c|}{ Treinamento Parciais 100 (nova) } \\
\hline 100 & $4.2581 \mathrm{E}-06$ & $9.8785 \mathrm{E}-04$ & 7.2900 \\
\hline 200 & 4.2675E-06 & $9.8868 \mathrm{E}-04$ & 7.2900 \\
\hline 300 & $6.9528 \mathrm{E}-06$ & $1.0142 \mathrm{E}-03$ & 10.2646 \\
\hline 400 & 2.9425E-08 & $1.2947 \mathrm{E}-04$ & 0.2580 \\
\hline 500 & 2.5921E-08 & $1.2321 \mathrm{E}-04$ & 0.2268 \\
\hline 600 & 2.5933E-08 & $1.2323 \mathrm{E}-04$ & 0.2268 \\
\hline \multicolumn{4}{|c|}{ Treinamento Parciais 250 } \\
\hline 250 & $2.3281 \mathrm{E}-08$ & $1.1911 \mathrm{E}-04$ & 0.1139 \\
\hline 500 & 2.0870E-08 & $1.1517 \mathrm{E}-04$ & 0.0653 \\
\hline 750 & 2.0195E-08 & $1.1325 \mathrm{E}-04$ & 0.0674 \\
\hline 1000 & 2.0219E-08 & $1.1331 \mathrm{E}-04$ & 0.0674 \\
\hline 1250 & 2.0193E-08 & $1.1326 \mathrm{E}-04$ & 0.0674 \\
\hline 1500 & $1.9835 \mathrm{E}-08$ & $1.1225 \mathrm{E}-04$ & 0.0630 \\
\hline 1750 & 1.9793E-08 & $1.1213 \mathrm{E}-04$ & 0.0622 \\
\hline 2000 & $1.9784 \mathrm{E}-08$ & $1.1213 \mathrm{E}-04$ & 0.0629 \\
\hline \multicolumn{4}{|c|}{ Treinamento Parciais 250 (nova) } \\
\hline 250 & $8.4866 \mathrm{E}-05$ & $1.7254 \mathrm{E}-03$ & 29.3787 \\
\hline 500 & 8.5074E-05 & $1.7217 \mathrm{E}-03$ & 29.3787 \\
\hline 750 & 2.4842E-08 & $1.2232 \mathrm{E}-04$ & 0.1675 \\
\hline 1000 & 2.4749E-08 & $1.2218 \mathrm{E}-04$ & 0.1675 \\
\hline 1250 & 2.4683E-08 & $1.2208 \mathrm{E}-04$ & 0.1675 \\
\hline 1500 & $2.4706 \mathrm{E}-08$ & $1.2214 \mathrm{E}-04$ & 0.1675 \\
\hline 1750 & 2.4584E-08 & $1.2132 \mathrm{E}-04$ & 0.3604 \\
\hline 2000 & 2.3442E-08 & $1.2003 \mathrm{E}-04$ & 0.1932 \\
\hline \multicolumn{4}{|c|}{ Treinamento Parciais 500 } \\
\hline 500 & $2.1153 \mathrm{E}-08$ & $1.1602 \mathrm{E}-04$ & 0.0660 \\
\hline 1000 & $1.9986 \mathrm{E}-08$ & $1.1269 \mathrm{E}-04$ & 0.0605 \\
\hline 1500 & 1.9973E-08 & $1.1269 \mathrm{E}-04$ & 0.0605 \\
\hline 2000 & $1.9985 \mathrm{E}-08$ & $1.1275 \mathrm{E}-04$ & 0.0605 \\
\hline \multicolumn{4}{|c|}{ Treinamento Parciais 500 (nova) } \\
\hline 500 & $1.0232 \mathrm{E}-05$ & $3.1913 \mathrm{E}-04$ & 18.0040 \\
\hline 1000 & 3.1935E-08 & $1.3051 \mathrm{E}-04$ & 0.8580 \\
\hline 1500 & 2.2065E-08 & $1.1684 \mathrm{E}-04$ & 0.3532 \\
\hline 2000 & 2.2109E-08 & $1.1697 \mathrm{E}-04$ & 0.3532 \\
\hline
\end{tabular}


Analisando-se a tabela pode-se percebe que para as três situações apresentadas a rede neural já previamente treinada com os dados do simulador, sempre apresenta os três erros calculados menores que a outra. Isto ocorre porque a rede já conhece previamente um processo similar ao real, tanto que a redução que o erro apresenta é pequena com o passar do tempo.

A rede sem treinamento prévio apresenta para as três situações um erro grande no início e depois de certo número de treinamentos consegue apreender alguns padrões e o erro apresenta uma drástica redução.

A Figura 6.15 apresenta o erro obtido entre a resposta estimada pelo sensor sem treinamento prévio após ter sido treinado com 200 pontos e o valor esperado oriundo do processo. As Figura 6.16 mostra os valores esperado e estimado pelo sensor e a Figura 6.17 exibe em detalhe uma região.

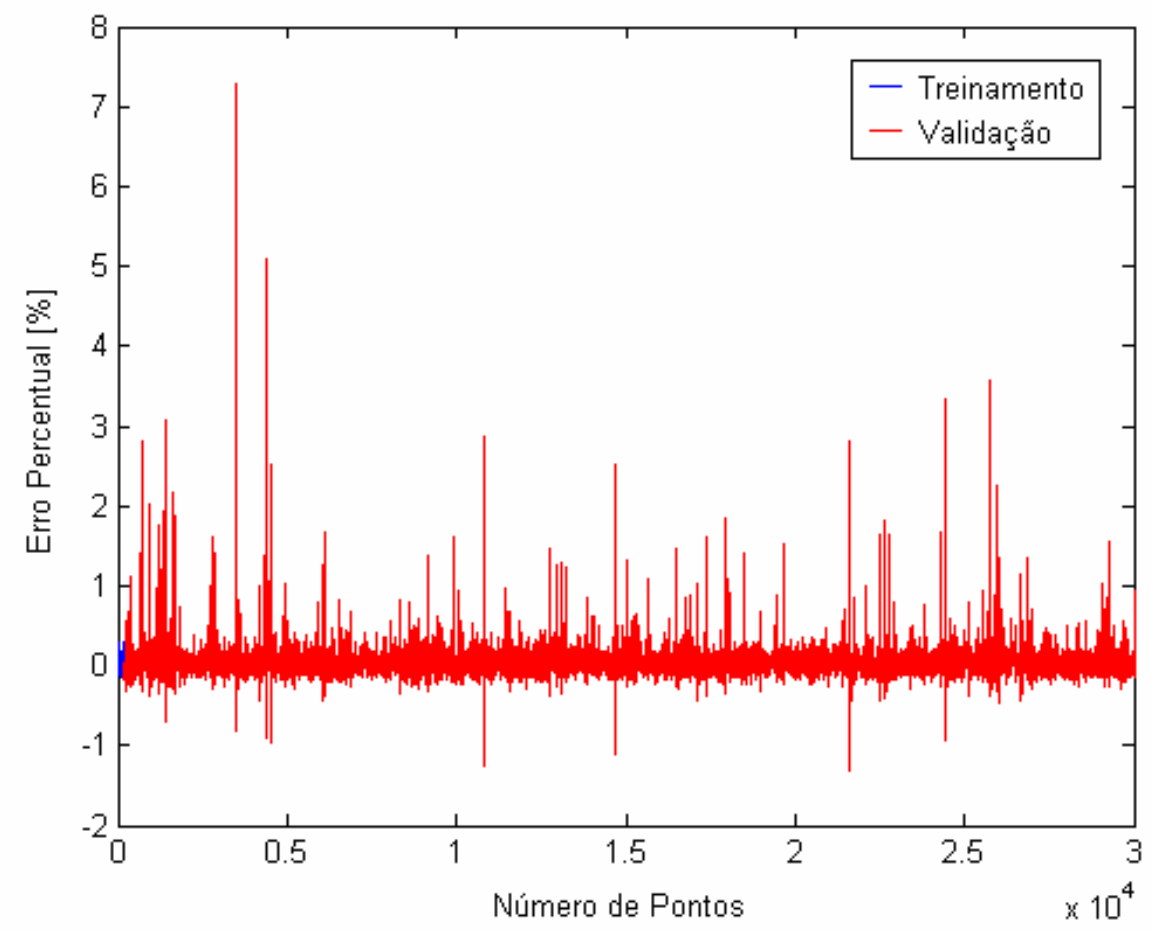

Figura 6.15: Erro apresentado pelo sensor sem treinamento prévio 


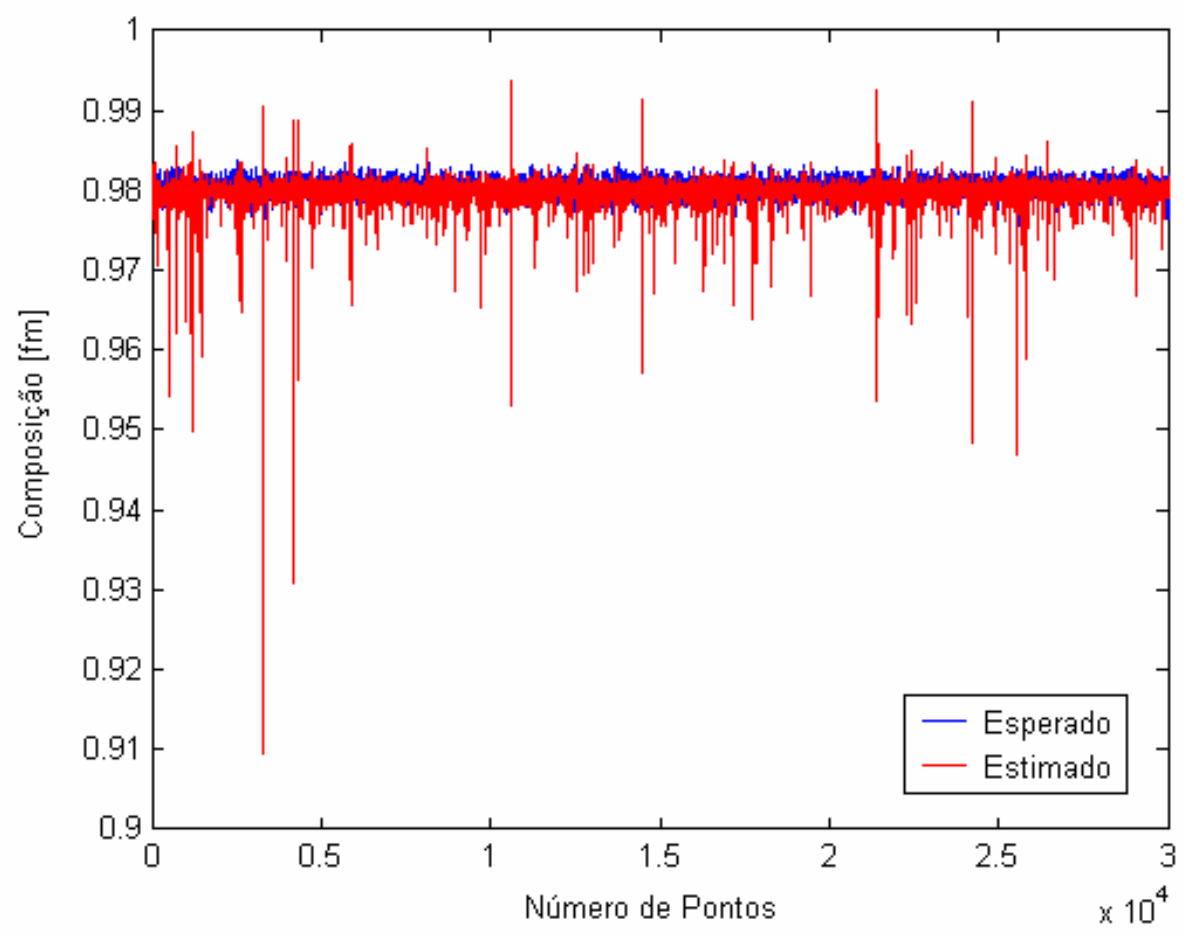

Figura 6.16: Resultados apresentados pelo sensor sem treinamento prévio

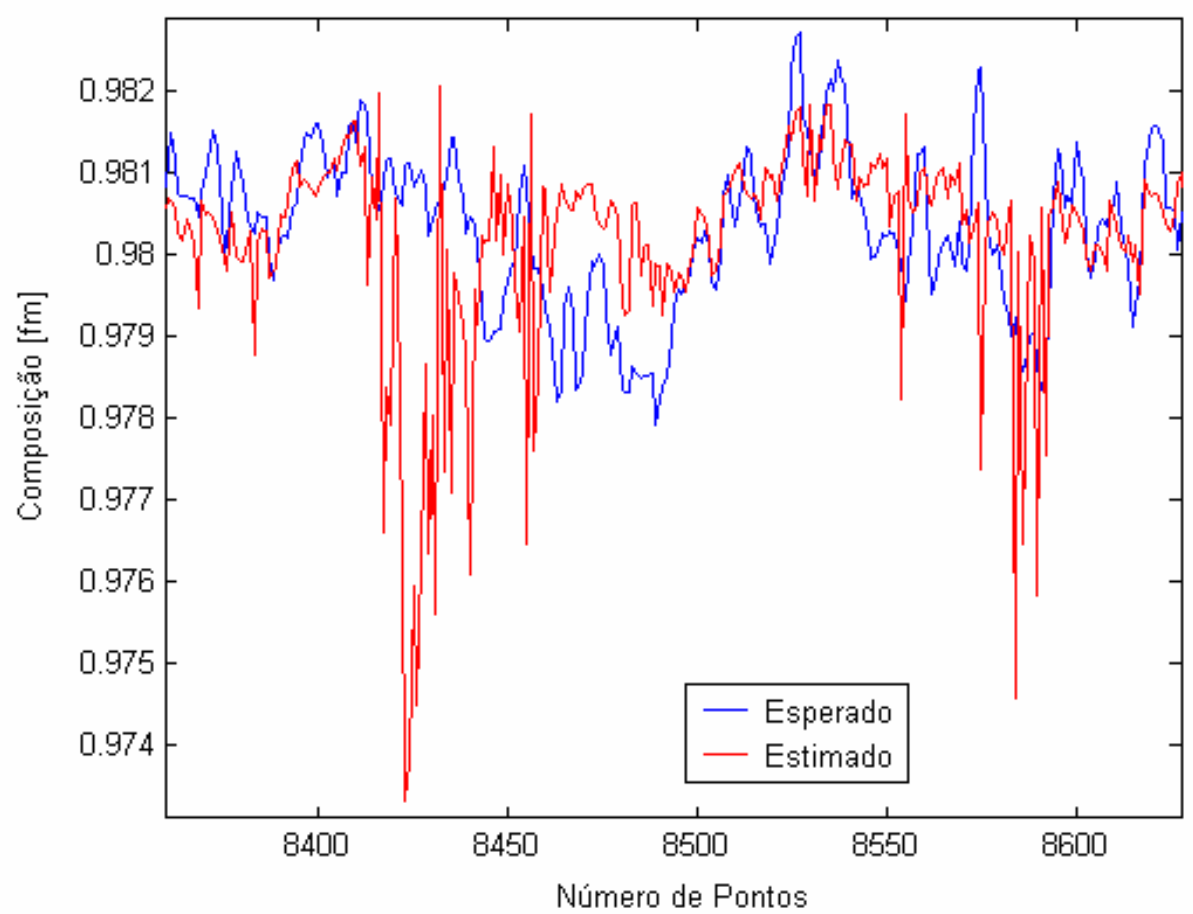

Figura 6.17: Detalhe dos resultados apresentados pelo mesmo sensor 
Pode-se ver que o sensor em alguns momentos apresenta grande erro nos valores estimados, o que ocorre devido ao pequeno número de pontos (apenas 200) apresentado no treinamento deste. Portanto pode-se concluir que a rede ainda não conseguiu apreender os padrões necessários para estimar com precisão

A Figura 6.18 apresenta o gráfico da dispersão obtida entre os dados esperados (fornecidos pelo simulador alterado) e os dados estimados pelo sensor após treinamento com 200 pontos para o conjunto de dados de treinamento.

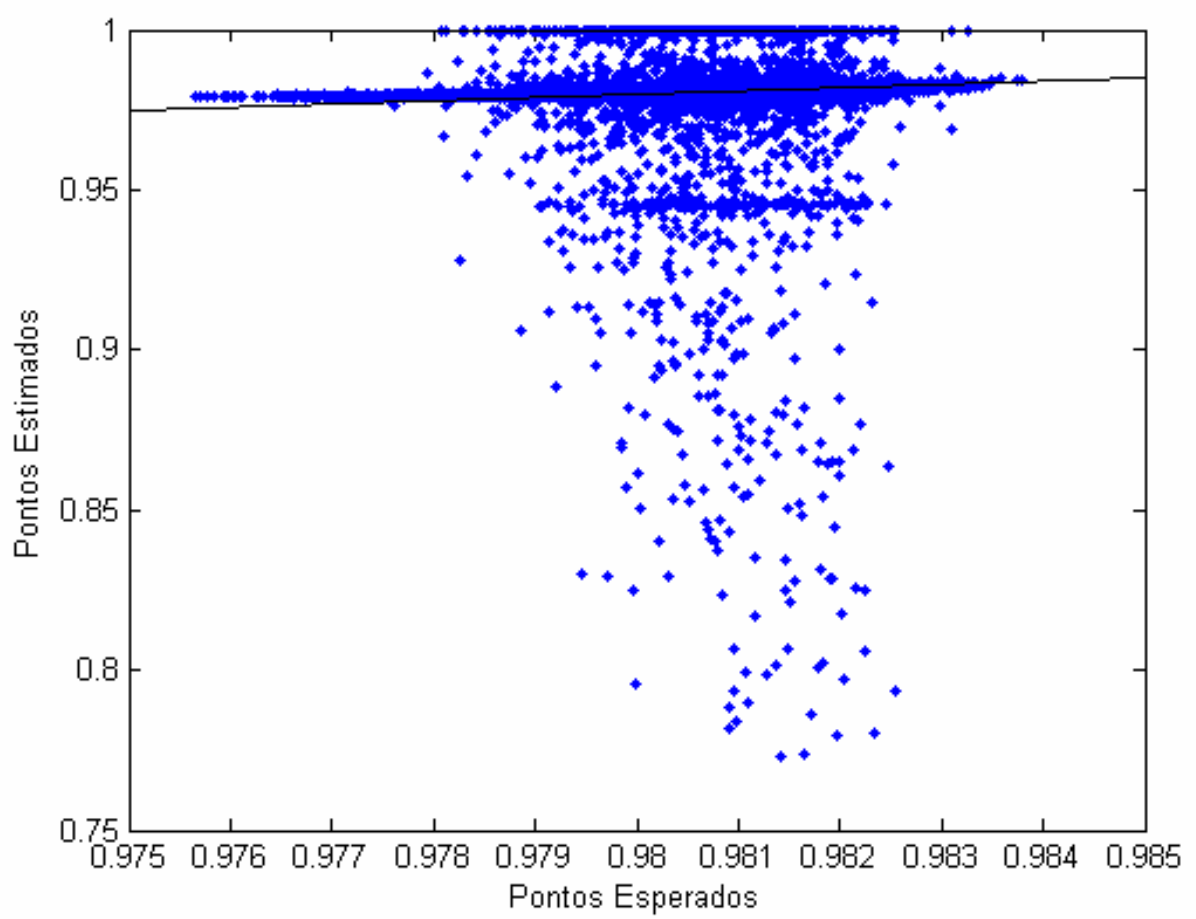

Figura 6.18: Resultado apresentado pelo sensor para os dados de treinamento

Analisando-se agora o mesmo sensor sem treinamento prévio, porém após ter sido treinado com 2.000 pontos (em parciais de 500) pode-se ver que a estimação melhorou muito, conforme a Figura 6.19.

A Figura 6.20 apresenta o erro MSE apresentado na estimativa do sensor para uma grande faixa de operação da planta. 


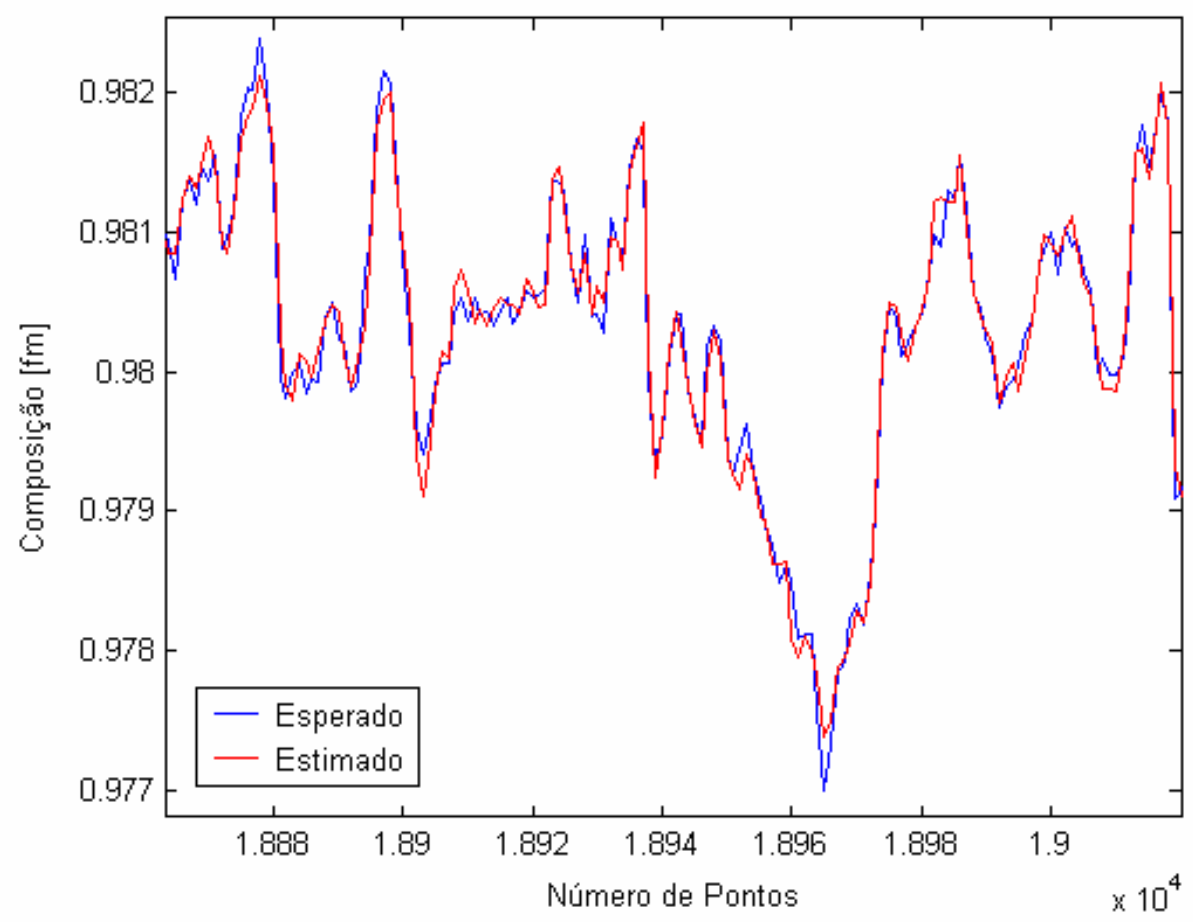

Figura 6.19: Detalhe da resposta estimada após treinamento com 2.000 pontos

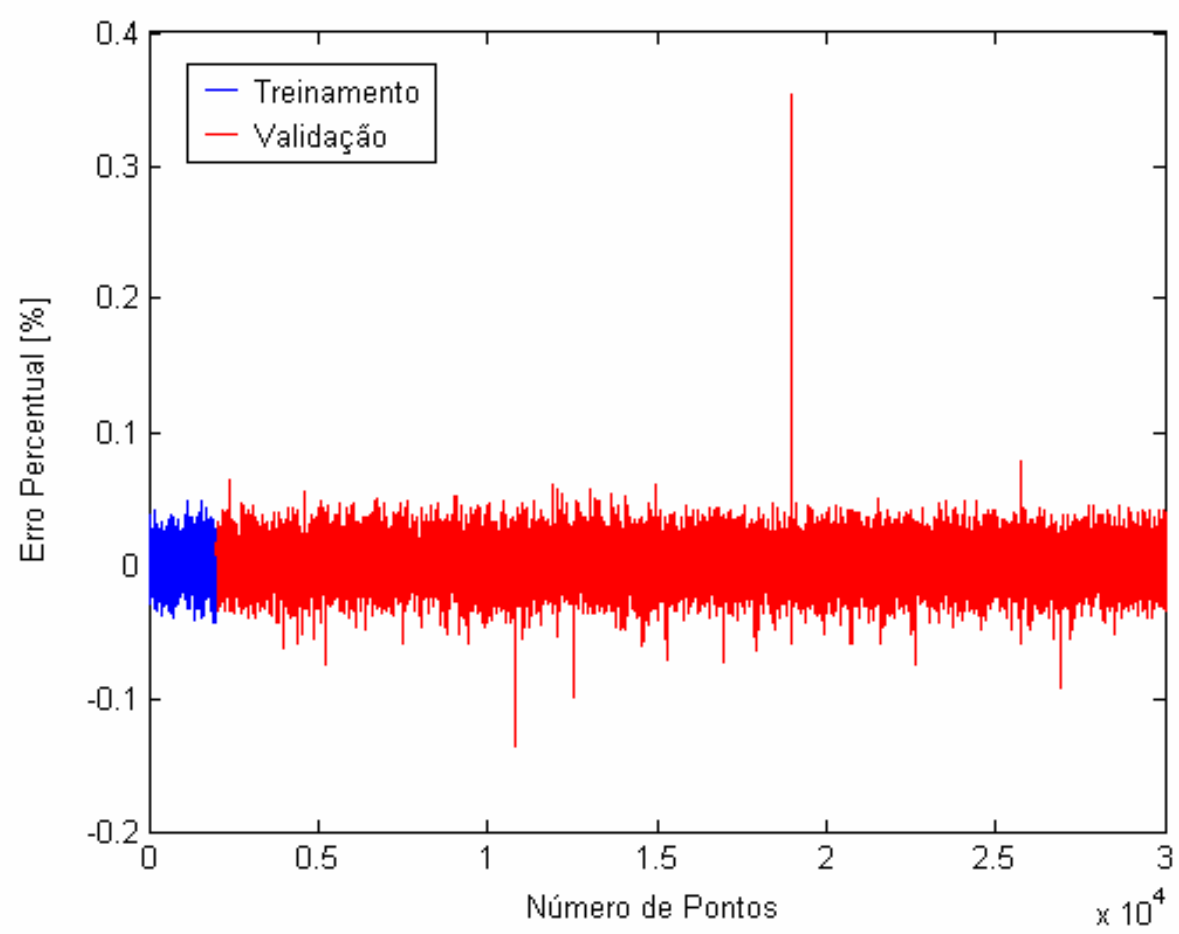

Figura 6.20: Erro apresentado pelo sensor sem treinamento prévio 


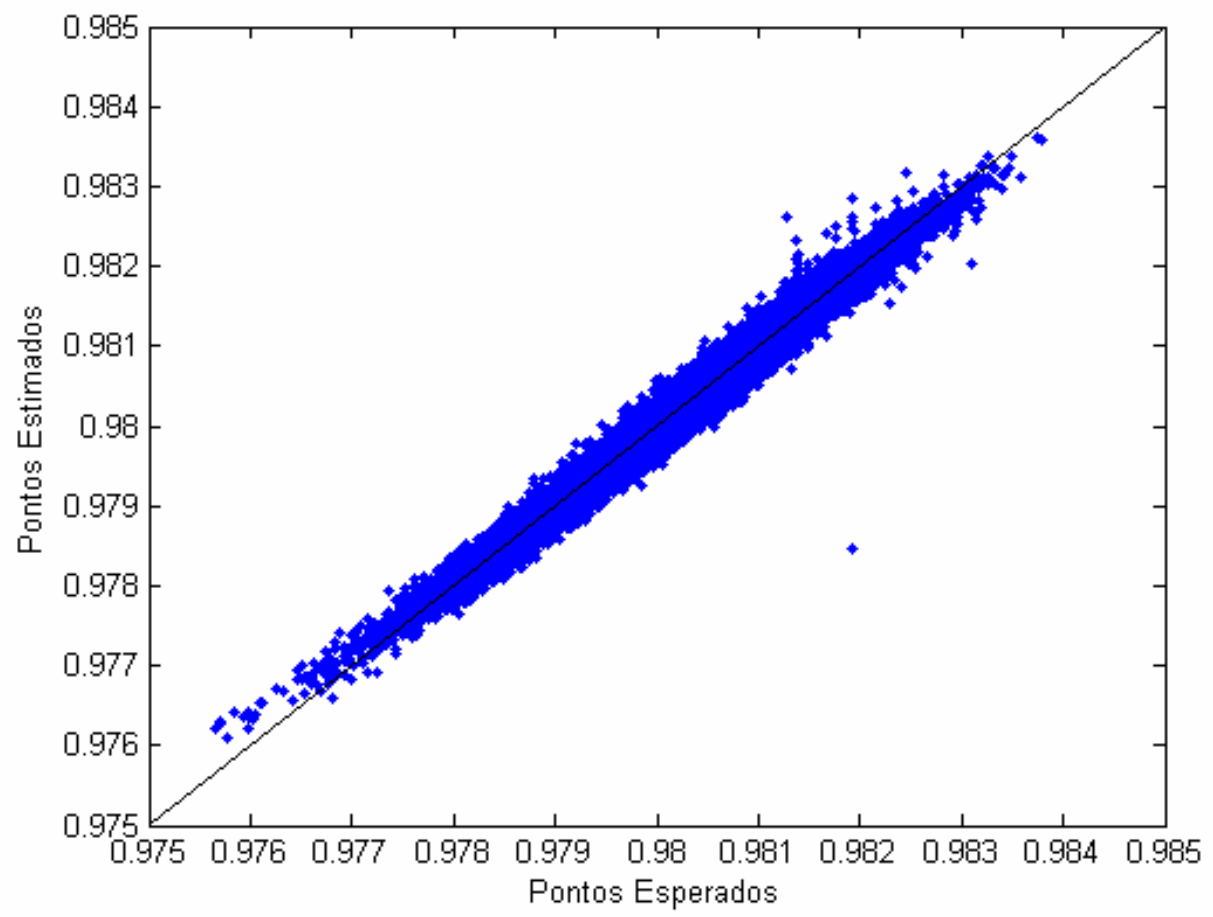

Figura 6.21: Erro apresentado pelo sensor sem treinamento prévio

Comparando-se a Figura $6.20 \mathrm{com}$ a Figura 6.15, pode-se perceber que o sensor melhorou muito a sua capacidade estimativa e este se tornou bem mais uniforme, porém ainda ocorrem alguns picos de erros esporádicos. Isto se deve ao fato de que o sensor foi treinado com pontos insuficientes para algumas regiões.

Os mesmos dados foram apresentados ao sensor treinado previamente com os 5.000 pontos provenientes do simulador dinâmico e retreinado em parciais de 250 com mais 2.000 pontos do processo alterado. A Figura 6.22 apresenta o erro obtido pela estimação do sensor com os mesmos dados da figura anterior.

Observa-se que este sensor apresenta uma amplitude de erro menor, maior homogeneidade e ausência de picos de erro, o que mostra que o sensor está preparado para realizar estimativas melhores para uma grande amplitude de situações. 


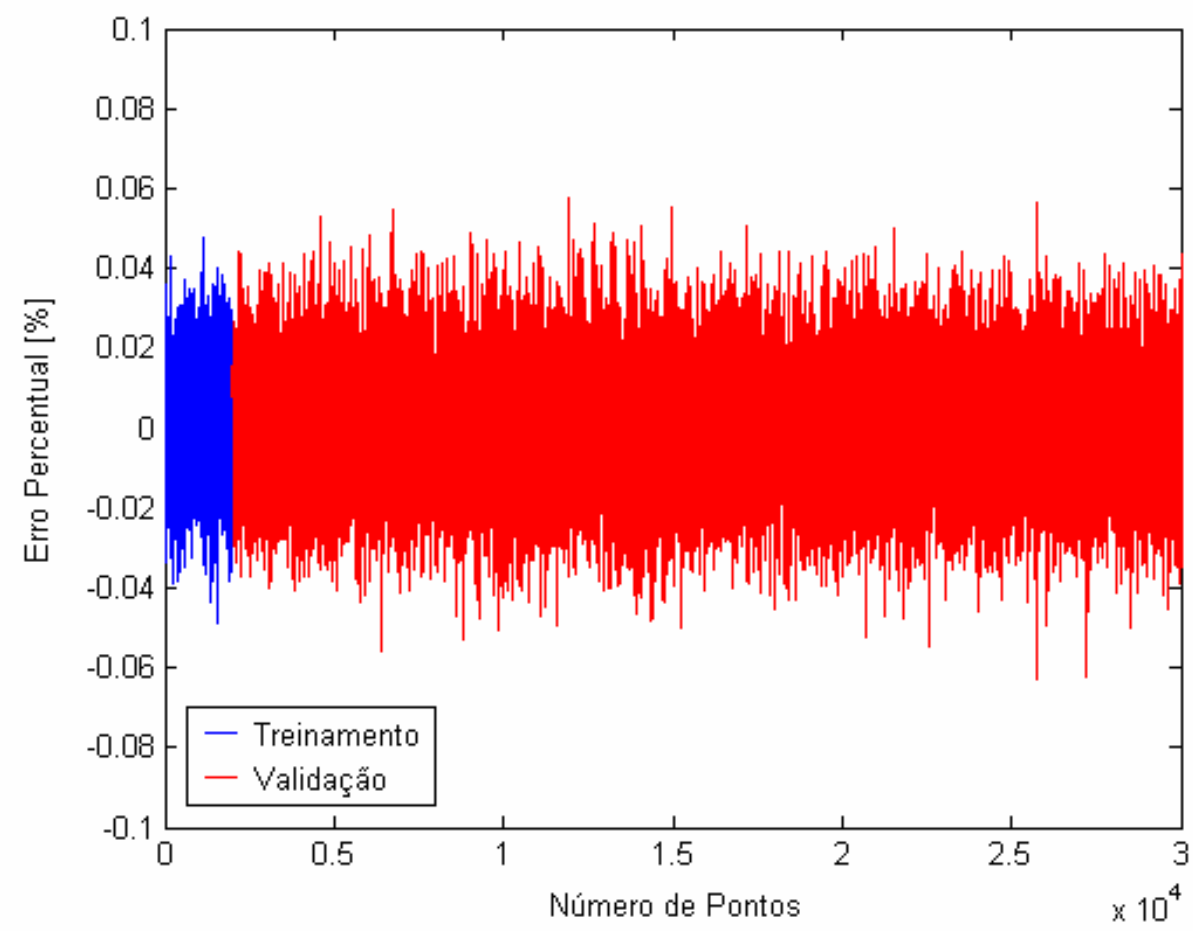

Figura 6.22: Erro apresentado pelo sensor treinado com o simulador

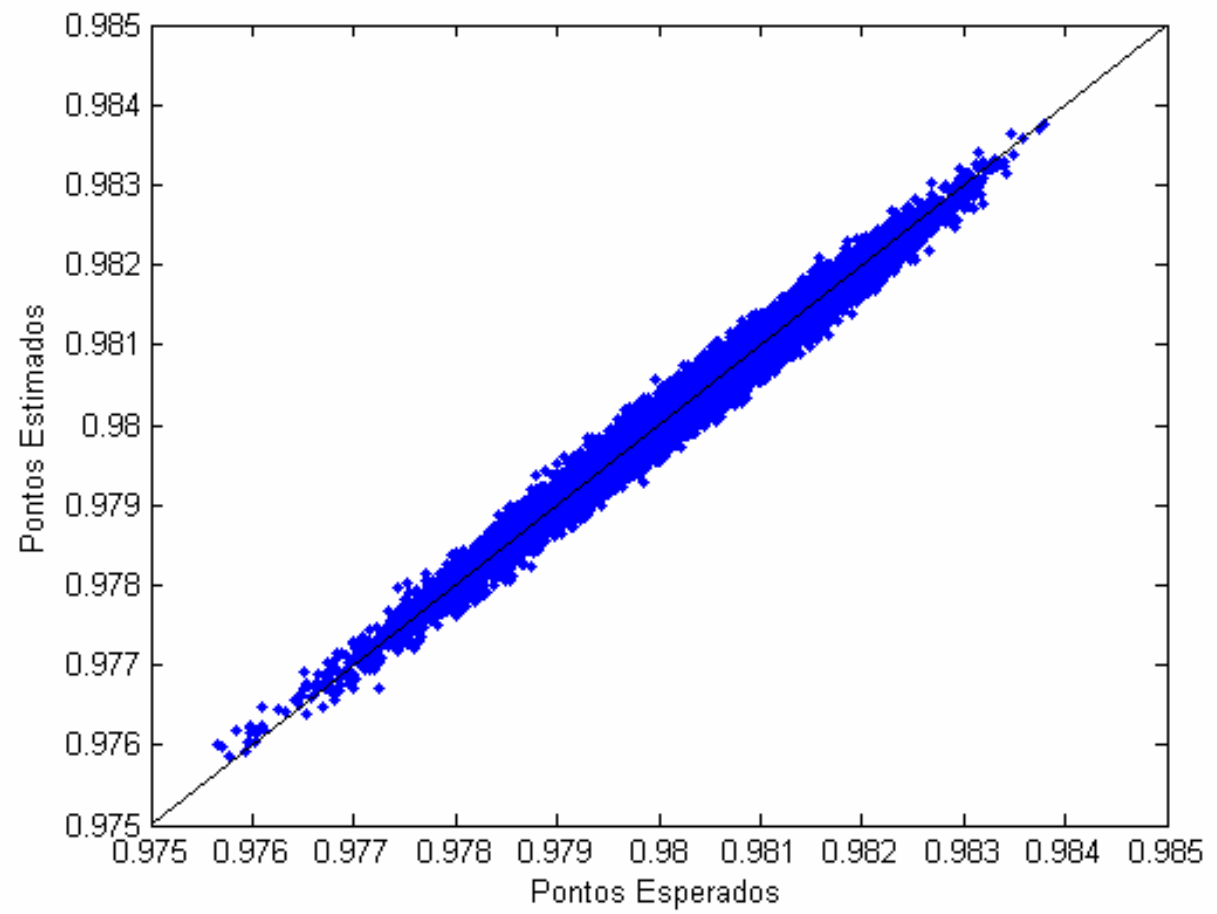

Figura 6.23: Erro apresentado pelo sensor treinado com o simulador 
Um último esclarecimento quanto ao modo de realização dos treinamentos é que tanto o sensor pré-treinado como o sem treinamento foram treinados apenas com os dados provenientes do novo processo.

\section{Conclusão}

Neste capítulo foi apresentado o estudo do comportamento do sensor virtual frente ao treinamento parcial da rede neural e os efeitos que este tipo de treinamento produz. Também foi realizado todo o treinamento do sensor virtual com os dados oriundos de um simulador dinâmico. Além disso, determinou-se um novo conjunto de dados do processo alterado para retreinamento do sensor imitando uma coluna ligeiramente diferente. Finalmente, realizou-se o retreinamento do sensor e a sua comparação com um sensor sem treinamento prévio.

Pudemos perceber que o sensor virtual desenvolvido apresenta erro satisfatório mesmo para as diversas circunstâncias pela qual a rede neural pode passar. Além disso, o treinamento prévio com dados de uma coluna provê mais precisão nas estimações realizadas e maior confiabilidade, recebendo dados de uma ampla faixa de operação sem apresentar picos de erro. E também, garante-se a disponibilidade de um estimador da composição antes da posse de um histórico de dados da planta real estar disponível.

Os bons resultados apresentados pelo treinamento parcial da rede com dados de um processo ligeiramente diferente permitem a possibilidade da utilização destes como meio para aprimorar o comportamento do sensor. Assim, pode-se utilizar para o treinamento inicial da rede um simulador e depois realizar-se um novo ajuste para operação na planta real quando mais dados estiverem disponíveis. Deste modo, combinando-se os dois conjuntos de dados no treinamento do sensor, chega-se a um melhor resultado do que seria possível alcançar com qualquer uma delas independentemente. 


\section{Capítulo 7}

\section{Sensor Virtual com Correção de Erros}

\subsection{Introdução}

Uma vez tendo sido desenvolvido o sensor virtual, que é o objetivo principal da presente dissertação, previa-se também a realização de um estudo sobre os erros mais comuns que ocorrem nestes medidores inferenciais, bem como a elaboração de métodos que pudessem vir a corrigir estes erros.

Ao se trabalhar com sensores virtuais, as estimativas realizadas não possuem nenhum tipo de realimentação, de modo que se o sensor estiver indicando um valor fora da realidade, ele, em princípio, não tem como se autocorrigir. Como é comum nas plantas industriais que a composição dos produtos destilados seja medida periodicamente "off-line" através de técnicas laboratoriais, propõe-se aqui que se suponha que existam valores reais da composição dos produtos destilados disponíveis periodicamente, muito embora com um significativo atraso.

Dessa forma, supondo-se que em um determinado instante de tempo uma amostra do produto destilado tenha sido coletada e enviada para o laboratório, o 
resultado das análises estará disponível alguns minutos ou horas depois. Com base nessa informação atrasada no tempo, pretende-se fazer algumas verificações no comportamento do sistema inferencial.

Foi feita uma pesquisa bastante abrangente nos principais mecanismos de busca que estão disponíveis na Internet, visando encontrar artigos que se relacionassem com o tema. Porém, não se encontrou nenhum texto que se dedicasse a propor ou analisar técnicas de correção do erro do valor fornecido pelo sensor virtual, com base em uma medida laboratorial mais precisa.

Muitos dos sensores propostos encontrados nos periódicos pesquisados apresentam resultados de estimação considerados satisfatórios. Porém, os próprios autores normalmente já explicitam que isto ocorre para uma determinada faixa de operação para o qual o medidor foi projetado ou treinado.

Medjell e Skogestad (1991b) afirmam na conclusão de seu artigo que: "Uma área importante para trabalhos futuros é a de encontrar estimadores que combinem eficientemente dados baseados em simulações e medidas reais". Mesmo efetuando uma busca em todas as publicações posteriores e anteriores a este artigo, dos referidos autores, não se encontrou nenhum artigo que tratasse do tema.

Neste capítulo é apresentada uma proposta de análise e implementação de métodos de correção para alguns erros. E no prosseguimento do projeto, realiza-se a implementação dos métodos de correção da predição feita.

\subsection{Propostas}

Não é comum encontrar artigos que relatem os erros ocorridos nas implementações nem as dificuldades que surgiram no desenvolvimento dos sensores virtuais, o que dificulta a determinação das principais falhas que ocorrem neste 
assunto. Talvez isto ocorra devido a uma cultura de ocultar as falhas que aparecem no desenvolvimento dos projetos e exibir apenas os bons resultados.

Analisando, porém, alguns projetos de formatura de alunos do último ano de Engenharia Elétrica da Escola Politécnica da USP, que haviam projetado sensores virtuais baseados em redes neurais, pode-se observar que apareciam normalmente dois tipos de erros bastante distintos, mas relativamente freqüentes nestas implementações. Estes erros foram denominados de erro espúrio e erro sistêmico. Ver (MURAKAMI; TANABE; OKAMOTO, 2002) e (CAMARGO; TAKESAKO, 2003).

\section{Erro Espúrio}

O primeiro tipo de erro, aqui denominado de espúrio, está relacionado a uma variação brusca na variável de saída durante um intervalo de tempo bastante curto. Assim, o sensor que está operando normalmente com boa estimação da variável analisada, de repente, apresenta na resposta um valor bastante fora dos anteriores e diferente do esperado para, em seguida, voltar ao seu funcionamento normal. Um exemplo deste tipo de erro pode ser observado na Figura 7.1.

Analisando-se melhor as condições nas quais este erro acontece, percebe-se que ele só se apresenta quando o sensor passa por uma região em que não foi treinado ou o treinamento efetuado foi realizado com poucos dados desta região de operação. Pode-se concluir, portanto, que este erro é proveniente de problemas no treinamento da rede neural, e assim, uma solução para corrigi-lo seria retreinar a rede "on-line", fornecendo a ela mais dados provenientes desta região.

A detecção deste tipo de erro não é muito difícil de realizar, pois é possível detectá-lo através do instante em que o valor apresentado como resposta seja relativamente diferente das estimações próximas, nos instantes anteriores. 


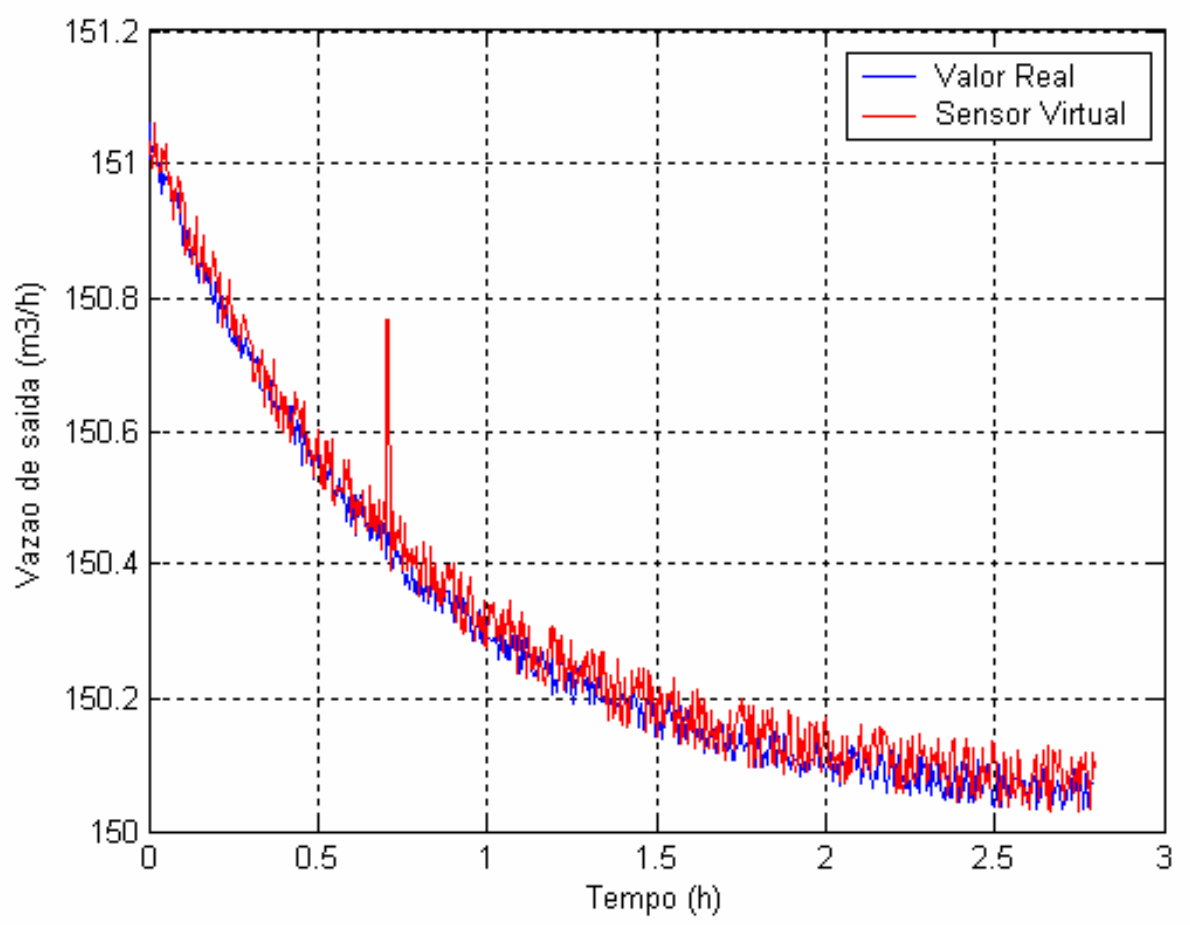

Figura 7.1: Exemplo de resposta do sensor virtual com erro espúrio

Antes, porém de se dedicar à correção do erro, propõe-se um método para limitá-lo. Assim, a proposta consiste em limitar a variação de um instante para o seu seguinte, de modo que se eliminem oscilações muito bruscas. Devem-se levar em consideração as constantes de tempo do sistema e a variação das entradas, na escolha destes limites. Um exemplo seria limitar a variação de um instante para o seguinte em $0,1 \%$, o que evitaria pontos muito fora da região de operação, mas que ainda seriam perceptíveis quando comparados com os outros pontos em instantes próximos.

Esta proposta de limitar a variação da saída do sensor virtual seria implementada prevendo-se que este tipo erro possa ocorrer, porém, com o intuito único de se evitar grandes variações na resposta (e eventualmente no sistema de controle), e não de se corrigir o treinamento do sensor para impedi-lo de acontecer. A detecção de que este erro aconteceu e o instante em que ocorreu são importantes na determinação da região em que o sensor está apresentando funcionamento insatisfatório para que se possa efetuar a correção. Esta correção visa ter caráter 
permanente eliminando o erro através do retreinamento da rede com dados da região em questão.

\section{Erro Sistêmico}

O segundo tipo de erro que foi encontrado nos sensores virtuais analisados foi aqui chamado de erro sistêmico. Este tipo de erro caracteriza-se pelo fato da variável de saída apresentar um valor bastante diferente do esperado (valor real) e permanecer nesta situação com o passar do tempo. A Figura 7.2 apresenta uma ilustração deste tipo de erro.

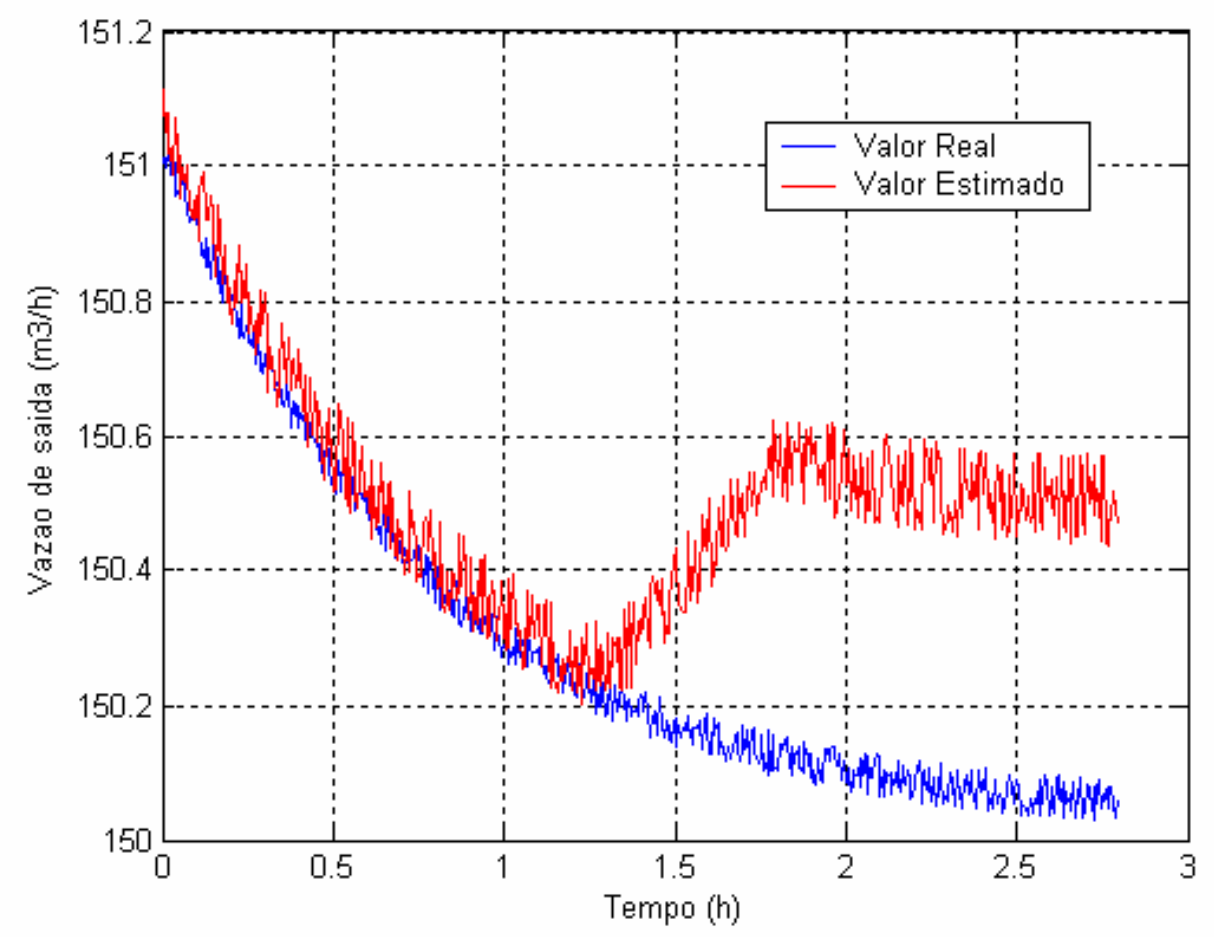

Figura 7.2: Exemplo de resposta do sensor virtual com erro sistêmico

Analisando-se melhor este tipo de erro percebe-se que ele também ocorre devido a um despreparo da rede neural para continuar estimando valores em determinadas regiões, o que pode ocorrer se a rede for treinada de forma deficiente ou se sua faixa de operação for limitada a uma região menor (limitações da arquite- 
tura da rede). Porém, neste tipo de erro a saída estimada não volta a apresentar o comportamento esperado, mesmo depois que o sensor saia da região em que apresentou problemas.

A detecção deste tipo de erro não é tão fácil de ser efetuada, pois é difícil saber se o valor apresentado pelo sensor está correto ou não. Para isto, uma proposta seria utilizar periodicamente o valor obtido pela medição laboratorial, mesmo atrasado, para informar se no momento da coleta da amostra o sensor está operando corretamente. Esta solução apresenta o inconveniente de que se pode ter um erro espúrio no momento da coleta e isto induzir a pensarmos que ocorreu um erro sistêmico. Só se consideraria a presença de um erro sistêmico se a comparação com diversas medições laboratoriais seguidas indicasse a presença de um erro. Isto, no entanto, poderia ser uma forma lenta de detecção deste erro.

Outra proposta para detecção mais rápida do erro seria a utilização de $3 \mathrm{ou}$ mais sensores virtuais operando em paralelo em um sistema tipo votação. Porém, estes sensores precisam ter arquiteturas internas da rede diferentes. Supõe-se ainda que quando um deles apresentar valor discrepante os demais permaneçam operando corretamente.

A correção deste tipo de erro também não é simples. Propõe-se que se utilize um conjunto composto por 4 sensores virtuais com estruturas internas diferentes. Supondo que ocorram apenas falhas simples espaçadas no tempo, ou seja, que nunca ocorram duas falhas simultâneas, pode-se facilmente detectar qual dos sensores está avariado.

Uma vez detectado qual dos sensores está com problemas, este seria afastado da estimação e um aviso seria emitido ao usuário de que um dos sensores está fornecendo saídas não confiáveis. O fato do sistema de votação conter quatro, e não três sensores, é para que o sistema de votação continue operando mesmo após o afastamento de um deles. 
Em seguida, os esforços seriam concentrados na recuperação do sensor avariado, através do retreinamento deste, após terem sido efetuadas algumas alterações na estrutura da rede, como número de nós nas camadas, tipo de função de transferência utilizada, etc.

Juntamente com o sistema de votação, propõe-se que seja armazenado um histórico dos erros de operação de cada sensor em comparação com os resultados obtidos das medidas laboratoriais. Assim, caso outro sensor apresente erro, enquanto o primeiro ainda não foi concertado, outro aviso deve ser emitido ao usuário de que outro sensor também está com problemas e que será afastado e assim continuaria a operação com apenas dois sensores, porém, em caso de discrepância entre os dois, o voto de decisão seria concedido ao sensor que apresentou menor erro acumulado até o presente momento.

Nos trabalhos estudados, o erro sistêmico era eliminado através do abandono da rede falha e da escolha de uma nova arquitetura e treinamento desta que não apresentasse erro.

Particularmente neste trabalho, o erro sistêmico apareceu apenas para uma condição muito específica de arquitetura de rede neural utilizada, em contraposição ao erro espúrio que foi bem mais freqüente. Acredita-se que uma das possíveis origens deste tipo de erro esteja relacionada com a utilização da estimativa da rede como realimentação do próprio sensor, o que pode fazer com que um pequeno erro seja propagado e afete o desempenho do sensor. Voltaremos a este erro na seção 7.4 .

A seguir são apresentados os resultados obtidos no estudo do erro espúrio que apareceu durante o desenvolvimento do projeto. 


\subsection{Erro Espúrio}

Dedicar-nos-emos nesta seção ao estudo mais aprofundado do erro espúrio que ocorreu durante o desenvolvimento do sensor virtual e nas propostas de correção do mesmo que foram implantadas.

A Figura 7.3 apresenta o erro do sensor (valor esperado menos valor estimado) obtido após o treinamento da rede com 1.000 pontos de forma única (direto) e avaliado contra um outro conjunto de dados de teste também com 1.000 pontos. Repare que o sensor apresenta um erro espúrio para a região em torno do ponto 620 do conjunto de teste (ponto 1620 do gráfico).

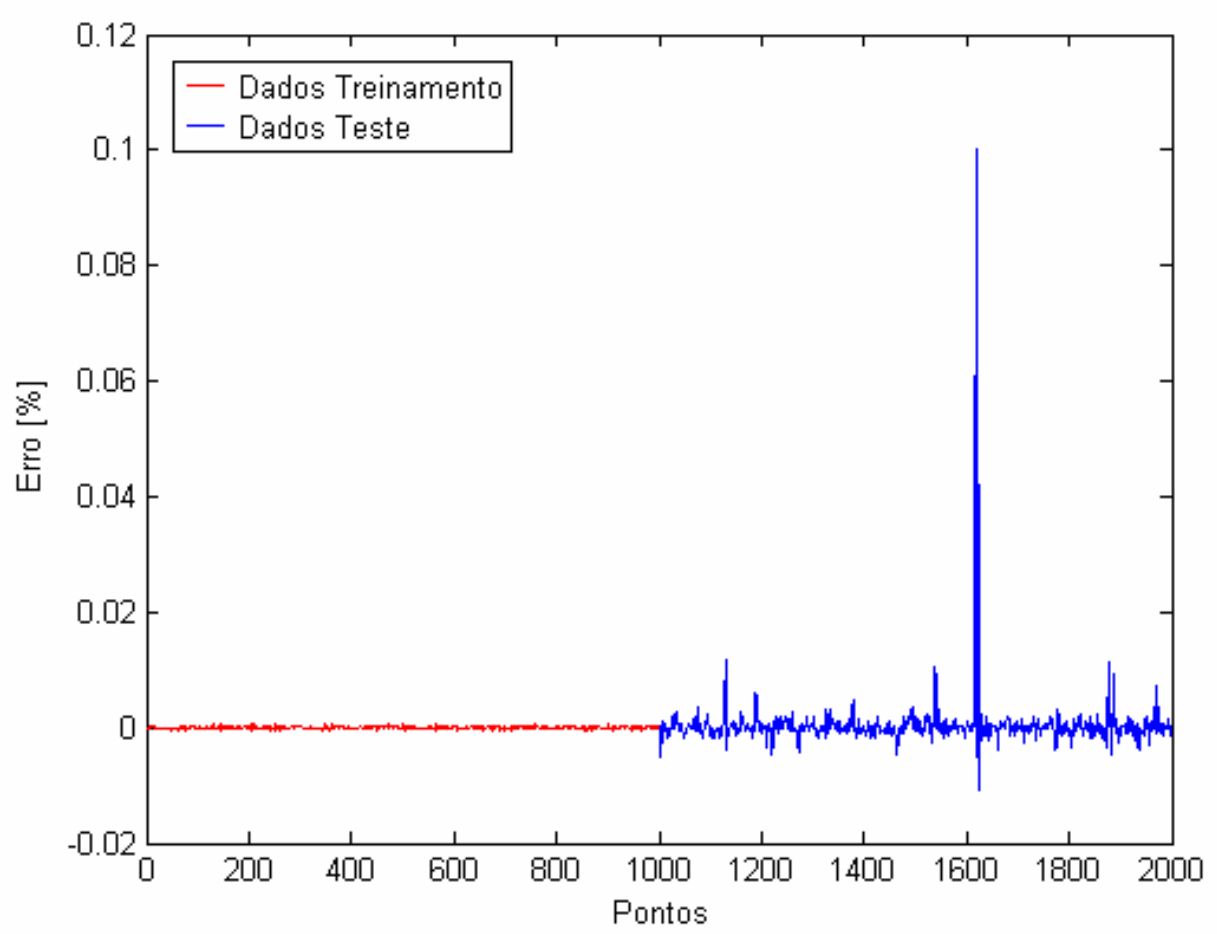

Figura 7.3: Erro apresentado pelo sensor virtual

A Figura 7.4 apresenta a comparação entre as respostas estimada fornecida pelo sensor e a resposta real fornecida pela planta simulada. A Figura 7.5 mostra o detalhe da figura anterior com destaque para a região onde ocorre o erro espúrio. 


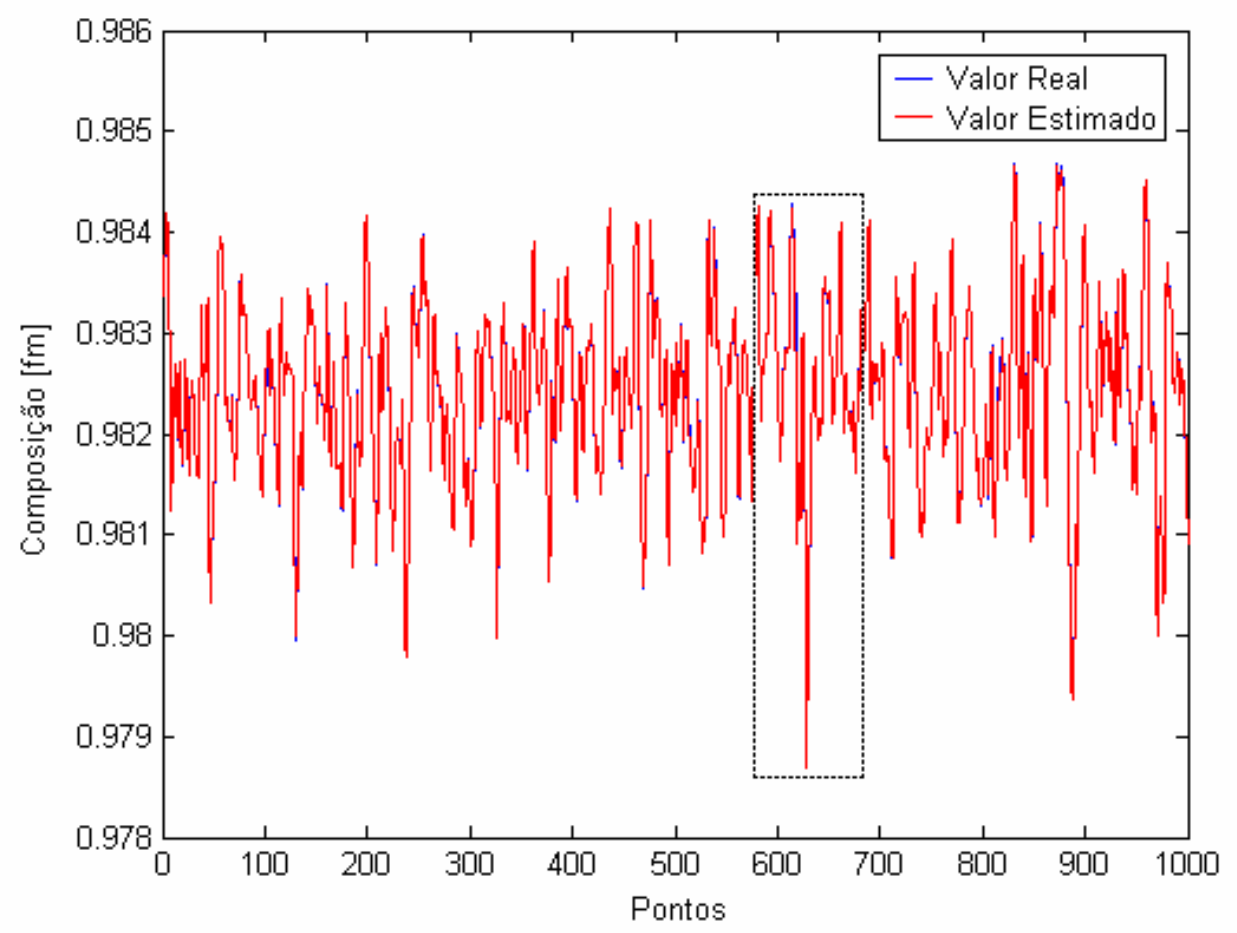

Figura 7.4: Comparação das respostas apresentadas pelo sensor e pela planta

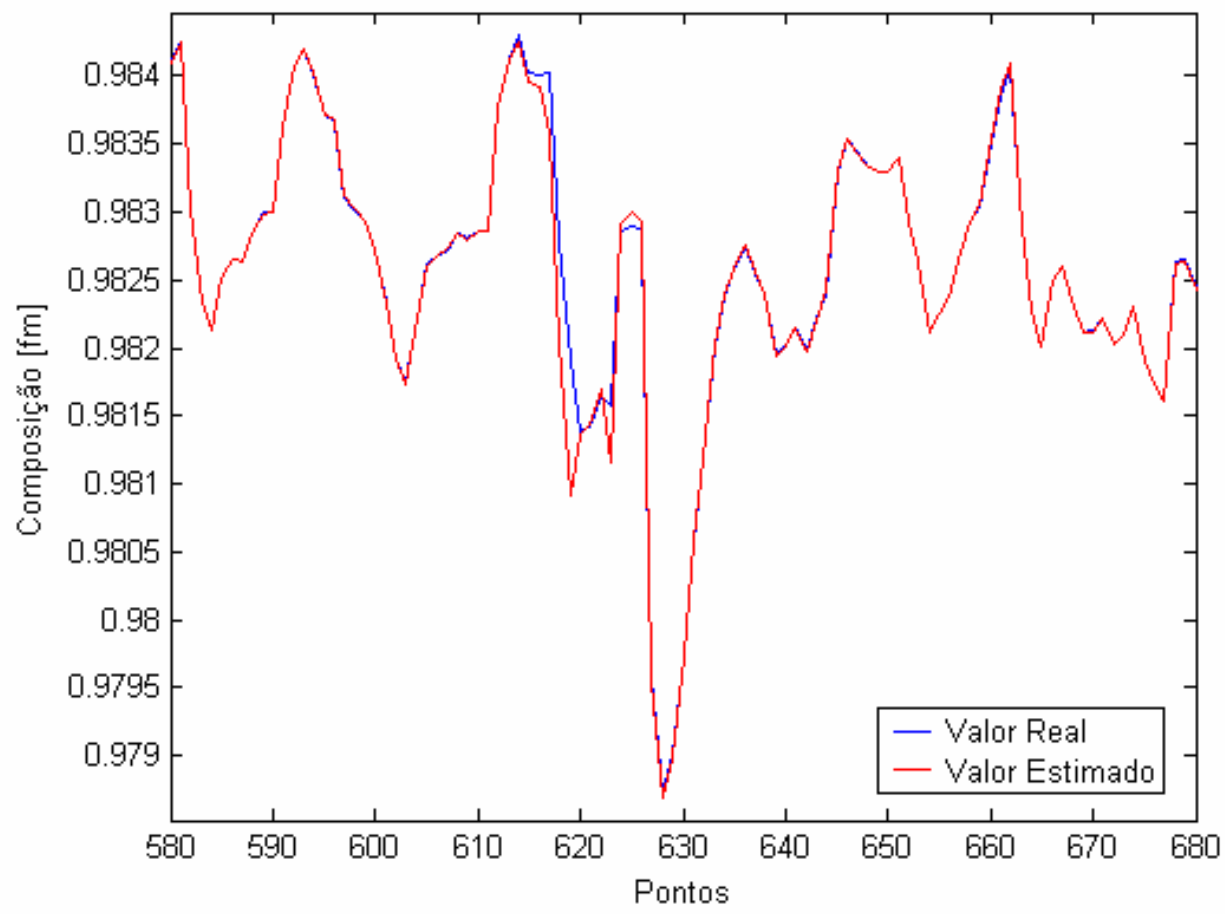

Figura 7.5: Detalhe do pico de erro entre sinal esperado e estimado 
Destaca-se da Figura 7.3 que o erro apresentado pela rede é bastante pequeno tanto para o conjunto de treinamento (erro médio quadrático MSE = $8,381.10^{-10}$ ) quanto para o conjunto de teste $\left(\mathrm{MSE}=4,428.10^{-8}\right.$ ), o que mostra que a rede apresenta bom treinamento e capacidade de estimação satisfatória. Porém, para uma determinada região o erro apresentado é bastante superior ao esperado $(0,1 \%$ de erro). Pode-se observar na Figura 7.5 que este erro ocorre em faixa de cerca de 15 pontos para os quais a rede não estava suficientemente treinada.

A seguir para tratar da correção do erro espúrio serão apresentadas três alternativas que foram implementadas e que ajudam no processo de compreensão de um melhor método para solução deste erro.

\section{Retreinamento com a região deficitária}

Para corrigir o erro espúrio realizou-se um novo treinamento da rede com um conjunto de dados constituído apenas pelos 100 pontos ao redor do pico máximo de erro (50 pontos antes e 50 pontos depois). A idéia original era fazer com que o sensor que já apresentava uma boa capacidade de estimação pudesse aperfeiçoar seu funcionamento e evitar novos erros para esta mesma região.

Na Figura 7.6 pode-se observar que a rede após algumas iterações conseguiu reduzir o erro para este novo pequeno conjunto de dados de treinamento. Porém, houve uma perda considerável na qualidade da estimação dos outros pontos. O erro espúrio foi resolvido, porém outros erros surgiram indicando que a condição obtida com o treinamento inicial foi perdida em parte (comparado com a Figura 7.3). 


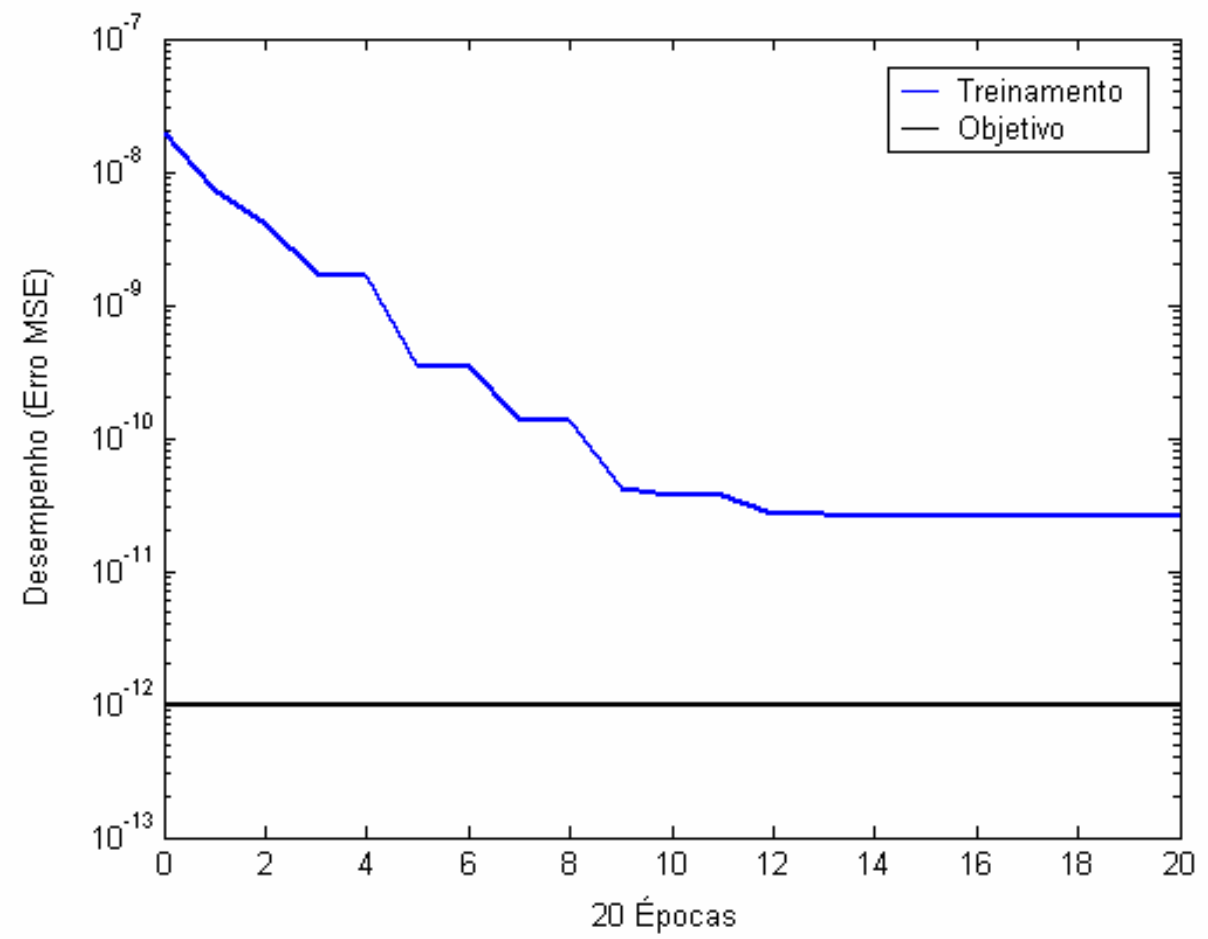

Figura 7.6: Convergência do erro no retreinamento da rede com 100 pontos

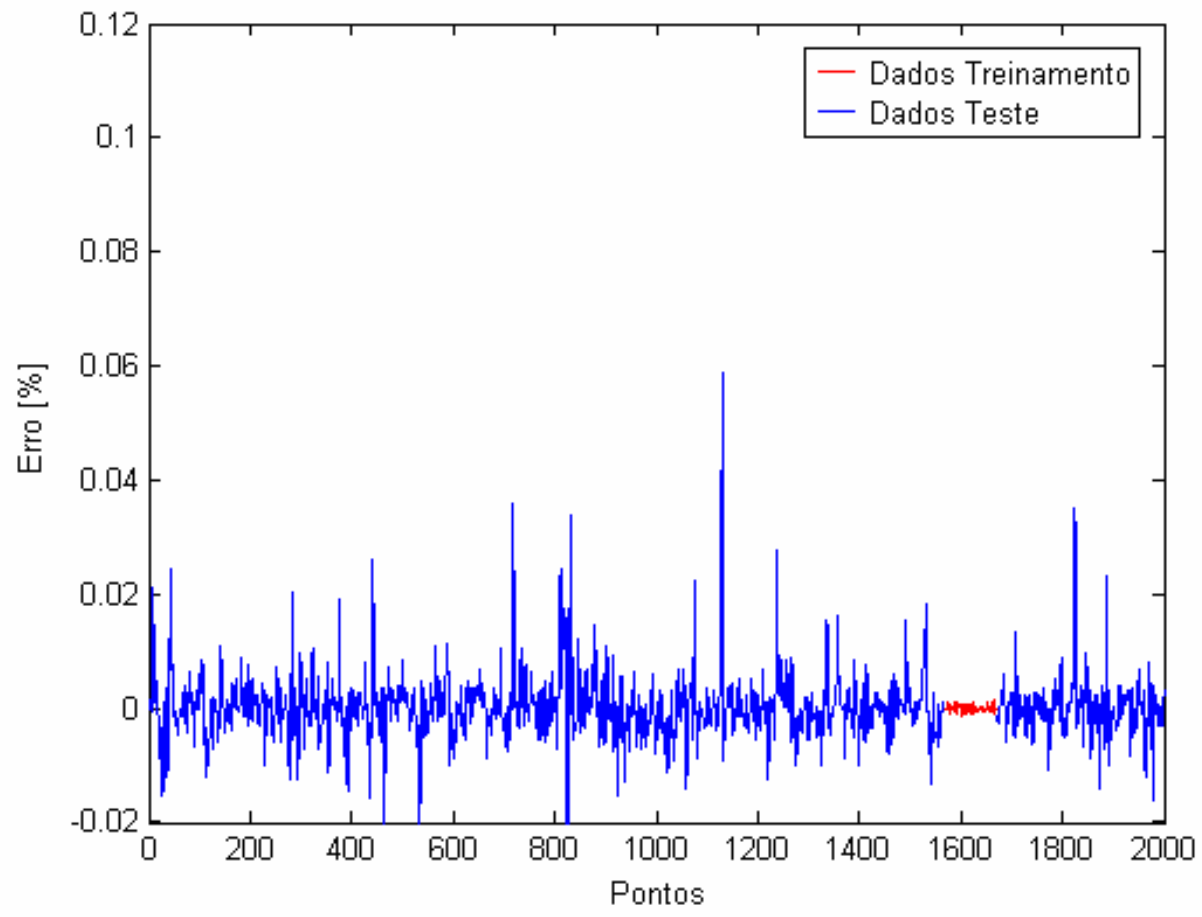

Figura 7.7: Erro após retreinamento com 100 pontos 
Este alternativa de correção mostra que para realizarmos ajustes sucessivos em um sensor virtual é necessária a armazenagem do conjunto de dados de treinamento utilizado previamente. À este conjunto de dados original vão sendo acrescentados mais dados de regiões deficitárias com vistas a melhorar o desempenho do sensor.

\section{Retreinamento com acréscimo da região deficitária}

Para reduzir o erro espúrio e não perder o treinamento anterior realizou-se um novo treinamento da rede com um conjunto de dados composto agora pelos 1.000 pontos iniciais acrescidos dos 100 pontos da região na qual o sensor apresentava erro espúrio.

A Figura 7.8 apresenta a convergência do erro para o retreinamento com o novo conjunto de dados com o acréscimo dos 100 pontos da região de pico.

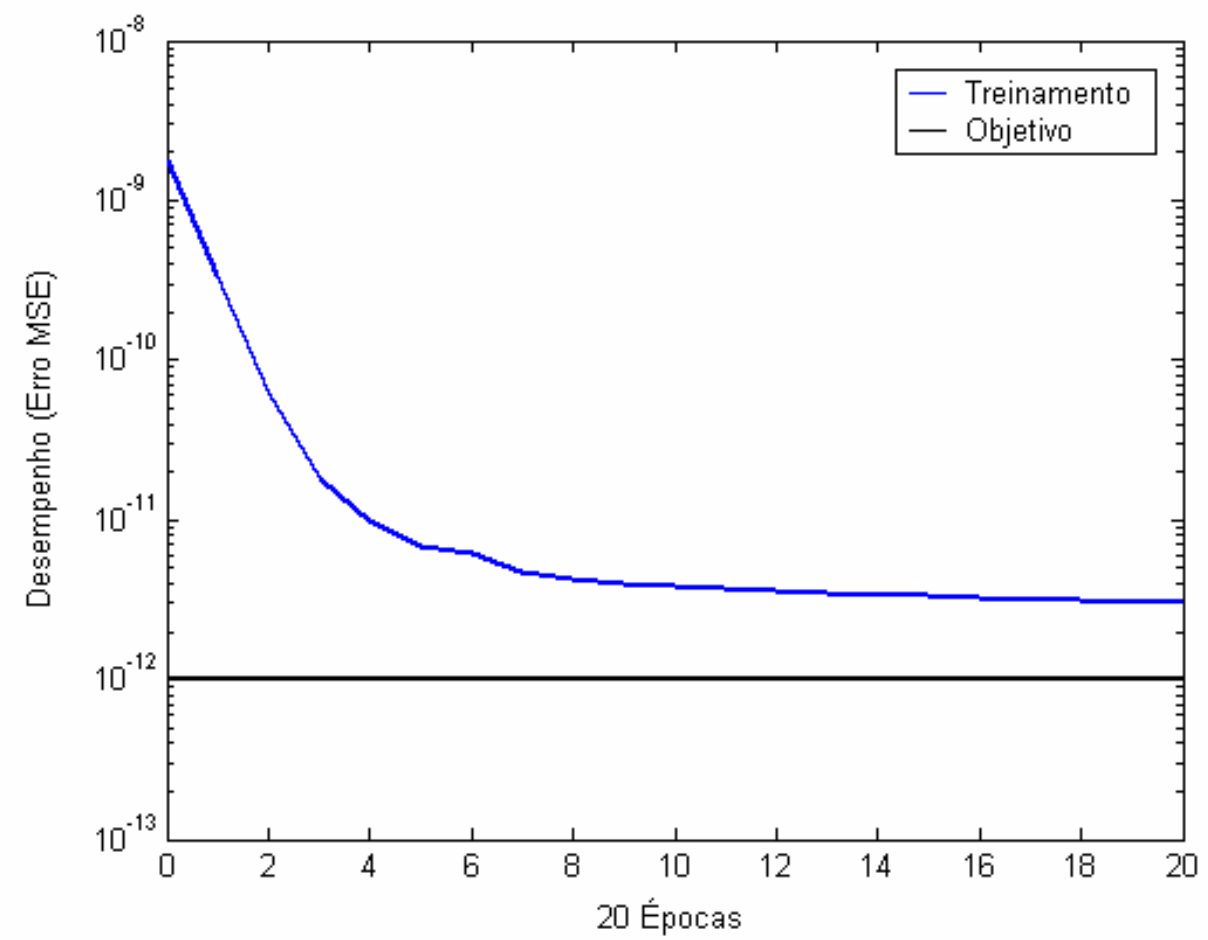

Figura 7.8: Convergência do erro no retreinamento da rede com 1.100 pontos 
A Figura 7.9 mostra o erro apresentado pelo sensor após o treinamento com o novo conjunto de dados. É notável a melhora do desempenho da rede, o erro espúrio foi completamente eliminado.

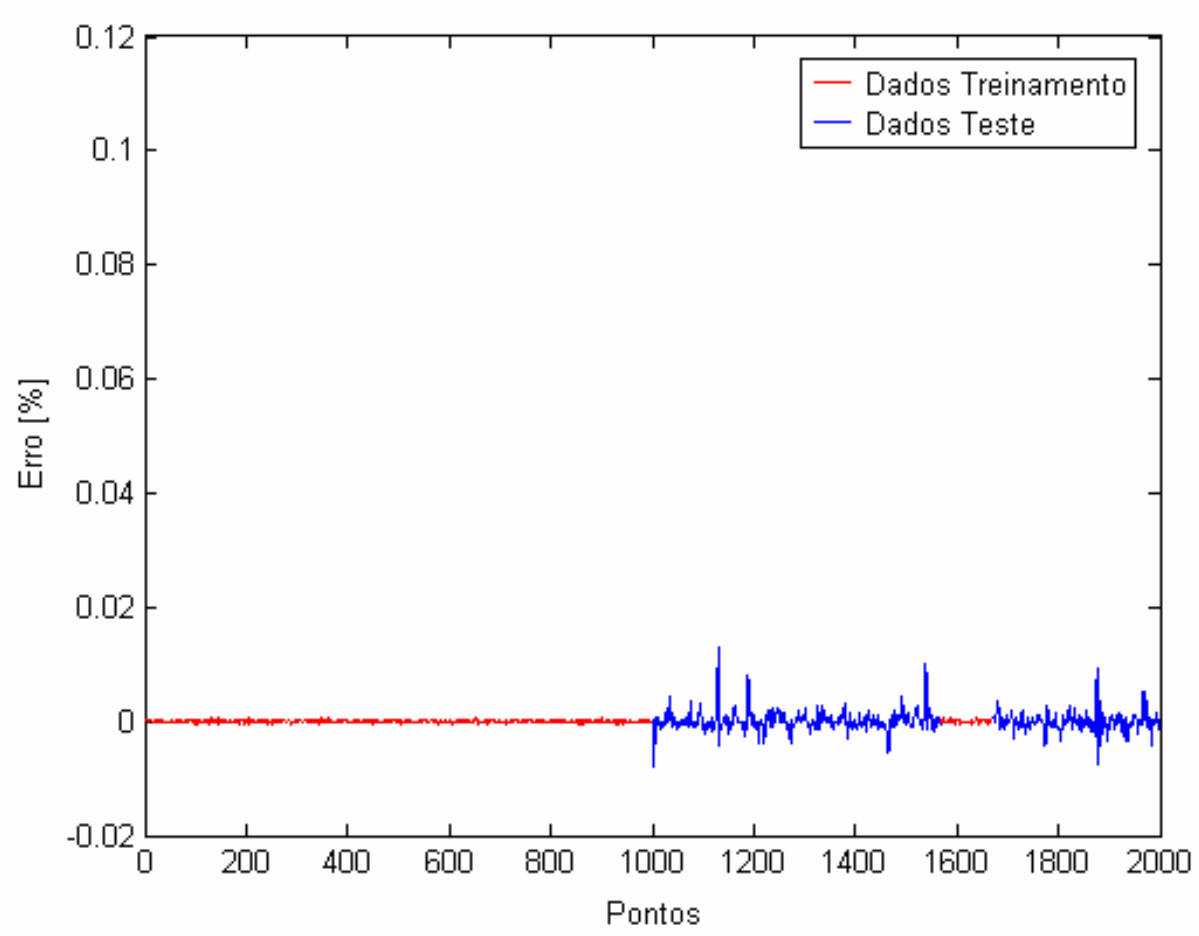

Figura 7.9: Erro após retreinamento com 1.100 pontos

Pode-se observar ainda que o sensor apresentou uma ligeira melhora na estimação, o que mostra que o treinamento parcial através de um retreinamento sucessivo da rede traz resultados satisfatórios.

A fim de se poder avaliar a melhora obtida para outras regiões são apresentados nas Figura 7.10, Figura 7.11 e Figura 7.12 de forma comparativa os erros apresentados pelo sensor virtual antes, com a rede treinada apenas com os 1.000 pontos iniciais, (em verde e amarelo) e sobre este o novo erro apresentado após o retreinamento com os 1.100 pontos (em vermelho e azul). A Figura 7.11 e Figura 7.12 mostram detalhes desta comparação onde se pode observar a alteração da resposta do sensor. 


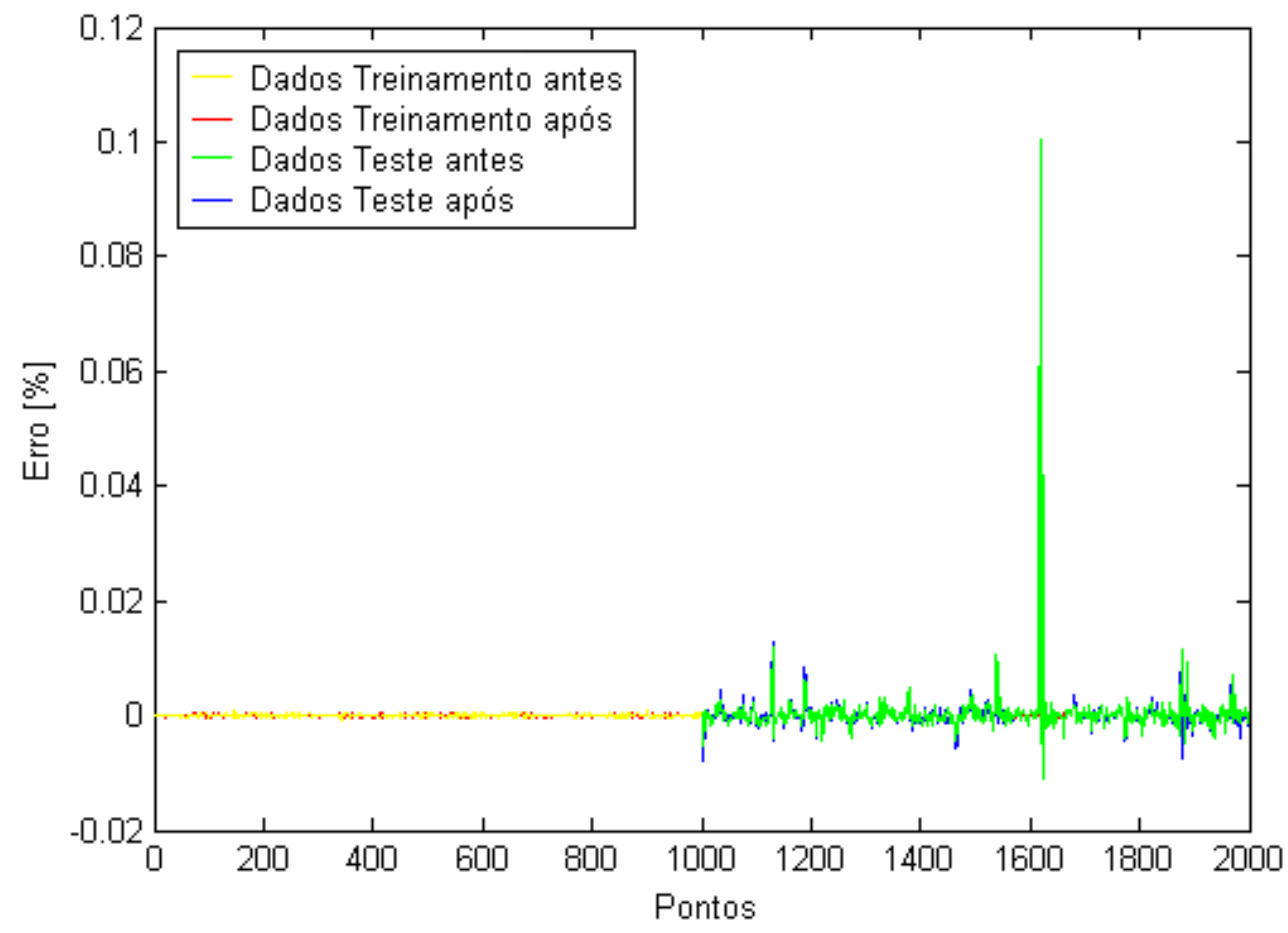

Figura 7.10: Comparação dos erros antes e após retreinamento (1.100 pontos)

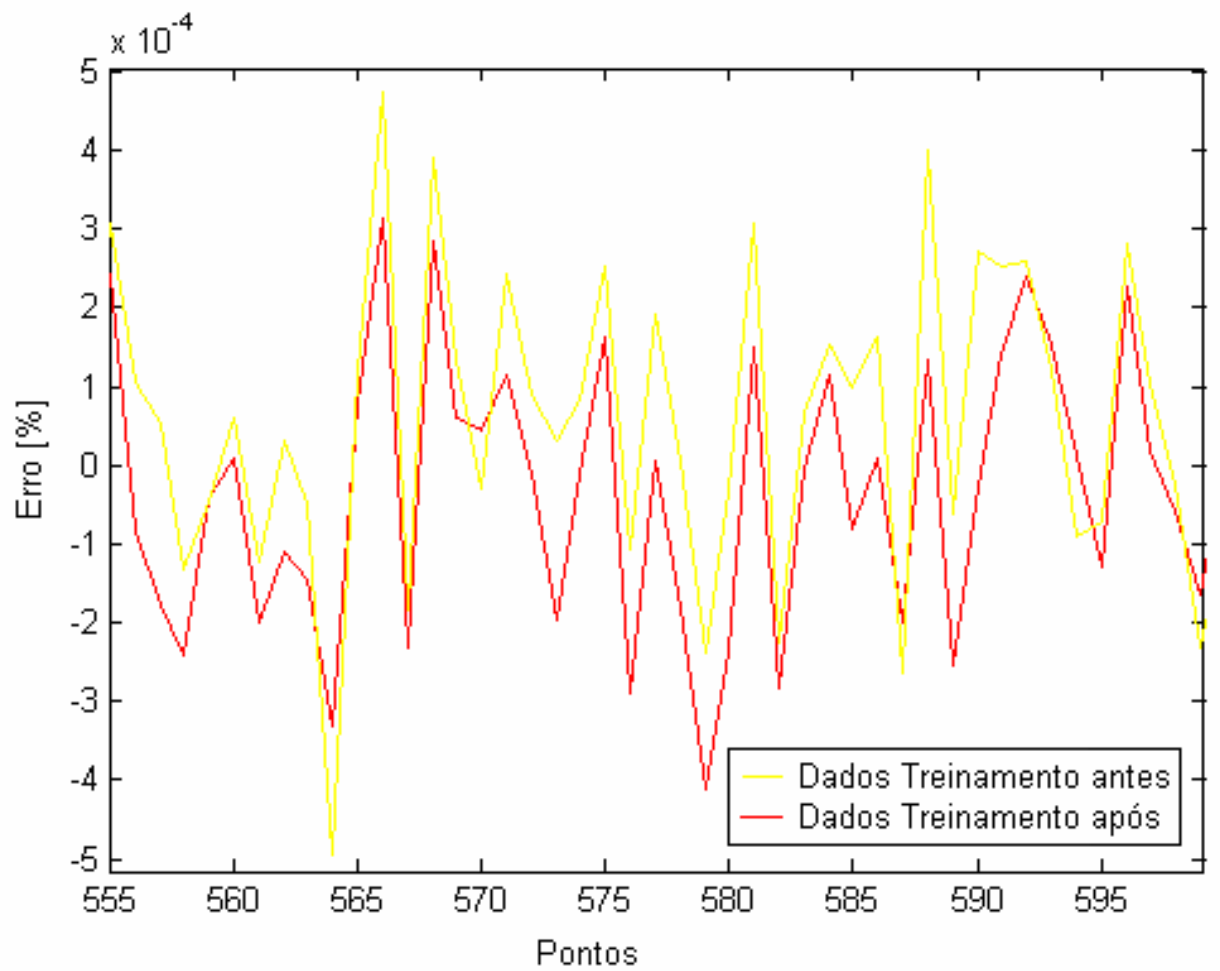

Figura 7.11: Detalhe do erro antes e após retreinamento com 1.100 pontos 


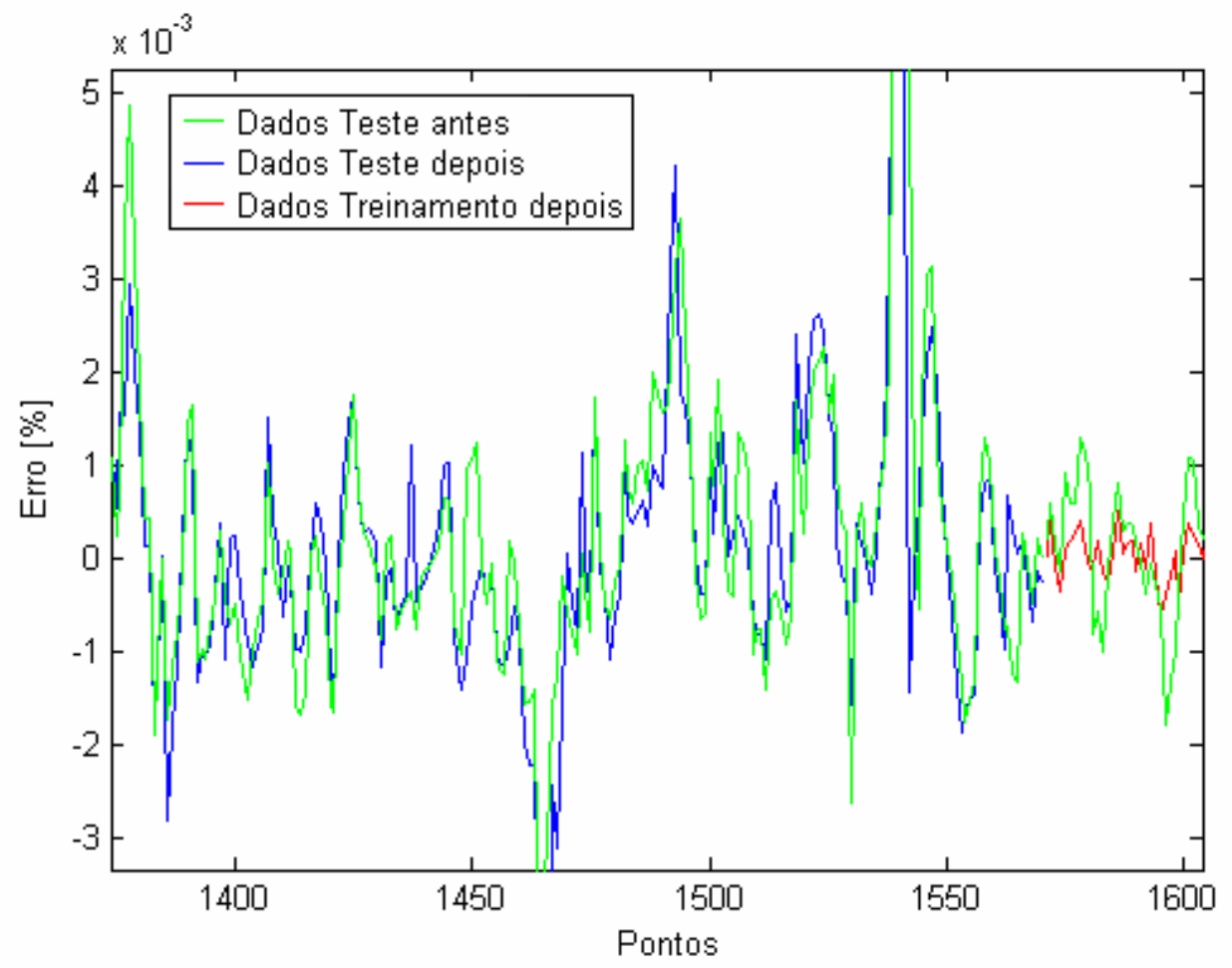

Figura 7.12: Detalhe do erro antes e após retreinamento com 1.100 pontos

Observando atentamente podemos ver que na Figura 7.11 houve uma melhora ainda maior do erro apresentado (erro MSE $=3,04.10^{-12}$ ), porém para a Figura 7.12 pode perceber que houve um pequeno aumento do erro (MSE = $7,31.10^{-8}$ ) comparativamente com a Figura 7.3. Apesar da região de erro máximo (pico) ter sido bem reduzida. Isto pode nos levar a perceber que a rede está começando a apresentar sinais de especialização para o conjunto de treinamento ("overtraining").

\section{Treinamento através dos erros máximos}

Analisando os resultados anteriores surge uma nova alternativa que poderia ser empregada para o treinamento da rede. Esta opção seria realizar o treinamento da rede através dos picos de erro. 
Assim, a rede seria inicialmente treinada com um conjunto pequeno de dados (500 pontos, por exemplo) e depois através da detecção dos picos de erros, seria retreinada com novos conjuntos de dados compostos por faixas de dados próximos destes pontos, de modo semelhante com o realizado na seção anterior. Espera-se ainda que esta alternativa além de reduzir o número de dados necessários para o treinamento apresente também melhores resultados.

A Figura 7.13 a seguir apresenta a convergência do erro apresentado pelo treinamento inicial da rede com 500 pontos.

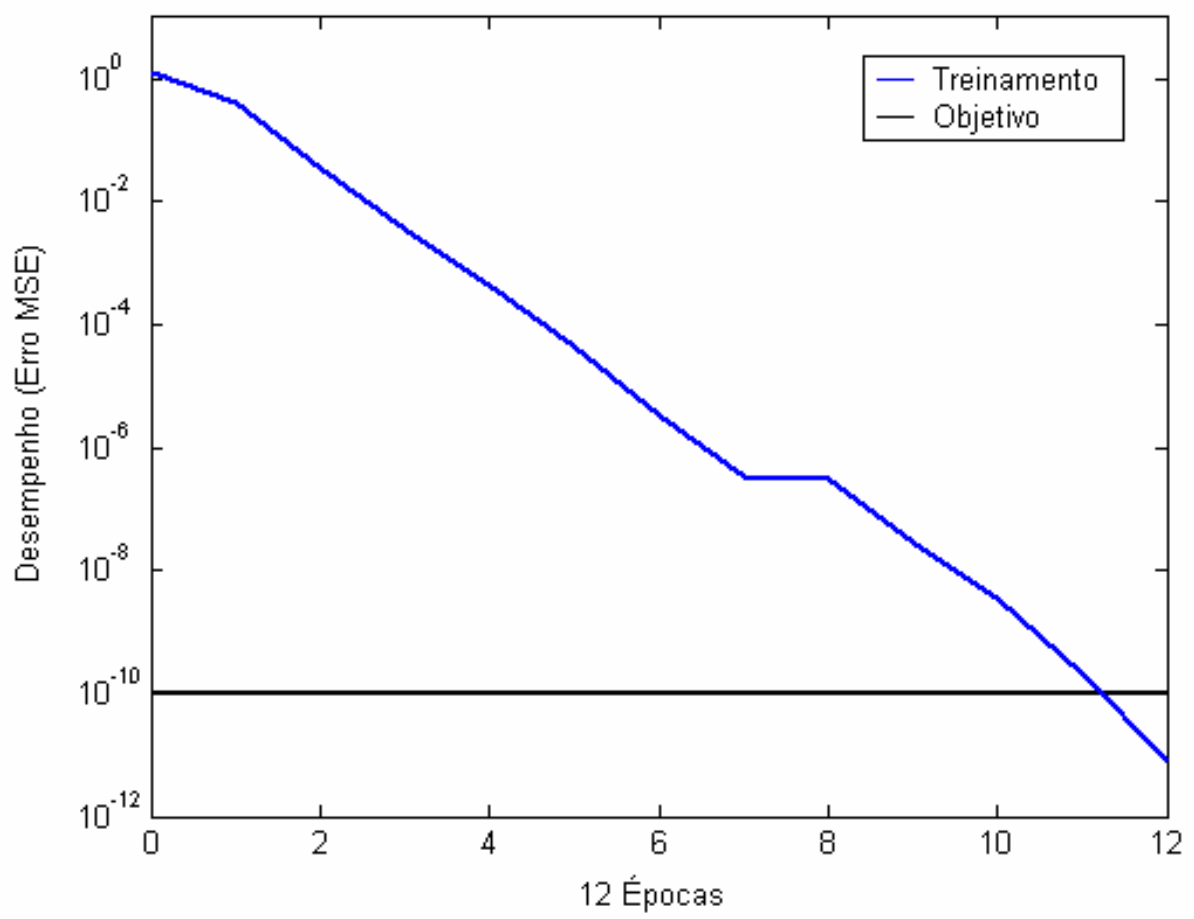

Figura 7.13: Convergência do treinamento da rede com 500 pontos

A Figura 7.14 apresenta o erro obtido com este sensor após o primeiro treinamento. A seguir serão detectados os pontos onde aprecem os maiores picos de erro e através da coleta de dados próximos estes será realizado o retreinamento do sensor. Conforme pode ser visto na Figura 7.15. 


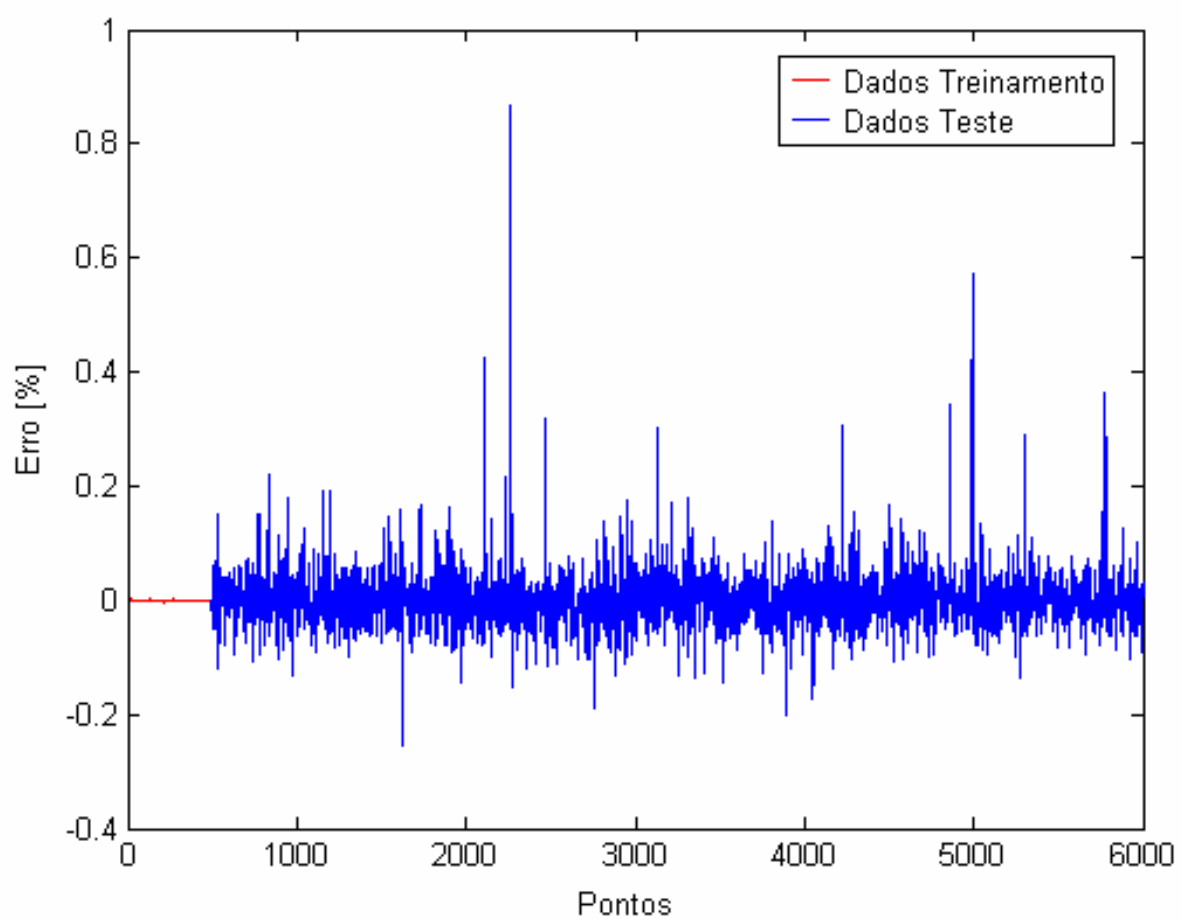

Figura 7.14: Erro apresentado após treinamento com 500 pontos

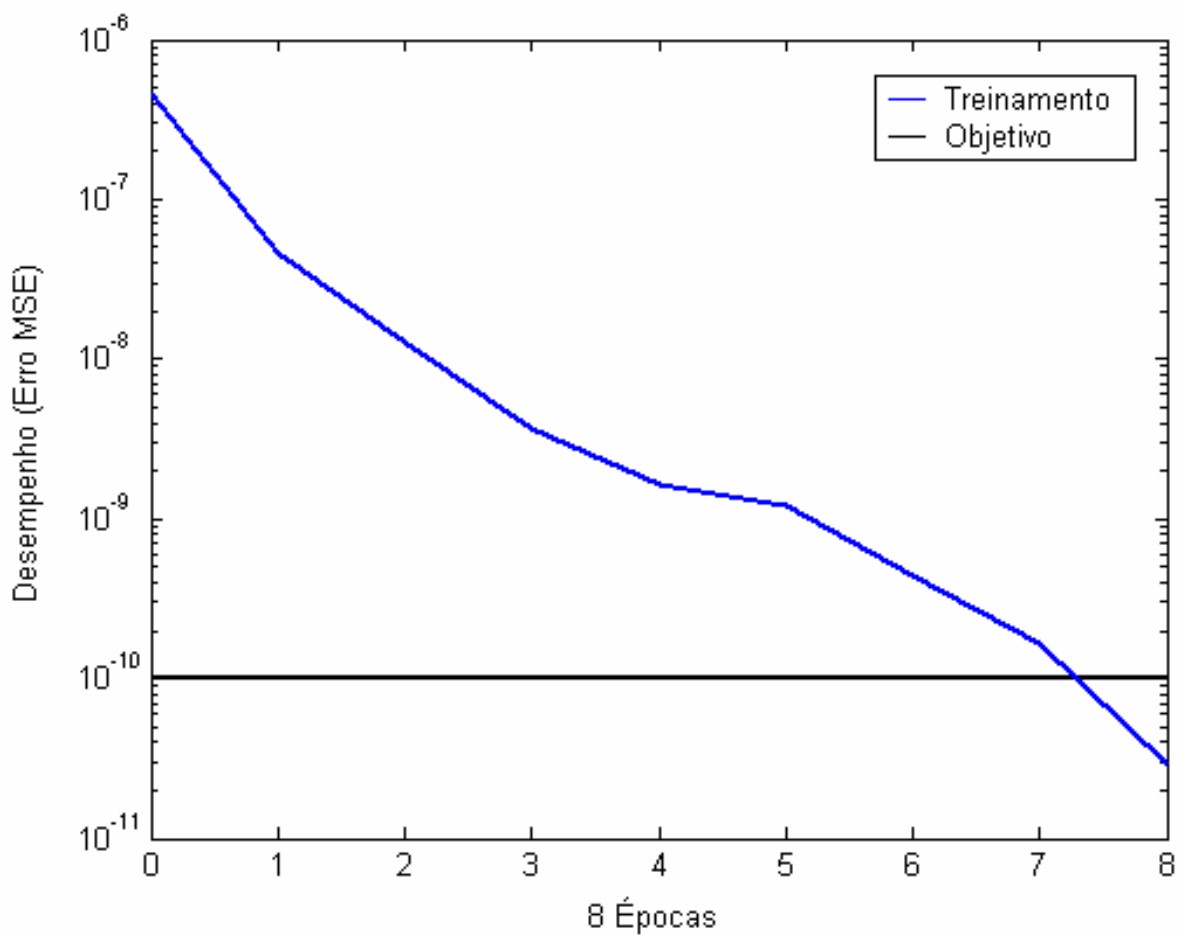

Figura 7.15: Convergência do treinamento da rede anterior para novos pontos 


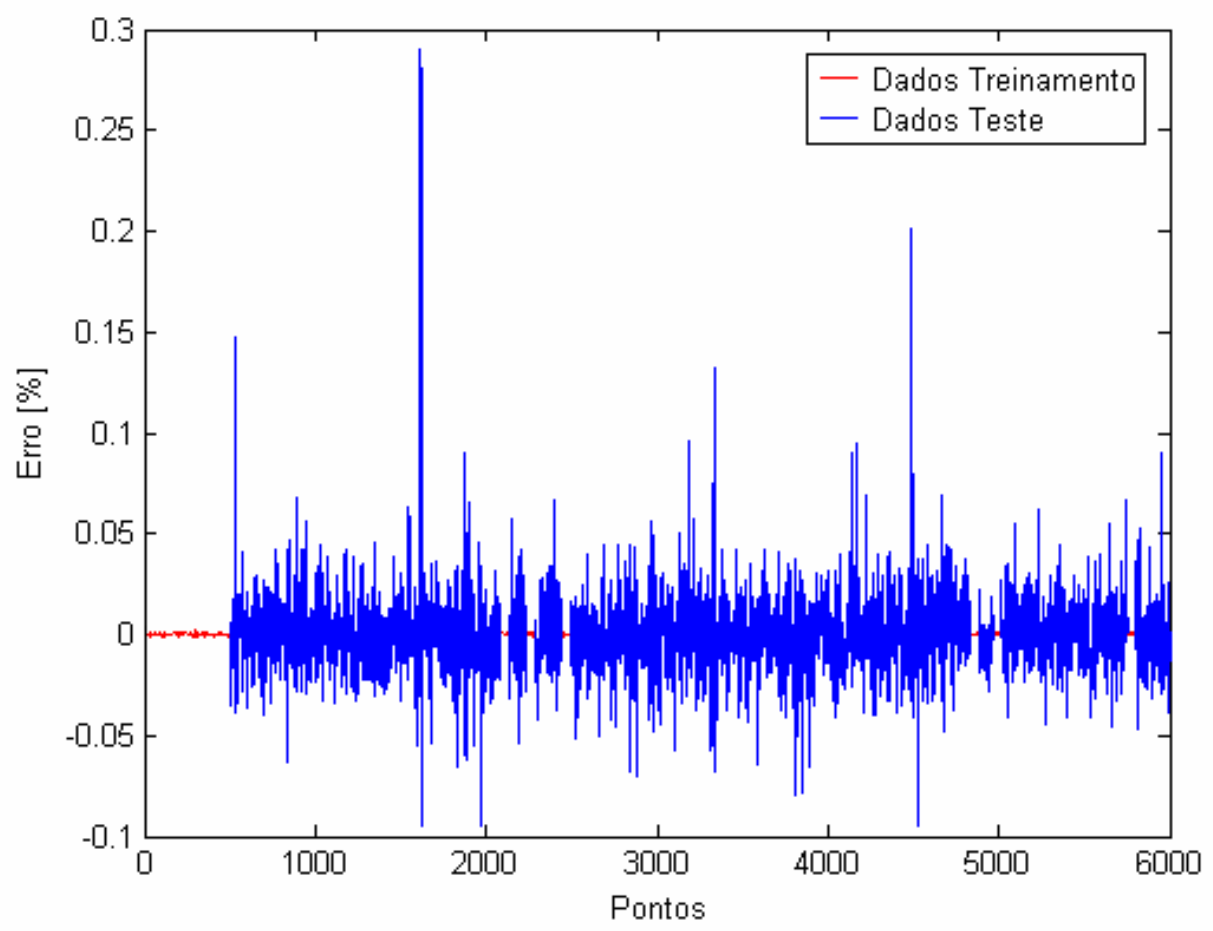

Figura 7.16: Erro apresentado após retreinamento com $(500+100)$ pontos

A Figura 7.16 apresenta o novo erro do sensor virtual após o retreinamento da rede. Observa-se as regiões oriundas do novo treinamento com erro bem menor que as demais (em vermelho) no gráfico.

Em seguida, procede-se a um novo treinamento semelhante ao anterior, no qual são novamente detectados os picos de erro e coletados dados próximos e é retreinada a rede como pode ser visto na Figura 7.17. O novo erro apresentado pela rede pode ser visto na Figura 7.18.

Observa-se que o erro do sensor virtual vem diminuindo conforme se aumenta o número de pontos no conjunto de dados, porém este aumento é mais lento que o obtido com a rede treinada de uma única vez com este mesmo número de dados. 


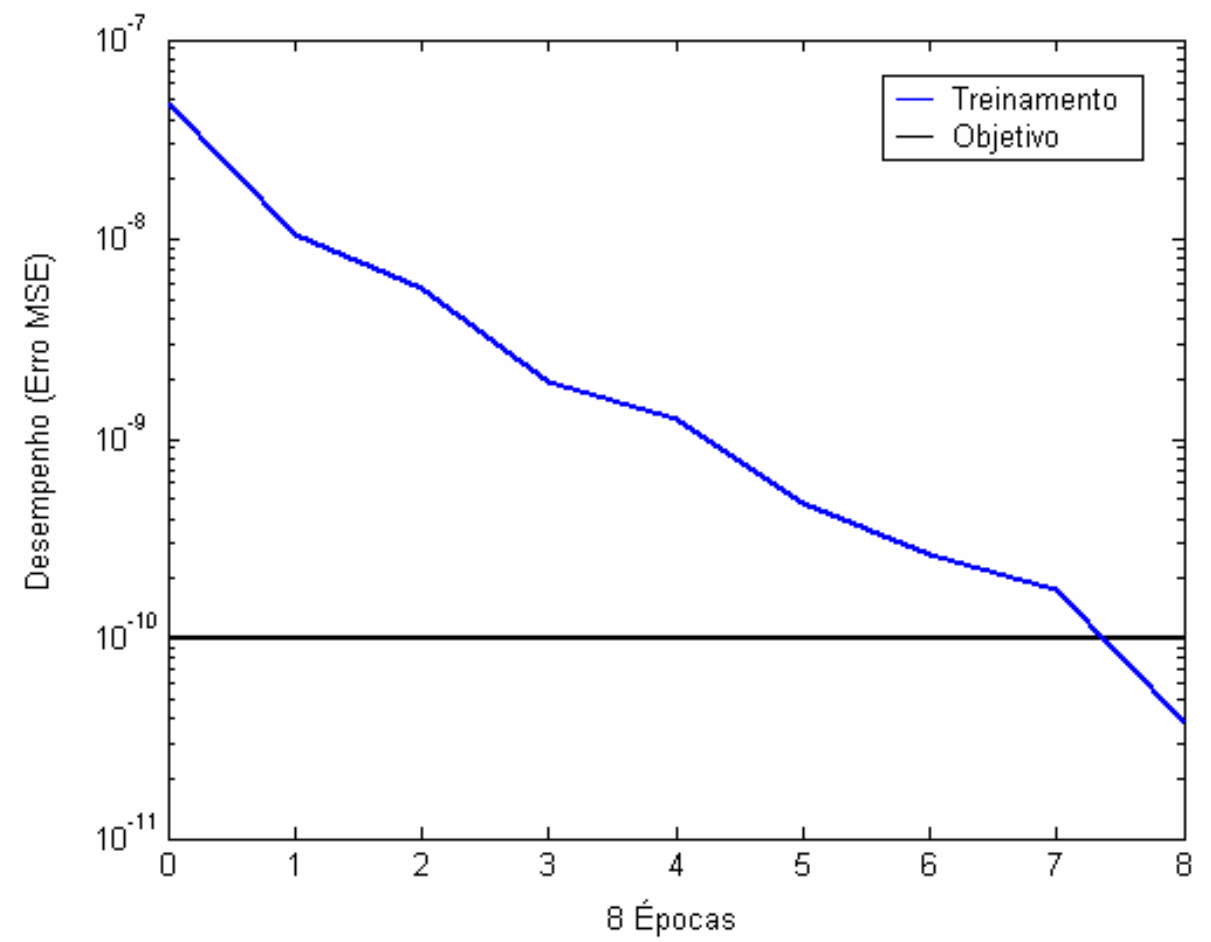

Figura 7.17: Convergência do treinamento da rede com 100 pontos do pico

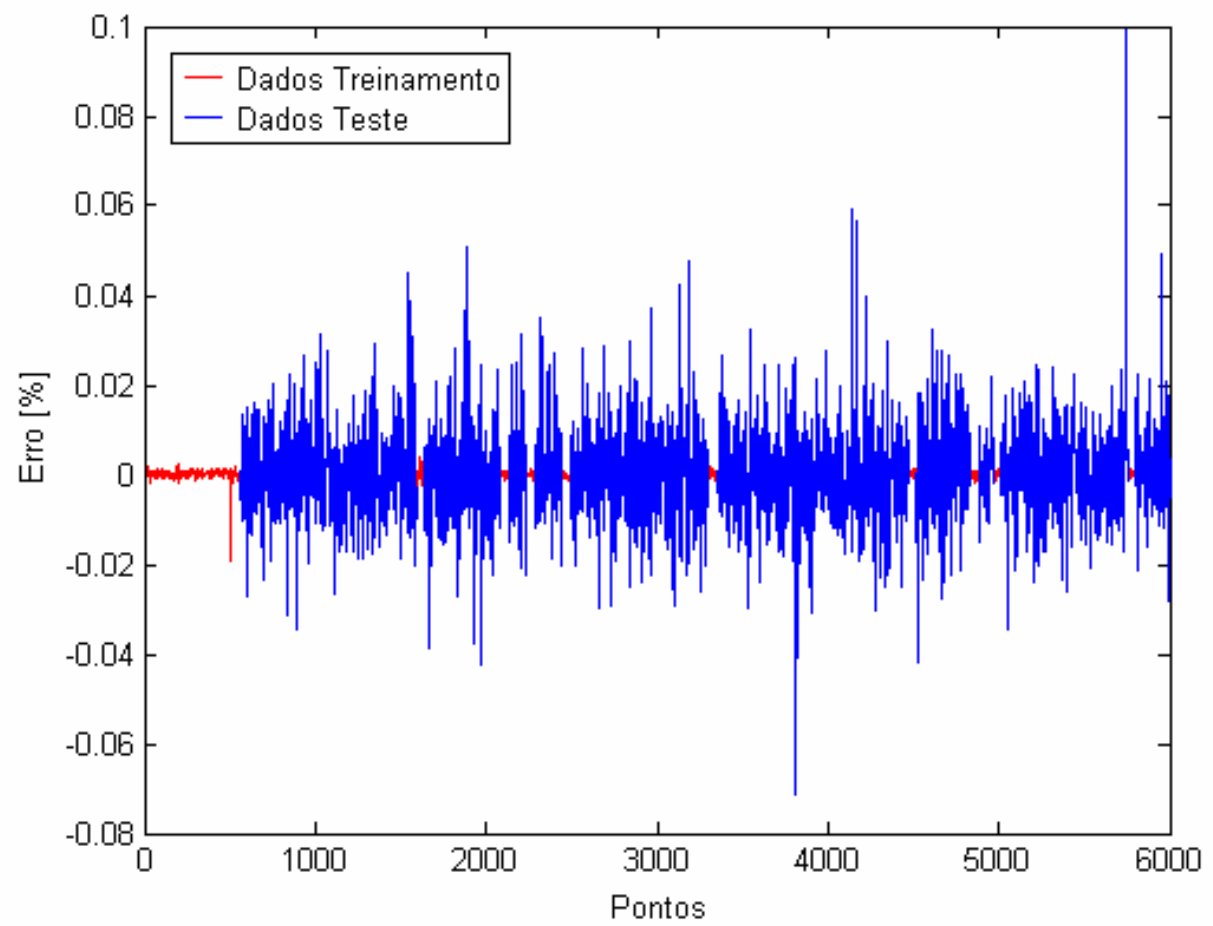

Figura 7.18: Erro geral após retreinamento com $(500+100+100)$ pontos 
Observa-se destas figuras que o resultado obtido pelo treinamento focados nos maiores erros gera uma melhora da capacidade estimativa da rede, porém esta melhora é inferior ao resultado obtido com o mesmo número de pontos treinados de modo direto. Isto pode ser atribuído ao fato de que quando fornecemos à rede apenas os pontos referentes aos picos estamos de fato treinando a rede com uma região de dados em que está deficiente, porém a forma de introduzir apenas os dados das regiões onde aparecem os maiores erros não significa que estamos resolvendo problemas para várias falhas no treinamento, mas pode ser apenas uma mesma região.

Assim uma rede treinada inicialmente com um pequeno número de pontos e com deficiência em uma pequena região de dados pode apresentar vários picos de erros toda vez que esta mesma região aparecer no conjunto de dados. A escolha destes pontos para o retreinamento da rede pode ser, na verdade, um fornecimento de dados repetidos de uma mesma região. Devido a isto a rede pode apresentar evolução lenta na diminuição do erro.

\section{Conclusões}

Podemos ver que o erro espúrio pode ser eliminado de forma "on-line" através do retreinamento da rede com dados oriundos das regiões deficientes. Porém, neste retreinamento é necessária a utilização dos dados utilizados em treinamentos anteriores.

Outra conclusão é que o método de retreinamento é útil para corrigir erros isolados que a rede possa vir a apresentar, mas não é a melhor opção para se realizar o treinamento padrão da rede. 


\subsection{Erro Sistêmico}

Nesta seção trataremos do estudo mais aprofundado sobre o erro sistêmico e das condições nas quais este ocorreu durante o desenvolvimento do sensor virtual e de como poderia ser corrigido e evitado.

A Figura 7.19 apresenta a convergência do erro durante o treinamento de uma rede neural realizado com 1.000 pontos. Esta rede possui 22 entradas sendo as 10 variáveis normais amostradas no instante atual, as mesmas 10 no instante de amostragem anterior (variáveis regredidas), mais os valores da composição do componente 2 no topo da coluna regredidos de dois tempos de amostragem (conforme apresentado na seção 5.5).

Além disto, esta rede neural possui como função de transferência no neurônio da camada de saída a função linear simples (comando "purelin" no Matlab ${ }^{\circledR}$ ). Para as demais camadas continuava sendo utilizada a função tangente hiperbólica sigmóide (comando "tansig” no Matlab ${ }^{\circledR}$ ). A estrutura utilizando a função linear na camada de saída é uma das mais comuns e preferidas quando se deseja construir redes neurais aproximadoras de funções. 


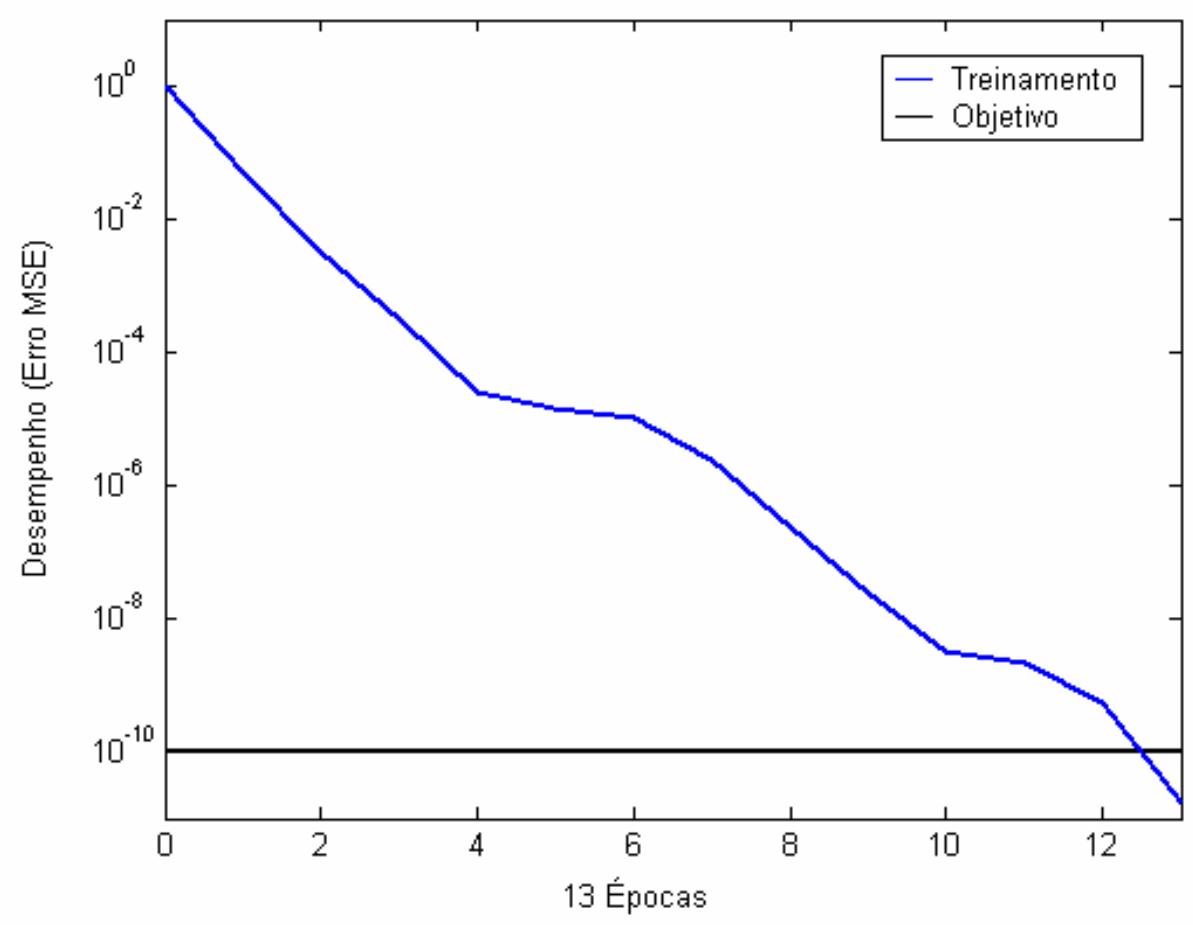

Figura 7.19: Convergência do erro durante o treinamento da rede

Da Figura 7.19 destaca-se que a convergência do treinamento ocorre de modo normal, com boa precisão da rede tanto para o conjunto de treinamento $\left(\mathrm{MSE}=2,54 \cdot 10^{-11}\right)$, como para o conjunto de validação $\left(\mathrm{MSE}=9,31.10^{-8}\right)$, o que mostra uma rede bem treinada e com capacidade de estimação satisfatória. A rede apresenta bom comportamento, com erro pequeno mesmo para o conjunto de testes, porém a partir de um determinado momento o erro cresce e a rede passa a apresentar valores irreais, como pode ser observado na Figura 7.20. 


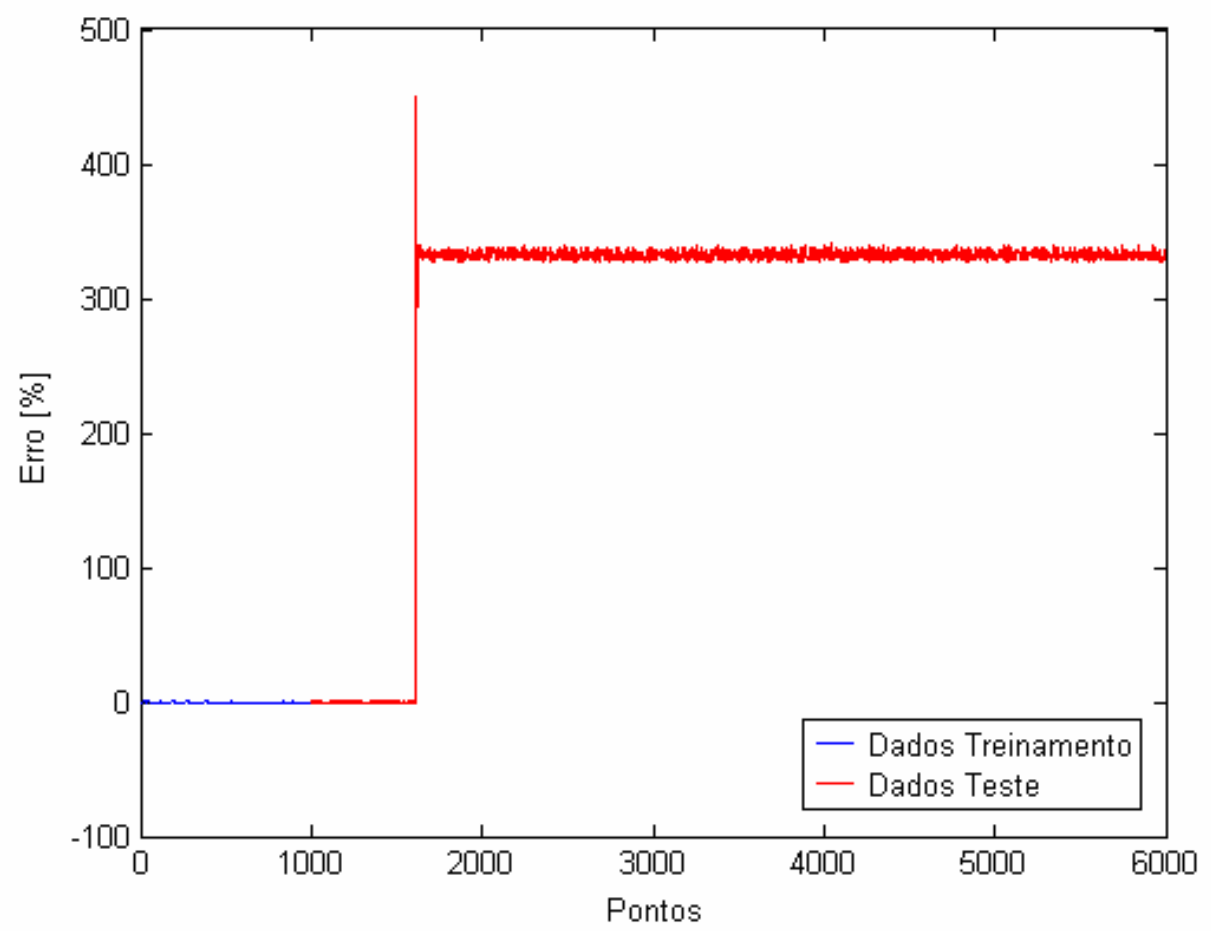

Figura 7.20: Erro apresentado pela rede durante validação com estimadores

Repara-se no gráfico que a resposta da rede é muito boa com todo o conjunto de treinamento e mesmo durante o início do conjunto de teste. Destaca-se aqui que a rede durante o treinamento recebeu como entradas os valores reais (fornecidos pelo simulador) da composição do componente 2 no topo da coluna, porém, para esta avaliação de seu comportamento são fornecidos como entradas os valores estimados pela própria rede regredidos de 2 tempos de amostragem. Mesmo assim a rede apresenta resultados muito bons para o início do teste.

Observa-se também que a rede apresenta a partir de um determinado momento erro muito grande, da ordem de $330 \%$. Na Figura 7.21 e Figura 7.22 podese observar a razão do erro ser tão grande, o valor estimado é de aproximadamente -2,3 (o que gera diferença absoluta de 3,3, ou seja, $330 \%$ de erro). Destaca-se que este valor não possui significado físico, uma vez que a composição da coluna deveria estar entre 0 e 1 . Porém, isto ocorre, pois não há limitação no valor de saída da rede (função linear na camada de saída). 


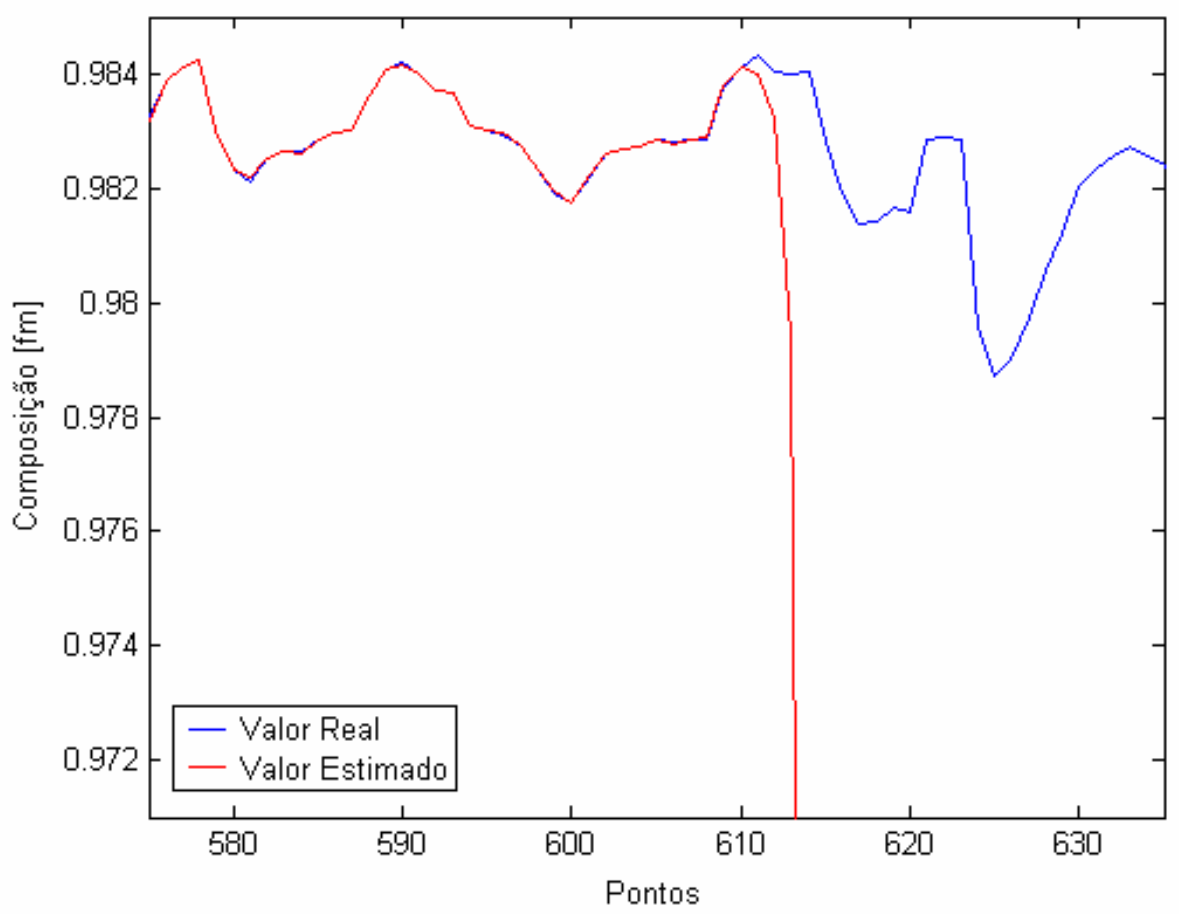

Figura 7.21: Comparação das composições no início do erro sistêmico

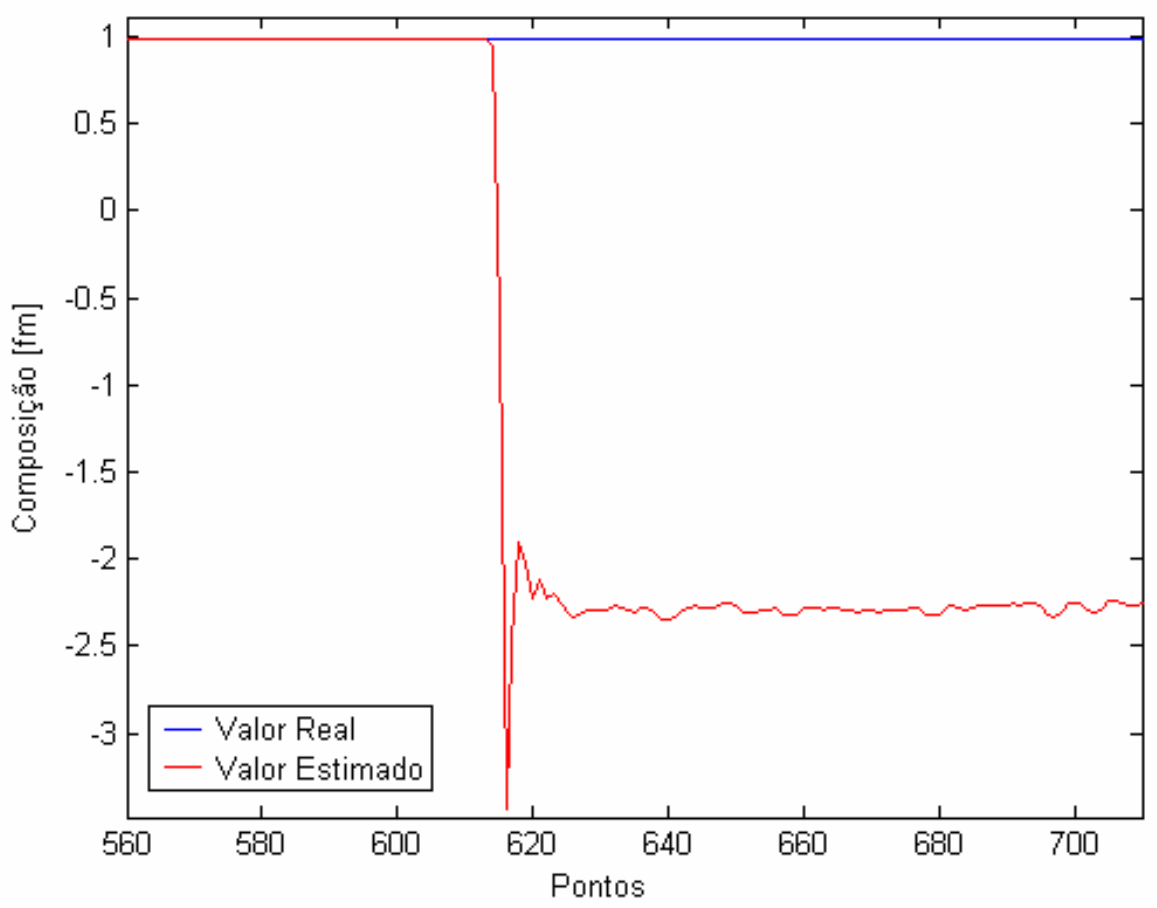

Figura 7.22: Visão geral das composições esperada e estimada pelo sensor 
Considerando-se a influência da função de transferência utilizada pode-se dizer que o valor irreal obtido é fruto da falta de limitações na amplitude das respostas fornecida pela rede neural. A Figura 7.23 mostra as funções de transferência utilizadas respectivamente nas camadas ocultas (não-lineares) e de saída (linear).
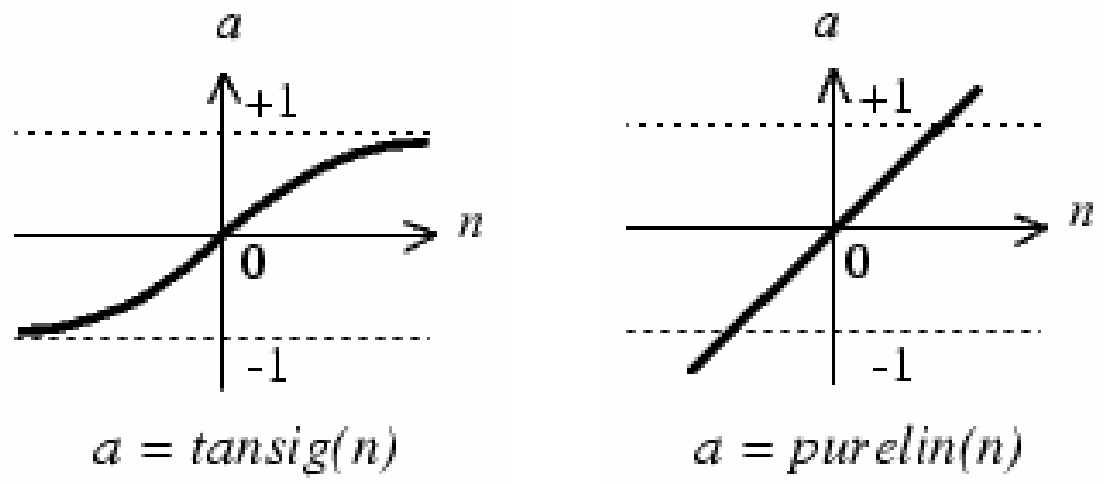

Figura 7.23: Funções de transferência utilizadas

A fim de se conhecer as causas que levaram a rede a apresentar este erro, foi realizado outro teste, porém, fornecendo como entradas para a rede apenas os valores apresentados pelo simulador, ou seja, as entradas da rede não eram mais os valores estimados pelo sensor nos instantes anteriores, mas sim os valores corretos fornecidos pelo simulador nos instantes anteriores. Deste modo, avaliam-se os efeitos da ausência dos estimadores.

A Figura 7.24 mostra o erro entre os sinais esperado e estimado. Repara-se que o erro é pequeno tanto para o conjunto de treinamento $\left(\mathrm{MSE}=1,74 \cdot 10^{-11}\right.$ ), como para o conjunto de teste $\left(\mathrm{MSE}=8,72 \cdot 10^{-8}\right)$. Isto mostra que o sensor apresenta um bom treinamento, com resultados ligeiramente melhores dos que os apresentados quando utilizados os estimadores como realimentação.

Destaca-se ainda, que o sensor apresenta um erro espúrio com amplitude de 1,4\%. Na Figura 7.25 é apresentada em detalhe a comparação entre as composições do componente 2 no topo da coluna apresentado pelo sensor virtual (estimado) e a real (fornecida pelo simulador). 


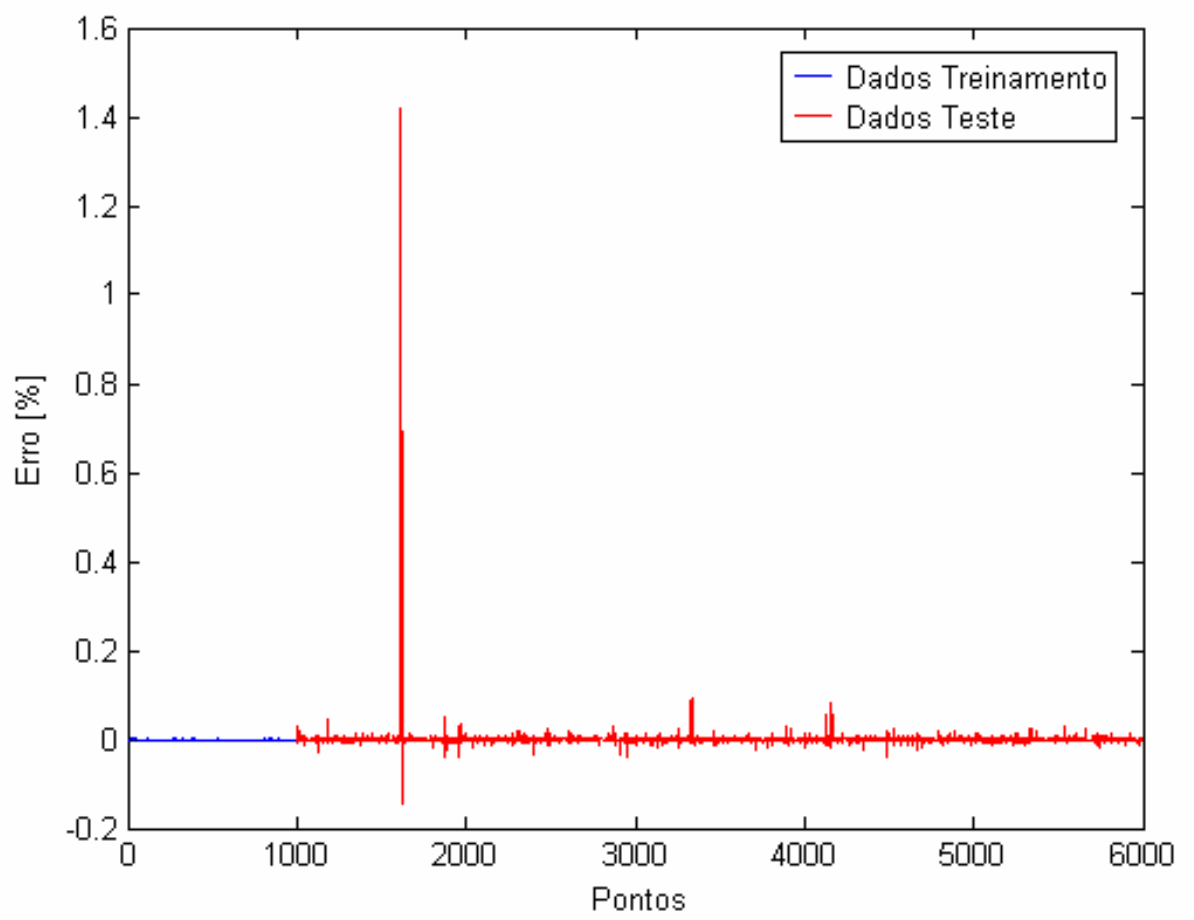

Figura 7.24: Erro apresentado durante validação com dados do simulador

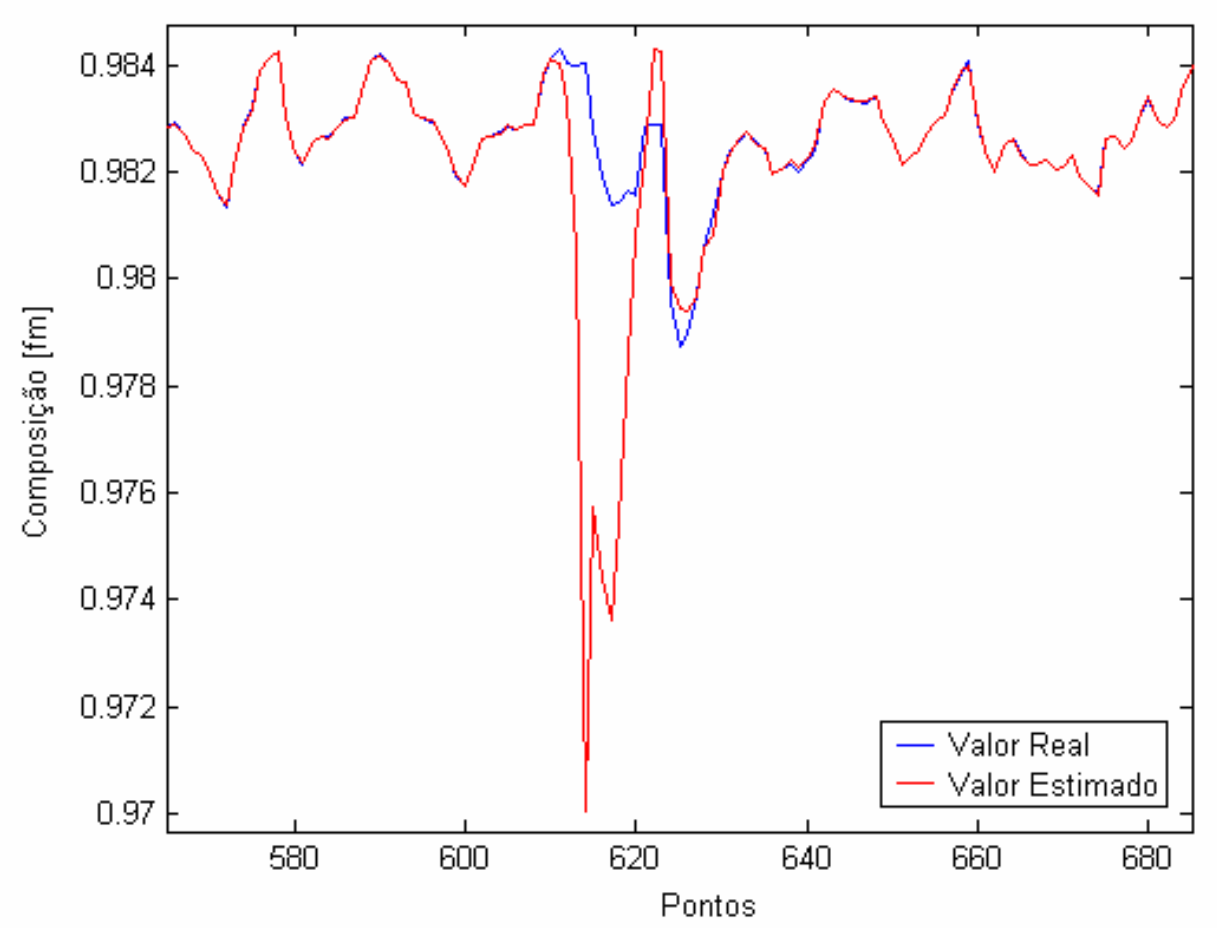

Figura 7.25: Composições esperada e estimada durante o erro espúrio 
Lembrando que os valores fornecidos como entrada para estimação pela rede agora foram os valores reais (em azul) regredidos, e não mais os valores estimados (em vermelho), como pode ser visto na Figura 7.25.

Pode-se observar uma grande correlação entre os erros sistêmico e espúrio apresentados respectivamente na Figura 7.21 e Figura 7.25. O início do erro sistêmico ocorre no mesmo instante em que se dá o erro espúrio, o que pode mostrar a influência deste erro na estimação dos valores futuros. Na verdade o erro espúrio inicia o erro sistêmico, uma vez que a rede é realimentada com o valor estimado errado, propagando o erro. Na Figura 7.25 a rede é capaz de voltar e corrigir-se, pois os valores fornecidos como entradas são os valores corretos apresentados pelo simulador (linha azul).

\section{Conclusões}

Podemos concluir que a rede neural com a função de transferência linear na camada de saída pode fornecer valores sem sentido físico, além de aumentar as possibilidades de erros na estimação do sensor. Porém, para todos os outros testes realizados foi utilizada a função tangente hiperbólica sigmóide que limita a saída do sensor entre - 1 e 1 , o que ainda permite uma faixa de valores impossíveis durante a operação. Ressalta-se no entanto, que esta função de transferência foi a que permitiu à rede apresentar os melhores resultados de convergência e acuidade na resposta. Dentre todos os demais treinamentos realizados nunca se observou o aparecimento de erro semelhante para nenhuma outra rede.

Finalmente, a alimentação da rede com estimadores da composição - valores fornecidos (estimados) pelo sensor virtual em instantes anteriores - como entradas da rede neural podem propagar erros ocorridos na estimação e levar o sensor a apresentar resultados insatisfatórios. A presença destas variáveis que aparentemente auxiliam a rede a encontrar uma melhor estimação do valor futuro, 
introduzem também um maior fator de risco para o próprio funcionamento da rede.

Destaca-se finalmente, que as referências encontradas sobre os erros sistêmicos (MURAKAMI; TANABE; OKAMOTO, 2002 e CAMARGO; TAKESAKO, 2003) não trazem um estudo mais detalhado das possíveis causas do surgimento deste erro, porém destaca-se que ambos os trabalhos realizados utilizavam realimentação com os valores estimados para a futura previsão do sensor.

Portanto, vimos que a aparição deste erro está ligada principalmente a problemas de estrutura interna da rede neural, apesar de que os defeitos no treinamento também colaboram na sua aparição. Os erros sistêmicos são de correção bem mais complicada e difícil de ser realizada "on-line" do que os erros espúrios. Para sua correção é necessário alteração na arquitetura da rede neural. No entanto, pra evitá-los, deixam-se duas sugestões: a primeira relativa à escolha das funções de transferências a serem utilizadas na arquitetura da rede neural escolhida, privilegiando-se funções não lineares internamente e saída limitadas; e a segunda quanto à utilização rigorosa, quando utilizada, dos estimadores regredidos na alimentação da própria rede neural. 


\section{Capítulo 8}

\section{Considerações Finais}

\subsection{Contribuições do trabalho}

O presente trabalho foi motivado por uma necessidade industrial para a medição instantânea, de forma confiável e precisa e com custo de implantação e manutenção baixos, da composição do produto de topo em colunas de destilação.

Para solucionar este problema foi proposto o desenvolvimento de um sensor virtual empregando técnicas baseadas em redes neurais artificiais que pudesse satisfazer à maioria destes requisitos com um grau superior ao das alternativas de mercado.

Porém, acrescentou-se ao trabalho um estudo das contribuições que poderiam ser obtidas através da utilização de um modelo simulado dinamicamente no desenvolvimento do sensor, dos efeitos que poderiam advir da utilização de treinamento parcial no projeto e finalmente, uma proposta de análise e solução para os dois principais erros encontrados em sensores virtuais.

Estes pontos de estudo levantados foram a principal contribuição do trabalho, no que diz respeito à inovação. Além disso, inclui-se o desenvolvimento do 
sensor virtual realizado através das redes neurais que possui paralelo com várias propostas que têm surgido recentemente para a construção de projetos semelhantes. A utilização de um simulador dinâmico para o treinamento da rede neural e a possibilidade de realização de treinamentos sucessivos, melhorando o desempenho da rede possibilita o desenvolvimento de sensores para operarem em plantas novas e acompanhar variações que possam ocorrer com o tempo de funcionamento do processo.

Outra contribuição importante é o estudo realizado sobre os principais erros que podem ocorrer com este tipo de sensores, que são raramente tratados em

publicações científicas. É também proposta uma metodologia para detecção e correção dos dois tipos de erros mais freqüentes: espúrio e sistêmico.

\subsection{Conclusões}

Neste trabalho foi inicialmente proposto o desenvolvimento de um sensor virtual empregando redes neurais artificiais para medição inferencial da composição do produto de topo em colunas de destilação. Um dos objetivos era familiarizar-se com o processo de destilação e sua modelagem para desenvolvimento de simuladores dinâmicos, bem como aprofundar-se no conhecimento sobre redes neurais e suas capacidades e possibilidades de utilização para reconhecimento de padrões e identificação de sistemas.

Desta etapa pode-se concluir que os resultados foram alcançados. Outro objetivo era realizar um avanço no sensor desenvolvido, conhecendo melhor as possibilidades originárias do treinamento parcial das redes neurais para um sensor desenvolvido a partir de dados de um simulador dinâmico do processo. E, finalmente, o estudo dos principais erros levou-nos a defrontar com os dois tipos destes, denominados de espúrios e sistêmicos, que afetam o comportamento do sensor, alterando sua precisão e capacidade de ser utilizado em um controle inferencial da planta. 
Podemos concluir que os resultados obtidos foram muito bons, o sensor apresentou-se com um erro bastante pequeno para os padrões exigidos e ainda possibilitou um ajuste mais fino ao longo do tempo, com os treinamentos sucessivos, que melhoram o seu desempenho e permitem acompanhar uma evolução temporal do processo.

\subsection{Trabalhos futuros}

Há uma série de pontos neste trabalho que dão margem para desenvolvimentos posteriores, avanços e melhorias que poderiam ser realizadas.

Uma primeira proposta seria realizar a validação dos resultados obtidos com dados coletados de uma planta real, para verificar a evolução do comportamento do sensor para adequar-se às condições da unidade industrial e ainda acompanhar sua evolução temporal.

Outro ponto que poderia ser levantado seria quanto à amplitude de processos aos quais o sensor desenvolvido poderia adaptar-se. No trabalho apresentado é utilizada uma coluna contínua para separação de cinco componentes sem reação e com características não muito díspares entre si. O seu comportamento para colunas batelada, processos de fracionamento múltiplo e colunas especiais teria que ser avaliado. 


\section{Referências Bibliográficas}

AGUIRRE, L. A. Introdução à identificação de sistemas: técnicas lineares e não-lineares aplicadas a sistemas reais. Belo Horizonte: Ed. UFMG, 2004. 554p.

BHARTIYA, S.; WHITELEY, J. R. Development of inferential measurements using neural networks. ISA Transactions, v.40, n.4, p.307-323, 2001.

BOZENHARDT, H. F. Modern Control tricks solve distillation problems. Hydrocarbon Processing, v.67, n.6, p.47-50, 1988.

BRAGA, A. P.; CARVALHO, A. C. P. L. F.; LUDERMIR, T. B. Fundamentos de

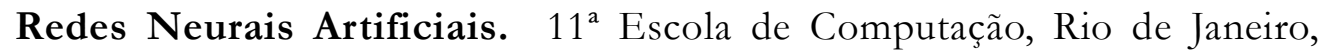
1998. 246p.

CAMARGO, L. T.; TAKESAKO, R. T. Desenvolvimento de um sensor virtual baseado em redes neurais da concentração de oxigênio dissolvido em um processo de tratamento de águas residuais. 2003. Trabalho de conclusão do curso de Engenharia Elétrica (Automação e Controle), Escola Politécnica, Universidade de São Paulo. São Paulo., 2003.

CAMPOS, M. M., SAITO, K. Sistemas inteligentes em controle e automação de processos. Rio de Janeiro: Ed. Ciência Moderna Ltda., 2004. 235p. 
CHOI, D. J.; PARK, H. A hybrid artificial neural network as a software sensor for optimal control of a wastewater treatment process. Water Research, v.35, n.16, p.3959-3967, 2001.

CHU, J.; SU, H.; GAO, F.; WU, J. Process control: art or practice. Annual Reviews in Control, v.22, p.59-72, 1998.

DONG, J. W.; QIAN, J. X.; SUN, Y. X. Recurrent neural networks for recursive identification of nonlinear dynamic process. Proceedings of the IEEE International Conference on Industrial Technology, Hangzhou: China, p.794-798, 1994.

FILETI, A. M. F.; PEDROSA, L. S.; PEREIRA, J. A. F. R. A self tuning controller for multicomponent batch distillation with soft sensor inference based on a neural network. Computers \& Chemical Engineering Supplement, v.23, p.S261-S264, 1999.

GARCIA, C. Modelagem e Simulação de Processos Industriais e de Sistemas Eletromecânicos. São Paulo: EDUSP, 1997. 458p.

GUSTAVSSON, I. Survey of applications of identification in chemical and physical processes. Automatica, v.11, n.1, p.3-24, 1975.

HAYKIN, S. Redes neurais: Princípios e prática. $2^{\text {a }}$ ed. Editora Bookman, 2000. 900 p.

HONG, S. J.; JUNG, J. H.; HAN, C. A design methodology of a soft sensor based on local models. Computers \& Chemical Engineering Supplement, v.23, p.S351-S354, 1999.

JAMES, S. C.; LEGGE, R. L., BUDMAN, H. On-line estimation in bioreactors: A review. Reviews in Chemical Engineering, v.16, n.4, p.311-340, 2000. 
JIANXU, L.; HUIHE, S. Soft sensing modeling using neurofuzzy system based on Rought set Theory. Proceedings of the American Control Conference, Anchorage: USA, v.1, p.543-548, 2002.

JOSEPH, B.; BROSILOW, C. B. Inferential Control of Processes: Part I, II e III. AIChE Journal, v.24, n.3, p.485-509, 1978.

KANO, M.; MIYAZAKI, K.; HASEBE, S.; HASHIMOTO, I. Inferential control system of distillation compositions using dynamic partial least squares regression. Journal of Process Control, v.10, n.2, p.157-166, 2000.

KANO, M.; SHOWCHAIYA, N.; HASEBE, S.; HASHIMOTO, I. Inferential control of distillation compositions: selection of model and control configuration. Control Engineering Practice, n.11, p.927-933, 2003.

LJUNG, L. System Identification: theory for the user. $2^{\text {a }}$ ed. Englewood Cliffs: Prentice Hall, 1999.

LUYBEN, W. L. Process Modeling, Simulation and Control for Chemical Engineers. $2^{a}$ ed. New York: Ed. McGraw-Hill, 1990. 725p.

MARLIN, T. E. Process Control - designing processes and control system for dynamic performance. New York: McGraw-Hill, 1995. 640p.

MEJDELL, T.; SKOGESTAD, S. Estimation of distillation compositions from multiple temperature measurements using partial-least-square regression. Industrial \& Engineering Chemistry Research, v.30, n.12, p.2543-2555, $1991 \mathrm{a}$.

MEJDELL, T.; SKOGESTAD, S. Composition estimator in a pilot-plant distillation column using multiple temperatures. Industrial \& Engineering Chemistry Research, v.30, n.12, p.2555-2564, 1991 b. 
MEJDELL, T.; SKOGESTAD, S. Output estimation using multiple secondary measurements: high-purity distillation. AIChE Journal, v.39, n.10, p.1641$1653,1993$.

MURAKAMI, J. R.; TANABE, R. K.; OKAMOTO, U. K. Desenvolvimento de sensor virtual de pH em processo de neutralização. 2002. Trabalho de conclusão do curso de Engenharia Elétrica (Automação e Controle), Escola Politécnica, Universidade de São Paulo. São Paulo., 2002.

NASCIMENTO, C. A. O.; ODLOAK, D.; ZANIN, A. C.; GUEDES, L. R. S.; TIUMAN, L. M.; MATSUDA, M. M.; KARASAWA, W. Y. Simulação Modular Dinâmica de uma Coluna de Destilação Multicomponente. In: SEMINÁRIO SOBRE APLICAÇÕES E DESENVOLVIMENTO EM SIMULADORES DE PROCESSO. Rio de Janeiro, 1990. Anais. Rio de Janeiro, PETROBRÁS, 1990, p.1-57.

NGUYEN, D.; WIDROW, B. Improving the learning speed of 2-layer neural networks by choosing initial values of the adaptive weights. IJCNN: International Joint Conference on Neural Networks, p.21-26, 1990.

NETO, E. A. Controle Preditivo Multimodelos de uma Torre Debutanizadora. São Paulo, 1999. 179p. Dissertação (Mestrado) - Escola Politécnica, Universidade de São Paulo. São Paulo, 1999.

PARK, S.; HAN, C. A nonlinear soft sensor based on multivariate smoothing procedure for quality estimation in distillation columns. Computers \& Chemical Engineering, v.24, n.2, p.871-877, 2000.

SKOGESTAD, S. Dynamics and control of distillation columns - a critical survey. Modeling, Identification and Control, v.18, n.3, p.177-217, 1997a.

SKOGESTAD, S. Dynamics and control of distillation columns: a tutorial introduction. Chemical Engineering Research \& Design, Transactions of 
the Institute of Chemical Engineers, Part A, v.75, n.6, Sep. 1997b, p 539562.

SOROUSH, M. State and parameter estimations and their applications in process control. Computers and Chemical Engineering, v.23, n.2, p.229-245, 1998.

SPINELLI, M. A. Controle e Simulação Dinâmica de Colunas de Destilação: Aplicação Prática em uma Coluna com Refluxo por Gravidade. 1997. 107p. Dissertação (Mestrado) - Escola Politécnica, Universidade de São Paulo. São Paulo.

WANG, Y.; RONG, G. A self-organizing neural-network-based fuzzy system. Fuzzy Sets and Systems, v.103, n.1, p.1-11, 1999.

WILLIS, M. J.; DI MASSIMO, C.; MONTAGUE, G. A.; THAM, M.T.; MORRIS, A. J., Artificial neural networks in process engineering. IEE Proceedings Part D: Control Theory and Applications, v.138, n.3, p 256-266, 1991.

WILliS, M. J.; MONTAGUE, G. A.; DI MASSIMO, C.; THAM, M.T.; MORRIS, A. J., Artificial neural networks in process estimation and control. Automatica, v.28, n.6, p.1181-87, 1992.

ZAMPROGNA, E.; BAROLO, M.; SEBORG, D. E. Composition estimations in a middle-vessel batch distillation column using artificial neural networks. Chemical Engineering Research and Design, v.79, n.6, p.689-696, 2001.

ZANATA, D. R. P. Desenvolvimento de modelo matemático dinâmico rigoroso em Simulink/Matlab ${ }^{\circledR}$ de coluna de destilação multicomponente. 2002. Projeto de Iniciação Científica, processo FAPESP nº 01/06511-0, São Paulo, 2002. 


\section{Apêndice A}

\section{Fundamentos de Destilação}

\section{A.1 Introdução}

Neste anexo é apresentada de forma sucinta e esquematizada uma explanação sobre os fundamentos da destilação e os princípios básicos do funcionamento das colunas de destilação. O intuito é fornecer uma fundamentação conceitual para facilitar a leitura e compreensão da dissertação para o leitor menos familiarizado com este tipo de processo.

Destilação é um processo de separação de uma mistura em seus componentes, através da adição ou subtração de calor à mistura em função das diferentes temperaturas de ebulição dos seus elementos constituintes. Por exemplo, uma mistura homogênea de água e sal pode ser separada nos seus componentes mediante a adição de calor à mistura até que esta atinja a temperatura de ebulição da substância mais volátil (água), e continuando a adição até que toda a água evapore. $\mathrm{O}$ vapor produzido deve ser condensado num outro dispositivo que retire calor deste, liquefazendo-o novamente. O sal permanecerá no recipiente inicial. Deste modo têm-se os dois componentes da mistura separados. 
A destilação é um dos processos mais importantes para a separação de misturas numa unidade industrial e, normalmente, o maior responsável pelo consumo de energia destas plantas. Pode chegar facilmente a responder pelo consumo de cerca de 50\% dos custos de operação de uma planta industrial, devido ao alto consumo energético necessário para o aquecimento e resfriamento das soluções. Por isto, é tão vantajoso o controle eficiente desta operação, que pode gerar grande economia e vantagem competitiva para a empresa.

\section{A.2 Fundamentos de Destilação}

Serão apresentadas a seguir as noções fundamentais do processo de destilação, a análise da separação de misturas e as equações utilizadas para a modelagem matemática deste processo.

\section{Pressão de Vapor}

Ou pressão interna, como o próprio nome sugere refere-se à pressão que possui uma determinada substância (normalmente líquida), em função principalmente da temperatura a que está submetida. Quando esta pressão interna iguala-se à pressão externa local (atmosférica caso o processo seja aberto) o líquido entra em ebulição.

A pressão interna de vapor é uma característica de cada substância em específico e aumenta conforme a temperatura a que está submetida a mesma. Esta pressão possui forte dependência da temperatura e apresenta comportamento aproximadamente exponencial, como pode ser visto na Figura A.1.

A evaporação de um líquido está intimamente ligada à pressão de vapor deste, sendo que a mudança de estado físico processa-se quando a pressão interna 
do líquido iguala-se à pressão externa dando origem à formação de bolhas que levam o vapor para fora do líquido.

No processo de aquecimento de uma substância a temperatura do líquido aumenta conforme a taxa de calor fornecida. Conseqüentemente, a pressão interna de vapor aumenta exponencialmente até que as pressões interna do líquido e externa igualem-se, momento em que a temperatura cessa de aumentar até que toda a substância seja evaporada.

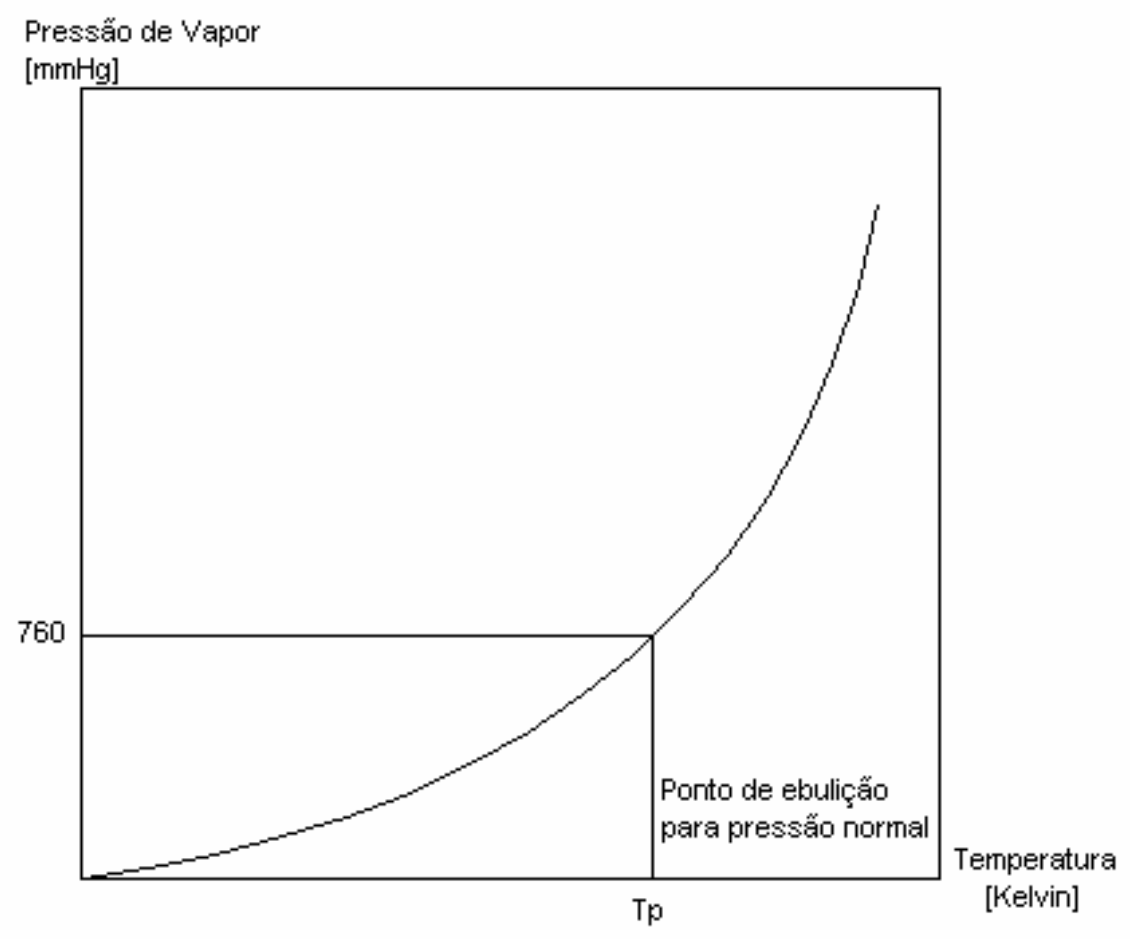

Figura A.1: Relação Temperatura x Pressão para uma substância

A pressão interna de vapor é uma característica de cada substância. As substâncias, que para uma mesma temperatura possuem maior pressão interna (estão mais próximas do ponto de mudança de estado) são ditas mais voláteis ou mais leves, em contraposição às outras que são ditas menos voláteis ou mais pesadas. A Figura A.2 mostra uma comparação entre duas substâncias com diferentes curvas de pressão interna pela temperatura. 


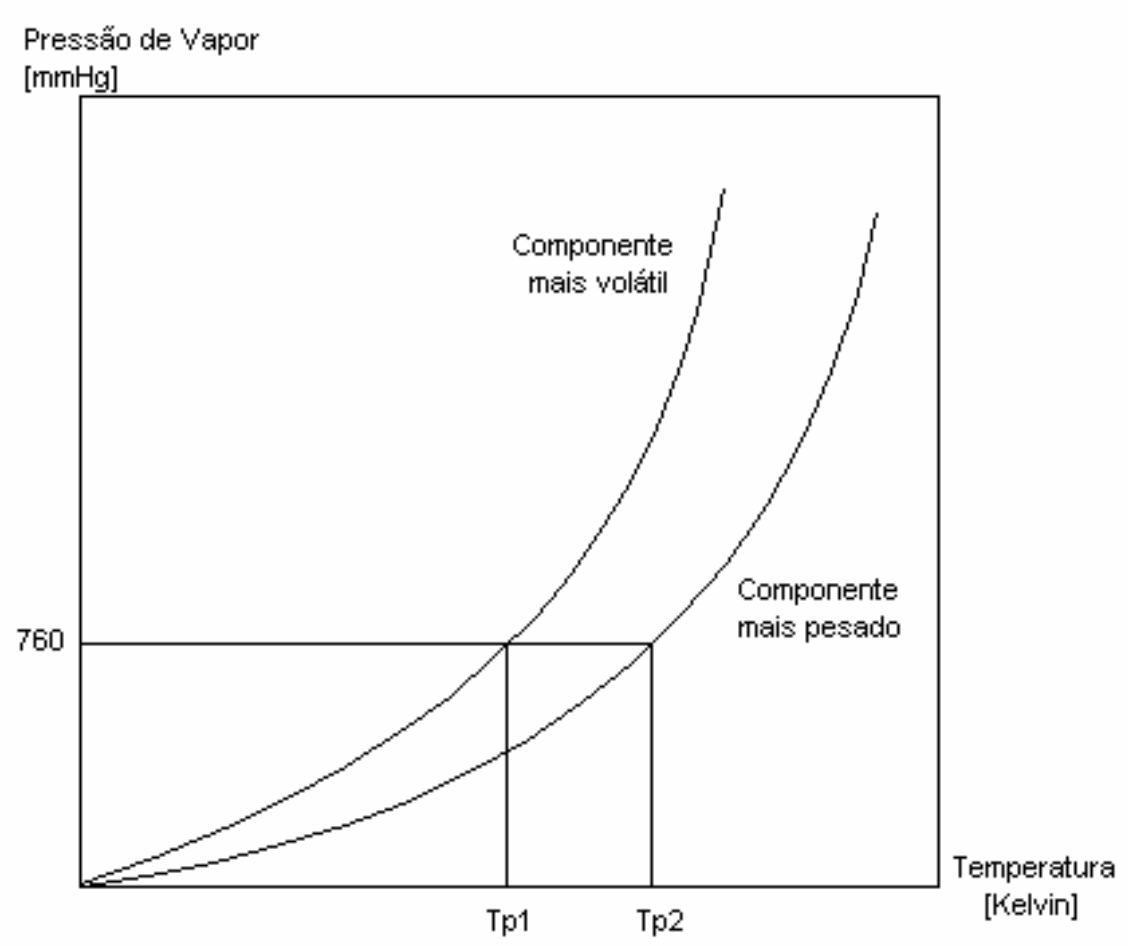

Figura A.2: Comparação das temperaturas de ebulição para duas substâncias

\section{Misturas}

Numa mistura normalmente encontram-se presentes substâncias com diferentes pontos de ebulição. Quando isto ocorre a pressão de vapor da mistura é uma combinação não-linear das pressões de vapor das substâncias envolvidas. $\mathrm{Ou}$ seja, a temperatura de ebulição da mistura possui um valor intermediário aos dos componentes.

Desta forma, analisando-se o comportamento da evaporação de uma mistura percebe-se que a temperatura de ebulição não permanece constante, mas é uma função da concentração instantânea dos componentes. Assim, uma mistura que está sendo aquecida entra em ebulição a uma temperatura ligeiramente maior que a temperatura de ebulição da substância mais volátil pura. A esta temperatura há maior evaporação da substância menos volátil, que diminui sua concentração na 
mistura resultante, deixando-a com concentração ligeiramente maior do componente mais pesado e conjuntamente maior ponto de ebulição.

A Figura A.3 mostra o comportamento da temperatura de ebulição para uma mistura binária em função da concentração em fração molar (fm) do componente mais leve. A curva superior refere-se analogamente à temperatura de condensação do vapor em função da sua composição.

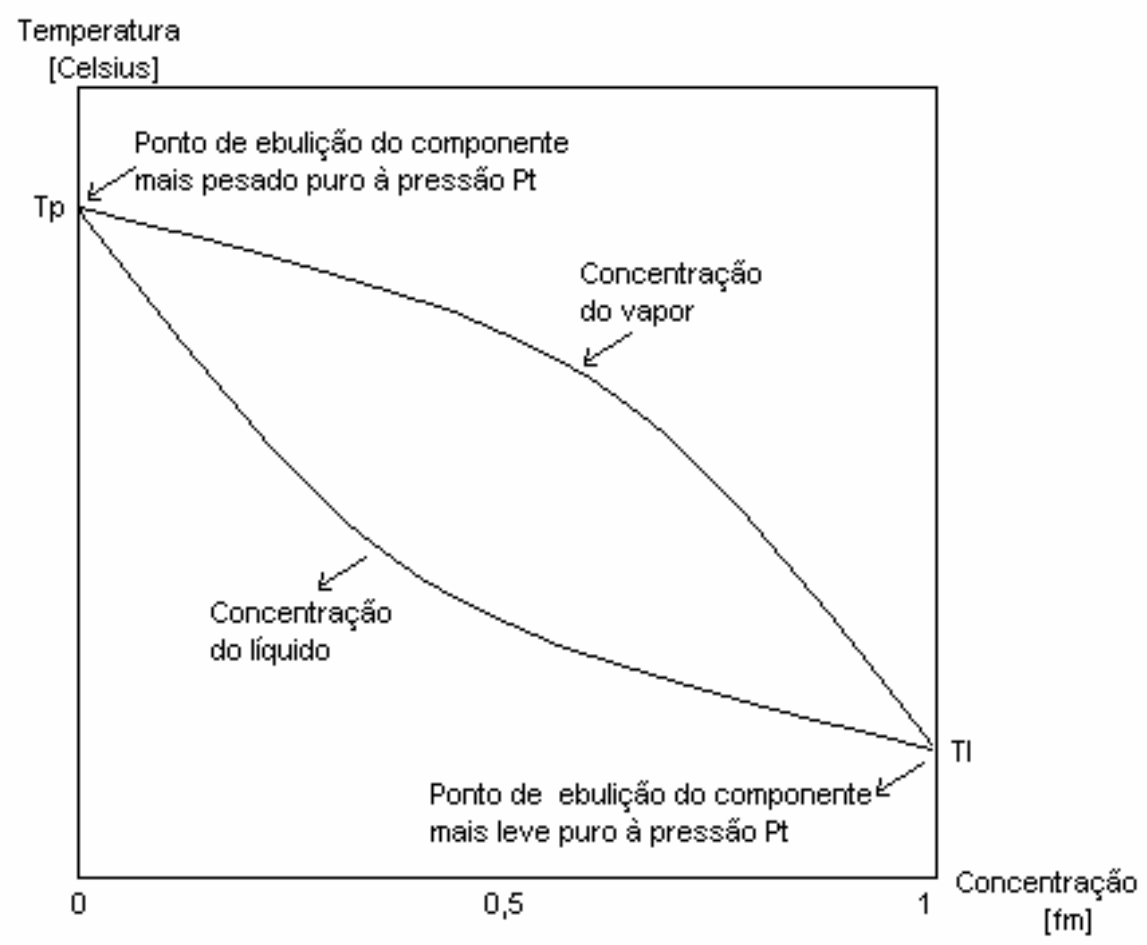

Figura A.3: Variação da temperatura de ebulição da mistura pela concentração à uma pressão externa constante

Para a pressão de vapor o processo é análogo. A pressão interna que a mistura deve atingir para entrar em ebulição tem de ser equivalente à externa. Porém, se houver maior concentração da substância mais volátil a mistura já iniciará com uma pressão interna mais elevada. A Figura A.4 mostra graficamente este comportamento. 


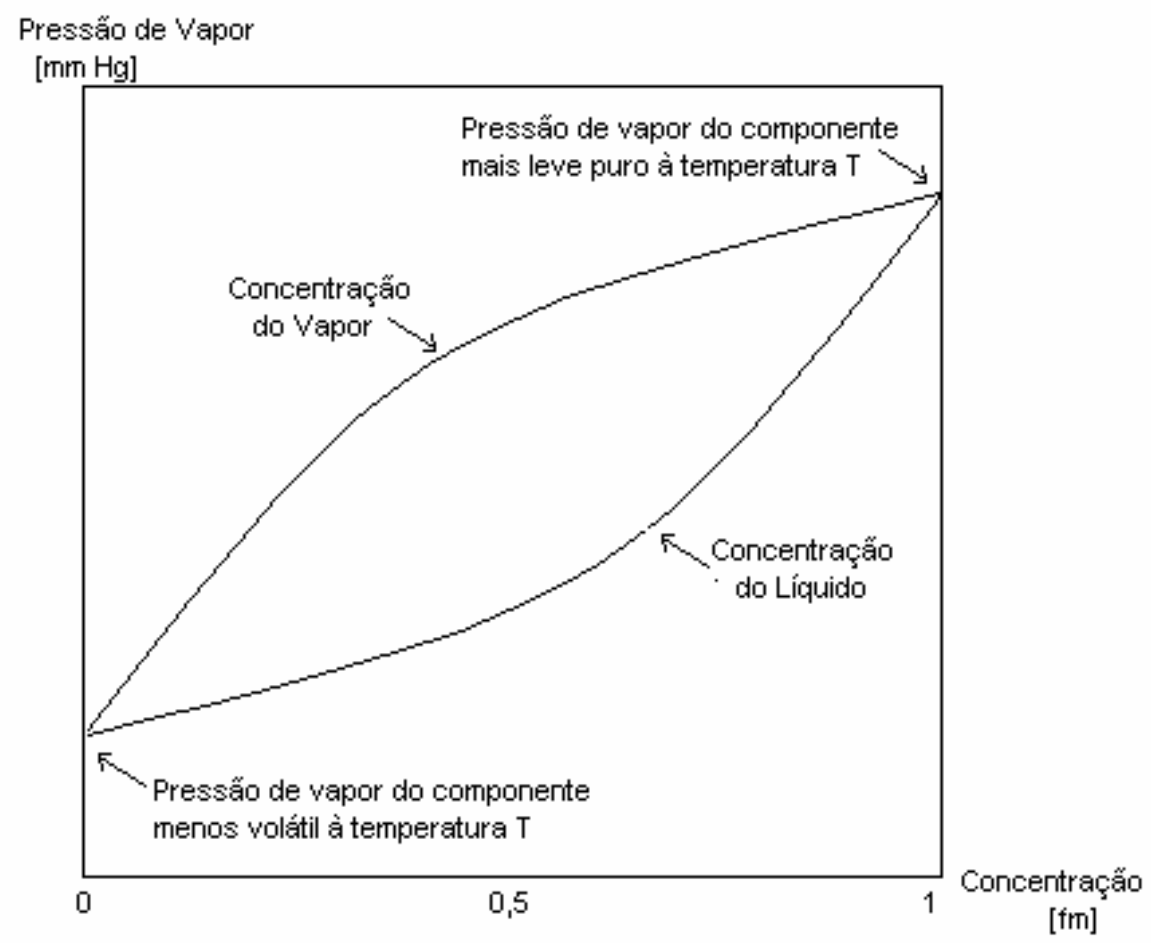

Figura A.4: Variação da pressão de vapor da mistura pela concentração à uma pressão externa constante

\section{Modelos}

A seguir, descrevem-se de forma resumida os dois principais modelos empregados para a modelagem do comportamento da pressão de vapor de uma substância. São as chamadas equação de Clapeyron e de Antoine.

O modelo de Clapeyron baseia-se numa fórmula simples para expressar o valor da pressão de vapor para uma dada substância e é extremamente útil quando se possui apenas 2 pontos como referência $\left(\mathrm{P}_{1}, \mathrm{~T}_{1}\right)$ e $\left(\mathrm{P}_{2}, \mathrm{~T}_{2}\right)$, que serão utilizados para obter os parâmetros A e B da curva.

$$
\ln P=A-\frac{B}{T}
$$


Onde: $\quad A=\ln P_{1}+\frac{B}{T_{1}} \quad$ e $\quad B=\frac{\ln \left(\frac{P_{2}}{P_{1}}\right)}{\left(\frac{1}{T_{1}}-\frac{1}{T_{2}}\right)}$

Esta equação apresenta as vantagens de não precisar de parâmetros externos e ser relativamente simples, porém é necessário conhecer os valores para os dois pontos de análise. Além de que, esta equação fornece uma aproximação do comportamento real da pressão de vapor tanto melhor quanto mais próximo os pontos utilizados estiverem entre si.

Uma alternativa mais rigorosa e com maior precisão é a equação de correlação de Antoine estendida, que apesar de ser mais complexa apresenta melhores resultados para uma maior faixa de operação:

$$
\ln P=A-\frac{B}{T+C}+D \cdot \ln T+E \cdot T^{F}
$$

Na qual os parâmetros A, B, C, D, E e F são obtidos através de regressão de dados experimentais que podem ser encontrados tabulados para várias substâncias em "databooks" específicos. Esta equação apresenta uma formulação mais complexa, porém apresenta uma melhor aproximação para uma maior amplitude de temperatura e pressão. Pode-se notar que esta equação é uma generalização da equação de Clapeyron vista anteriormente. 


\section{A.3 Coluna de Destilação}

As colunas de destilação são o instrumento mais utilizado nas indústrias para efetuar a separação de misturas, sendo que uma única planta pode conter dezenas destas. A seguir, descreve-se sucintamente a parte física construtiva de uma coluna, sua dinâmica de funcionamento e algumas características de colunas industriais.

\section{A.3.1 Descrição Física}

Uma coluna de destilação é basicamente composta por 3 partes: coluna propriamente dita, condensador e refervedor.

Coluna: A coluna é um grande tubo cilíndrico com diâmetro que pode variar de alguns centímetros até alguns metros. No interior desta encontram-se os pratos ou bandejas. Estes são como discos que preenchem todo o diâmetro da coluna e possuem um vertedouro longitudinal que mantém uma lâmina de líquido sobre eles. Estes pratos recebem o líquido proveniente de um prato superior, que desce por uma abertura e passam líquido, que transborda do vertedouro, para um prato inferior. Os pratos possuem furos pelos quais o vapor oriundo do prato inferior passa formando bolhas que aquecem o líquido. Nestes furos podem ser adaptadas capas ou válvulas para melhorar o rendimento da passagem do vapor, como será visto mais à frente.

Condensador: é um trocador de calor, responsável por condensar o vapor que chega ao topo da coluna, através da retirada de calor deste, normalmente utiliza água fria. Pode ser parcial ou total, de acordo com a parcela do vapor que é condensado neste, os condensadores parciais permitem a retirada de destilado também na forma de vapor além do líquido, que é mais freqüentemente empregado. O líquido condensado em parte é devolvido à coluna para ser processado 
novamente, este é denominado de refluxo, e parte é retirado como produto destilado final, pode ainda haver retirada de destilado no estado de vapor quando este for um condensador parcial.

Refervedor: Assim como o condensador, também efetua troca de calor, porém, aquecendo o líquido do seu interior e retornando este, já na forma de vapor, para a coluna. Normalmente fica localizado na base da coluna. No refervedor existe uma retirada do chamado produto de base, que é a fração mais pesada do que resta na coluna.

A Figura A.5 mostra um desenho esquemático de uma coluna de destilação de acordo como descrito anteriormente.

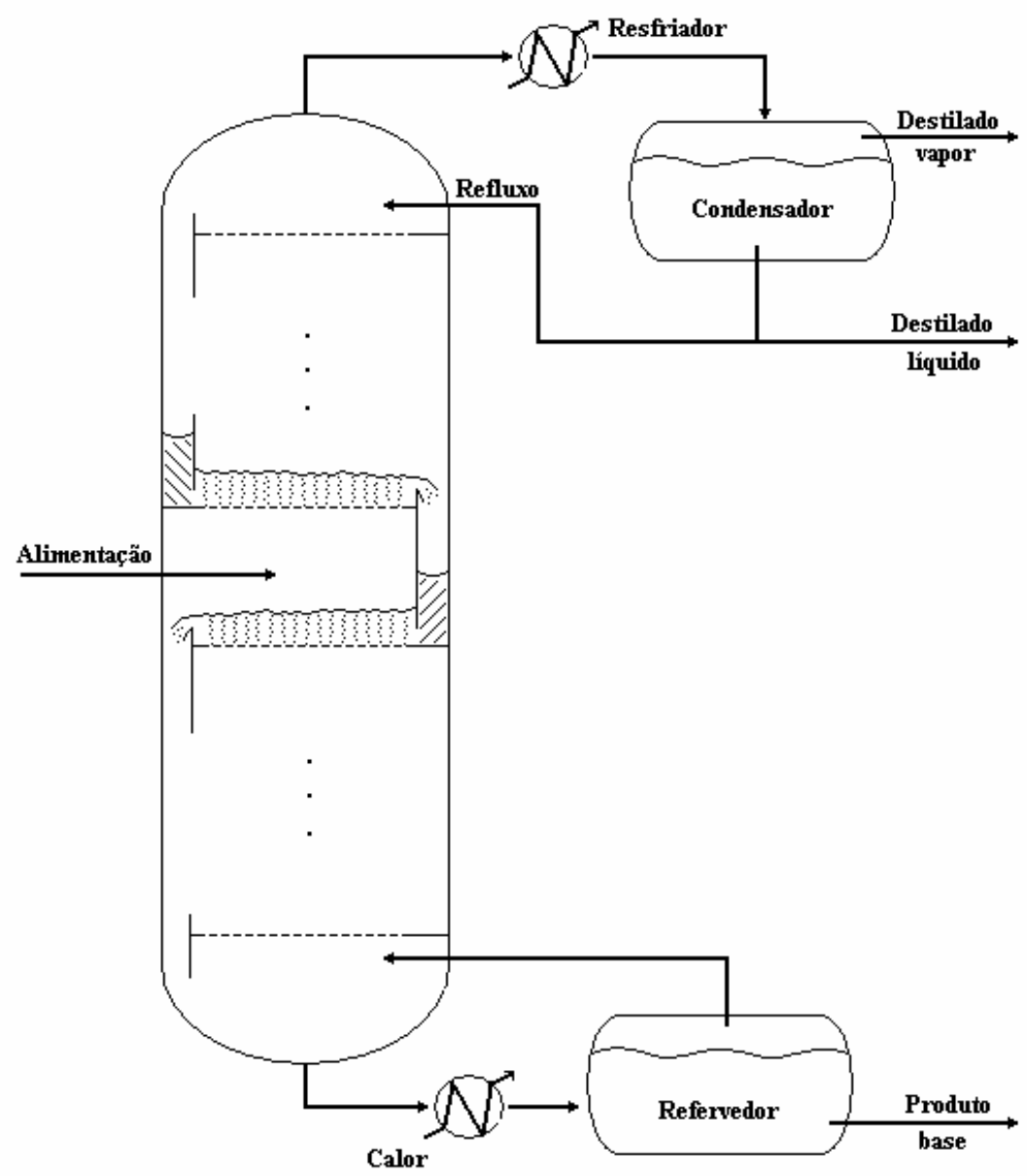

Figura A.5: Esquema geral de uma coluna de destilação 


\section{A.3.2 Funcionamento}

O ponto de partida é a entrada (mistura) que é inserida na bandeja de alimentação, localizada normalmente na parte central da coluna. A partir deste estágio, ocorre a alimentação de forma contínua ou batelada da mistura a ser separada.

Em cada bandeja, existe um obstáculo (vertedouro) de sustentação do líquido (semelhante à borda de uma forma). Quando o nível ultrapassa a altura do vertedouro, o líquido excedente escoa por cima desta e desce por uma passagem para a bandeja imediatamente inferior, iniciando um efeito em cascata, no qual o líquido começa a descer de bandeja em bandeja.

$\mathrm{Na}$ base da coluna, está localizado o refervedor que é responsável por fornecer calor ao processo. Assim, o líquido que chega até este é vaporizado e retorna para a coluna. Este vapor sobe até o prato imediatamente acima e devido à diferença de pressão atravessa os pequenos orifícios da bandeja na forma de bolhas. Esse vapor mais quente aquece o líquido da bandeja que também produzirá vapor que se juntará a este e subirão para o prato de cima e assim sucessivamente. Desta forma estabelece-se um gradiente de temperatura em toda a coluna, mais quente na base e mais frio no topo.

As bolhas de vapor também têm a função de melhorar a pureza do vapor. Assim, o vapor que sai do prato ao atravessar os pratos superiores, dependendo da temperatura e pressão que encontra, volta a liquefazer-se e desce novamente para a base, melhorando a concentração dos produtos, enquanto os mais voláteis sobem pelos pratos em direção ao topo da coluna.

$\mathrm{Na}$ base da coluna também é feita uma retirada de produto mais pesado, como produto final. 
A Figura A.6 mostra em detalhe os fluxos de líquido e vapor que fluem pela coluna.

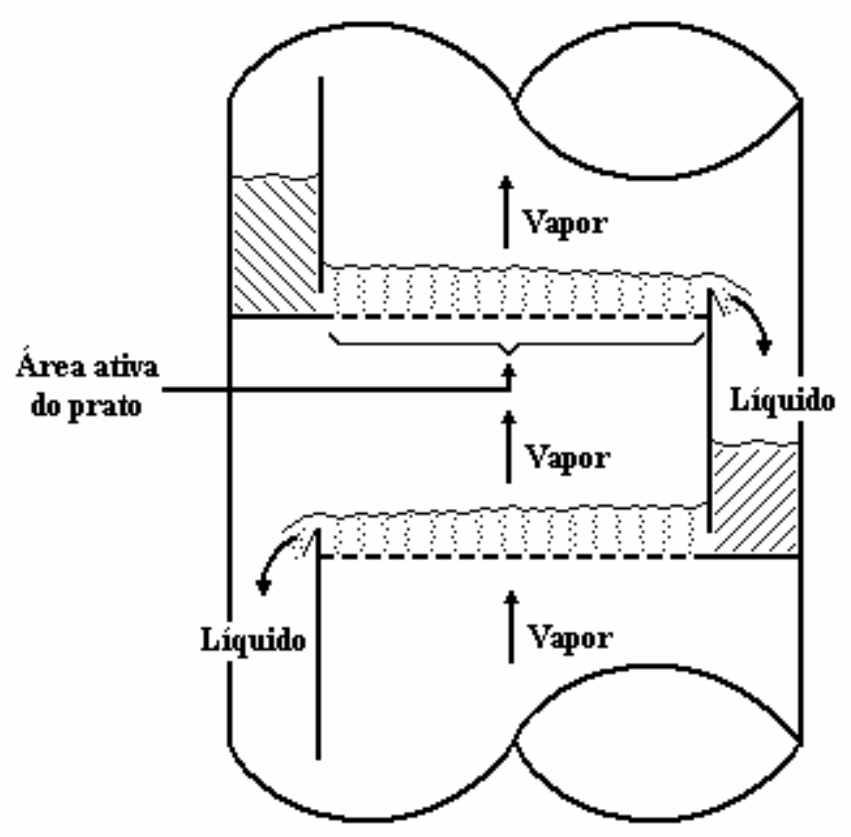

Figura A.6: Dinâmica interna de operação da coluna

Portanto, existe ao longo da coluna um gradiente de temperatura e de pressão. $\mathrm{Na}$ base, mais perto do refervedor, têm-se maior concentração do componente mais pesado e, portanto maior pressão, conforme se sobe o líquido menos volátil predomina e a pressão diminui. Logo, a composição da mistura em cada bandeja vai variando conforme a altura desta. O número de pratos da coluna é diretamente proporcional à pureza dos produtos finais. Muitos outros fatores também influenciam a pureza do destilado, dentre eles: tipo de prato, tipo de encapsulamento, distância entre pratos, etc.

O vapor que sobe pelos pratos chega ao topo da coluna e passa pelo condensador que retira calor e o liquefaz. Uma parte deste líquido do condensador, o refluxo, volta para o prato mais alto da coluna de onde começa a descer escorrendo pelos pratos e, de acordo com a temperatura que possui, o componente mais volátil volta a evaporar e sobe novamente melhorando a pureza do produto no topo da 
coluna. A outra parte do líquido do condensador é retirada como produto destilado final. Se o condensador for parcial - quando liquefaz apenas uma parte do vapor que recebe - pode haver retirada também na forma de destilado vapor.

\section{A.3.3 Detalhes Funcionamento}

A seguir são descritos alguns detalhes do funcionamento das colunas de destilação e dos processos que nela ocorrem.

\section{Tipos de Processos}

Normalmente os processos de destilação ocorrem na forma de destilação batelada ou contínua

Destilação Batelada: Uma coluna de destilação de batelada é inicialmente alimentada com a mistura a ser separada e, a partir de então, cessa-se a alimentação e o processo de destilação é realizado. Após a separação da mistura nos componentes, a coluna é alimentada novamente com uma nova quantidade de mistura a ser separada.

Destilação Contínua: Em uma coluna de destilação contínua, o processo é alimentado continuamente. Ao contrário da destilação em batelada, nesta o processo está ativo todo o tempo, trazendo geralmente melhor rendimento. Para efeitos de modelagem deste trabalho será utilizada uma coluna deste tipo. 


\section{Estrutura interna}

A fim de melhorar o rendimento de uma coluna pode-se mudar suas especificações de projeto. Uma das maneiras de implementar estas melhorias é alterando o número de pratos que compõe a coluna, porém isto gera perdas de pressão que devem ser compensadas por uma maior injeção de calor pelo refervedor. Outra maneira é alterar o tipo dos pratos que podem possuir geometrias diferentes de distribuição do líquido em sua superfície e alturas variadas de lâmina líquida. No entanto, um dos pontos mais manipuláveis da coluna é quanto aos furos para passagem do vapor que vem do prato inferior. Assim, podem-se variar seu tamanho, sua forma e a cobertura para melhorar o contato vapor-líquido. Alguns tipos de pratos são melhor vistos abaixo.

Sieve Cap (Prato tipo peneira): Neste tipo de prato são feitos pequenos orifícios por onde o vapor passa em forma de bolhas pelo líquido (vide Figura A.7). É o tipo mais fácil de ser construído. Sua eficiência é tanto maior quanto menor o tamanho dos furos (pois gera bolhas menores, com maior superfície de contato), porém furos muito pequenos podem entupir o que bloqueia o processo.
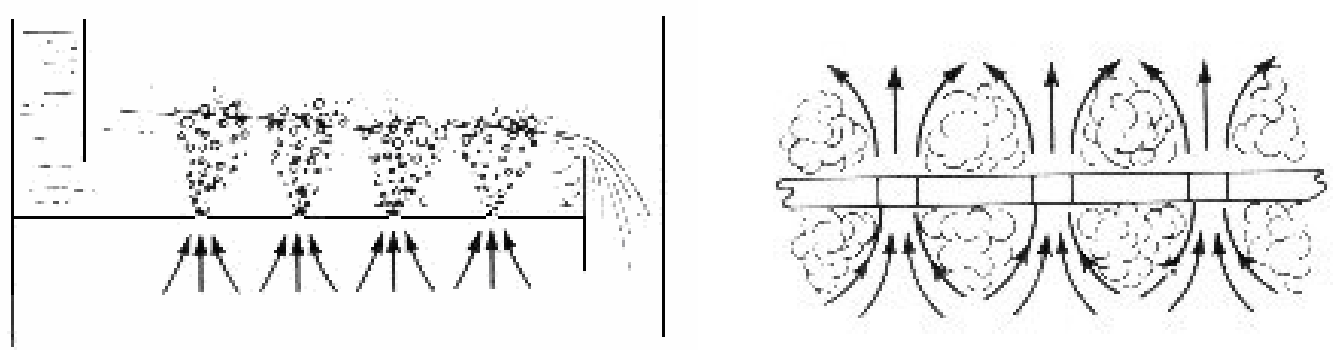

Figura A.7: Prato com furos (Sieve cap) e detalhe dos furos 
Bubble Cap (Pratos com encapsulamento): O “bubble cap" é um tipo de encapsulamento colocado sobre os furos de um prato perfurado. Estas capas apresentam frestas menores por onde o vapor que penetrou pelo furo é dividido em bolhas mais finas (vide Figura A.8). O nível do líquido deve ser superior à altura dos encapsulamentos.
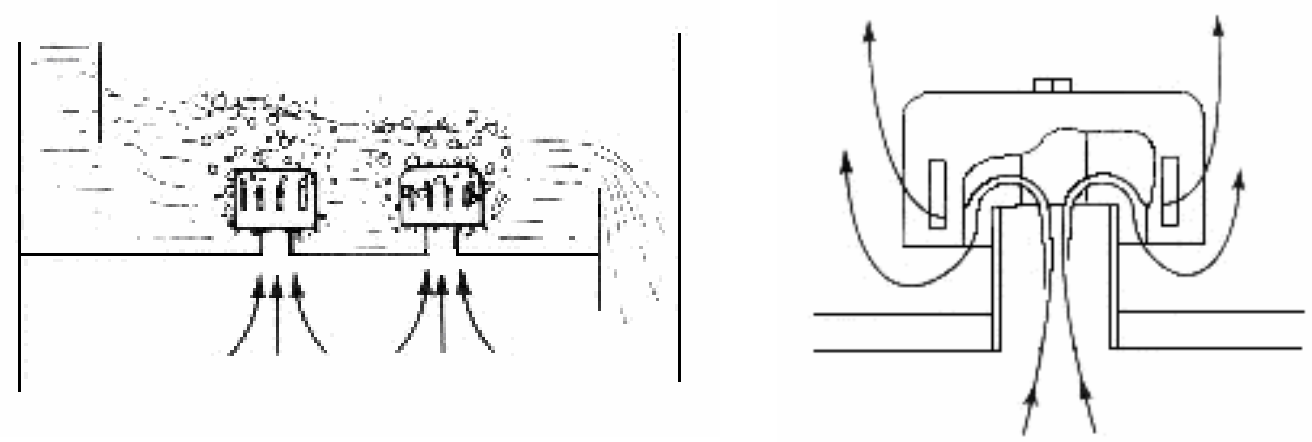

Figura A.8: Prato com encapsulamento (bubble cap) e detalhe do encapsulamento

Veja na Figura A.9 alguns tipos de encapsulamentos que podem ser utilizados em unidades industriais.

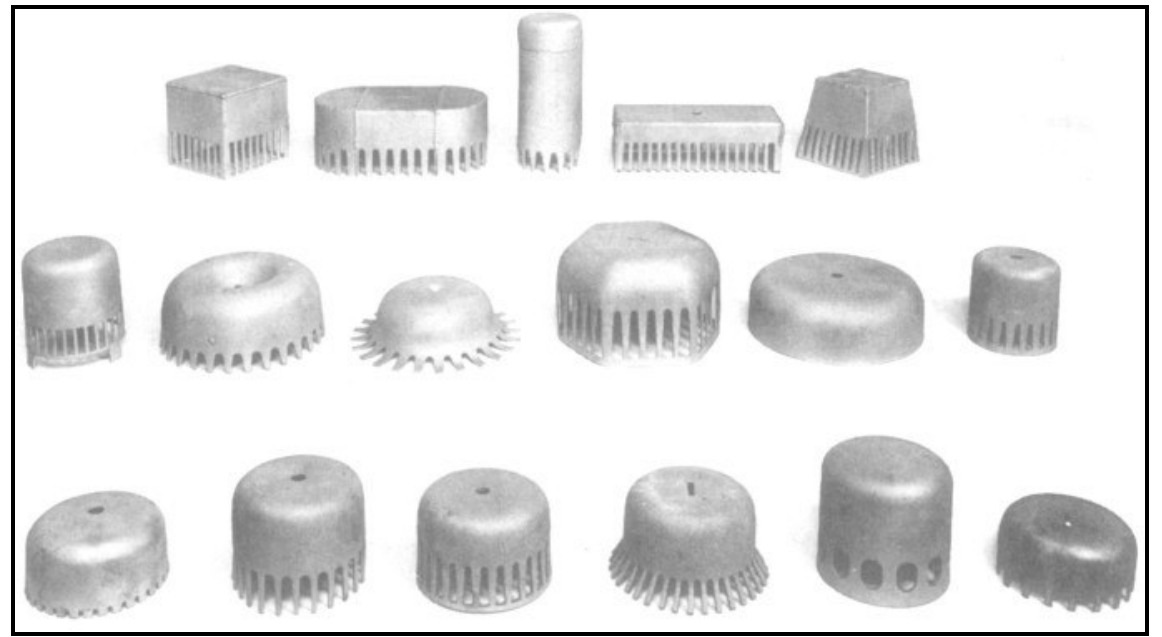

Figura A.9: Exemplos de alguns tipos de encapsulamentos 
Valve Cap (Pratos com dispositivo tipo válvula): Nestes pratos ao invés dos encapsulamentos são colocados sobre os furos válvulas que permitem ou não a passagem do vapor. As válvulas apresentam abertura proporcional à pressão do vapor. Quando a pressão cai a válvula diminui sua abertura, impedindo que o líquido volte pelo orifício. Existem válvulas com restrições na base (pernas) e válvulas com limitadores, conforme Figura A.10.
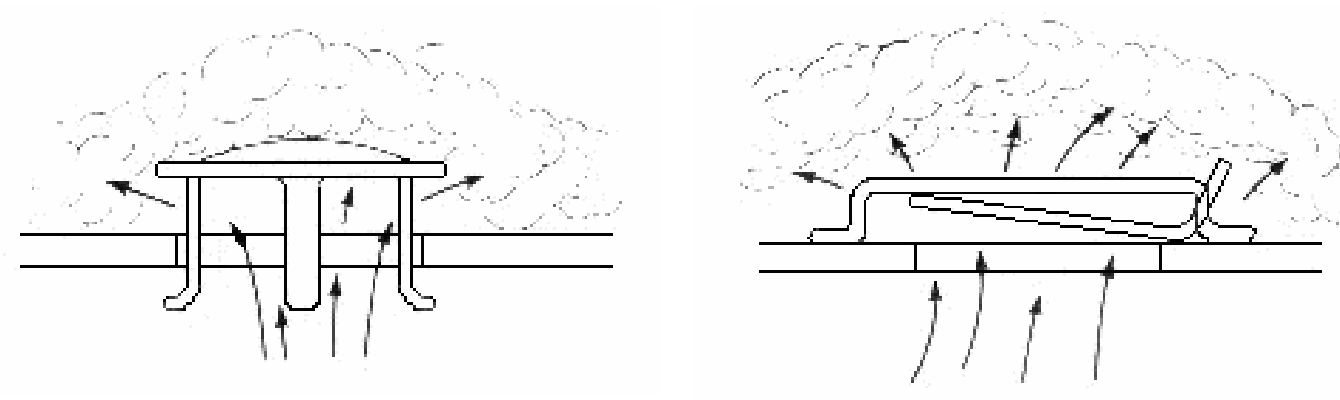

Figura A.10: Válvula com restrição e válvula com limitador

Dois problemas comuns que podem ocorrer no funcionamento de colunas de destilação são quanto ao comportamento do líquido e do vapor na área ativa do prato, pois o líquido não deve escorrer pelos buracos dos pratos, e nem estes ficarem descobertos sem o líquido. Assim, a pressão não pode ser muito alta, pois neste caso forçaria o líquido a voltar e não escorrer pelos vertedouros, gerando o que é chamado "coluna seca". Por outro lado, a pressão deve ser suficiente para impedir a passagem de líquido pela área ativa, forçando que o líquido escorra somente pelas laterais da bandeja. Se essa pressão for insuficientemente alta, então a força da gravidade é capaz de vencer a pressão exercida pelo vapor e o líquido começa a descer pelas perfurações da bandeja. Quando isso ocorre, é normalmente denominado no jargão industrial que a coluna está "chorando".

Por isso, deve-se regular o refervedor com uma temperatura suficientemente alta para que a pressão interna permita o vapor chegar até o topo da coluna, passando por todas as bandejas. 


\section{Apêndice B}

\section{Descrição do Modelo Simulado}

\section{B.1 Introdução}

A seguir são apresentadas as principais considerações efetuadas e as equações utilizadas para a modelagem da coluna de destilação, conforme já especificada no capítulo três desta dissertação, e em seguida, são listadas as principais telas do programa implementado em Simulink ${ }^{\circledR}$.

A coluna estudada possui alimentação multicomponente, ou seja, uma mistura de vários componentes, e mista, nos estados líquido e vapor. Os produtos retirados são os componentes mais leves, no topo da coluna, e os mais pesados na base.

\section{B.2 Considerações mais significativas}

Vejamos a seguir algumas considerações que foram empregadas no desenvolvimento do modelo matemático da coluna de destilação: 
- O líquido acumulado em cada prato é considerado incompressível e homogêneo (mistura instantânea e perfeita).

- O acúmulo de vapor é desprezado, pois apesar do volume deste ser grande, o número de mols é normalmente pequeno, uma vez que a densidade do vapor é muito menor que a do líquido. O efeito matemático desta consideração é que é necessária uma equação de energia para cada prato. Esta consideração não é satisfatória para colunas de alta pressão.

- As dinâmicas do condensador e do refervedor também são desprezadas. Em colunas de escala comercial a resposta dinâmica destes trocadores de calor é normalmente muito mais rápida que a resposta da coluna isolada. Entretanto, para alguns sistemas, as dinâmicas destes equipamentos são importantes e podem ser incluídas no modelo.

- Não foi considerado nenhum atraso (tempo morto) na linha de vapor do topo da coluna para o refluxo e nem na linha de refluxo para o prato de topo (em escala industrial esta é normalmente uma boa aproximação, mas não para colunas de laboratório em pequena escala). Note que a composição do vapor no topo é dinamicamente diferente da composição do líquido no condensador, sendo que as duas são iguais somente no estado de equilíbrio.

- O sobrefluxo é considerado não-equimolal, ou seja, não há paridade no número de mols do vapor que condensa e do líquido que evapora, quando o calor molar de vaporização dos dois componentes é aproximadamente o mesmo.

- É considerado um gradiente linear de pressão entre o condensador e o refervedor da coluna, e invariante no tempo.

- Considera-se que há dois controladores de nível perfeitos, um localizado no condensador e o outro no refervedor, de modo que mantenham sempre constante o nível de líquidos nestes dois. 
- Na elaboração do modelo foram incluídos o condensador e o refervedor como dois estágios extras, o primeiro no topo da coluna e o segundo na base. Portanto, as variáveis relacionadas a estas duas estruturas foram referenciadas como estágio NT e estágio 1, respectivamente. Esta consideração não ocasiona perda de generalidade do modelo.

\section{B.3 Equações empregadas}

A seguir são mostradas as principais equações e fórmulas de correlação empregadas na modelagem do processo e de suas propriedades físicas e químicas.

\section{Pressão de vapor}

Para calcular o valor da pressão de vapor da mistura utilizou-se a fórmula de Clapeyron com dois pontos como referência $\left(\mathrm{P}_{1}, \mathrm{~T}_{1}\right)$ e $\left(\mathrm{P}_{2}, \mathrm{~T}_{2}\right)$, que serão utilizados para obter os parâmetros A e B da curva.

$$
\ln P=A-\frac{B}{T}
$$

Onde: $\boldsymbol{P}$ é a pressão interna de vapor do líquido;

$\boldsymbol{A}$ e $\boldsymbol{B}$ são constantes determinadas a partir dos valores fornecidos de duas pressões internas de vapor em duas temperaturas distintas.

Assim:

$$
A=\ln P_{1}+\frac{B}{T_{1}}
$$

e

$$
B=\frac{\ln \left(\frac{P_{2}}{P_{1}}\right)}{\left(\frac{1}{T_{1}}-\frac{1}{T_{2}}\right)}
$$




\section{Fluxos de líquido no prato}

O fluxo de líquido pela coluna não será o mesmo dinamicamente, mas dependerá do mecanismo do fluido no prato. A relação de Francis fornece a vazão por cima do vertedouro do prato para escoamentos com vertedouros retangulares.

$$
F_{L}=3,33 \cdot L_{W} \cdot\left(h_{O W}\right)^{1,5}
$$

Onde: $\boldsymbol{F}_{\boldsymbol{L}}$ é a vazão de líquido que flui por cima do vertedouro $\left[\mathrm{ft}^{3} / \mathrm{s}\right.$ ]

$\boldsymbol{L}_{W}$ é a altura do vertedouro naquela seção da coluna $[\mathrm{ft}]$

$\boldsymbol{h}_{\text {OW }}$ é a altura de líquido acima do vertedouro do prato [ft]

\section{Eficiência}

Considera-se que os pratos são ineficientes, isto é, o vapor que está saindo do prato não está em equilíbrio com o líquido no prato. Esta eficiência dos pratos é uma característica não-ideal e é expressa pela fórmula de Murphree.

$$
E_{N, J}=\frac{y_{N, J}-y_{N-1, J}^{T}}{y_{N, J}^{*}-y_{N-1, J}^{T}}
$$

Onde: $\boldsymbol{E}_{N, J}$ é o coeficiente da eficiência de Murphree

$\boldsymbol{y}_{N, J}$ é a composição atual do vapor no prato $\mathrm{N}$ do componente $\mathrm{J}$

$\boldsymbol{y}_{N, J}^{*}$ é a composição anterior do vapor no prato $\mathrm{N}$ do componente $\mathrm{J}$

$\boldsymbol{y}_{N, J}^{T}$ é a composição do vapor no prato $\mathrm{N}$ do componente $\mathrm{J}$, afetado pela alimentação 


\section{Entalpia}

A entalpia é uma medida da quantidade de energia que possui uma determinada substância. É função da temperatura e depende do estado físico e dos calores de mudança de estado. Deve ser obtida tanto para o líquido como para o vapor. A seguir são mostradas duas curvas que modelam o comportamento desta de forma simples para uma região não muito grande:

$$
H_{V}=C_{P} \cdot T \quad H_{L}=C_{P} \cdot T+l_{V}
$$

Onde: $\boldsymbol{H}_{\boldsymbol{V}}$ é a entalpia do vapor

$\boldsymbol{H}_{\boldsymbol{L}}$ é a entalpia do líquido

$\boldsymbol{C}_{\boldsymbol{P}}$ é a capacidade térmica (considerado constante)

$\boldsymbol{T}$ é a temperatura

$\boldsymbol{I}_{\boldsymbol{V}}$ é o calor latente de vaporização

\section{Ponto de Ebulição}

O ponto de ebulição de uma mistura foi calculado utilizando-se uma forma iterativa bastante comum. Esta se inicia a partir da pressão externa e da composição do líquido e, para uma temperatura arbitrada inicialmente, calcula a pressão de vapor do líquido - segundo o método de cálculo da pressão de vapor empregado (equação de Clapeyron) - e este valor é comparado com a pressão externa. Esta diferença gera correções na temperatura arbitrada inicialmente e reinicia-se o processo. Deste modo a solução vai sendo refinada até se obter a precisão desejada. 


\section{Equações de balanço}

A seguir é mostrada a descrição das equações de balanço de massa global, por componente e o balanço de energia para a coluna em questão. Estas equações podem ser melhor entendidas com o auxílio da Figura B.1.

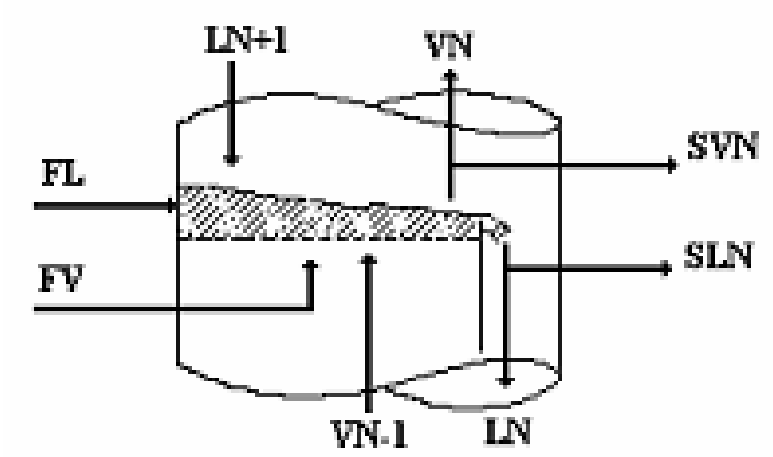

Figura B.1: Entradas (alimentação e fluxos internos) e saídas do prato

Onde: $\boldsymbol{L}$ é o fluxo de líquido que transborda sobre o vertedouro

$\boldsymbol{V}$ é o fluxo de vapor que sai do prato

$\boldsymbol{F L}$ é o fluxo de alimentação no estado líquido

$\boldsymbol{F} \boldsymbol{V}$ é o fluxo de alimentação no estado gasoso (vapor)

$\boldsymbol{S L N}$ e $\boldsymbol{S} \boldsymbol{V N}$ são as retiradas intermediárias na forma de líquido e vapor que podem ocorrem na coluna

\section{Balanço de massa global}

A seguinte equação é válida para uma coluna que pode conter alimentação em múltiplos pratos e em ambos os estados (líquido e vapor).

$$
\frac{d M_{N}}{d t}=L_{N+1}+F_{N}^{L}+F_{N-1}^{V}+V_{N-1}-V_{N}-L_{N}-S_{N}^{L}-S_{N}^{V}
$$

Onde: $\boldsymbol{M}$ é o acúmulo de líquido no prato 


\section{Balanço de massa por componente}

A equação de balanço de massa por componente é dada por:

$$
\frac{d\left(M_{N} \cdot x_{N J}\right)}{d t}=L_{N+1} \cdot x_{N+1, J}+F_{N}^{L} \cdot x_{N, J}^{F}+F_{N-1}^{V} \cdot y_{N-1, J}^{F}+V_{N-1} \cdot y_{N-1, J}-V_{N} \cdot y_{N, J}-L_{N} \cdot x_{N, J}-S_{N}^{L} \cdot x_{N, J}-S_{N}^{V} \cdot y_{N, J}
$$

Onde: $\boldsymbol{x}$ é a composição do líquido $\boldsymbol{y}$ é a composição do vapor

\section{Balanço de energia}

A equação de balanço de energia é dada por:

$$
\frac{d\left(M_{N} \cdot h_{N}\right)}{d t}=L_{N+1} \cdot h_{N+1}+F_{N}^{L} \cdot h_{N}+F_{N-1}^{V} \cdot H_{N-1}^{F}+V_{N-1} \cdot H_{N-1}-V_{N} \cdot H_{N}-L_{N} \cdot h_{N}-S_{N}^{L} \cdot h_{N}-S_{N}^{V} \cdot H_{N}
$$

Onde: $\boldsymbol{H}_{\boldsymbol{N}}$ é a entalpia do vapor $\boldsymbol{h}_{\boldsymbol{N}}$ é a entalpia do líquido.

Em geral, estas foram as principais equações utilizadas no desenvolvimento do modelo matemático dinâmico da coluna de destilação. Existem outras fórmulas para correlação dos dados mais precisas e válidas para amplitudes maiores das variáveis em questão, porém esta modelagem foge ao escopo do trabalho e poderia ser deixada para um trabalho futuro de desenvolvimento de um modelo matemático mais avançado.

A seguir, poderá ser observado a implementação destas equações no modelo da coluna implementado em Simulink ${ }^{\circledR}$ e as demais considerações realizadas nesta fase do projeto. 


\section{B.4 Validação}

Uma vez que o modelo foi desenvolvido e implementado para uma coluna multicomponente não-ideal, passou-se à etapa seguinte de verificação do seu comportamento, comparando-se suas saídas com as respostas apresentadas em (LUYBEN, 1990), submetendo ambos os modelos às mesmas entradas e condições, com o intuito de verificar se o comportamento dinâmico do modelo desenvolvido se assemelha ao do modelo citado na referência.

Os resultados referentes ao confronto dos valores obtidos e disponíveis para comparação da literatura citada foram considerados bons, satisfazendo aos critérios de avaliação utilizados. Destaca-se aqui apenas que o modelo apresentou discrepância máxima (erro) entre os valores esperados e os fornecidos pelo programa, em torno de 0,1\% (ZANATA, 2002).

\section{B.5 Telas do programa}

A seguir são exibidas todas as 75 telas que compõem o programa referente à modelagem realizado para a coluna de destilação multicomponente implementado em Simulink ${ }^{\circledR}$.

O objetivo é deixar a modelagem realizada disponível e permitir o conhecimento do que foi desenvolvido, bem como abrir espaço para melhorias futuras. 
Relação dos sistemas e subsistemas do Simulink ${ }^{\circledR}$.

曰

7. modelo_fl_fv_rand_def

$\because$.... A.tualização das variáveis integradas

$\rightarrow \cdots$ - Subsyster

... If Action Subsystem

(2)- If Action Subsystem1

$\rightarrow$ - If Action Subsystem2

ㄱ.. Balanço de massa

方... Subsystem

b-... Condensador

...- Subsystem

므- Cálculo dos Holdups iniciais

H.... Cálculo dos holdups iniciais

...- mwdens 1

$\square$.... Cálculo dos holdups iniciais 1

.... mi- midens

ㄱ..그 Cálculo dos holdups iniciais 16

. mo- midens 3

b... Cálculo dos holdups iniciais 7

. mi- midens

D...- Prato Genérico

ㄱ..그- Subsystem1

B. Subsystem

....- Subsystem1

-... Subsystem2

ํ... Cálculo dos Holdups iniciais

†ํ... Cálculo dos holdups iniciais 1

D... mwdens

[… Cálculo dos holdups iniciais 7

t. mudens

...

금 Subsystem3

可- Subsystem

-... For Iterator Subsystem

†... Cálculo dos Holdups iniciais

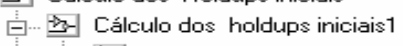

- $\gg$ - mwdens

[... Cálculo dos holdups iniciais7

i.... mwdens

$\rightarrow-$ Subsystem4

-... Refervedor

.... For Iterator Subsystem

D... Cálculo das taxas de vapor $(\mathrm{V})$

... Cálculo da entalpia da alimentação

$\checkmark$ C... Cálculo das taxas de vapor

..... If Action Subsystem

If- If Action Subsystem1

그- Cálculo das taxas de vapor 1

ㄱ- Cálculo das taxas de vapor2

D- Cálculo das taxas de vapor 4

Dub- Subsystem

Calculo dos novos fluxos de líquidos

F-... For Iterator Subsystem

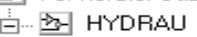

.... If Action Subsystem

...- If Action Subsystem1

…- mwdens

-... For Iterator Subsystem1

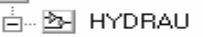

If- If Action Subsystem

... If Action Subsystem1

... mwdens

๑... Loop Principal

-... Loop Principal 2

금 For Iterator Subsystem

方... While Iterator Subsystem1

.... En- Enabled Subsystem

.... Subsystem

[... For Iterator Subsystem1

․ㅡ- Subsystem

ㄱ- Subsystem1

그- Subsystem2

-... For Iterator Subsystem2

ENT- ENT1 


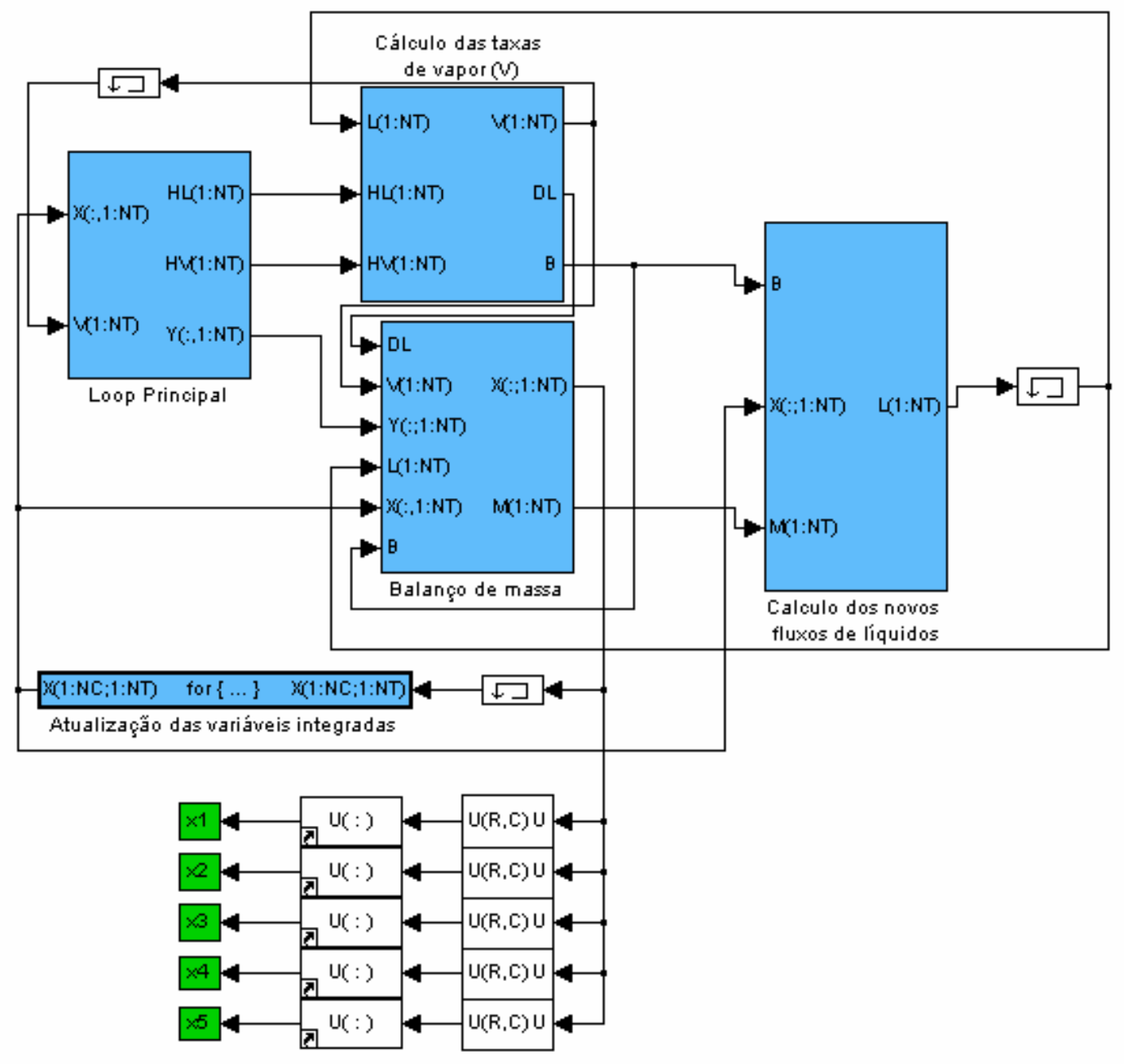

1 - Tela principal

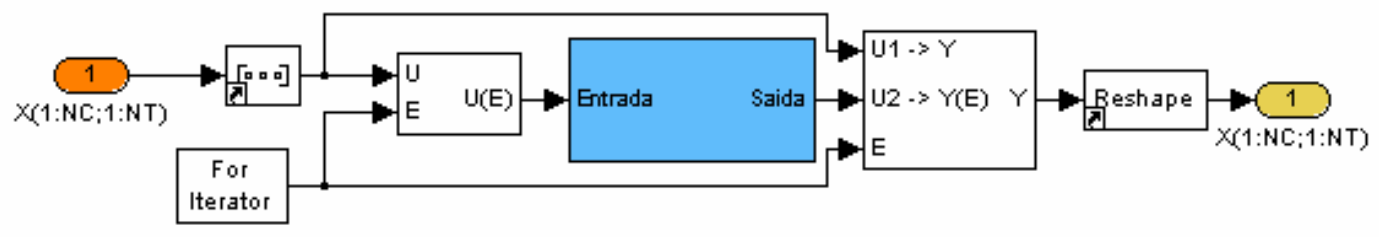

1.1 - Atualização das variáveis integradas 


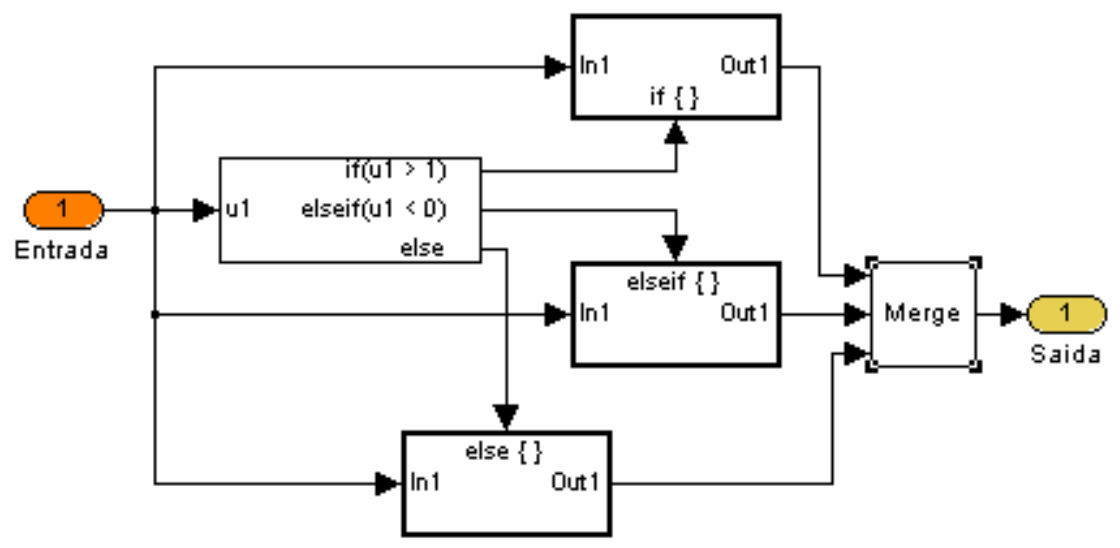

1.1.1 - Subsystem

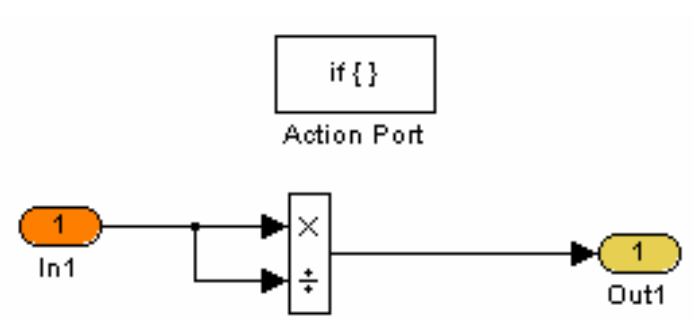

1.1.1.1 - If Action Subsystem

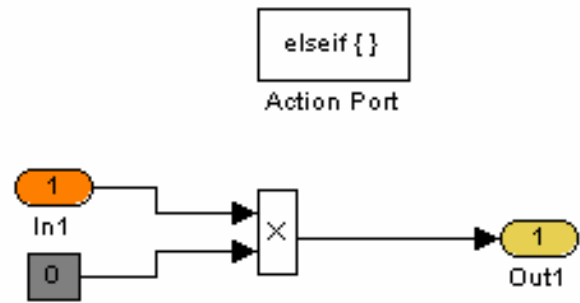

1.1.1.2 - If Action Subsystem1

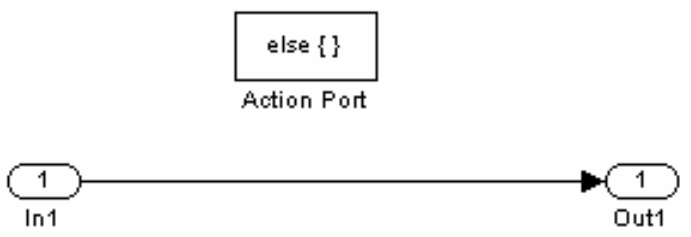

1.1.1.3 - If Action Subsystem2 


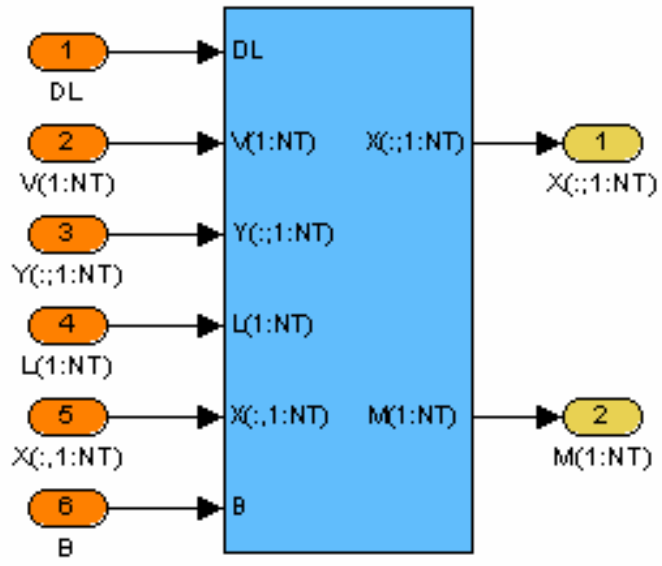

1.2 - Balanço de Massa

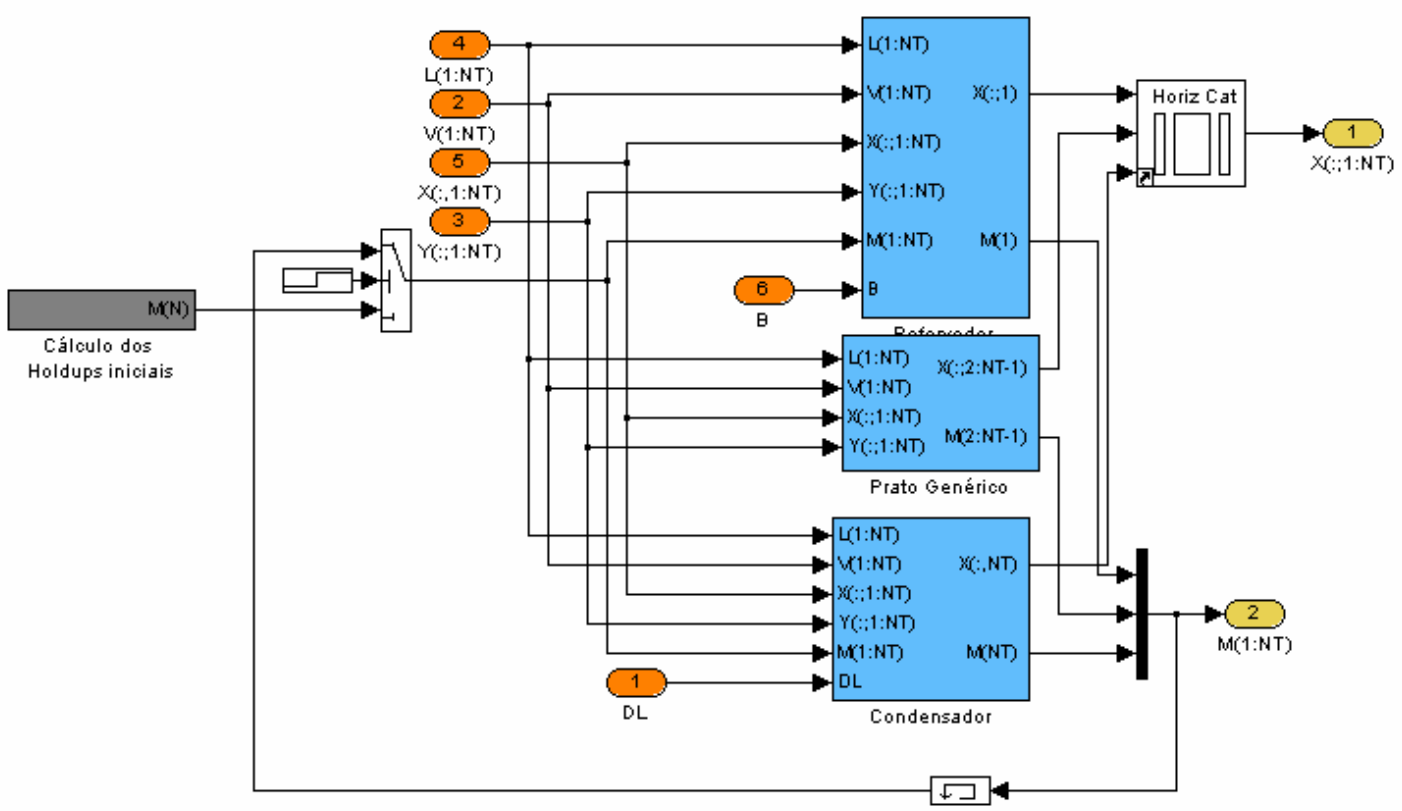

1.2.1 - Subsystem 


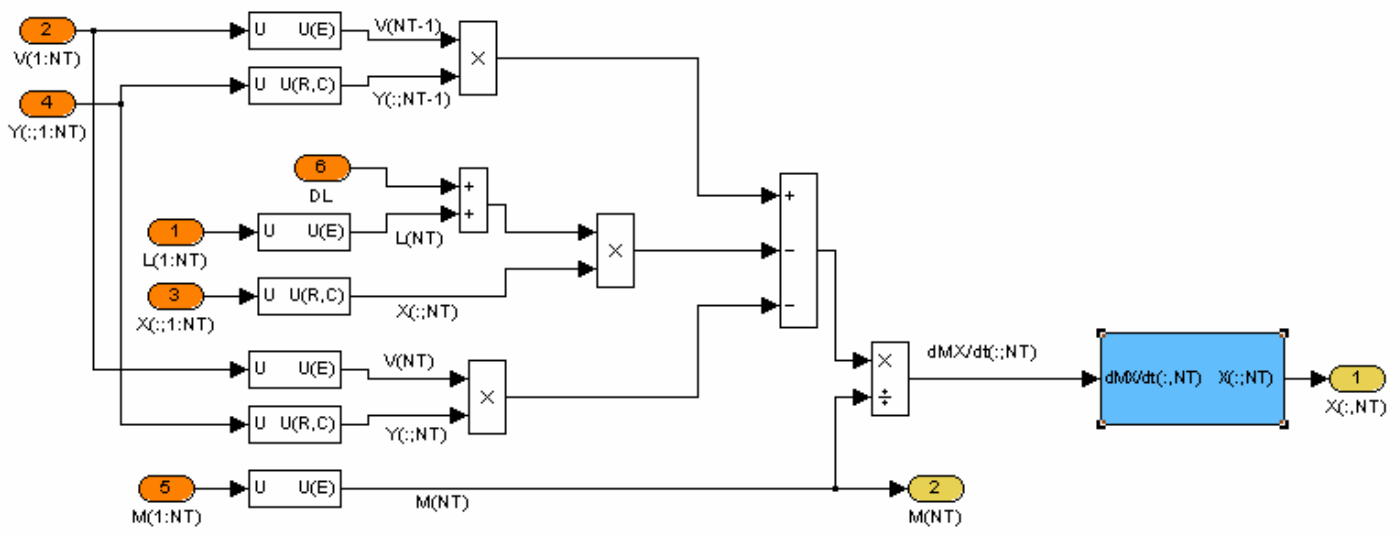

1.2.1.1 - Condensador

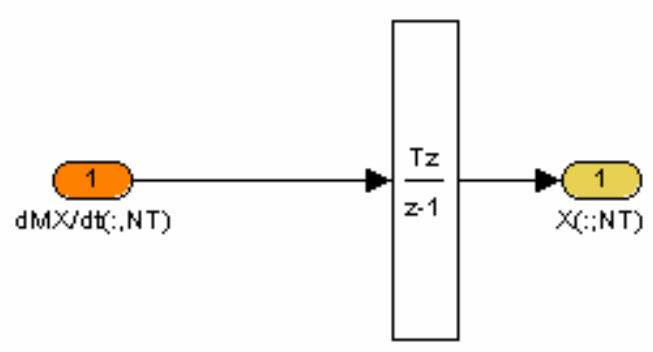

1.2.1.1.1 - Subsystem

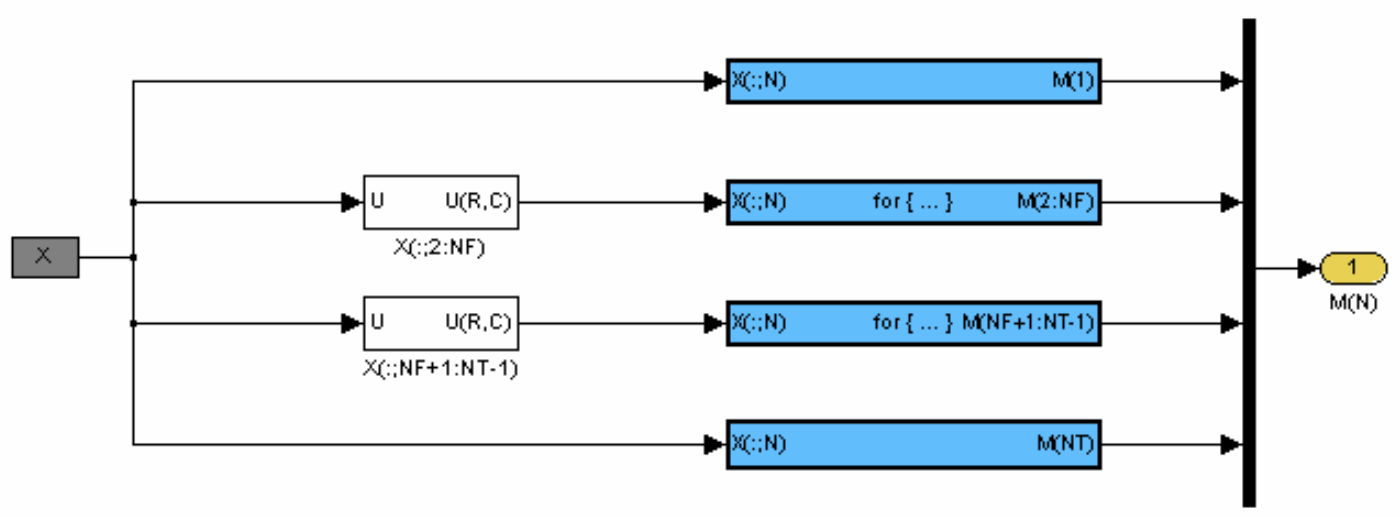

1.2.1.2 - Cálculo dos Holdups iniciais 


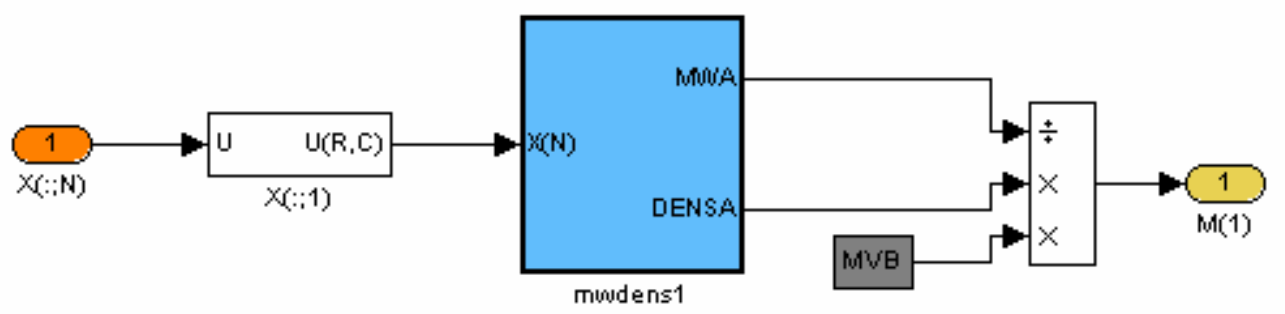

1.2.1.2.1 - Cálculo dos holdups iniciais

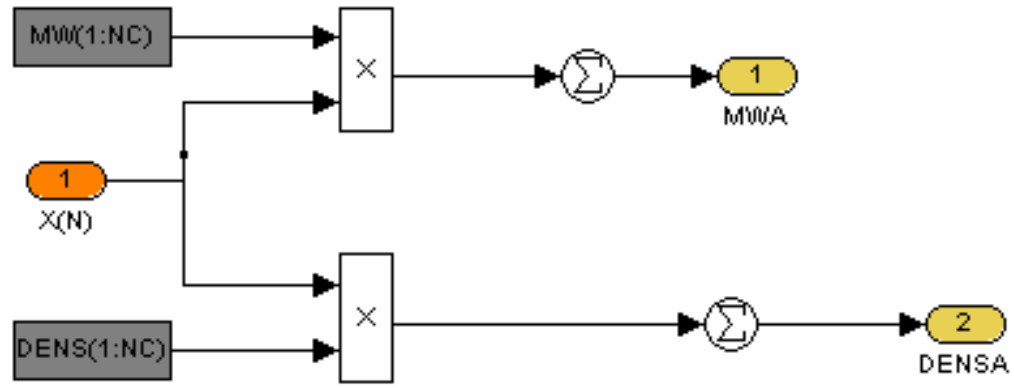

1.2.1.2.1.1 - mwdens1

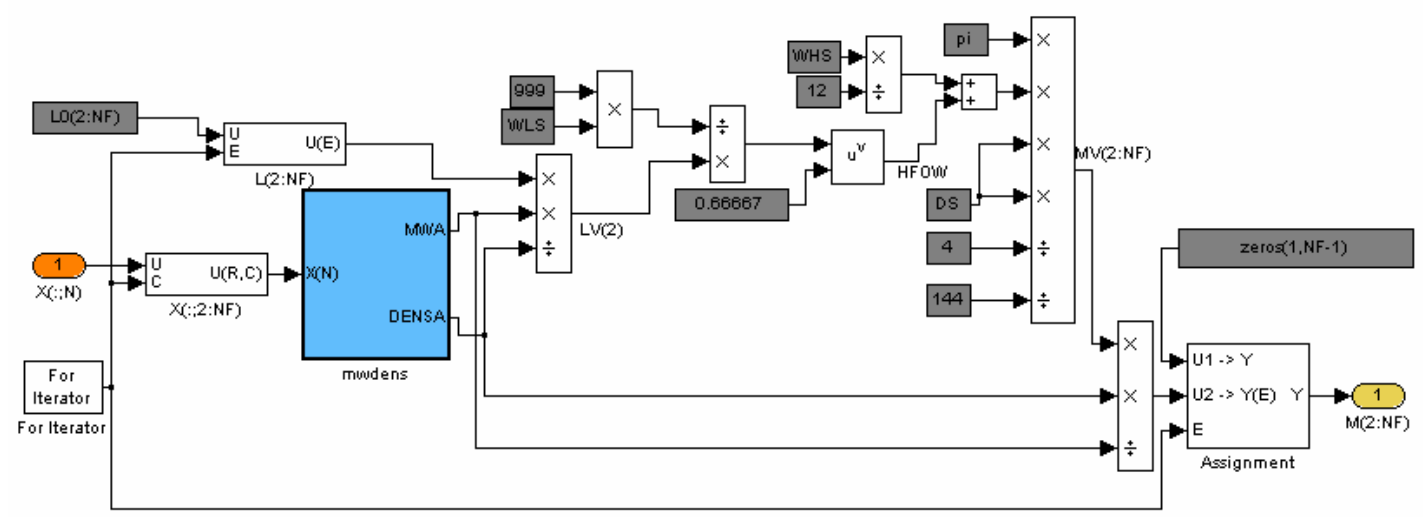

1.2.1.2.2 - Cálculo dos holdups iniciais1 


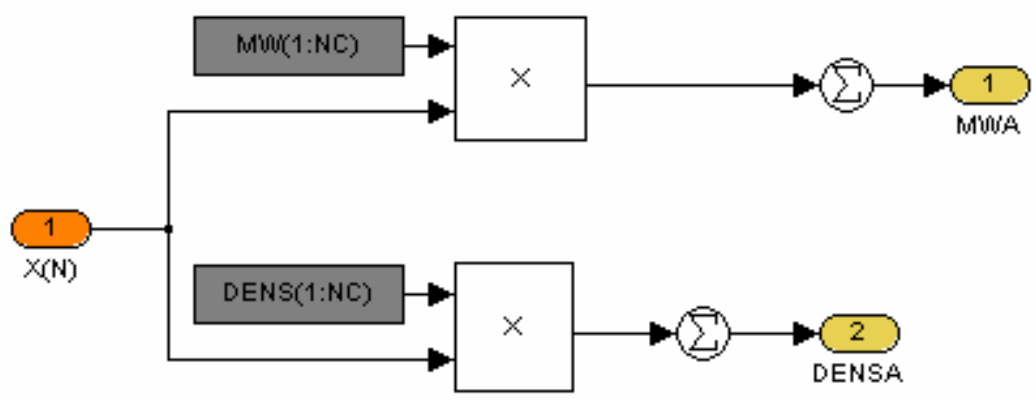

1.2.1.2.2.1 - mwdens

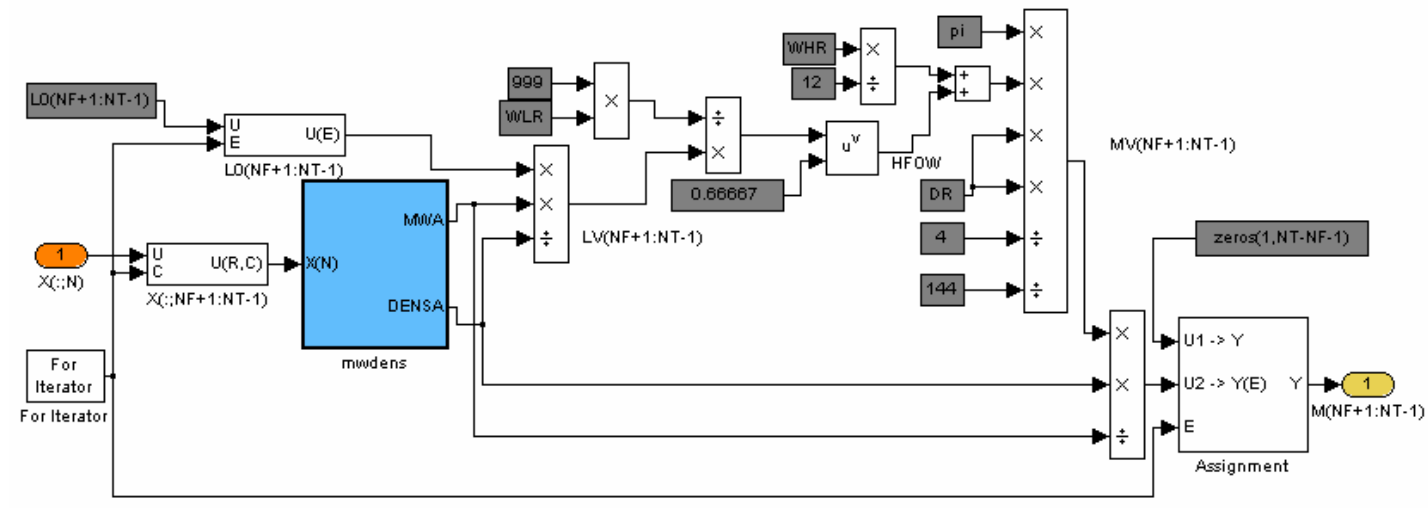

1.2.1.2.3 - Cálculo dos holdups iniciais16

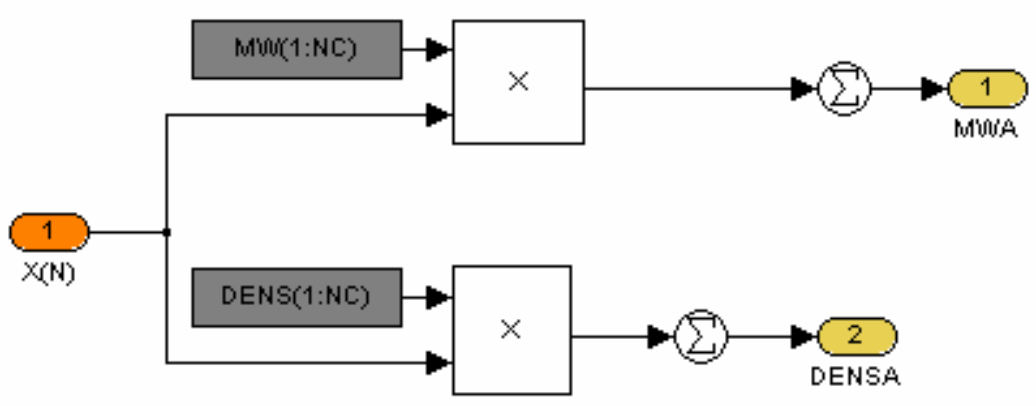

1.2.1.2.3.1 - mwdens3 


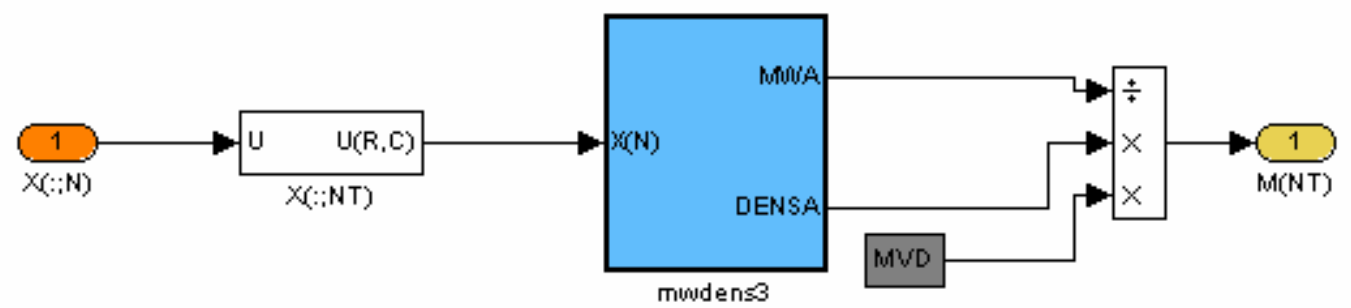

1.2.1.2.4 - Cálculo dos holdups iniciais7

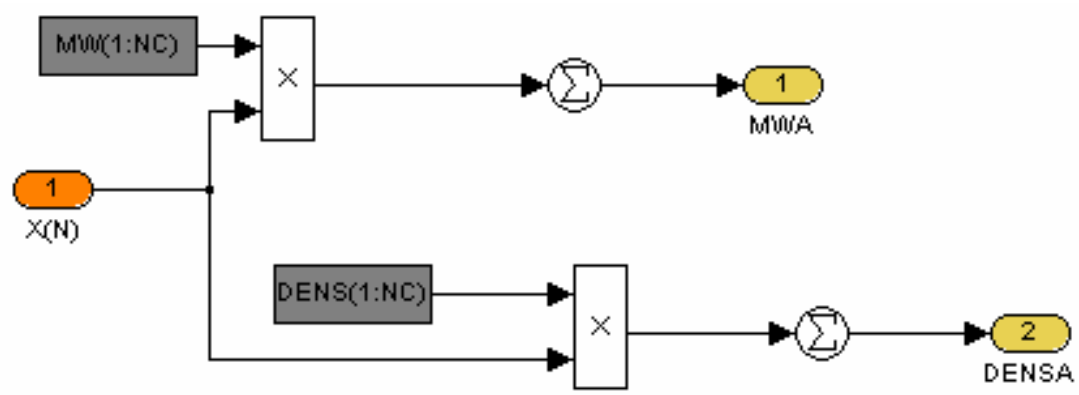

1.2.1.2.4.1 - mwdens

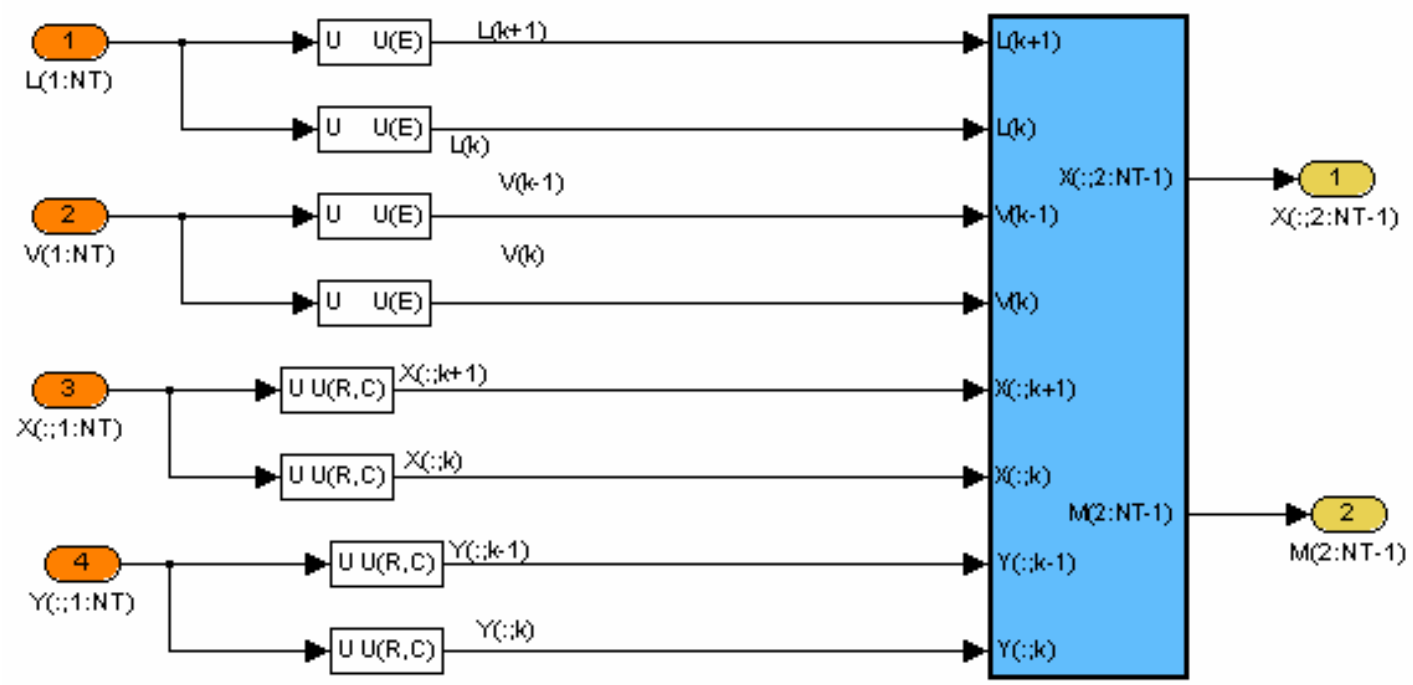

1.2.1.3 - Prato Genérico 


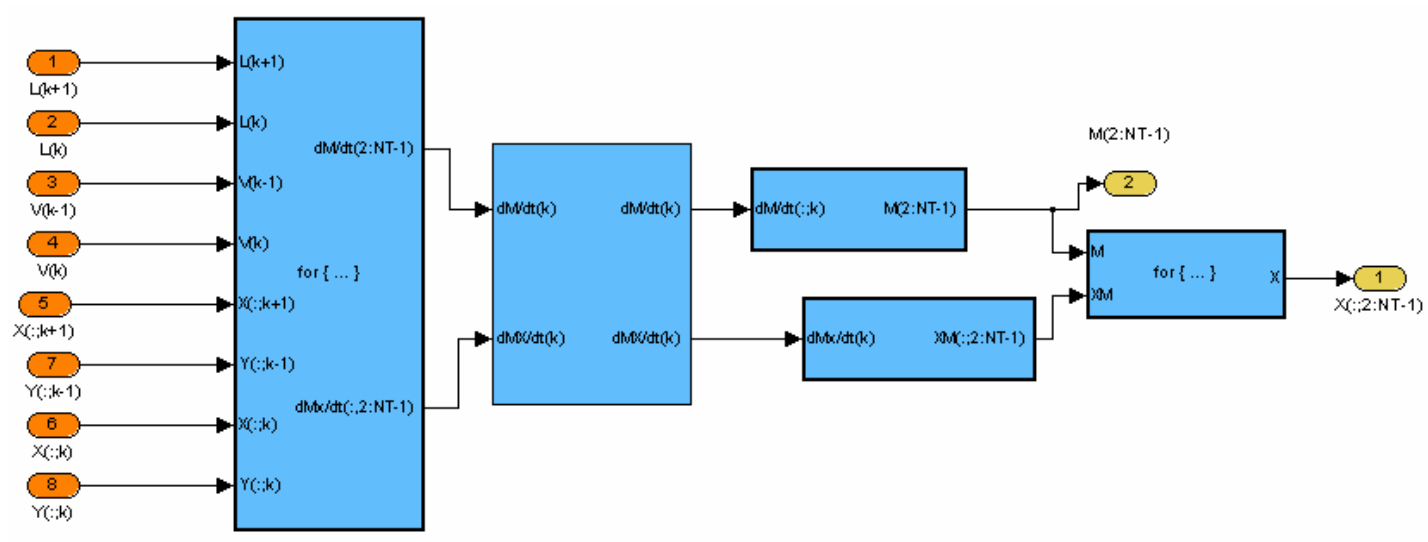

1.2.1.3.1 - Subsystem1

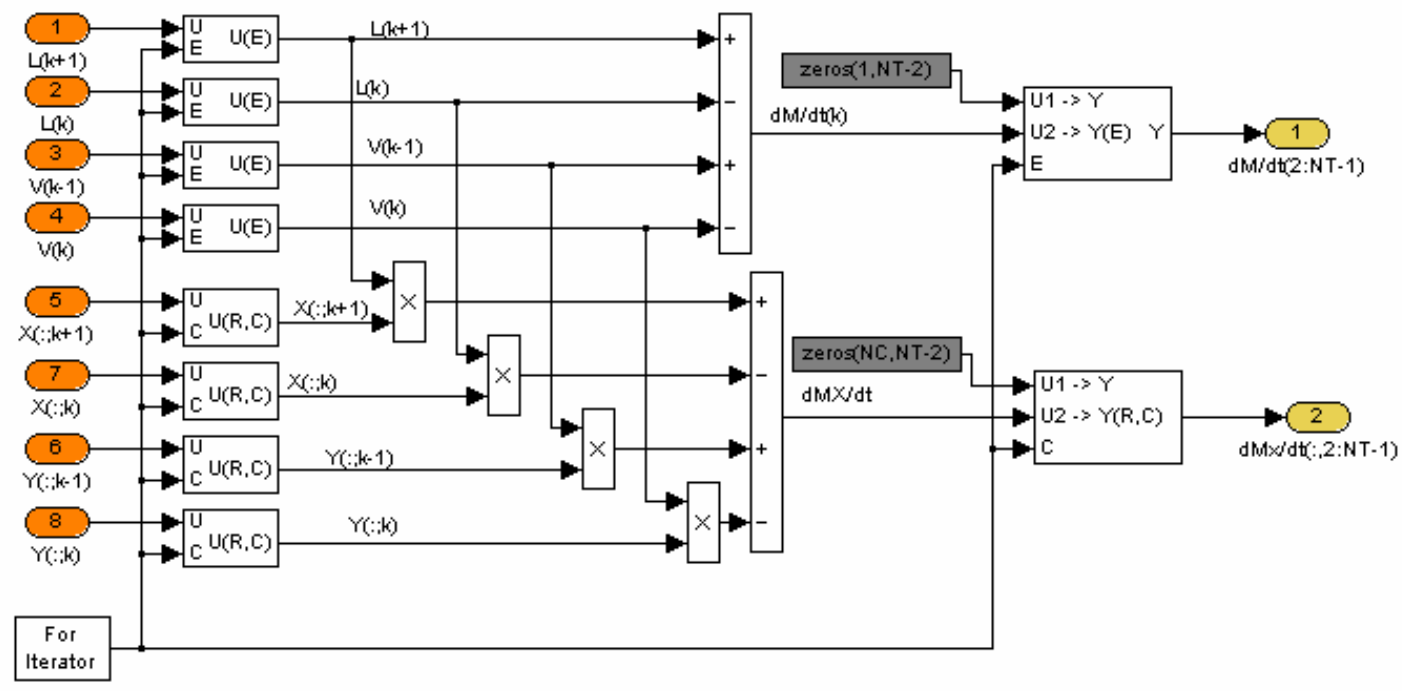

1.2.1.3.1.1 - Subsystem 


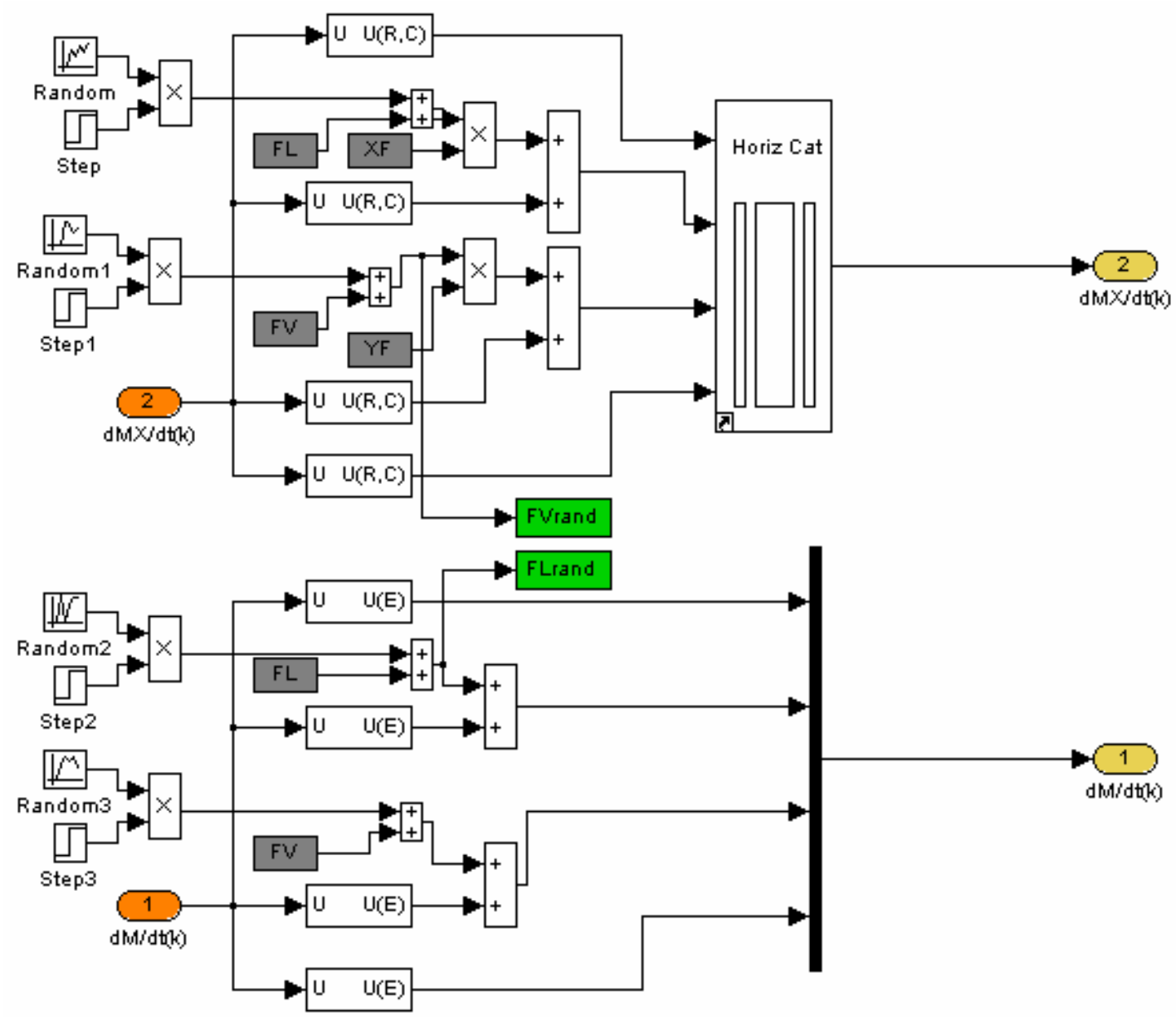

1.2.1.3.1.2 - Subsystem1

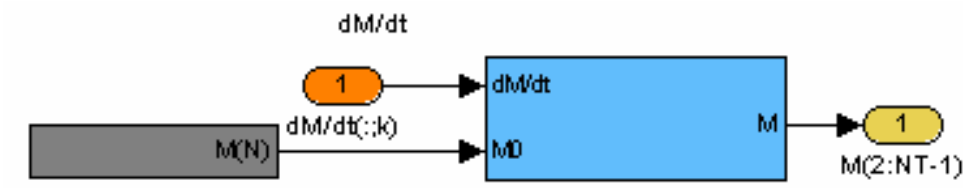

1.2.1.3.1.3 - Subsystem2

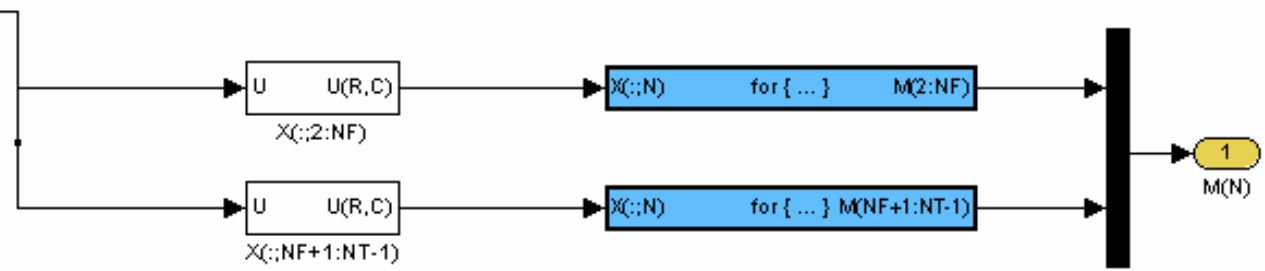

1.2.1.3.1.3.1 - Cálculo dos Holdups iniciais 


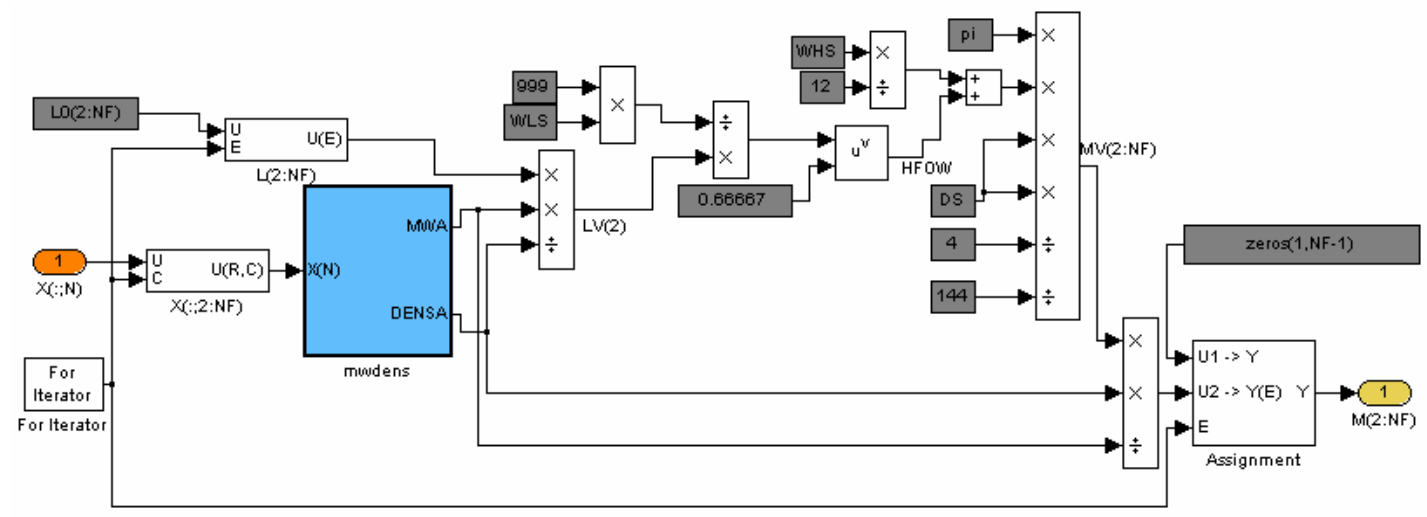

1.2.1.3.1.3.1.1 - Cálculo dos holdups iniciais1

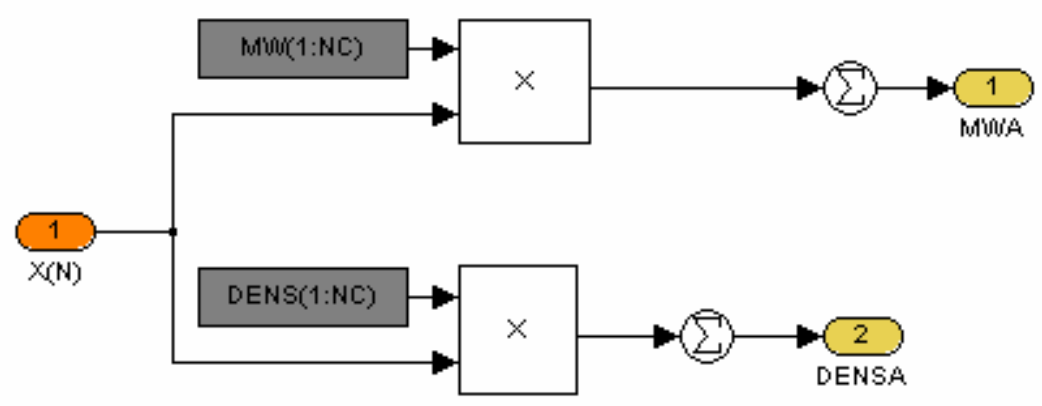

1.2.1.3.1.3.1.1.1 - mwdens

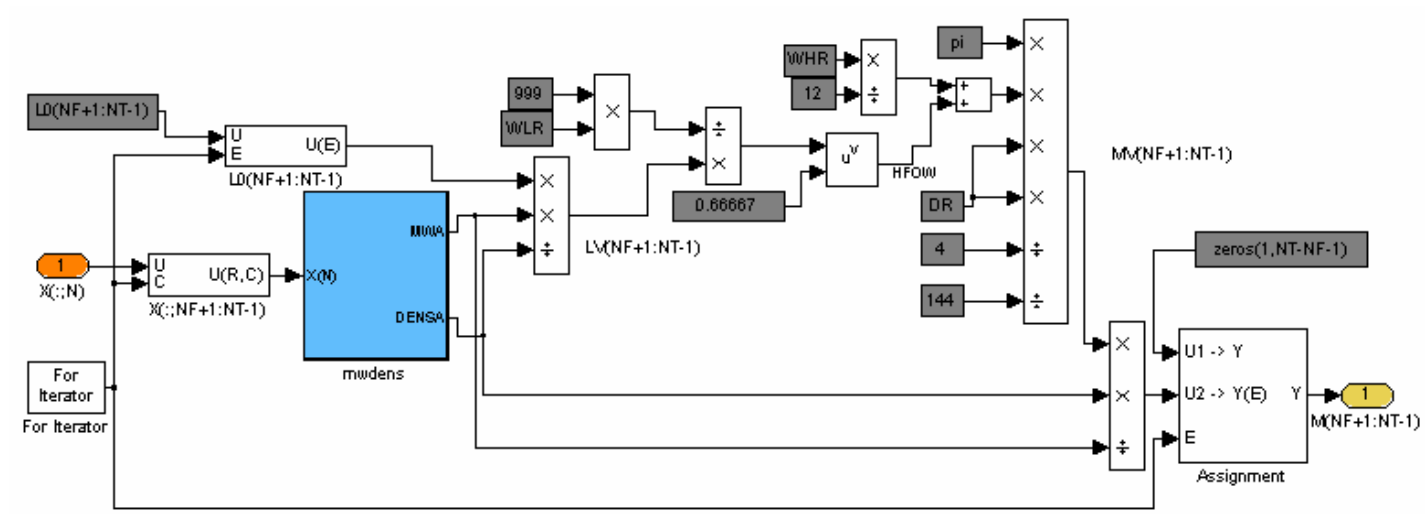

1.2.1.3.1.3.1.2 - Cálculo dos holdups iniciais7 


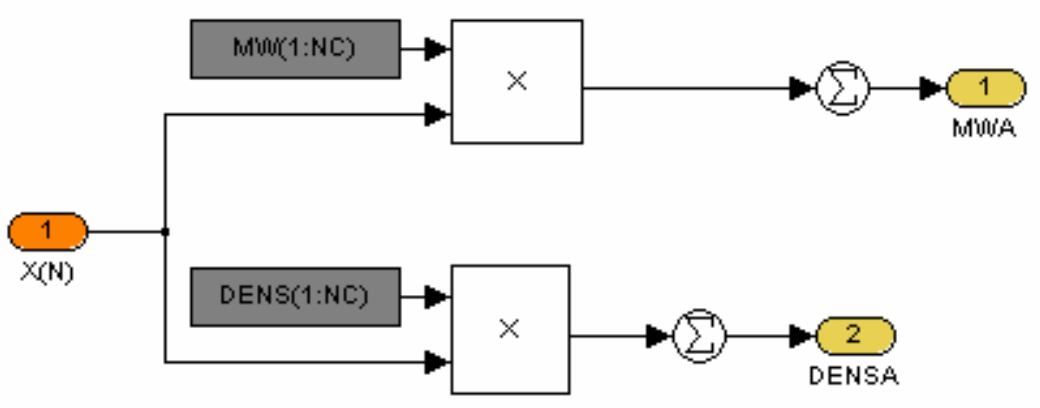

1.2.1.3.1.3.1.2.1 - mwdens

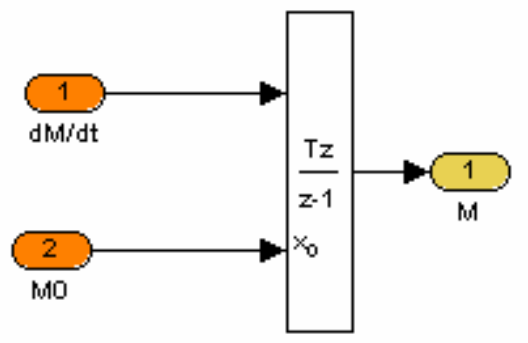

1.2.1.3.1.3.2 - Subsystem

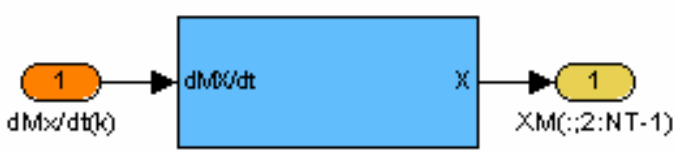

1.2.1.3.1.4 - Subsystem3

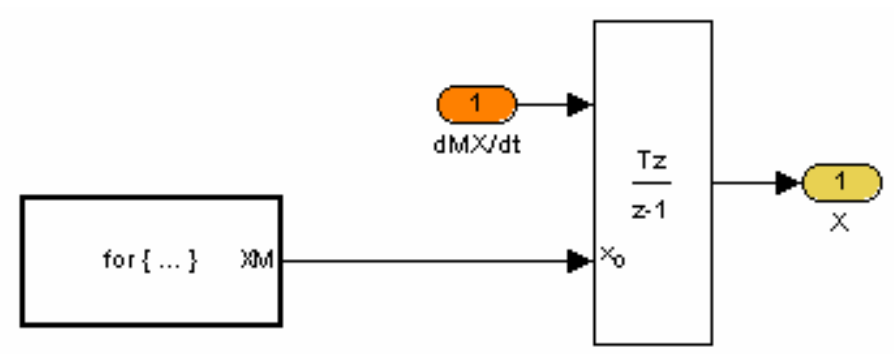

1.2.1.3.1.4.1 - Subsystem 


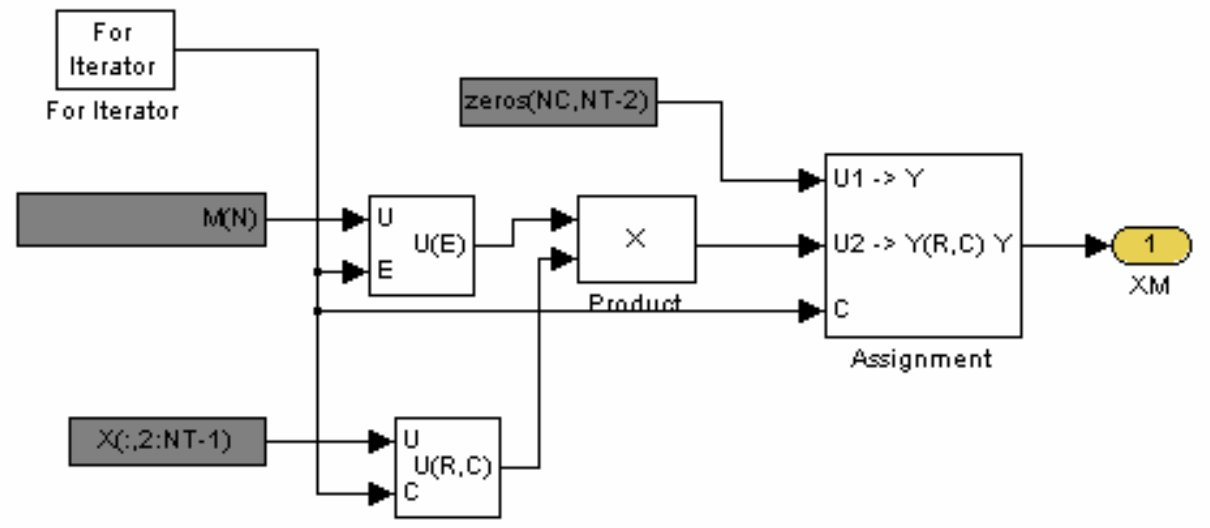

1.2.1.3.1.4.1.1 - For Iterator Subsystem

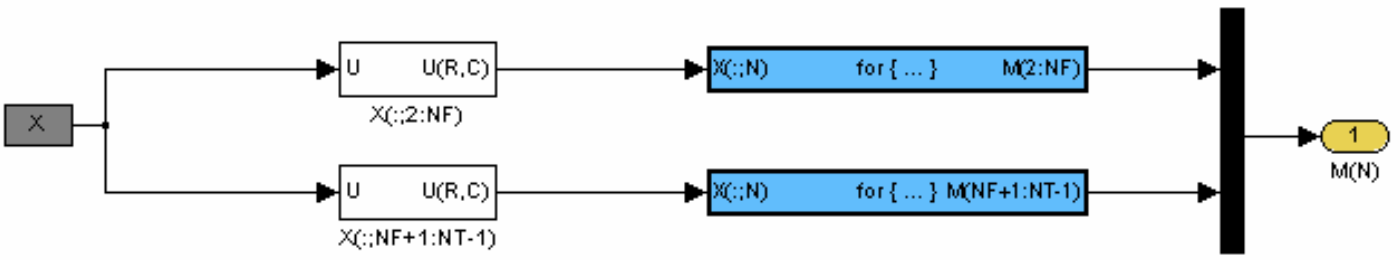

1.2.1.3.1.4.1.1.1 - Cálculo dos Holdups iniciais

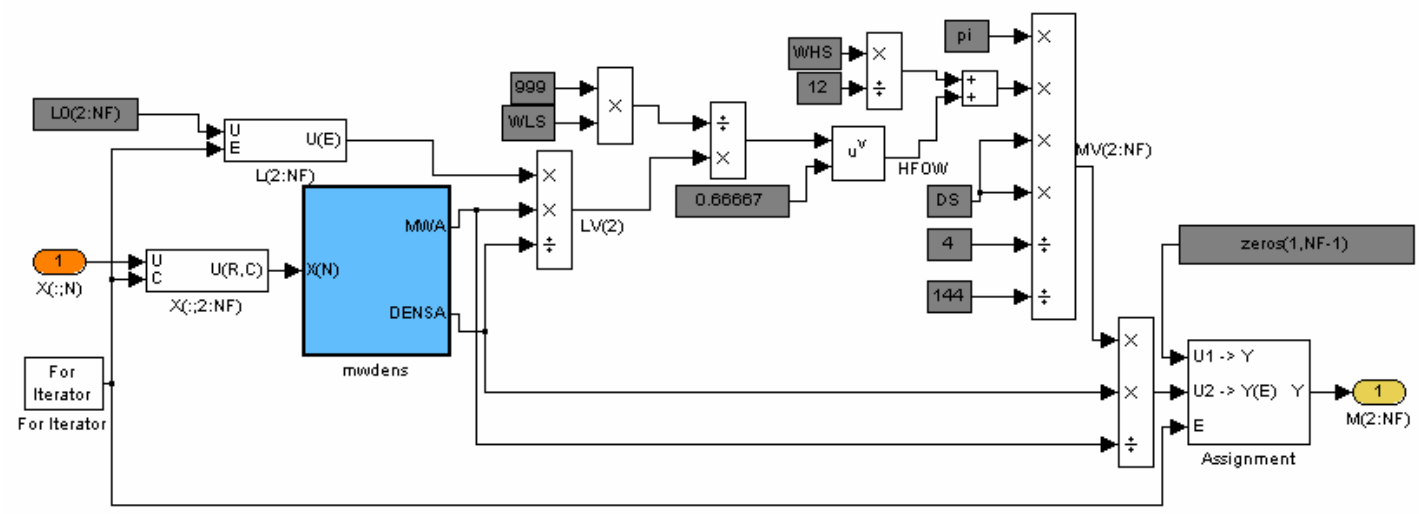

1.2.1.3.1.4.1.1.1.1 - Cálculo dos holdups iniciais1 


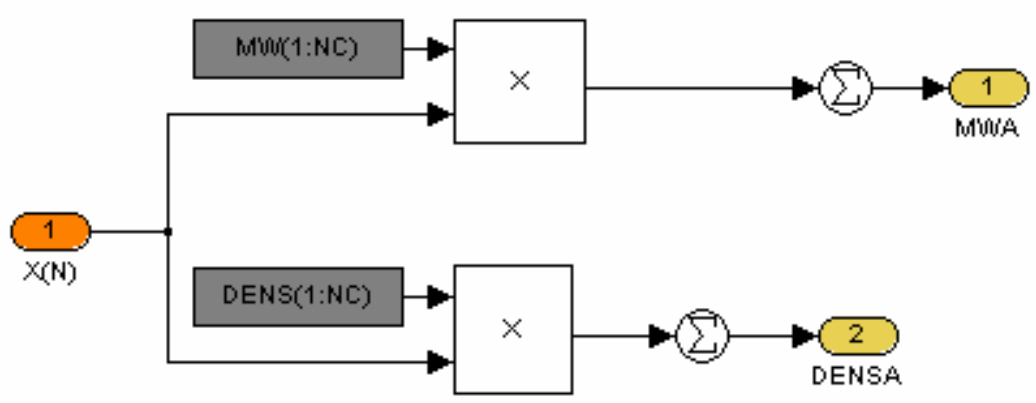

\subsection{1.1.1.1.1 - mwdens}

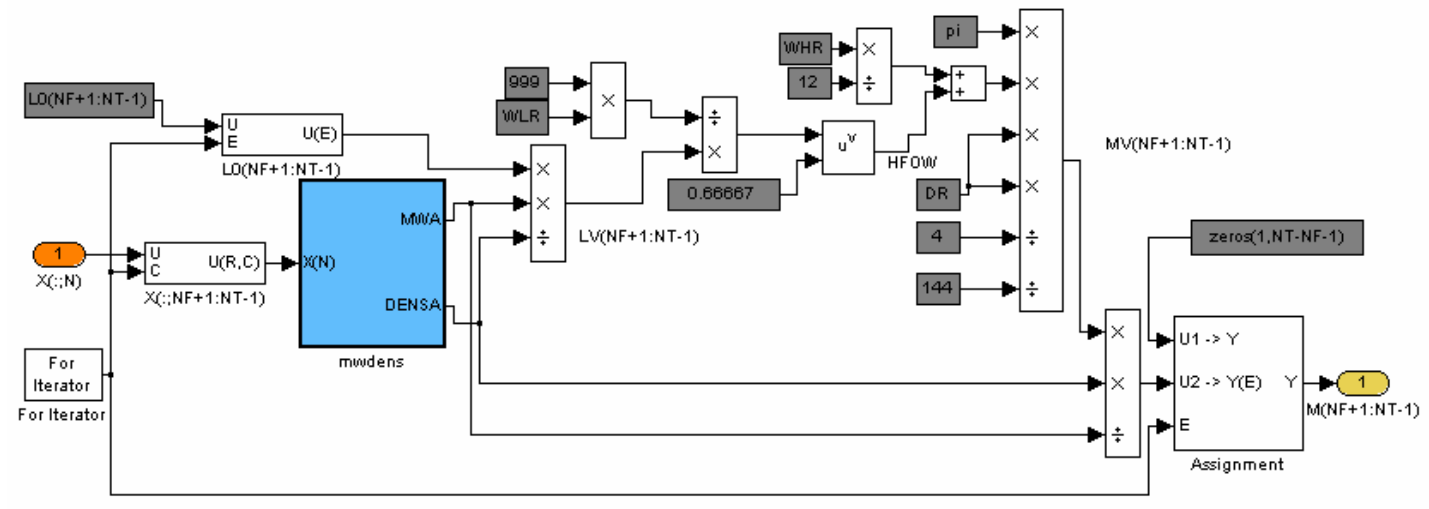

1.2.1.3.1.4.1.1.1.2 - Cálculo dos holdups iniciais7

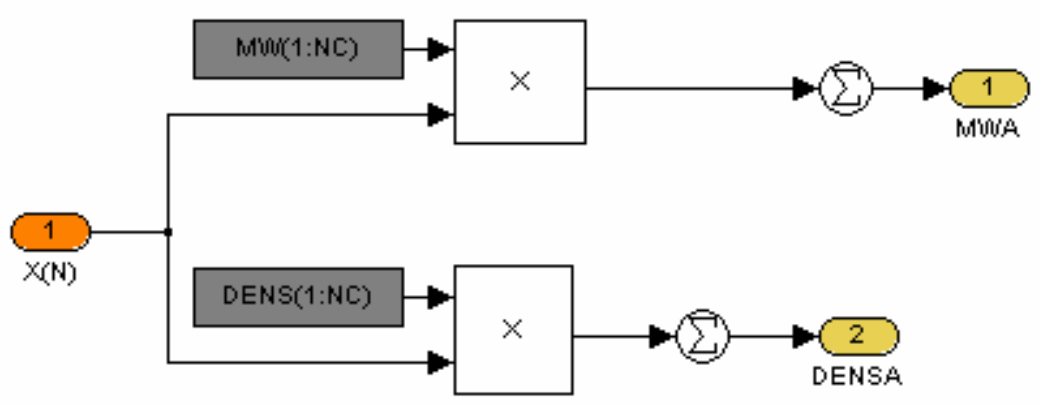

1.2.1.3.1.4.1.1.1.2.1 - mwdens 


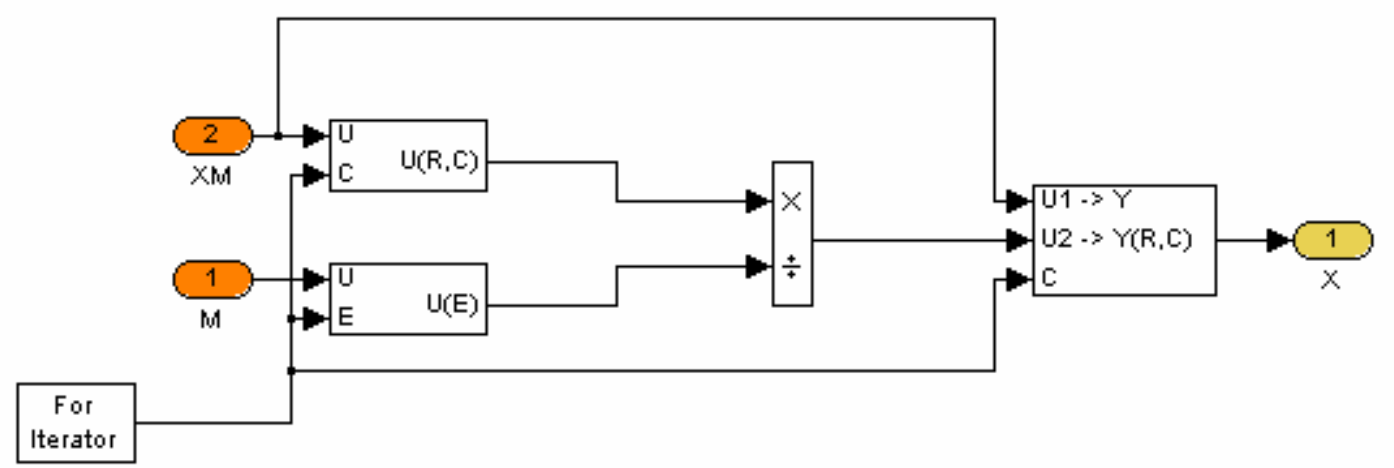

1.2.1.3.1.5 - Subsystem4

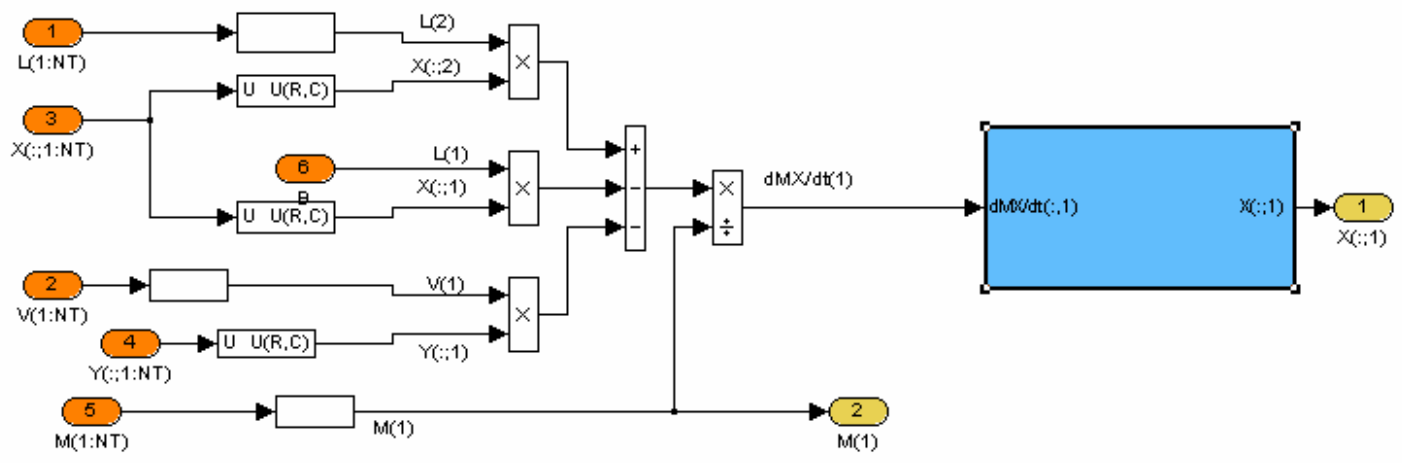

1.2.4 - Refervedor

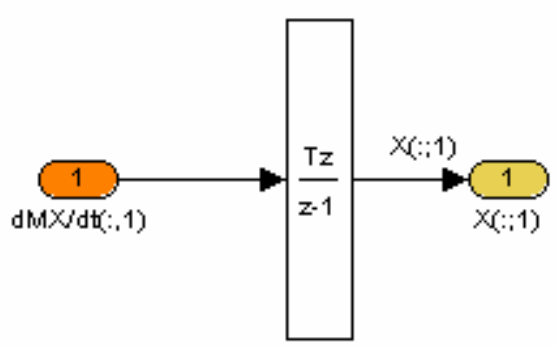

1.2.4.1 - For Iterator Subsyster 


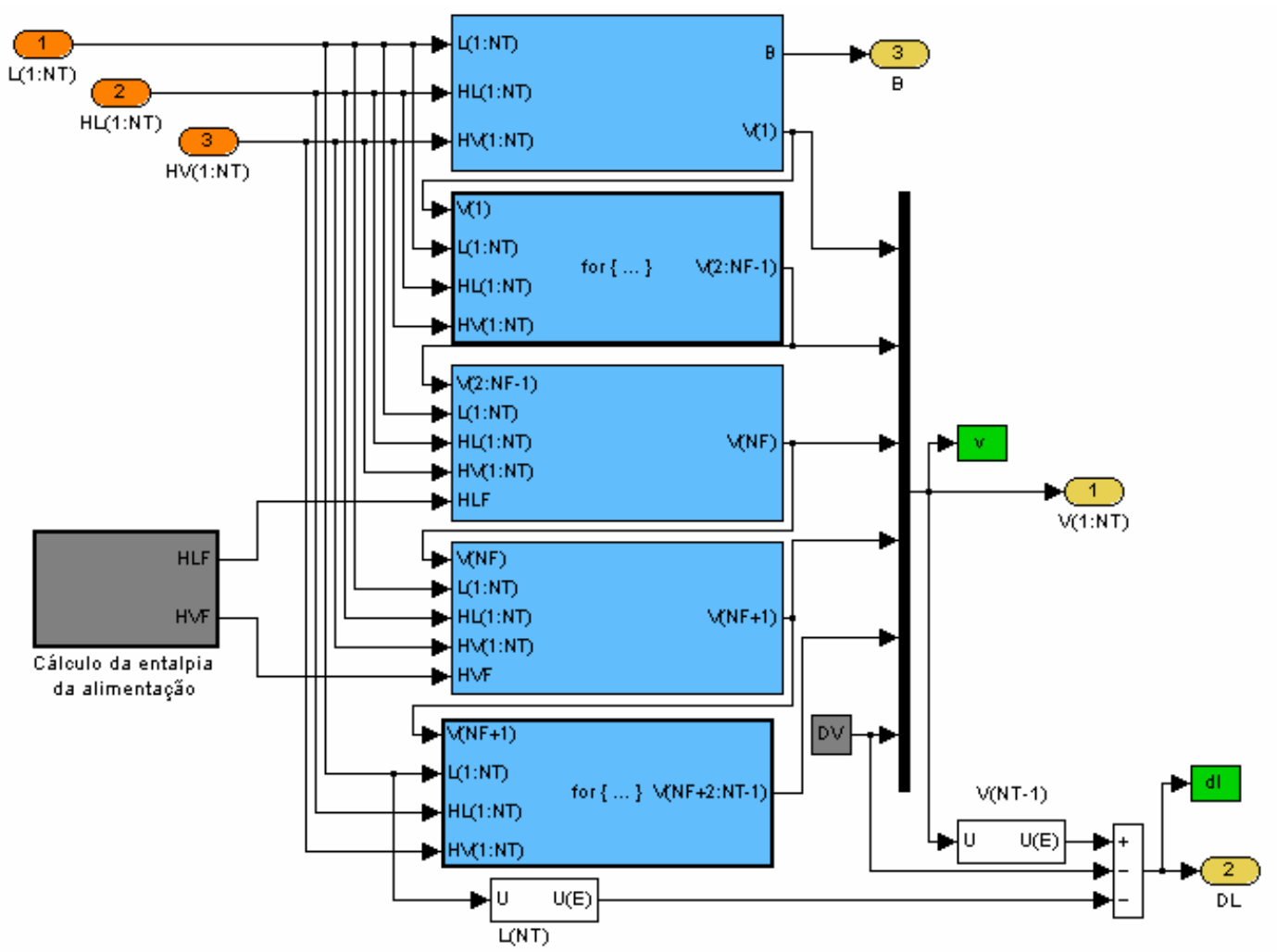

1.3 - Cálculo das taxas de vapor (V)

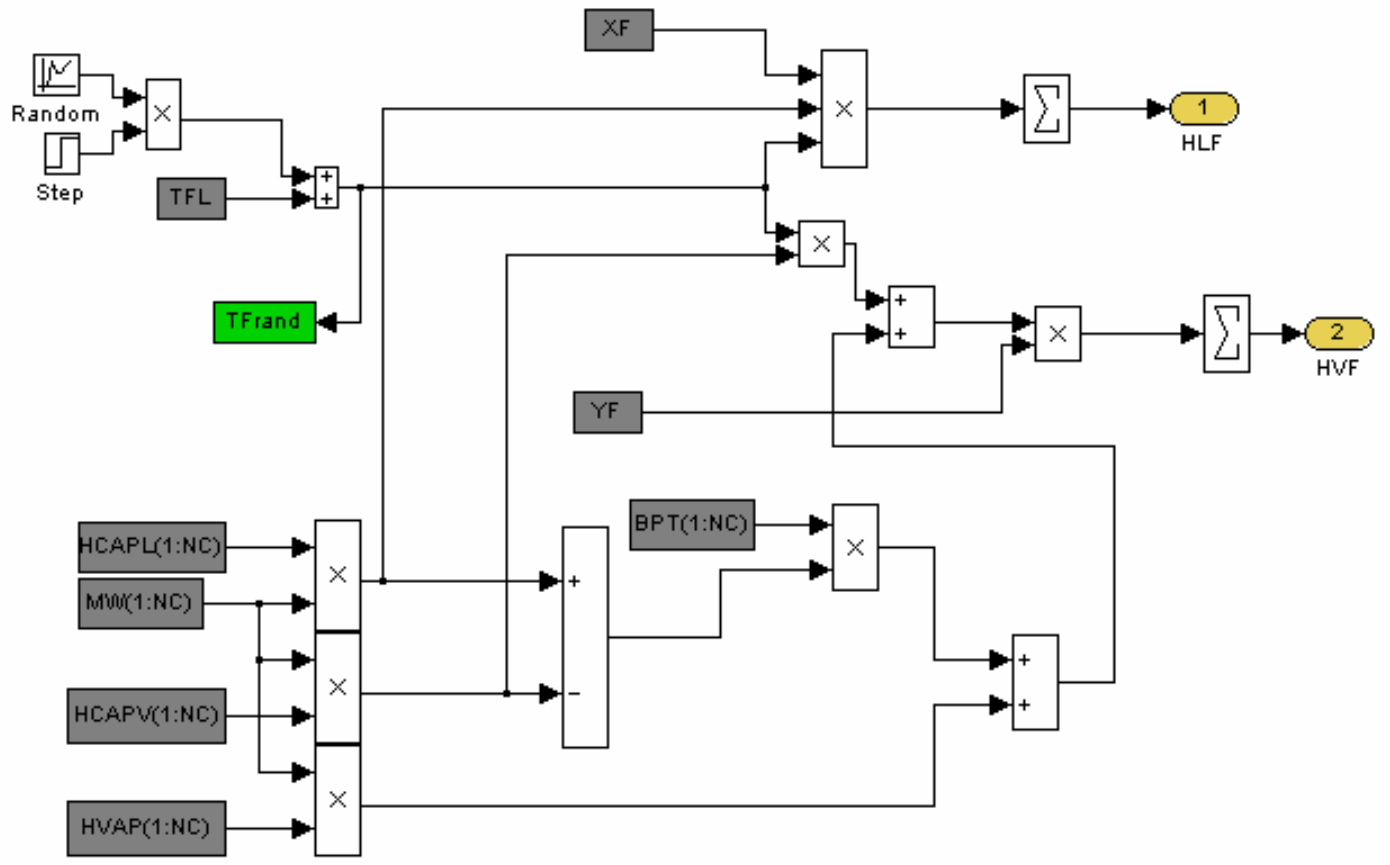

1.3.1 - Cálculo da entalpia da alimentação 


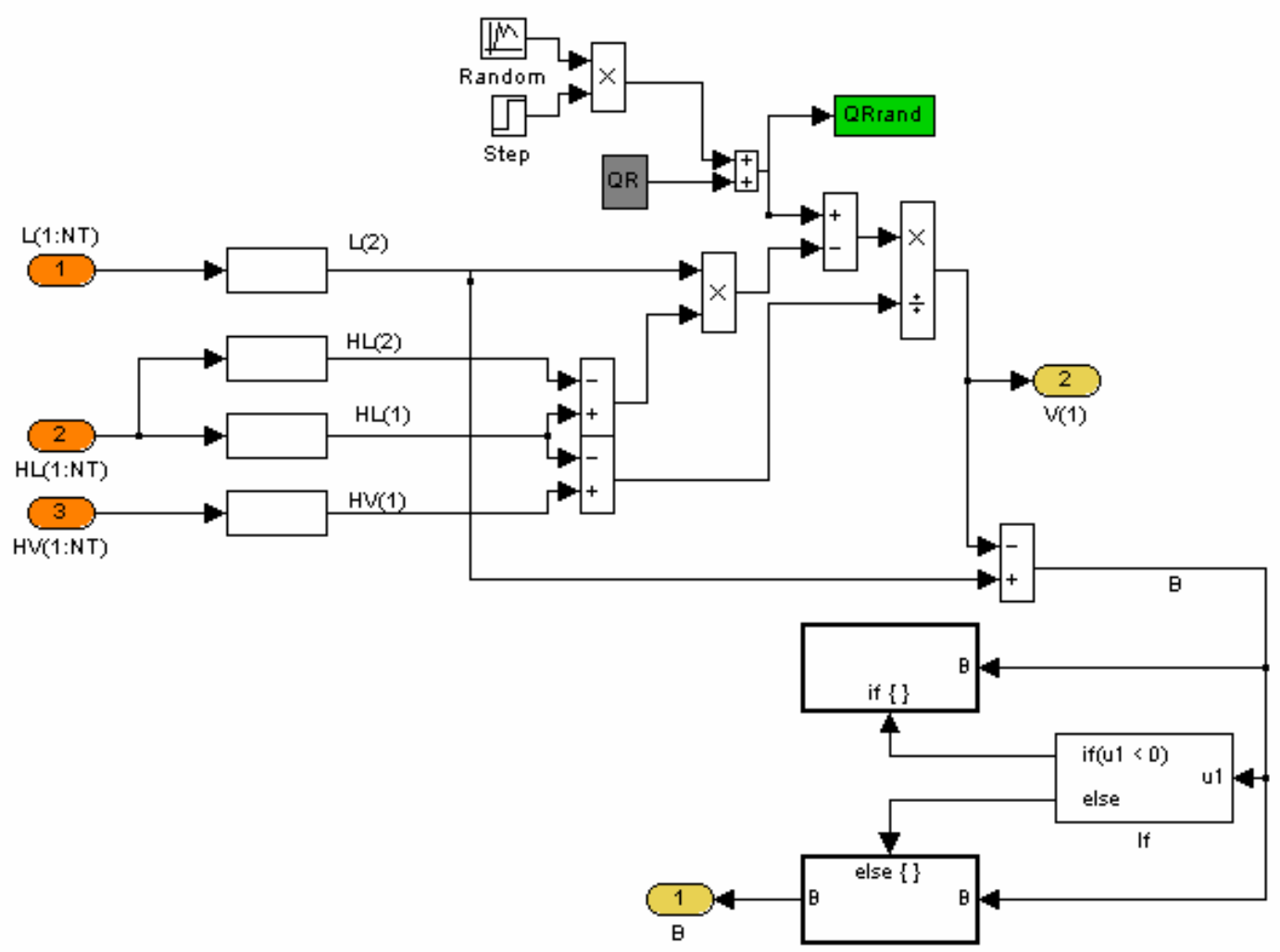

1.3.2 - Cálculo das taxas de vapor
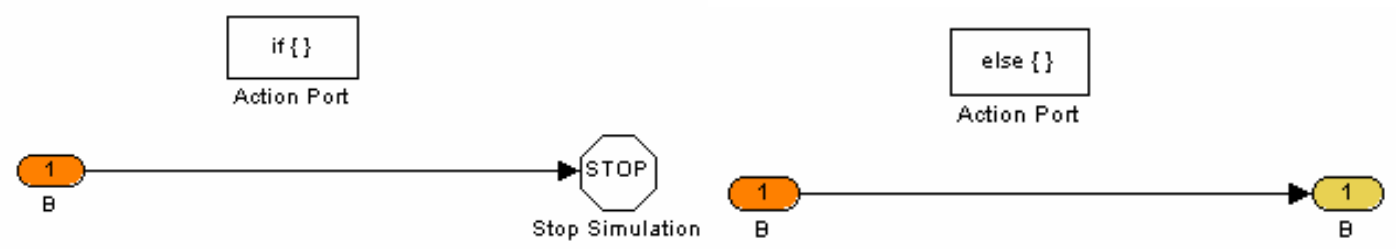

1.3.2.1 - If Action Subsystem

1.3.2.2 - If Action Subsystem1 


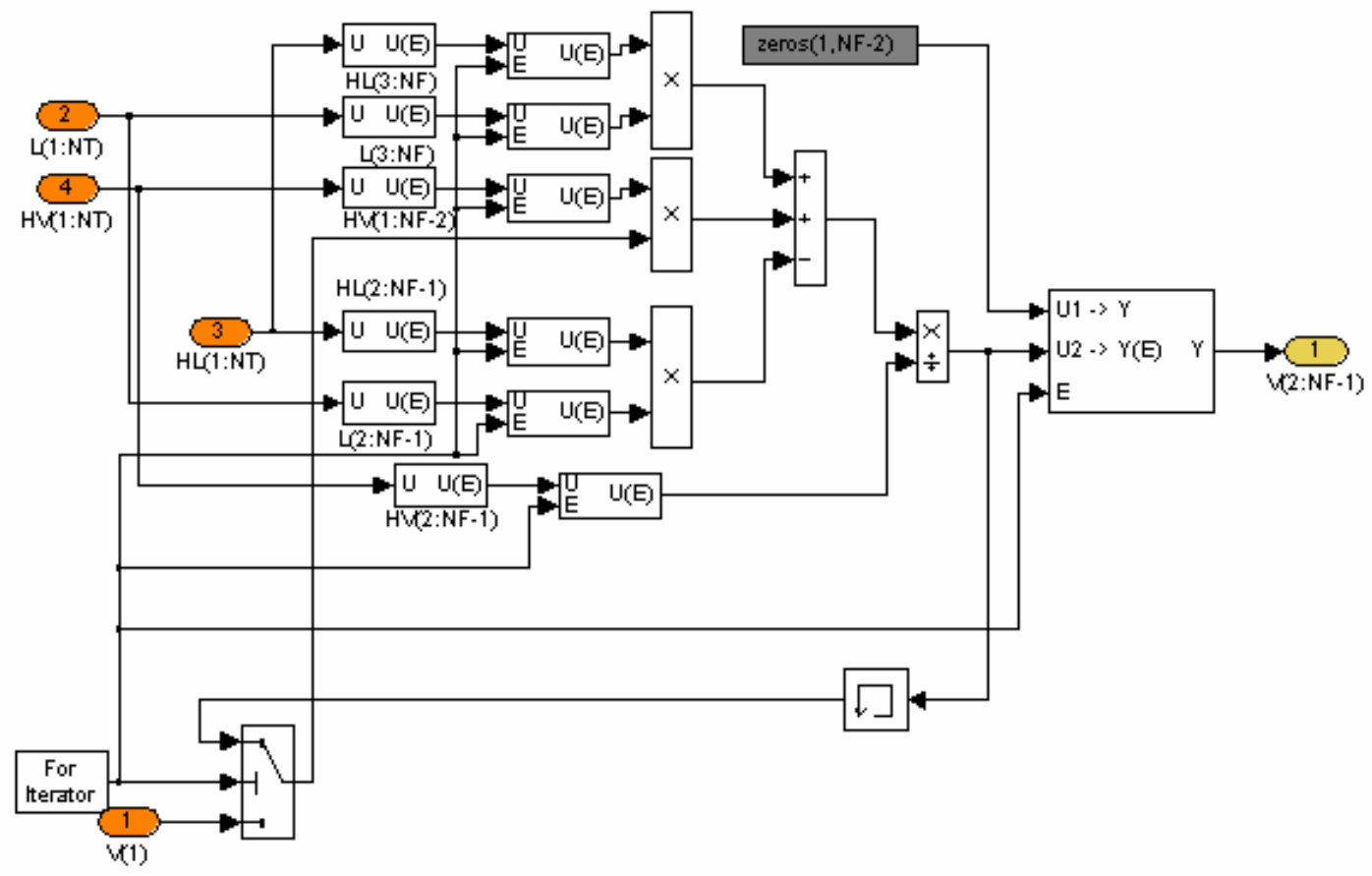

1.3.3 - Cálculo das taxas de vapor1

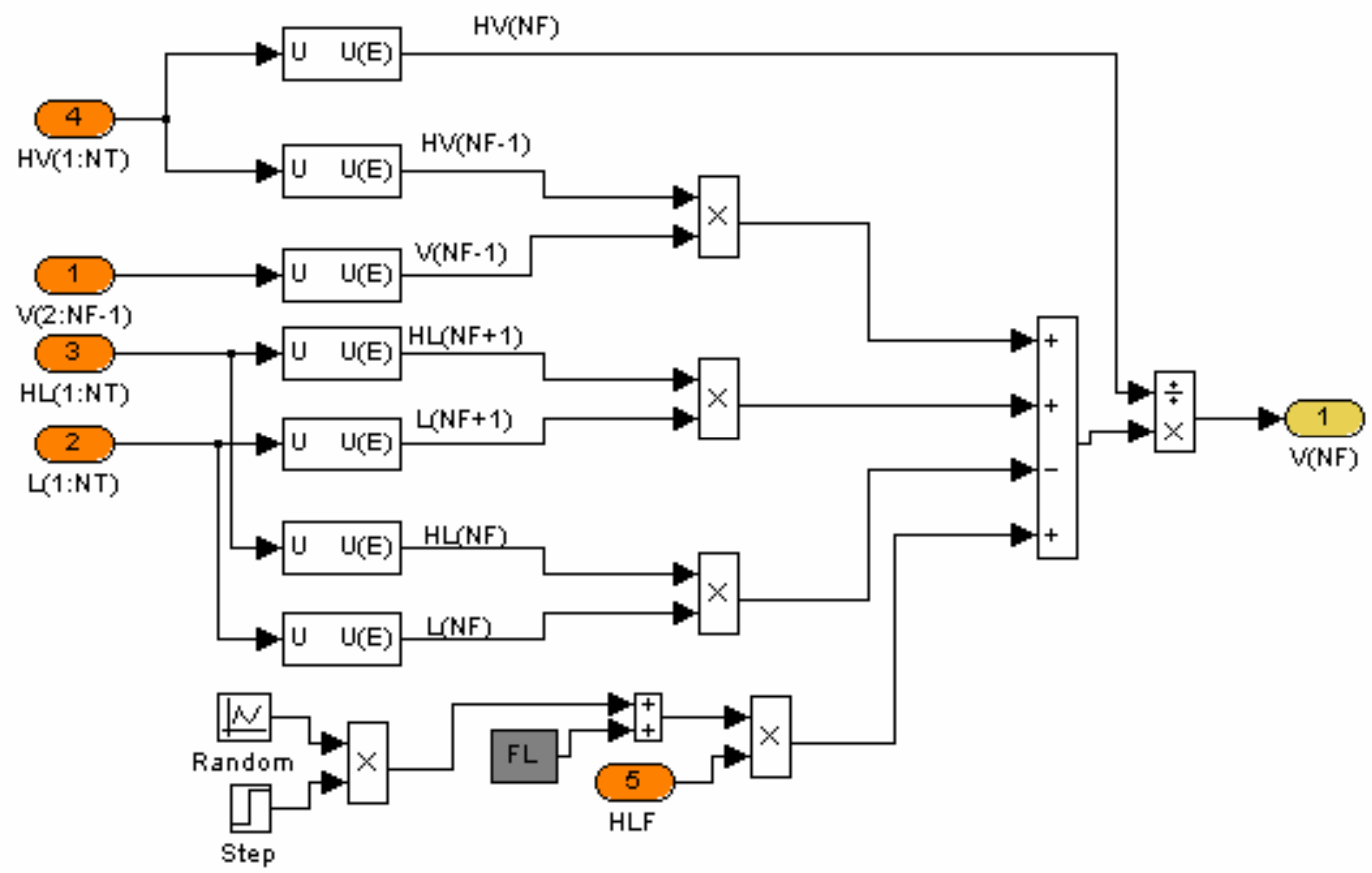

1.3.4 - Cálculo das taxas de vapor2 


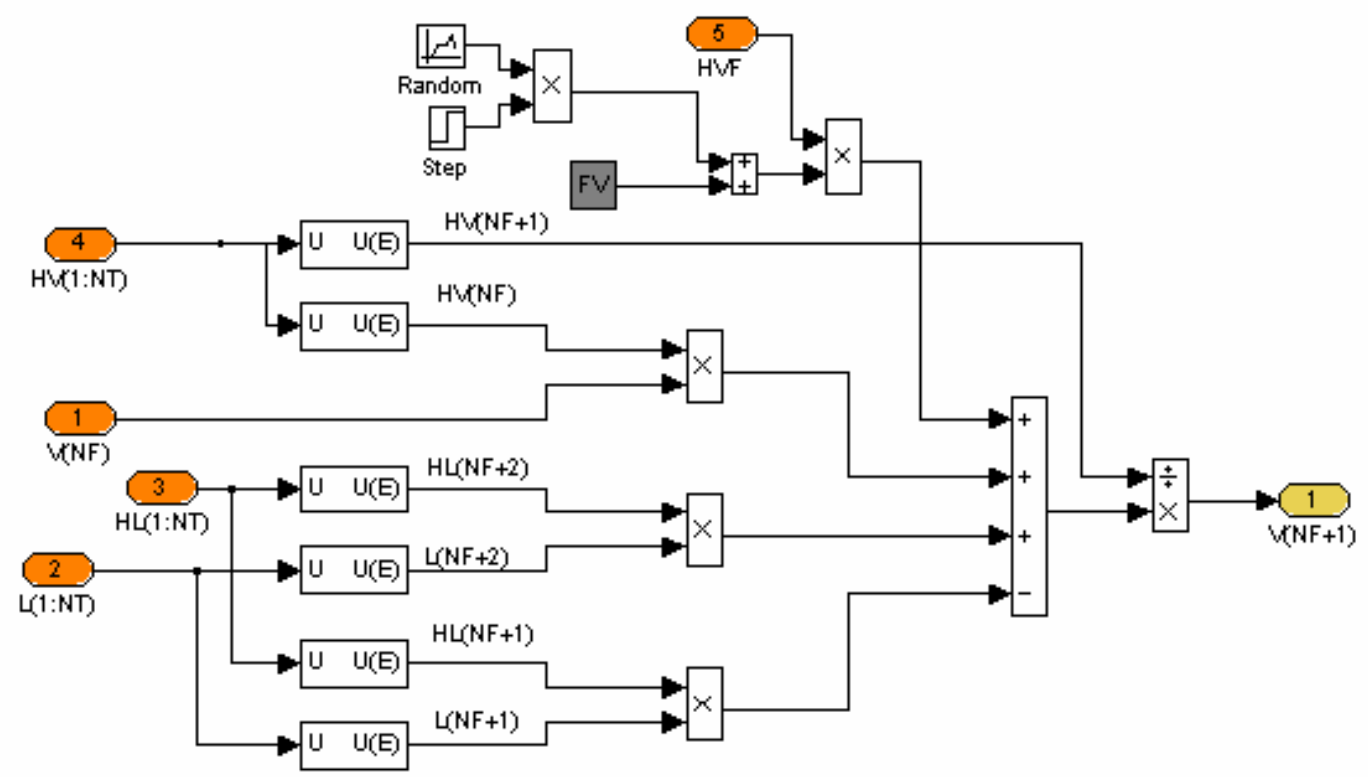

1.3.5 - Cálculo das taxas de vapor4

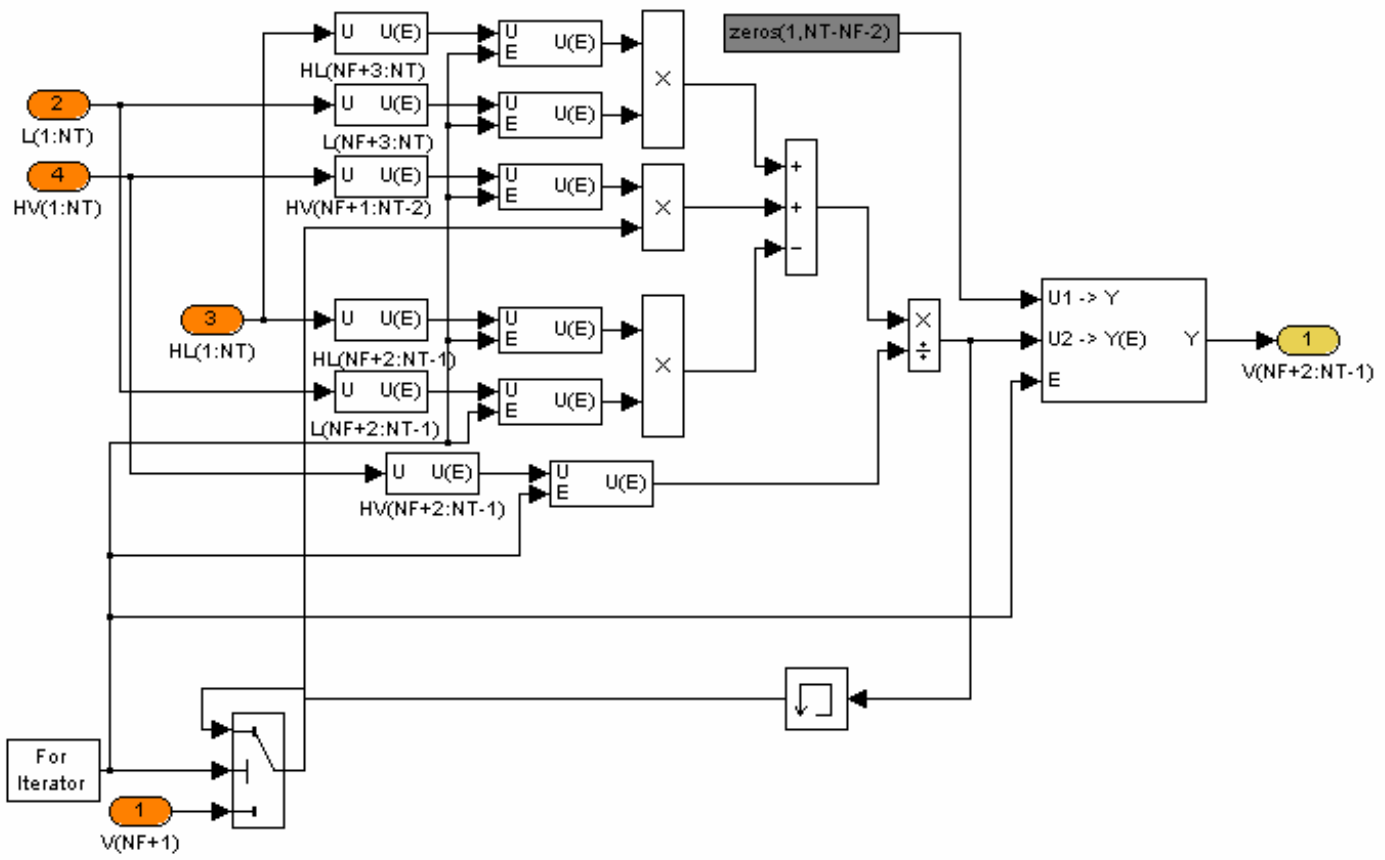

1.3.6 - Subsystem 


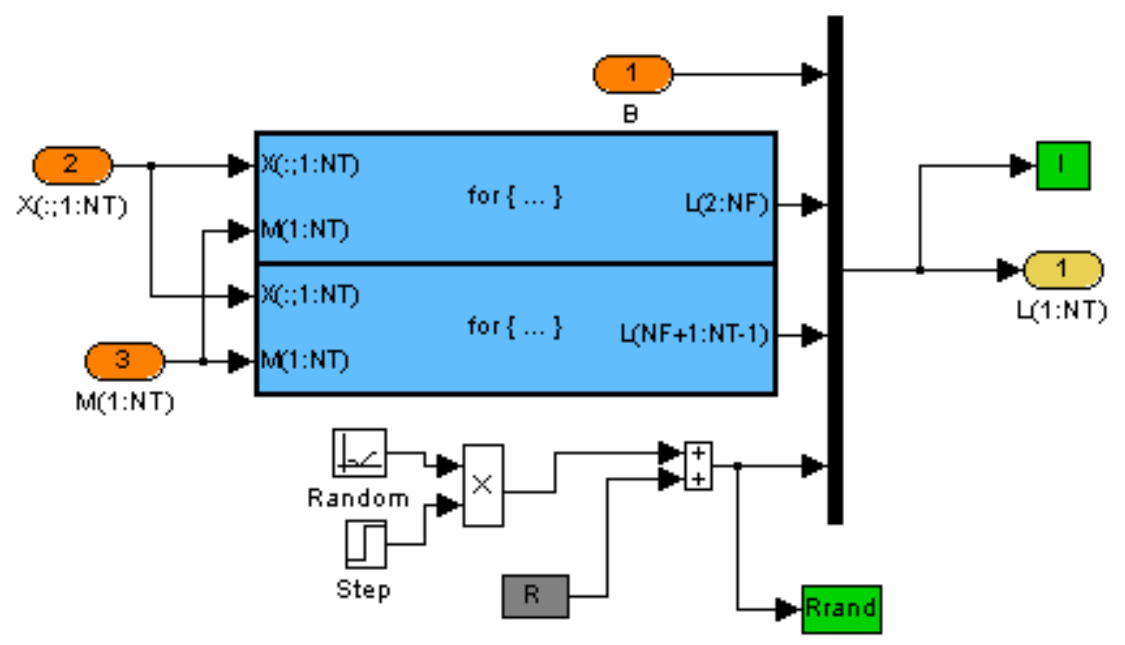

1.4 - Cálculo dos novos fluxos de líquido

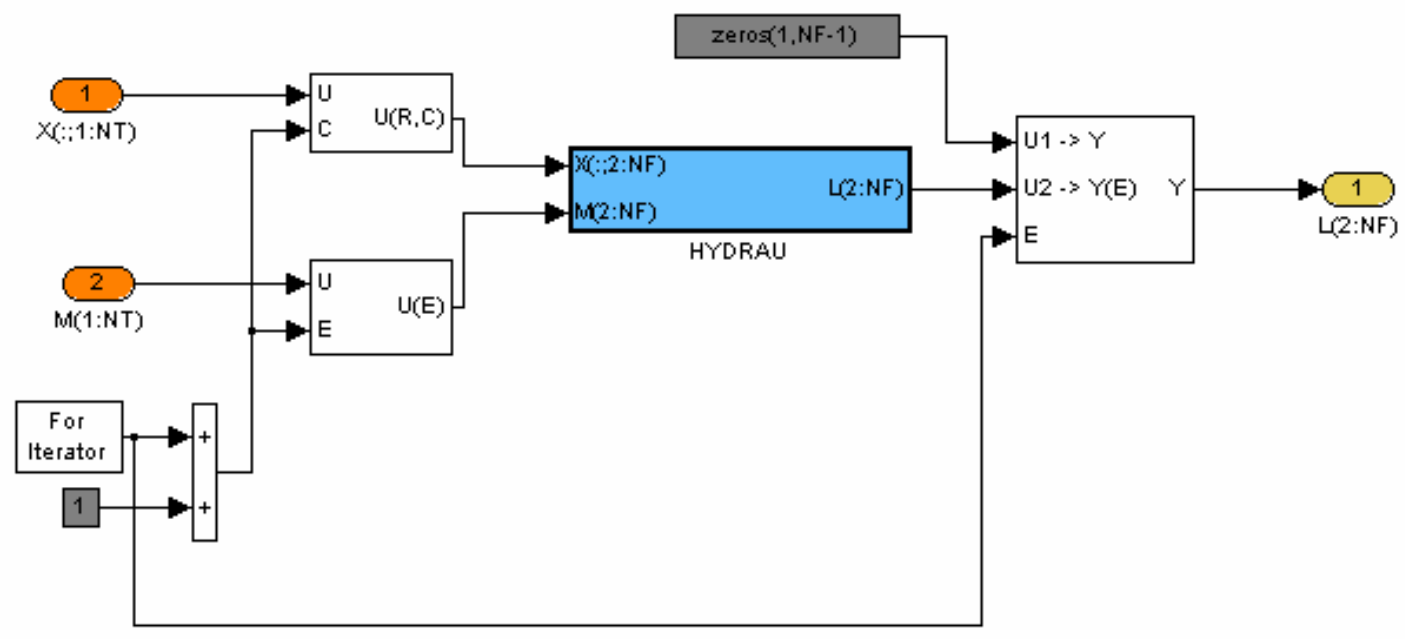

1.4.1 - For Iterator Subsystem 


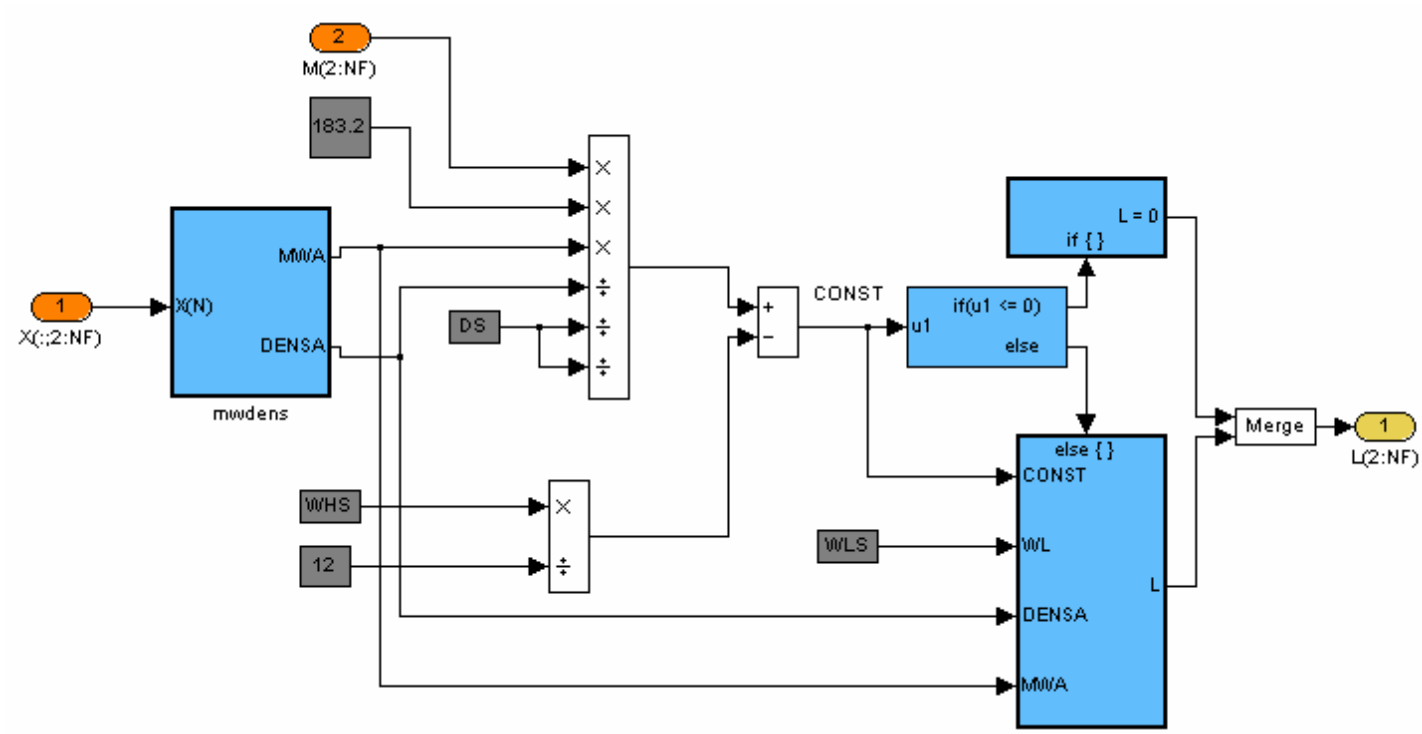

1.4.1.1 - HYDRAU

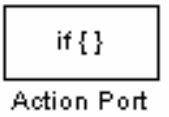

0

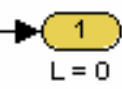

1.4.1.1.1 - If Action Subsystem

$$
\begin{array}{|l|}
\hline \text { else }\{\} \\
\text { Action Port }
\end{array}
$$

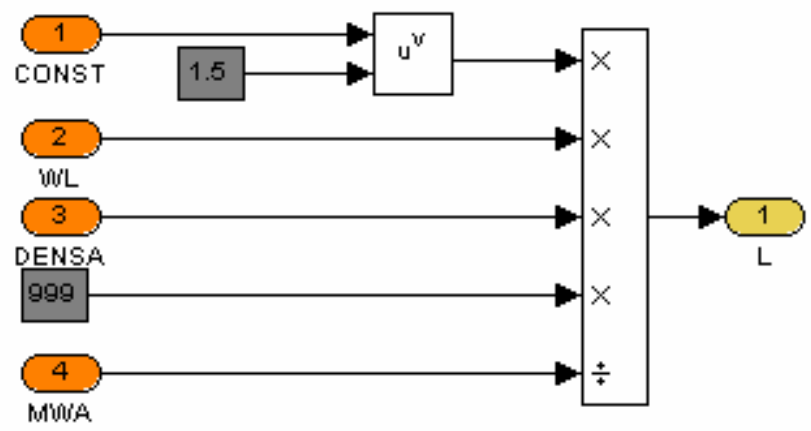

1.4.1.1.2 - If Action Subsystem1 


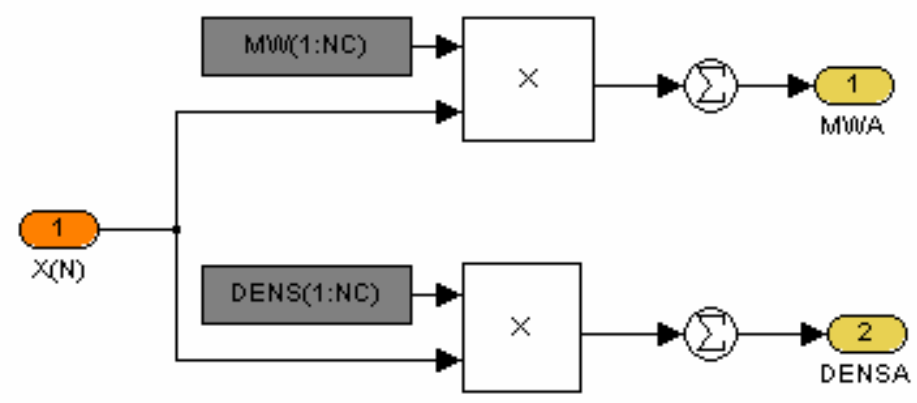

1.4.1.1.3 - mwdens

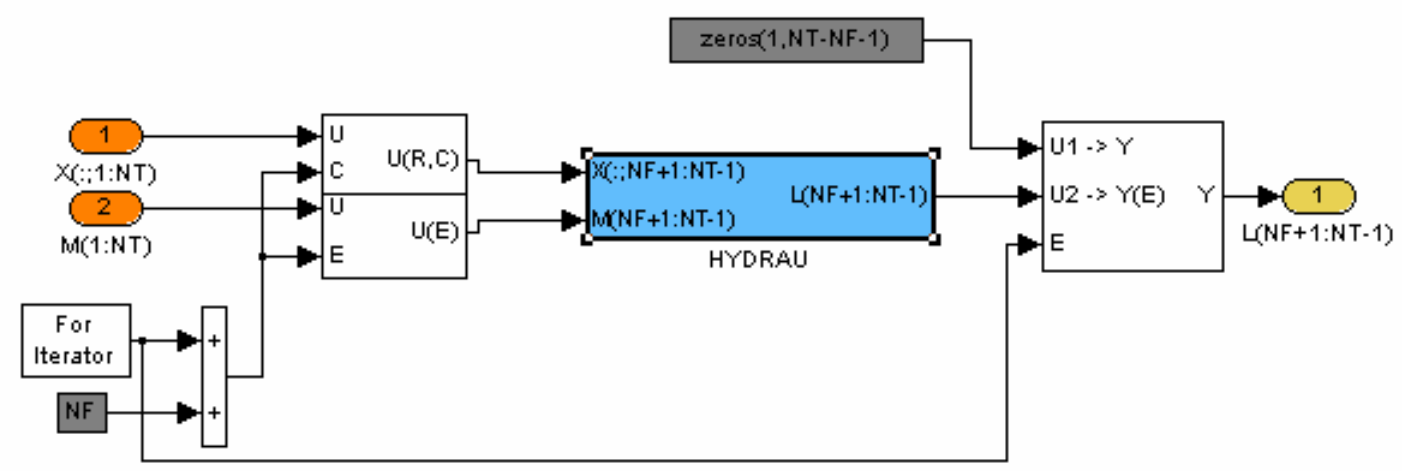

1.4.2 - For Iterator Subsystem1

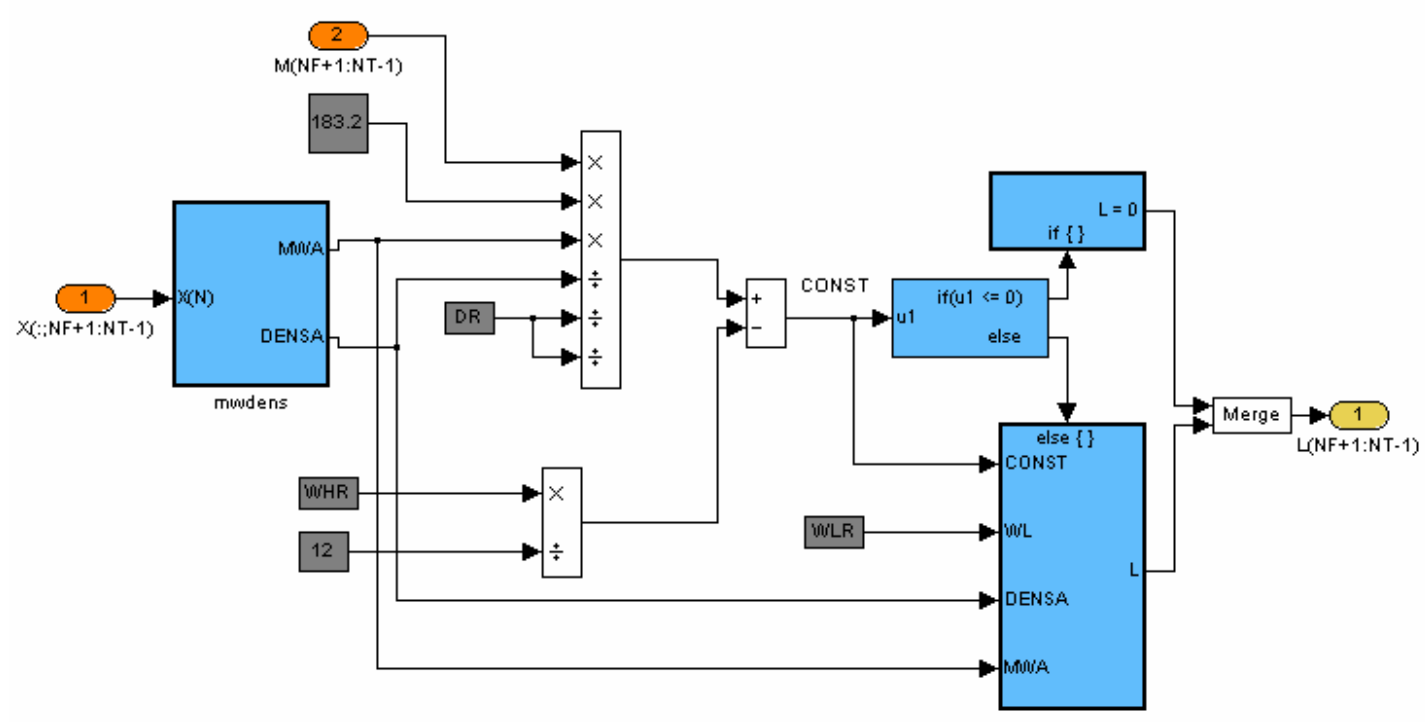

1.4.2.1 - HYDRAU 


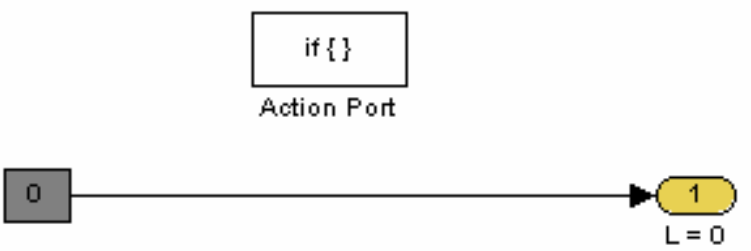

1.4.2.1.1 - If Action Subsystem

$$
\begin{aligned}
& \text { else }\{\} \\
& \text { Action Port }
\end{aligned}
$$

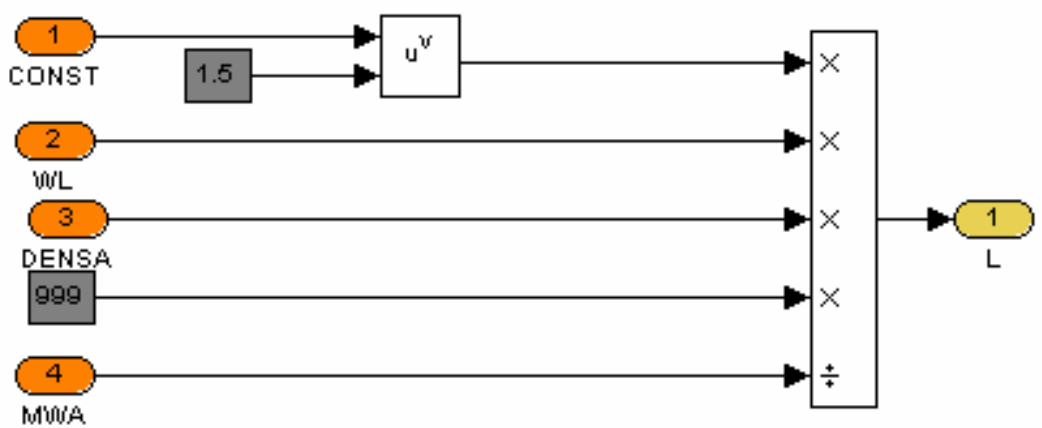

1.4.2.1.2 - If Action Subsystem1

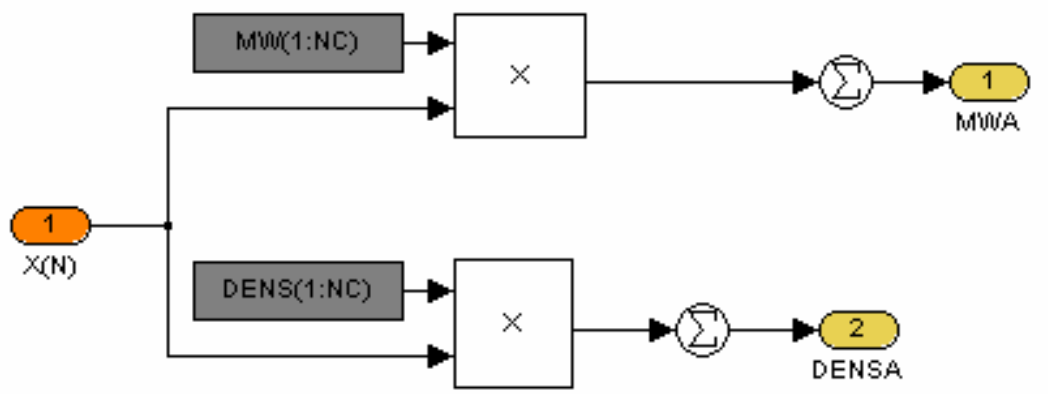

1.4.2.1.3 - mwdens 


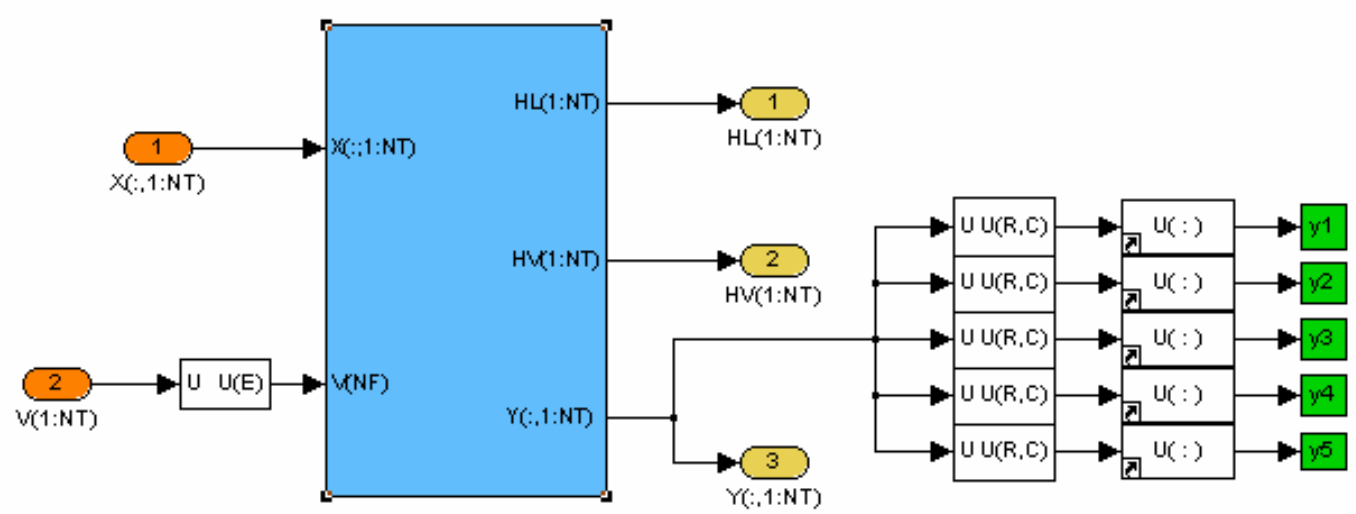

\section{5 - Loop Principal}

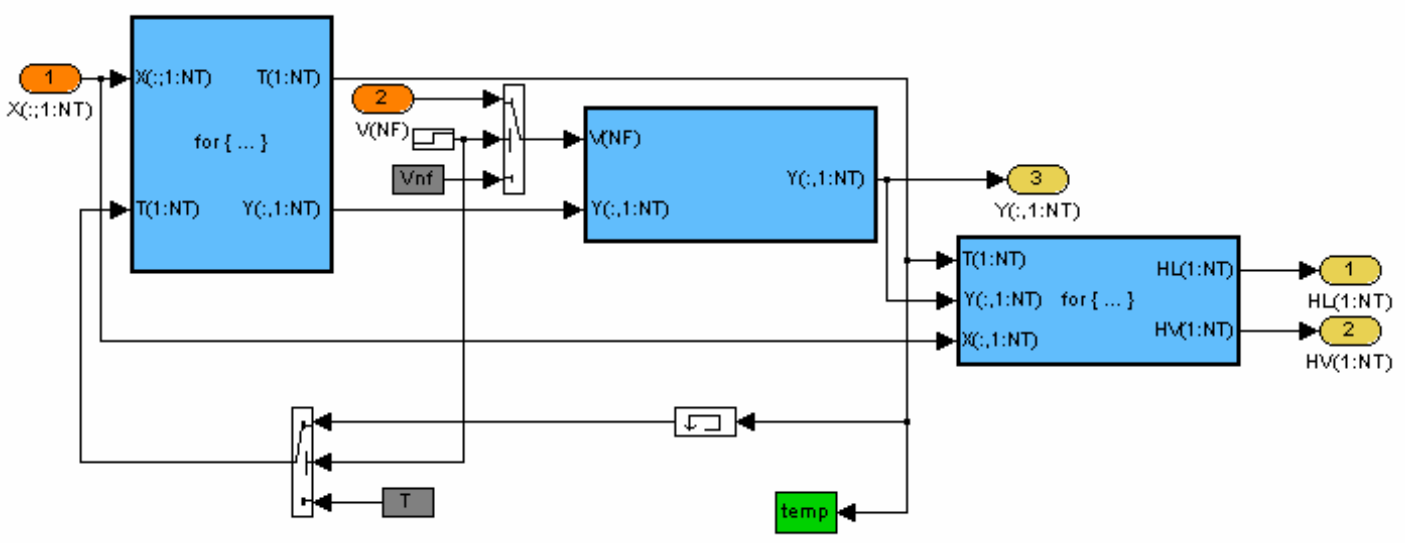

1.5.1 - Loop Principal 2 


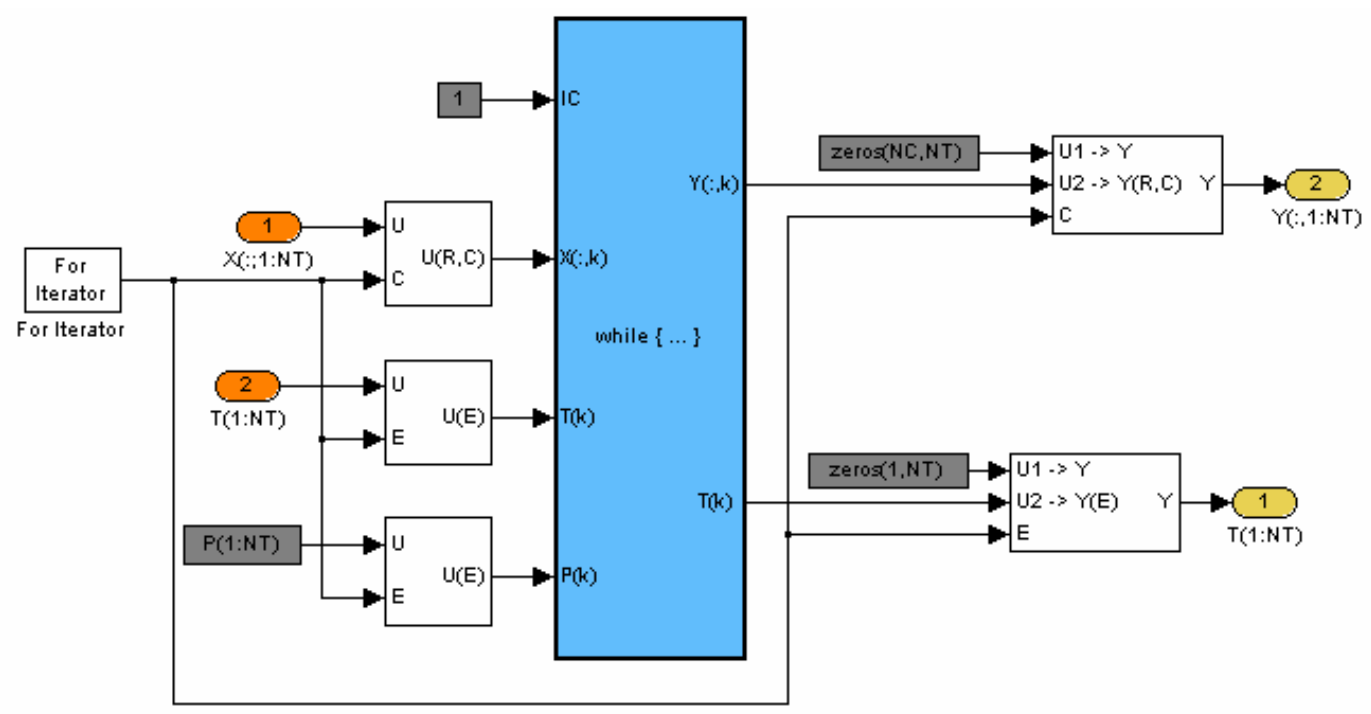

1.5.1.1 - For Iterator Subsystem

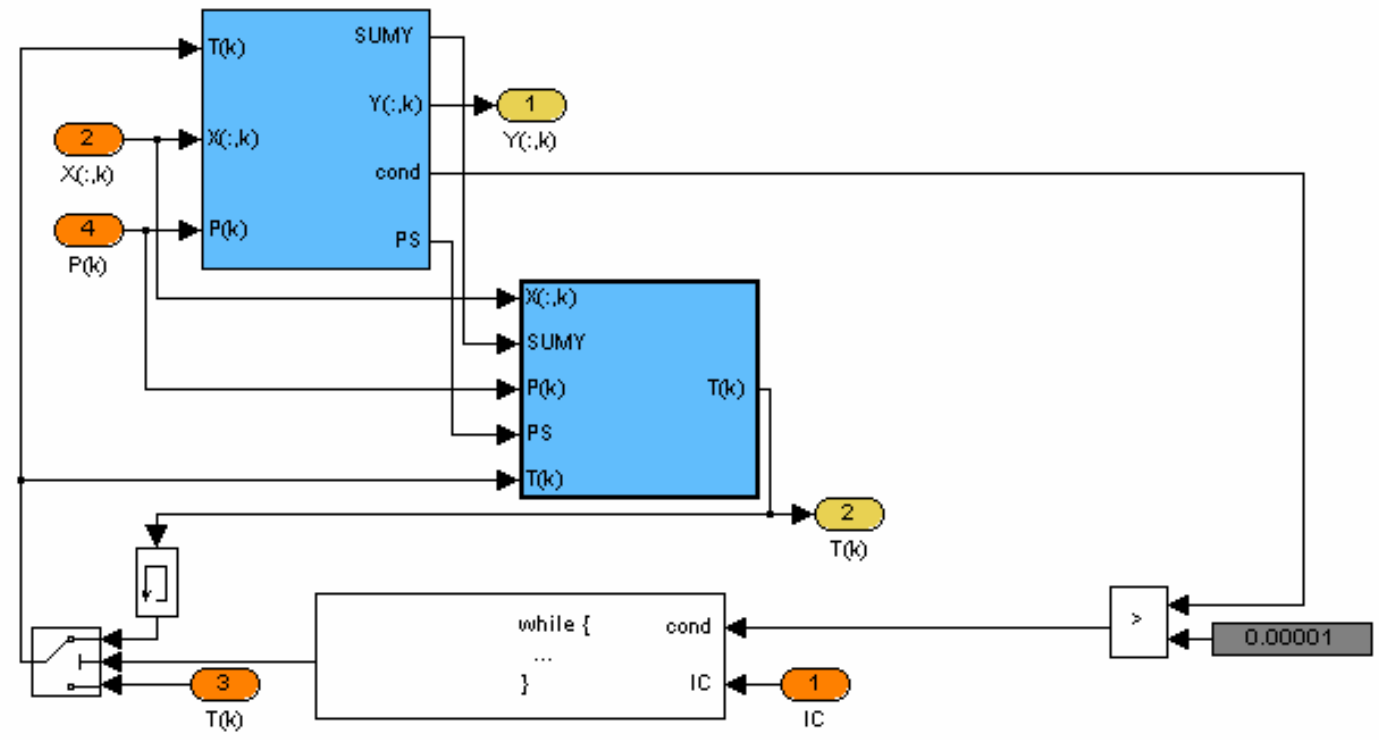

1.5.1.1.1 - While Iterator Subsystem1 


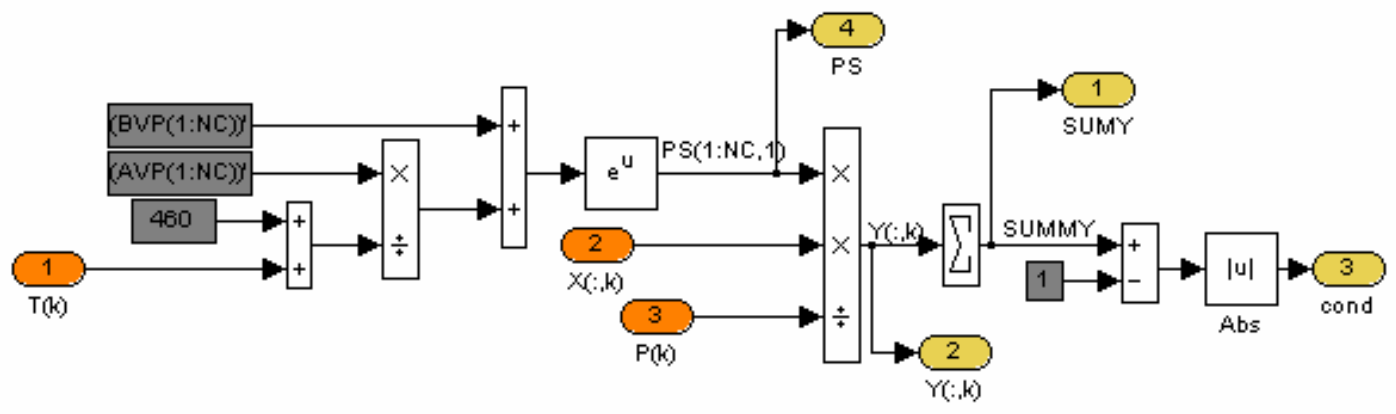

1.5.1.1.1.1 - Enabled Subsystem

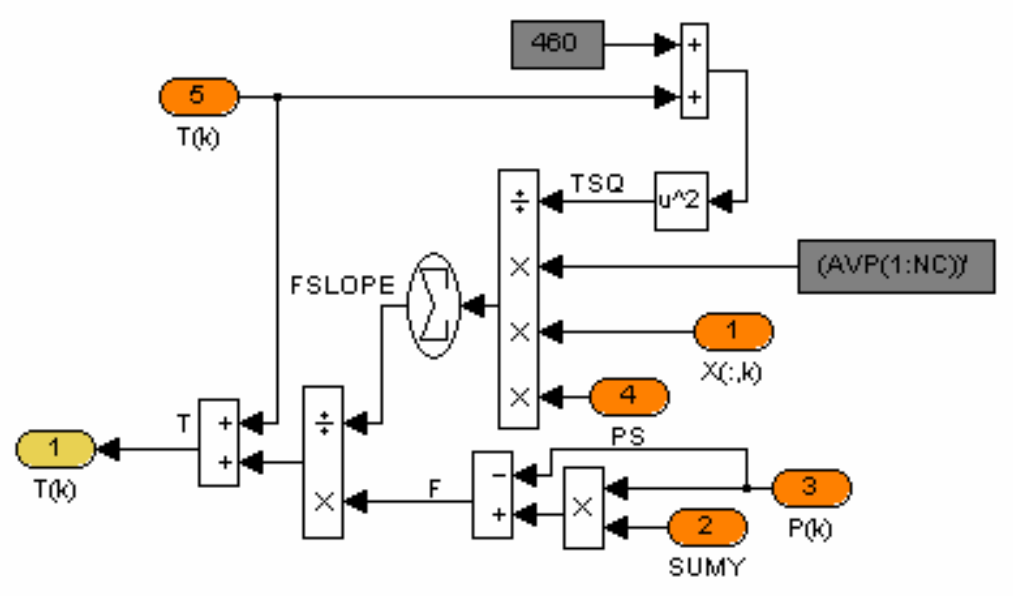

1.5.1.1.1.2 - Subsystem

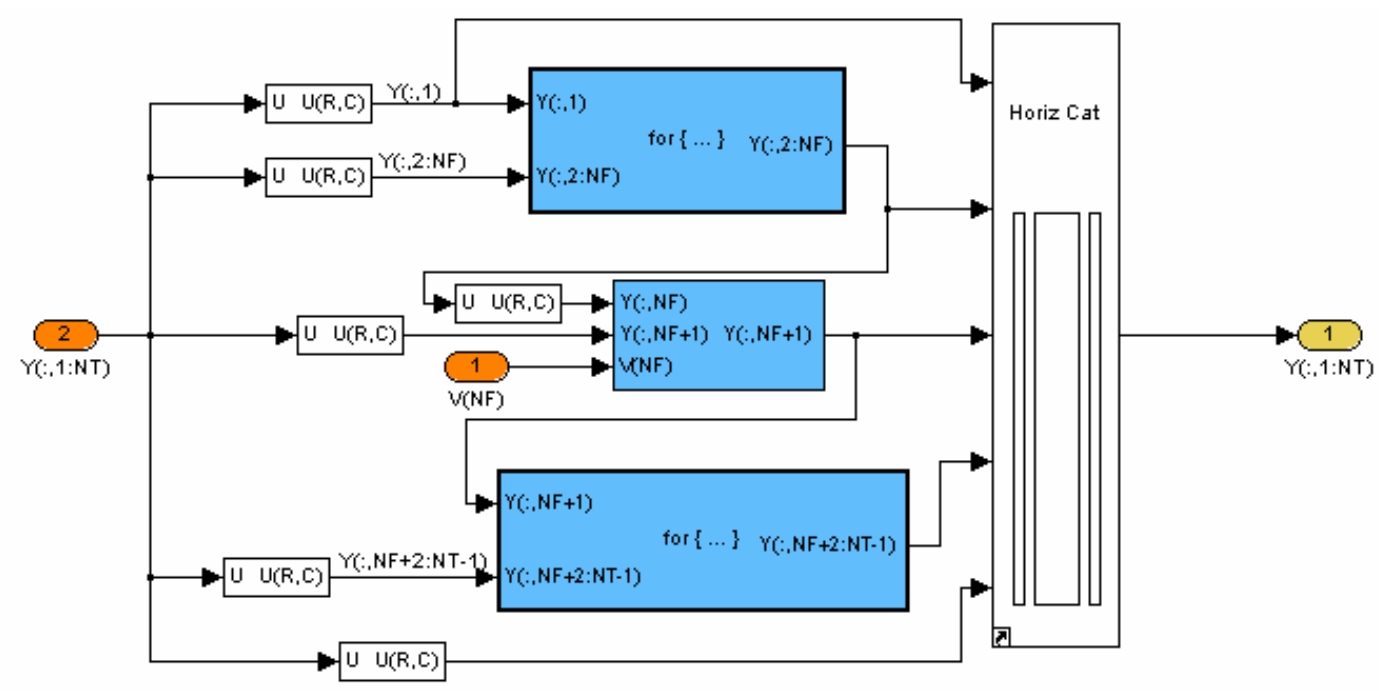

1.5.1.2 - For Iterator Subsystem1 


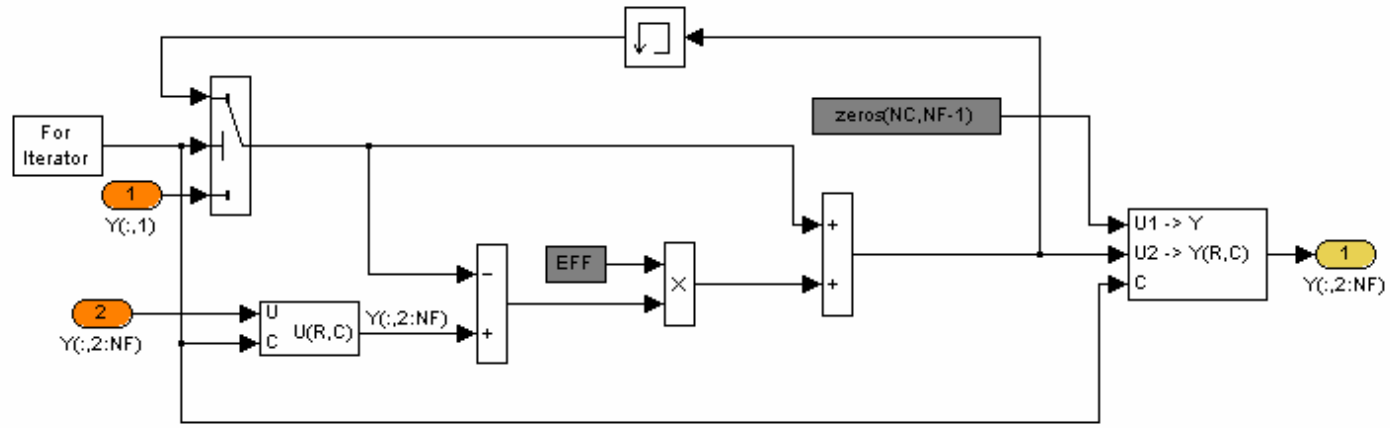

1.5.1.2.1 - Subsystem

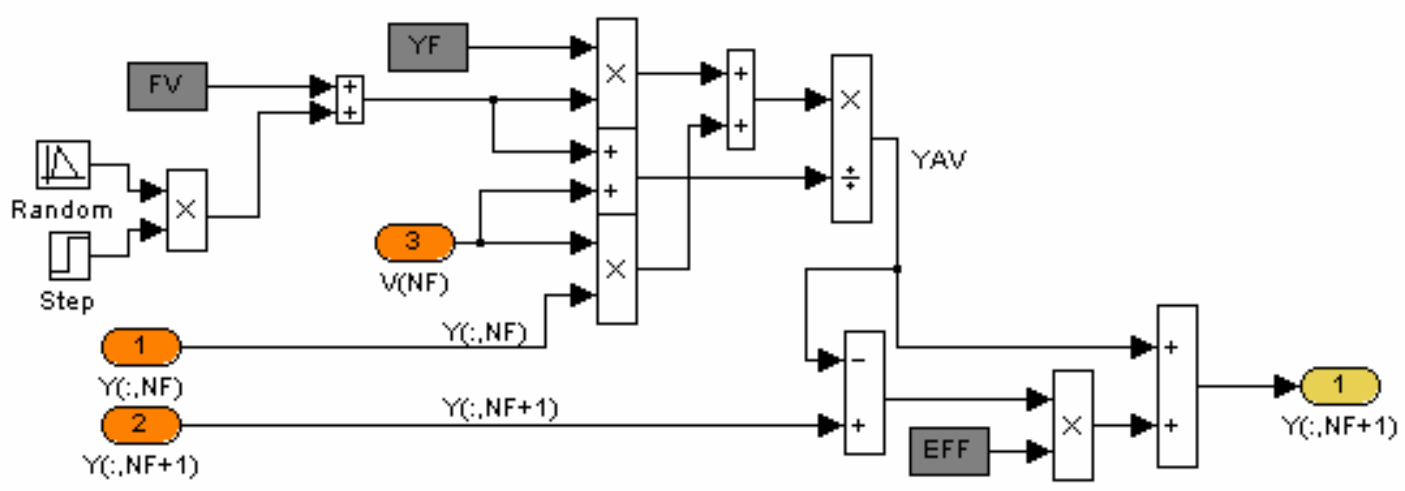

1.5.1.2.2 - Subsystem1

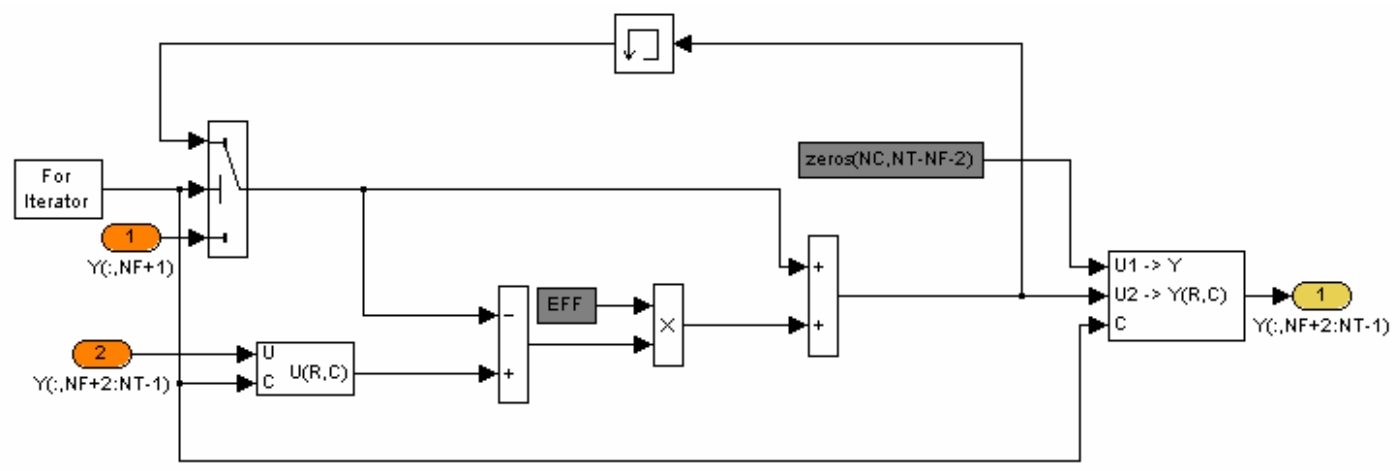

1.5.1.2.3 - Subsystem2 


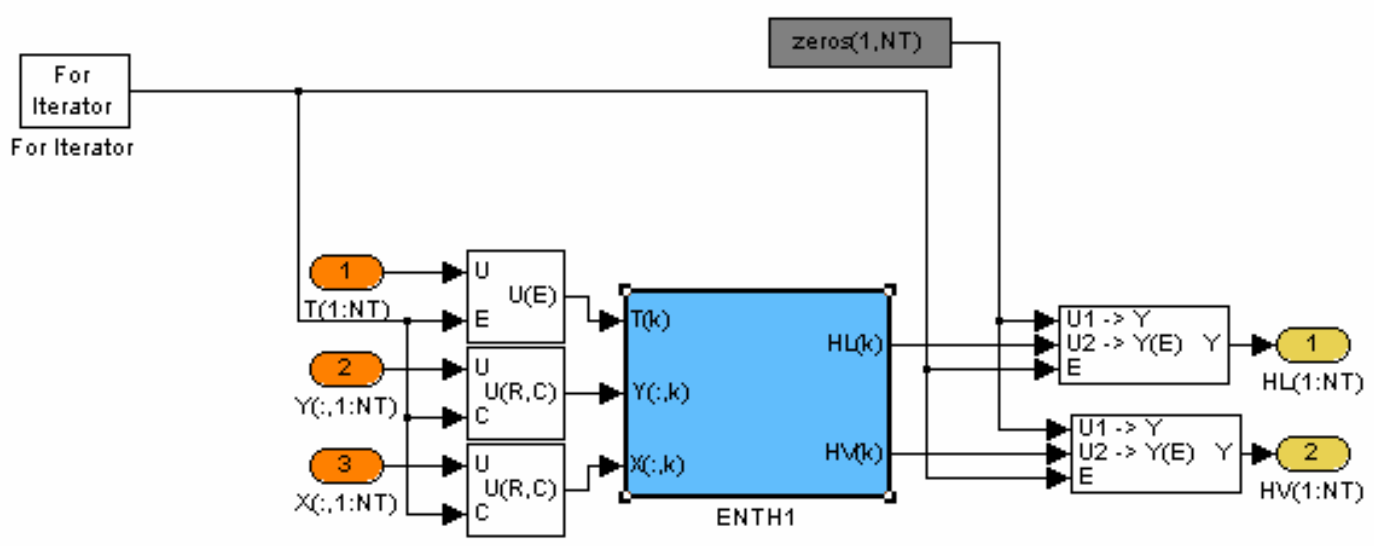

1.5.1.3 - For Iterator Subsystem2

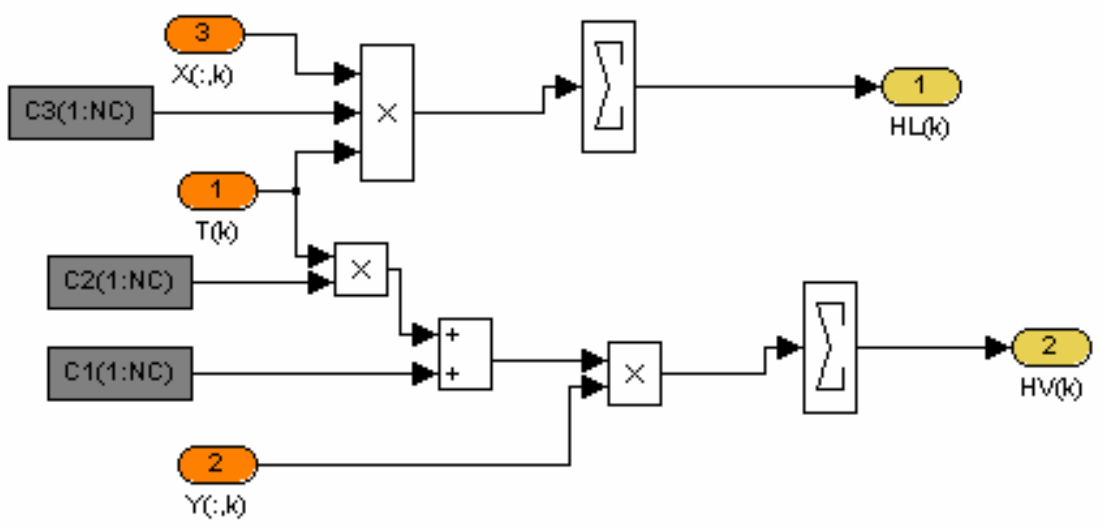

1.5.1.3.1 - ENTH1 